Thermal Power Systems

Advanced Solar Thermal Technology Project

\title{
Techno-Economic Projections for Advanced Small Solar Thermal Electric Power Plants to Years 1990-2000
}

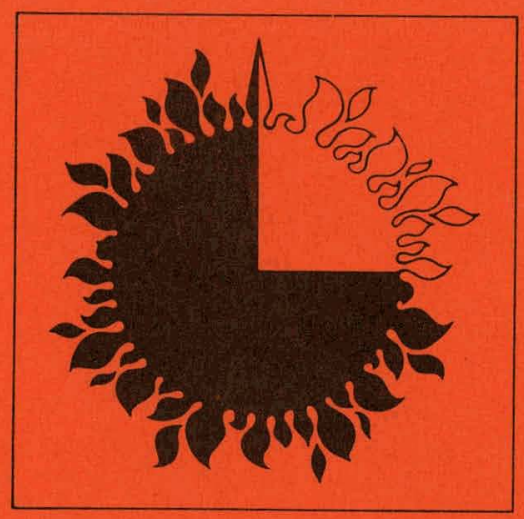

November 15, 1978

\section{Prepared for}

U.S. Department of Energy

by

Jet Propulsion Laboratory

California Institute of Technology

Pasadena, California

(JPL PUBLICATION 79-25) 


\section{DISCLAIMER}

This report was prepared as an account of work sponsored by an agency of the United States Government. Neither the United States Government nor any agency Thereof, nor any of their employees, makes any warranty, express or implied, or assumes any legal liability or responsibility for the accuracy, completeness, or usefulness of any information, apparatus, product, or process disclosed, or represents that its use would not infringe privately owned rights. Reference herein to any specific commercial product, process, or service by trade name, trademark, manufacturer, or otherwise does not necessarily constitute or imply its endorsement, recommendation, or favoring by the United States Government or any agency thereof. The views and opinions of authors expressed herein do not necessarily state or reflect those of the United States Government or any agency thereof. 


\section{DISCLAIMER}

Portions of this document may be illegible in electronic image products. Images are produced from the best available original document. 
$5102-99$

DOE/JPL-1060-4

Distribution Category UC-62

Thermal Power Systems

Advanced Solar Thermal Technology Project

Techno-Economic Projections

for Advanced Small Solar Thermal

Electric Power Plants

to Years 1990-2000
T. Fujita
R. Manvi
E. J. Roschke
N. El Gabalawi
G. Herrera
T. J. Kuo
K. H. Chen

November 15, 1978

\section{Prepared for}

U.S. Department of Energy

by

Jet Propulsion Laboratory

California Institute of Technology

Pasadena, California

(JPL PUBLICATION 79-25)

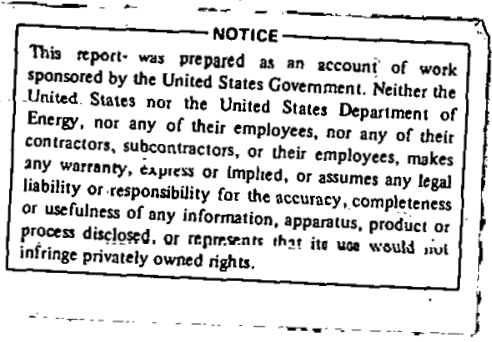


Prepared by the Jet Propulsion Laboratory, California Institute of Technology, for the U.S. Department of Energy by agreement with the National Aeronautics and Space Administration.

The JPL Solar Thermal Power Systems Prnjest is spnnsnred by the U.S. Lepartment of Encrgy and formis a pal of the Solar Thermal Program to develop low-cost solar thermal electric generating plants.

This report was prepared as an account of work sponsored by the United States Government. Neither the United States nor the United States Department of Energy, nor any of their employees, nor any of their contractors, subcontractors, or their employees, makes any warranty, express or implied, or assumes any legal liability or responsibility for the accuracy, completeness or usefulness of any information, apparatus, product or process disclosed, or represents that its use would not infringe privately owned rights. 
ABSTRACT

Advanced technologies applicable to solar thermal electric power systems in the 1990-2000 time-frame are delineated for power applications that fulfill a wide spectrum of small power needs with primary emphasis on power ratings < 10 MWe. Techno-economic projections of power system characteristics (energy and capital costs as a function of capacity factor) are made based on development of identified promising technologies. These projections are used as the basis for comparing technology development options and combinations of these options to determine developmental directions offering potential for significant improvements.

The key characteristic of advanced technology systems is an efficient low-cost solar energy collection while achieving high temperatures for efficient energy conversion. Two-axis tracking systems such as the central receiver or power tower concept and distributed parabolic dish receivers possess this characteristic. For these two basic concepts, advanced technologies including, e.g., conversion systems such as Stirling engines, Brayton/Rankine combined cycles and storage/ transport concepts encompassing liquid metals, and reversible-reaction chemical systems are considered. In addition to techno-economic aspects, technologies are also judged in terms of factors such as developmental risk, relative reliability, and probability of success.

Improvements accruing to projected advanced technology systems are measured with respect to current (or pre-1985) steam-Rankine systems, as represented by the central receiver pilot plant being constructed near Barstow, California. These improvements, for both central receivers and parabolic dish systems, indicate that pursuit of advanced technology across a broad front can result in post-1985 solar thermal systems having the potential of approaching the goal of competitiveness with conventional power systems; i.e., capital costs of $\$ 600 \mathrm{kWe}$ and energy costs of bu mills/kWe-hr (1977 dullars). 


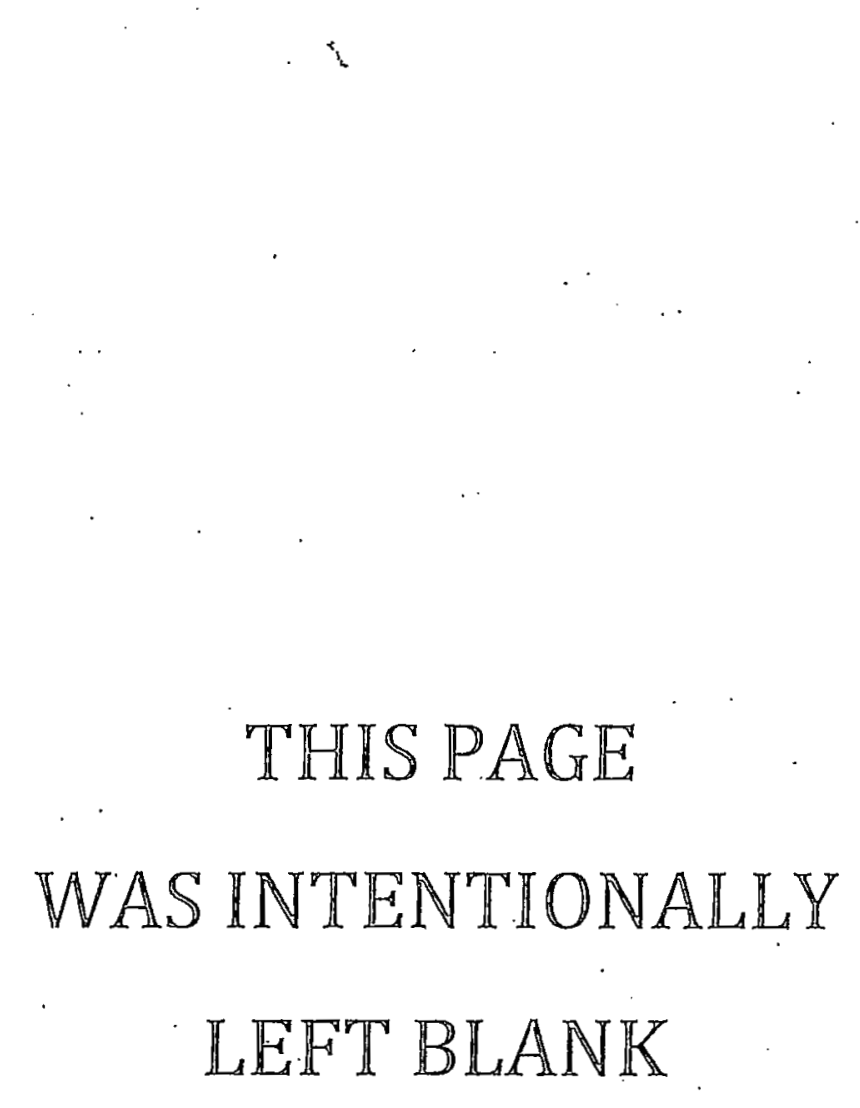


FOREWORD

The advanced thermal technology work reported herein is a part of the thermal power systems activities of the Department of "Energy's Division of Solar Technology. A primary objective of this effort is to. support development of advanced, low-cost, long-life and reliable solar thermal power systems which will supplement and eventually replace current fossil-fueled electricity generating plants.

The National Aeronautics and Space Administration's (NASA) Jet Propulsion Laboratory (JPL) and Lewis Research Center (LeRC) were selected in 1977 to assist in managing and coordinating this work. These two organizations, working with universities, government agencies, industry and the scientific community in general, are to lead in developing new concepts and establishing a broad technology base in advanced dispersed power systems which can be used to accelerate the commercialization of these systems.

This report presents results of a study aimed at identifying promising advanced technologies for solar thermal system applications. The study was conducted at JPL with support from LeRC in the form of major inputs to the energy conversion systems data base.

A prior study, "Projection of Distributed-Collector Solar-Thermal Electric Power Plant Economics to Years 1990-2000" (DOE/JPL-1060-77/1, 1977), provided a comparison of a spectrum of low-to-high temperature distributed systems in the context of a very limited cost data base. This study indicated that high-temperature two-axis tracking concepts provide the highest potential for solar thermal electric power generation.

The present study focuses on these high potential two-axis tracking systems and specifically delineates potential for improved technoeconomics via advanced technology development. The cost data base has been updated to reflect values indicated by rectil high-volume massproduction studies. These values are lower than used in the prior study and consequently lower energy cost values are being projected. 


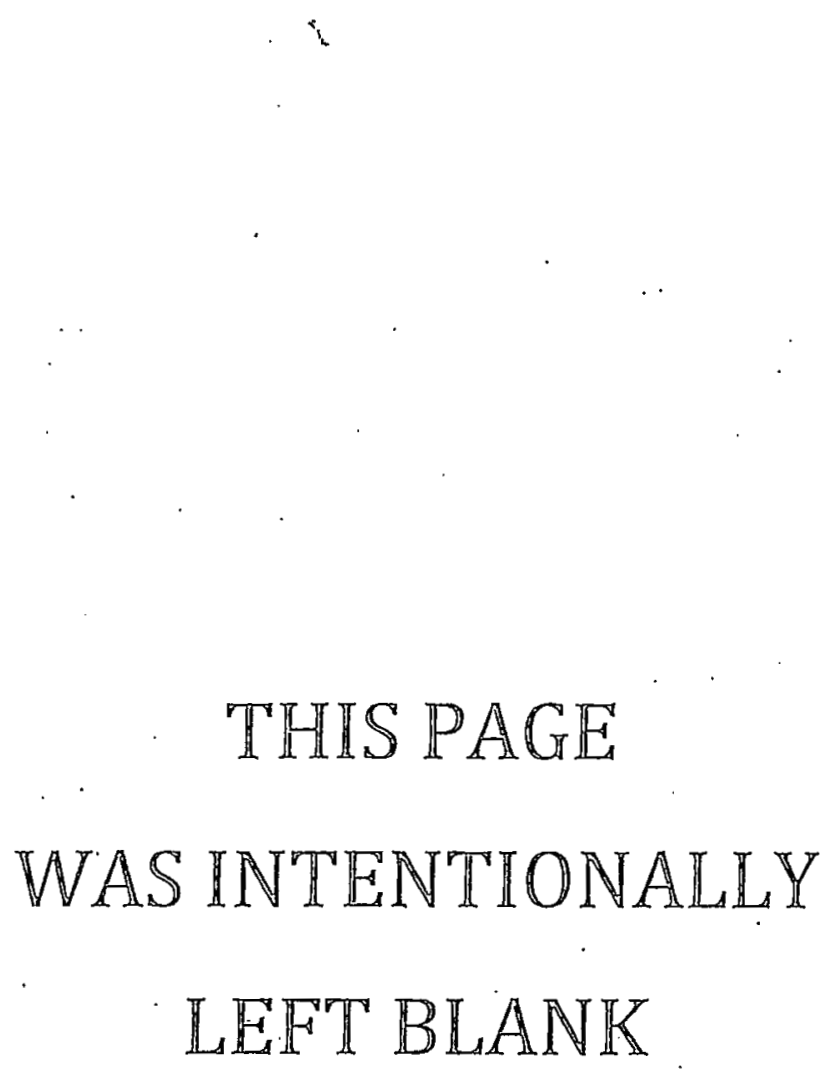




\section{ACKNOWLEDGMENTS}

The authors wish to especially acknowledge Vincent Truscello, Thermal Power Systems Project Manager, and John Becker, Advanced Solar Thermal Technology Project Technical Manager, for their guidance and support during all phases of the study presented in this report. In the initial planning and scoping stages of the study, Richard Caputo provided major inputs.

The data base and judgments concerning the technological potential of advanced systems developed in this study resulted from numerous interactions with technical analysts/specialists within the Thermal Power Systems program at NASA/JPL and LeRC, other Government/DOE laboratories, and relevant industries. This invaluable support is gratefully acknowledged. Particularly significant contributions are cited below:

- NASA-LeRC -- Major inputs to an extensive data base on advanced energy conversion systems and assistance in analyzing and interpreting these data were provided by a NASA-LeRC team managed by Robert Hyland. Members of this' team include Murray Bailey, who supplied essentially all of the material on small advanced reciprocating steam engines; Jack Heller, who made substantial contributions to the data base of Brayton cycles; Robert Stochl, who analyzed combined cycles; and Harry Cameron, who was instrumental in the assessment of Stirling cycle systems.

- Sandia Laboratories -- Insights and early impressions about advanced technology programs being directed at the Livermore facility were supplied via in-depth discussions with key personnel. Bill Wilson and Joe Iannucci provided information on reversible-reaction chemical storage systems, and Al Skinrood and Tom Brumleve did the same regarding advanced central receiver systems. At the Albuquerque facility, Jim Leonard, Dick Pettit, Ray Harrigan, LeRoy Torkelson, and Roscoe Champion provided information concerning the status of concentrator development activities, as well as background for other technologies being developed in their ongoing experimental programs.

This study was sponsored by DOE, Division of Solar Energy under Interagency Agreement, EX-76-A-29-1060, with NASA. The effort was performed under the management of Mr. Martin Gutstein, Program Manager, DOE Thermal Power Systems, and the authors are particularly appreciative of his support and helpful suggestions. 
During later phases of this effort, Jim Bowyer provided helpful support, particularly with regard to computer simulation and associated analyses. Computer programing and execution of the power system simulation code was competently handled by Gerrie Hill with assistance from Robert Arvizu and Dorothy Vetter. Their. contribution is greatly

appreciated.

Julia Sheldon and Laurel Flinn were responsible for editing and publishing the report, and Diane Tanahara and Cathy Sink typed the draft manuscript. Their efforts are gratefully acknowledged. 


\section{CONTENTS}

I

INTRODUCTION --C-1-- 1-1

A. OBJECTIVES-1- 1-1

B. APPROACH-- 1-2

C. TARGET TECHNO-ECONOMICS-_-_- 1-4

D. SUMMARY-C- 1-4

II. SYSTEMS SELECTION--

A. BASIC CONSIDERATIONS-- 2-1

1. Study Ground Rules-_- 2-1.

2. Fundamental Tradeoffs-_-_- 2-4

B. IDENTIFICATION OF ADVANCED TECHNOLOGIES--_-_-_ 2-10

1. Selected Technologies-_- 2-10

2. New Concepts-_ 2-15

C. DATA BASE COLLECTION- 2-1.9

1. Collectors-_-20

2. Energy Conversion--- 2-23

3. Transport- 2-27

4. Storage-- 2-29

D. ADVANCED POWER SYSTEMS-- 2-31

1. System Integration-- 2-32

2. Screening- 2-35

III. EVALUA'IION OF SELECTED ADVANCED FOWER SYSTEMS--------- 3-1,

A. RISK/DECISION ANALYSIS METHODOLOGY-- 3-1

1. Basic Premise-n-1

2. Probabiliatic Techniques--- 3-2 
B. RANKING OF ADVANCED SYSTEMS-- 3-5

1. System Risk Evaluation-- 3-5

2. Advanced Technology Investment Considerations-------- 3-10

3. Other Benefits-- 3-11

IV. CONCLUSIONS----- 4-1

V. RECOMMENDATIONS--

VI. REFERENCES--

APPENDICES

A. SURVEY OF ADVANCED ENERGY CONVERSION SYSTEMS----- A-1

B. ENERGY TRANSPORT AND STORAGE INVESTIGATION---------- B-1

C. SYSTEM SIMULATION DATA BASE--_- C-1

\section{Figures}

1-1. Study Plan Flow Diagram--_- 1-3

2-1. Solar Thermal Power Plant Schematic Diagram---------- 2-5

2-2. Performance Potential of Parabolic Dish-Stirling System--_---_- 2-7

2-3. Matrix of Candidate Subsystems-----11

2-4. Baseline Central Receiver System (Barstow Pilot

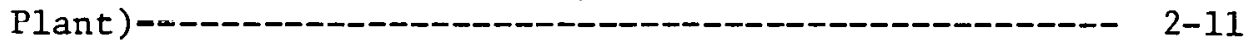

2-5. Point Focusing Fresnel Lens Collector System-------- 2-12

2-6. Electrochemical Conversion Cycle--

2-7. Receiver Performance and Cost Characteristics-------- 2-22

2-8. Receiver Heat Balance--_- 2-24

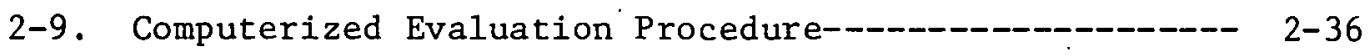

2-10. Improvement in Minimum Energy Cost Contour--------- 2-43 


\section{Figures}

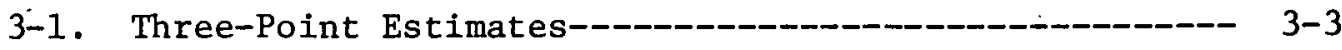

3-2. Probabilistic Simulation Methodology--_-_-_-_-_ 3---

3-3. Probabilistic Energy Cost Ranges-- 3-6

3-4. Relative Probability of Achieving Energy Cost Target- 3-9

3-5. Advanced Technology Investment - Risk Tradeoff------ 3-12

Tables

2-1. Economic Parameters for Utility-Owned Solar

Electric Systems-- 2-2

2-2. Concentrator Cost and Performance Characteristics---- 2-20

2-3. Energy Conversion System Cost and Performance Characteristics-_-25

2-4. Energy Transport System Cost and Performance Characteristics-_- 2-28

2-5. Energy Storage System Cost and Performance Characteristics-_- 2-30

2-6. Candidate Advanced System-- 2-33

2-7. Nominal Energy Costs for Central Receiver Systems---- 2-37

2-8. Nominal Energy Costs for Distributed Systems--------- 2-38

3-1. Risk Factor for Helinstat-Rankine with Steam Transport and 0il/Rock Thermal Storage (HR)--- 3-7 
SECTION I

INTRODUCTION

Small solar thermal electric power plants are herein defined as power systems that can fulfill a wide variety of needs by being located near application sites that are dispersed over wide regions. This distinguishes them from central power plants; that are larger in size and usually function as generating elements of a utility grid. For small systems, power ratings of $\leqslant 10 \mathrm{MWe}$ are of primary interest.

The spectrum of solar thermal power plant design concepts available for small power applications ranges from low-temperature $\left(\sim 300^{\circ} \mathrm{F}\right)$ non-tracking collection systems to high-temperature $\left(\sim 2000^{\circ} \mathrm{F}\right)$ two-axis tracking systems. The present study is focused specifically on advanced technology systems that maximize the efficiency of the plant in converting incoming or intercepted insolation (solar energy) to outgoing electrical energy. High efficiencies are associated with high-temperature two-axis tracking systems, and the present study therefore considers only these systems.

The following basic approaches to high-temperature two-axis tracking systems are included in this study.

- Central Receiver -- characterized by a tower on which a single receiver is mounted (Ref. 1): A field of two-axis tracking mirrors (heliostats) reflect insolation on the receiver. The heat thereby generated is.transported via heat exchange media (such as steam or helium) to the energy conversion unit where electrical energy is produced.

- Distributed Receiver -- generically identified by collector fields comprised of a multiplicity of concentrator-receiver modules (Ref. 2). Thermal energy generated at the receivers in the field is either transported to a central location for conversion to electricity or converted to electricity in the field via small heat engine-generator assemblies that are supplied by either a single concentrator-receiver or a cluster of concentrator-receivers.

\section{A. OBJECTIVES}

The main purpose of this study is to provide assistance in planning an advanced technology program for small solar-thermal power systems. Within the limited scope of this study, the following specific objectives must be met:

- Identification of a limited set of promising advanced technology subsystems/components. 
- Integration of selected subsystems into candidate advanced second generation solar power systems that could be implemented in the 1990-2000 time-frame.

- Analysis of selected advanced systems in terms of efficiency improvement potential and operational characteristics.

- Comparative evaluation of the most promising systems in terms of energy costs, advanced technology requirements, estimated technical risks and advanced technology expenditures.

It is emphasized that the objectives of the present study do not encompaes a comprehcnsive or in-depth examination of all the advanced technology possibilities. Such an effort cannot be accomnodated within the time and funds available. Thus, Llie study is based on using best judgments to focus on a limited set of advanced technologies that appear to offer the greatest promise:

Since the present effort is intended to serve as a basis for advanced technology planning, it was decided that study objectives could best be met by selecting concepts having potential for achieving high efficiencies. The activities associated with attaining these potential efficiency improvements could then serve as elements of an $R \& D$ or advanced technology program.

Ultimately, costs of the selected advanced technology subsystems/ components will have a significant impact on feasibility. Costs associated with projected advanced technology components are generally more uncertain than performance estimates, since a greater number of parameters are involved in projecting costs. Due to this inherently greater uncertainty and the fact that it is very difficult to demonstrate cost milestones (except under mass production conditions), cost considerations are regarded as subordinate to efficiency potential when selecting candidate technologies.

\section{B. APPROACH}

'The approach used in this study is depicted in Figure 1-1, which shows five subtasks (rectangles) that were performed as the basis for making recommendations (circles). These subtasks are described below:

- Data Base Collection. Candidate advanced technologies were I1rst selected on the basis of ongoing Department of Energy (DOE) subprograms, and the data base collection effort was initially focused on these technologies. As more data was collected, other options which appeared to have potential were included.

- New Concepts Identification. During the course of the data. base collection effort, attention was given to identification of new concepts which could not be: pursued within the scope of the present study. The potential advantages of the problems associated with these concepts were delineated as the basis for recommending further studies. 


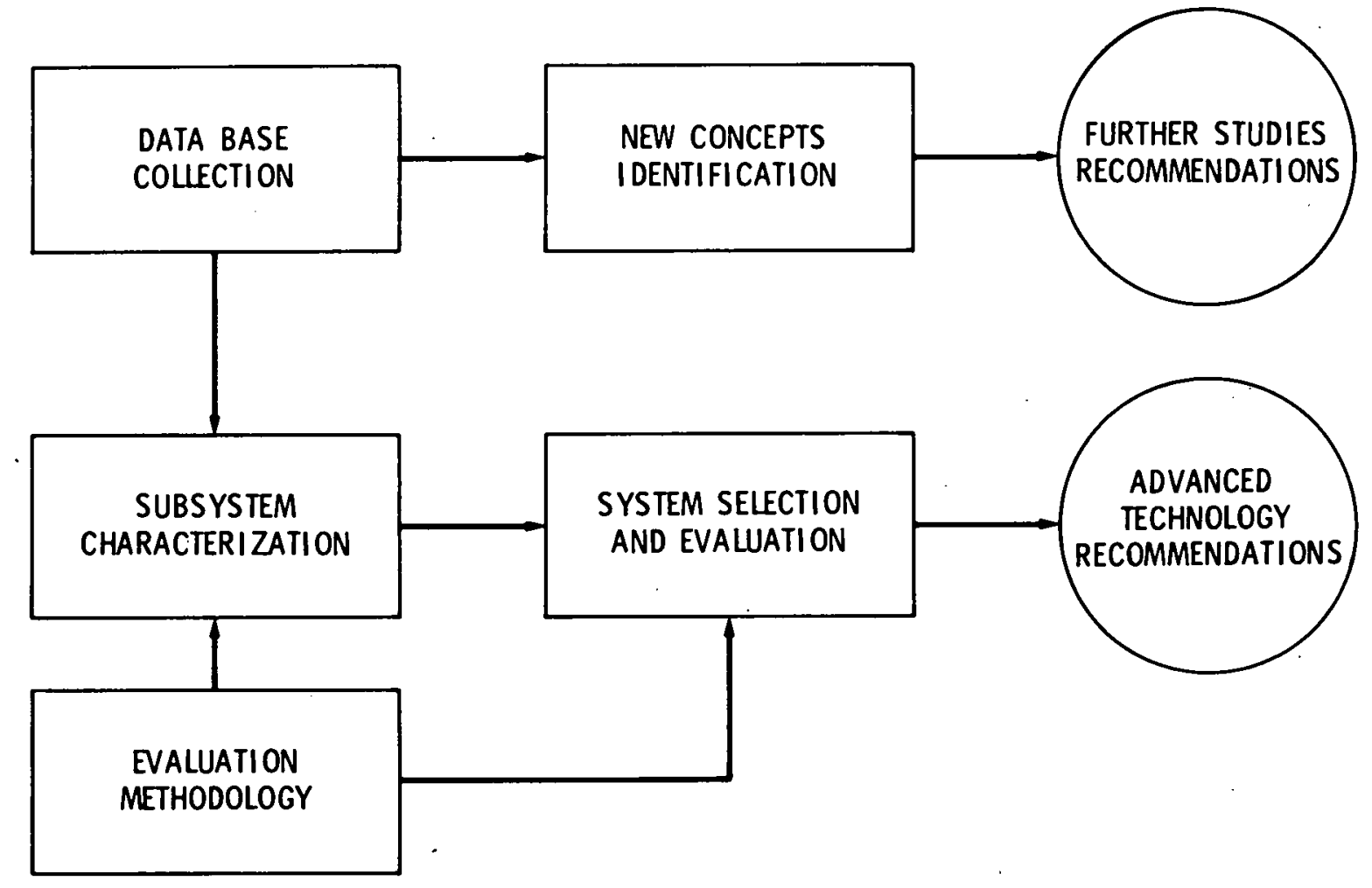

Figure 1-1. Study Plan Flow Diagram

- Evaluation Methodology. Since projections of the performance and costs of advanced technology systems involve inherently large uncertainties, a methodology predicated on a probabilistic treatment of uncertainties was adopted. This methodology employs risk/decision analysis methods of weighing costs savings (benefits) in relation to advanced technology funding (investment) and probability of success (risk).

- Subsystem Characterization. Each candidate subsystem or component was characterized in terms of potential performance, estimated mass-production costs, and the technological activity required to achieve the projected potential. This characterization was tailored to fit the probabilistic evaluation methodology; i.e., projections were made in the context of associated probabilities.

- System Selection and Evaluation. Candidate subsystems were first integrated into power plants where emphasis was placed on using complementary or matching subsystems to achieve the highest possible system performance. Systems formulated in this manner were then screened to select the most promising candidates which were then ranked by using the evaluation methodology. This ranking provided the basis for advanced technology recommendations. 


\section{TARGET TECHNO-ECONOMICS}

The solar thermal program has established the following technoeconomic system targets and associated component cost targets for the post-1985 time-frame:

SYSTEM TARGETS

(1977 Dollars)

$\begin{array}{ll}\text { - Capital Costs } & : \text { 600-1000 } \mathrm{s} / \mathrm{kWe} \\ \text { - Energy Costs } & : 50-60 \mathrm{mills} / \mathrm{kWe}-\mathrm{hr}\end{array}$

COMPONENT TARGETS

(1977 Dollars)

$\begin{array}{ll}\text { - } \text { Concentrators } & : 70-100 \$ / \mathrm{m}^{2} \\ \text { - Receivers } & : 20 \$ / \mathrm{kWe} \\ \text { - Power Conversion } & : 60 \$ / \mathrm{kWe} . \\ \text { - Energy Storage } & : 30 \mathrm{~s} / \mathrm{kWe}-\mathrm{hr}\end{array}$

The advanced systems identified in the present study represent significant strides towards achieving this performance. The projected values and ranges of uncertainties given in this study are based on very limited conceptual and preliminary design investigations and it is anticipated that further in-depth conceptual design iterations will result in more optimal power systems.

In this context, the systems presented herein are regarded as a starting point. In the analysis the projected energy and capital costs of these systems are expressed in an range bracketing system target costs. Further studies to refine or optimize these concepts are required, but in the present study can potentially achieve system target values if the higher performance values (component efficiencies) and lower costs of the projected uncertainty ranges are achieved.

\section{SUMMARY}

It is indicated that the target system costs for the post-1985 time-frame are achievable by using the advanced systems treated in this study. Compared to the present technology baseline system, these advanced systems improve the probability. of success in achieving target energy costs by a factor of 4 to 5. As these identified advanced systems are optimized, it is expected that, the target energy cost will be achieved, i.e., in a probabilistic sense, the most likely or nominal cost will be $50-60 \mathrm{mills} / \mathrm{kWe}-\mathrm{hr}$. 
The likelihood of achieving target system energy costs with advanced energy systems warrants substantial advanced technology expenditures in the over billion dollar range. The costs are based on fundamental decision/risk criteria and a penetration for solar thermal power of $\approx 10,000 \mathrm{MWe}$ (assumed to be $1.5 \%$ of incremental grid capacity added between $1978^{\prime}$ and the year 2000). This is expected to occur when target energy costs are achieved in the post-1985 time-frame.

A limited set of promising advanced technology subsystems and components were selected. These included the central receiver/heliostat, the two-axis tracking parabolic dish, and Fresnel lens concentrators; Stirling, Brayton, combined cycles and advanced steam Rankine engines for energy conversion; and energy storage encompassing sensible heat in bricks (checker stove concept), reversible chemical reaction systems, and liquid metals for both storage and transport.

These promising subsystems were integrated into power systems by employing subsystem interface matching criteria which produced efficient and cost-effective couplings. Analysis of advanced power systems possibilities can achieve substantial improvements in efficiency over the present technology steam Rankine system (as represented by the central receiver Barstow pilot plant). Efficient high-temperature $\left(1500^{\circ} \mathrm{F}\right.$ to $\left.2000^{\circ} \mathrm{F}\right)$ advanced systems offer operational benefits in terms of smaller land area requirements, enhanced adaptability to total energy/ cogeneration applications, and implementation flexibility for highly modular distributed systems.

A probabilistic evaluation methodology was used to compare the most promising systems. Benefits of advanced systems were determined by the cost savings resulting from operation of the advanced system as compared to the baseline. Technical risks associated with factors such as materials availability, technology development status, safety, etc., were assessed as the basis for determining the probability of success. The projected benefits/cost savings times the probability of success determine the allowable advanced technology expenditure.

A comprehensive survey of advanced energy conversion systems indicatcd that Stirling engines have the highest potential in terms of both efficiency and cost. Therefore, both the central receiver and distributed dish systems employing the Stirling engine showed the highest gains even when the higher risk of the Stirling relatively well established Brayton and combined cycles is taken into account. Brayton and Braytor/Rankine combined cycles were shown to be highly promising options which could be implemented with relatively small additional advanced technology expenditures since they would use the same collectors, storage, and transport as the systems employing Stirling engines. Generally; it is indicated that the largest benefits will result from focusing advanced technology efforts on the achievement of the highest possible conversion efficiencies in the $1500^{\circ} \mathrm{F}$ to $2000^{\circ} \mathrm{F}$ temperature range.

Liquid metal transport and storage is shown to have potential in linking receivers with engines due to its favorable heat transfer characteristics which results in compact receiver/heat exchanger destylls. Materials development activity is needed, particularly for temperatures 
$>1300^{\circ} \mathrm{F}$. Development of advanced batteries will enhance the viability of modular distributed systems which employ electrical transport to collect energy from the field.

It is noted that applications-related issues are not being addressed. The emphasis is on identifying a spectrum of promising options. Depending on the application, one option may be preferred to another. Since solar thermal systems are suitable for a wide range of diverse applications, it appears that several of the most promising advanced technology options should be pursued in a highly coordinated manner to benefit from synergism and use of common elements.

As indicated in this study, the primary thrust for advanced technology is to identify and then demonstrate in follow-on programs that high performance can be achieved by systems which are shown via studies to have a high probabillty of meeting cost targets. Only first order mass-production cost analyses can be performed because detailed optimized designs are generally not available for advanced systems. These cost analyses are used to screen out options that have little chance of ever being cost-effective and to identify components having the best potential for achieving low costs. Since projections, particularly those related to costs, are associated with uncertainties, it is suggested that interpreting results in a probabilistic context will provide the best insights. 
SECTION II

SYSTEMS SELECTION

Dispersed solar-thermal power plants incorporating advanced technologies that could be developed in the 1990-2000. timeframe are herein selected for analysis and evaluation. The selection process proceeds systematically from delineation of broad criteria derived from basic considerations to screening of candidate systems to identify those advanced technologies which appear to offer the greatest promise.

A. BASIC CONSIDERATIONS

A basic framework for selecting systems is established by first defining the study ground rules and then examining fundamental tradeoffs in terms of basic physics.

1. Study Ground Rules

The study ground rules essentially define the boundaries of the effort and provide the context within which the study findings are to be interpreted. The primary ground rules for this study are as follows:

1) Only solar-electric power production is considered. Fossil/ solar hybrid plants and total energy systems, where both electrical and thermal energy are supplied to the user, are not included.

2) A simple constant demand characteristic is assumed, where the solar plant is asked, to supply rated power whenever it is able to deliver this power. Utility interfacing issues such as margin analysis and associated backup requirements are not treated.

3) Power plant economics are based on uctlity=uwned solar electric systems as derived in Ref. 3 and previously used in Ref. 2, as well as earlier studies of Refs. 4 and 5. Table 2-1 presents values used in these studies.

4) Costs are given in 1977 base year dollars, with plant startup 25 years after the base year. To simplify comparisons with previous studles, the differential inflation characteristics over this period were kept the same as in the earlier efforts (see Ref: 5). Thus, the effect of differential inflation is to increase capital costs in base year (1977) dollars by a factor of 1.22 (see Ref. 2). 
Table 2-1. Economic Parameters for Utility-Owned Solar Electric Systems

\begin{tabular}{|l|c|}
\hline \multicolumn{1}{|c|}{ Factor } & Value \\
\hline $\begin{array}{l}\text { System Operating Lifetime, years } \\
\text { Annual "Other Taxes" as Fraction } \\
\text { of Capital Investment }\end{array}$ & 0.02 \\
$\begin{array}{l}\text { Annual Insurance Premiumo as Fraction } \\
\text { of Capital Investment } \\
\text { Effective Income Tax Rate }\end{array}$ & 0.0025 \\
Ratio of Debt to Total Capltalization \\
$\begin{array}{l}\text { Ratio of Common Stock to Total } \\
\text { Capitalization } \\
\begin{array}{l}\text { Ratio of Preferred Stock to Total } \\
\text { Capitalization } \\
\text { Annual Rate of Return on Debt. } \\
\text { Annual Rate of Return on Common Stock } \\
\text { Annual Rate of Return on Preferred } \\
\text { Stock }\end{array}\end{array}$ & 0.40 \\
\hline
\end{tabular}

5) Insolation data for Inyokern, CA, is used for all systems to provide common reference input for comparative evaluation purposes.

6) Battery storage systems are dedicated for snlar power plant operation. No other use of these systems by the grid (off peak) is considered. 
The ground rules above represent a simple and expedient basis for meeting the primary study objective of identifying promising advanced technologies by comparing options within a common frame of reference. It is felt that the simplifications inherent in the selected ground rules are such that promising technologies will not be obscured and that a reasonable relative ranking can be performed within limitations of data base uncertainties.

For small, dispersed solar power systems, integration of the solar plant into a total energy system application is a possibility which should be considered. For example, the solar plant could be located and designed so that the normally rejected heat from energy conversion/electric power generation could be supplied to an industrial plant to meet process heat needs. Although this possibility is not directly treated, it is tacitly assumed that the most critical step is to first delineate advanced and cost-effective techniques for generating solar-electric power. Then, in follow-on studies, the selected advanced options can be assessed in the context of their suitability for total energy systems.

A hybrid plant which uses fossil fuels to augment solar energy is a system possibility that could be advantageous, particularly for dispersed power plants that are not connected to a utility grid. The ground rules for the present study focus the primary effort on advanced solar generation aspects. After advanced candidates are identified, it is felt that follow-on studies should be undertaken to determine the relative merits of the most promising options in terms of their adaptability for hybrid operation where fossil generated heat is substituted for solar-derived heat.

Dispersed solar power plants will generally have to meet a wide spectrum of demand characteristics, depending on specifics of the application. The primary impact of demand characteristics on power plant design is that the collector field size and energy storage requirement must be sized to meet the demand curve. If the curve peaks during the daylight hours of solar energy availability, the collector field and storage size requirements will tend to be reduced. Peak demands during evening periods will increase these requirements. A larger collector field and storage capacity must be provided if the plant is to be designed to produce at least a portion of the demand during periods of inclement weather. If the plant is part of a utility grid, interfacing issues such as backup requirements will affect the design.

Demand characteristics and grid interfacing requirements can have a major impact on plant design and economics, since they directly affect the size of major subsystems. However, for a relative comparison of advanced technology designs, it is felt that use of the simple constant demand will suffice. It is recognized that advanced technology options will differ with regard to size-economy or scale effects. These effects and their influence on plant economics are encompassed in the constant demand analysis hy determining minimum energy cost as a function of collector field size and storage capacity over a large range of capacity factors where capacity factor is defined as the energy delivered over 
the energy that could have been delivered by a plant operating continuously at rated power. Low capacity factors are associated with relatively small fields and storage sizes, whereas attainment of large capacity factors necessitates large collector fields and storage capacities. Therefore, technologies having favorable size-economy characteristics can be delineated via the constant demand analysis as used in this study.

Interfacing of a solar plant with a utility grid system is primarily a function of the reliability and economics of the solar plant compared to those of other plants in the grid. Reliability is determined by downtime due to both weather-related causes and unscheduled as well as scheduled maintenance. When the same insolation data are used, all solar plants will experience similar weather-related downtime. For maintenance-related reliability, energy costs were first determined under the condition that all plants had the same down time. Then, in the evaluation process, the technologies associated with each plant were examined to arrive at a reliability rating which was used as a weighting factor in ranking the plants.

The financing and associated economic parameters for small dispersed power systems could differ from those of larger utility systems, listed in.Table 2-1. In future studies, the financing practices of small power systems should be investigated to determine their effect on system economics. To simplify the present study, large utility financing as seen in Table $2-1$ is used. The mode of financing will not materially affect the relative ranking of promising candidate technologies. In its strictest interpretation, Table 2-1 pertains to small dispersed power systems that are implemented as part of a large utility sys tem.

Insolation data for Inyokern, CA used in this study, is reflective of operation in the solar-intensive southwest. Thus; the projected performance and economics correspond to the highest levels available. The degradation due to operating in other regions having less insolation will be addressed in follow-on studies.

\section{Fundamental Tradeoffs}

The basic subsystems/components of a solar thermal power plant and their functional roles are depicted in Figure 2-1. A concentrator or reflector array accepts insolation and optically focuses this solar energy onto a receiver. The concentrated solar flux impinging on the receiver generates thermal energy, which is transported via heat transfer fluid to the energy conversion unit or to internal storage. The energy conversion unit generates electrical energy which is delivered to the user or sent to external storage for later use. The term internal storage refers to storage of thermal energy that occurs within the power generating portion of the plant, whereas external storage denotes storage of energy downstream from the power generating unit (Ref. 6).

In terms of basic systems operation (Figure 2-1), key fundamental tradeoffs can be delineated. For advanced technology systems, the 


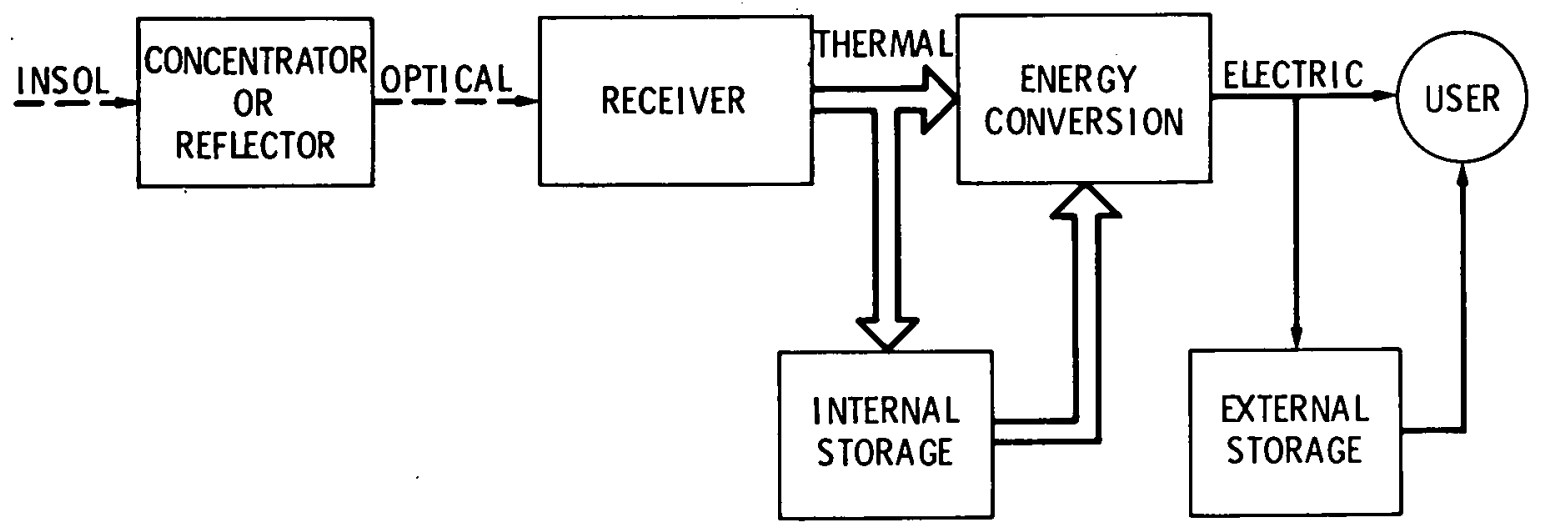

Figure 2-1. Solar Thermal Power Plant Schematic Diagram

achievement of a high efficiency in converting insolation to electrical energy is a major consideration. As this efficiency increases, a smaller field of collectors comprised of concentrators and receiver(s) will be required for a fixed plant rating and output. Since the collector field represents more than half the cost of projected solar thermal power systems (Ref. 2), size reductions via high efficiency have substantial potential for reducing costs to provide improved system techno-economic characteristics. For a net gain, it is necessary that any incremental costs incurred in achieving higher efficiencies be less than the savings due to plant size reduction, where minimization of incremental costs requires design advances. This implies that development. of innovative, low-cost mass production designs are required along with advanced technologies for high efficiencies to achieve the full benefits of advanced systems.

a. Operating Temperature Selection. A dominant element in attaining high overall system efficiencies is the efficiency of the energy conversion subsystem (Figure 2-1) which converts thermal to electrical energy. This efficiency is governed by basic thermodynamic heat engine cycles and can at best approach the ideal Carnot cycle efficiency which represents an upper bound. Since the efficiency of the Carnot cycle increases as the temperature of the heat supplied increases, high-efficiency advanced technology concepts are associated with high temperatures.

However, increases in temperature have a major impact on receiver efficiency. In particular, since reradiation losses are a function of the effective receiver temperature to the fourth power, receiver efficiency decreases at a rapid rate for high temperatures. Thus there is a basic tradeoff between receiver efficiency and energy conversion efficiency which varies as a function of temperature level. The overall system efficiency is proportional to the product of these two efficiencies. 
This tradeoff relation is illustrated in Figure 2-2 for a twoaxis tracking parabolic dish concentrator having a cavity receiver and Stirling engine-generator assembly at the focal point of the concentrator. This, particular system was shown to have promise in Ref. 2. The curves shown on Figure 2-2 depict performance potential and were generated with the aid of a cone-optics computer program described in Refs. 7 and 8 .

The flux distribution reflected from the concentrator toward the receiver is governed by four elements: solar reflectance, specular, spreading caused by microscopic surface roughness, surface slope (or waviness) departures from the ideal paraboloid due to limitations imposed by manufacturing tolerances, and misdirection and distortion due to tracking errors or deflection of the surfaces caused by various factors such as wind loads. The solar reflectance determines the fraction of insolation that is reflected from the surface, while the other elements result in spreading and distortion of the flux distribution compared to an idealized perfert optical surface that ie positioned with no tracking error.

The spreading and distortion of the flux distribution affects the quantity of energy. entering the aperture of the cavity receiver. If the aperture size is increased, a greater portion of the flux will enter the receiver. However, reradiation and convection losses through the larger aperture. will be greater. The cone-optics computer program has been designed to parametrically vary the receiver aperture area and to then select the area that corresponds to the optimum overall efficiency.

Thus, the curves of Figure 2-2 are based on the use of optimized aperture areas for maximum efficiency. In general, aperture area varies along each curve. For purposes of delineating performance potential, conduction losses from the receiver are considered to be small and have been disregarded. The receiver surface (inner cavity wall) is assumed to have an absorptivity $=$ emissivity $=0.95$. The incoming insolation is taken to be $0.8 \mathrm{~kW} / \mathrm{m}^{2}$ and the dish rim angle is 45 degrees.

The set of solid curves corresponds to perfect optics where all the incoming energy is reflected and the surface causes no distortion or spreading. Stirling engine performance projections estimate the achievement of approximately $60 \%$ of the upper bound Carnot efficiency. Advanced systems corresponding to the upper end of the pro= jected uncertainty band are associated with the $80 \%$ Carnot curve. The substantial improvement in the triple-product efficiency (collector $\mathbf{x}$ receiver $x$ engine) between the $60 \%$ and $80 \%$ Carnot curves is indicative of the gains which could results from pursuing advanced Stirling engine technology development. 

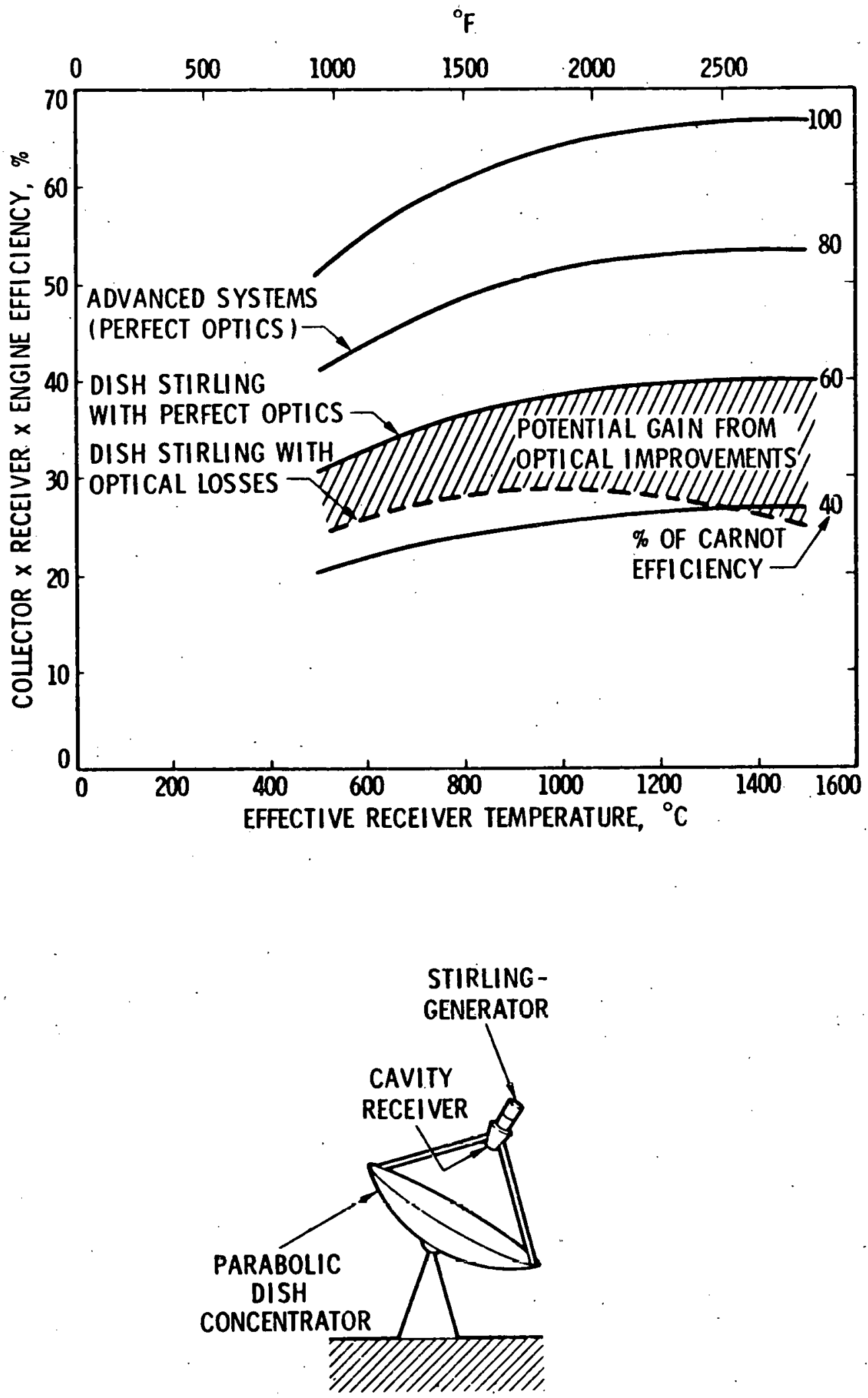

Figure 2-2. Performance Potential of Parabolic Dish-Stirling System 
The dashed line denotes a system with representative optical. losses and a nominal projected engine efficiency of $60 \%$ Carnot. For this curve, the surface slope error is 0.1 degrees, specular spreading is 0.05 degrees, and the pointing error is also 0.05 degrees. The difference between the dashed curve and the $60 \%$ Carnot curve (shaded region) with perfect optics therefore represents the maximum gain that could be attained via optical improvements. This gain is significant and is indicative of benefits which could accrue from developing advanced optical technology.

The effect of the fundamental. tradeoff involving increased engine efficiency and decreased receiver efficiency with increased temperature is manifest in Figure 2-2 as a relatively flat or constant triple-product efficiency over a wide temperature range from $800^{\circ} \mathrm{C}$ to $1400^{\circ} \mathrm{C}$ (or $\approx 1500^{\circ} \mathrm{F}$ to $f^{2} 2500^{\circ} \mathrm{F}$ ). Basically, this implies that engine efficiency improvements with increasing temperature are being essentially offset by higher reradiation and convection losses from the receiver. In fact, for the dashed curve, the triple-product efficiency decreases slightly for temperatures greater than about $1000^{\circ} \mathrm{C}$ $\left(1800^{\circ} \mathrm{F}\right)$. This occurs because optical losses associated with spreading of the flux distribution at the receiver require a larger aperture having greater reradiation and convection losses.

This fundamental tradeoff has major implications regarding advanced technology systems for electric power generation. It is indicated that most of the gain associated with increasing the temperature level is achieved at temperatures of about $800^{\circ} \mathrm{C}$ (or $1500^{\circ} \mathrm{F}$ ). Since the potential for gains beyond this temperature is relatively small, pursuit of higher temperature advanced technology options must be undertaken in a highly selective manner. Only sophisticated concepts and associated technologies which can utilize higher temperatures without significantly increasing costs or reducing reliability will provide a net system gain.

It is to be noted that the above limitations regarding high temperature operation pertain only to electric power generation systems. If solar thermal systems are to be used for applications such as process heat or other industrial/chemical applications, the temperature level will be dictated by the specifics of each application.

It is also noted that the curves of constant percent Carnot are used on Figure 2-2 to illustrate trends in a general manner. For specific engines, the percent Carnot is also usually a function of the Lemperature lcvel (see Appendix A). Thus, if the percent Carnot of a particular engine increases with temperature, the peak of the triple product efficiency will tend to shift toward high temperatures. However, these shifts are perturbations which will occur within the framework of the overall trends described above. 
Although the tradeoff analyzed above pertains to the parabolic dish system, the general trends delineated are applicable to solar thermal systems in general. As evident from Figure 1-1,) all solar thermal systems will encounter the same basic tradeoff. From results in Ref. 9,' it is indicated that central receiver systems have similar characteristics in approximately the same temperature range as the parabolic dish system example of Figure 2-2.

These findings suggest that a major thrust of advanced technology for power generation should be directed toward developing energy conversion systems that achieve the highest projected efficiencies (percent Carnot) in the $1500^{\circ} \mathrm{F}$ to $2000^{\circ} \mathrm{F}$ temperature range.

b. Receiver Loss Reduction. Another fundamental approach toward improving efficiencies is to investigate methods of reducing reradiation and convection losses from the receiver aperture. Detailed investigations related to this approach could not be conducted within the scope of this effort. However, two methods that could potentially reduce reradiation and convection losses from the cavity receiver were identified. These are (1) the use of heat windows (transparent aperture coverings) which transmit solar flux while tending to block (or reflect inward) the infrared radiation generated inside the receiver and (2) the deployment of reflective surfaces around and forward of the aperture to intercept and concentrate the solar flux and thereby allow use of a smaller aperture having less losses.

The technique of using transparent heat windows was given a preliminary examination. This investigation indicated that heat windows could provide a net gain in receiver efficiency for operation at low concentration ratios of the order of 100 , coupled with high temperatures of approximately $1500^{\circ} \mathrm{F}$. However, the advanced technology concepts which offer potential for high performance operate at concentration ratios of the order of 1000 ; and the preliminary analysis indicates that for these concepts, there will be no net gain unless the operating temperatures greatly exceed $2000^{\circ} \mathrm{F}$.

Heat windows were also examined in Ref. 10, where it was indicated that net efficiency improvements would result for the low concentration ratio systems ( 100 ) being analyzed. Although high concentration systems ( 1000 ) were not specifically treated, the study showed the trend of decreasing gains with increasing concentration ratio. These results therefore generally confirm the findings of the preliminary investigation conducted for this study.

For the heat window concept, the basic problem involves overcoming the reduced amount of flux entering the receiver by retaining more of the flux that does enter. This means counteracting transmission losses through the transparent window with a reduction in infrared radiation and convection losses from the aperture. This heat balance is, of course, influenced by heat window design parameters such as type and quality of transparent material, window thickness, and thermal-optical properties. The inner surface of the mirror could be 
coated with materials such as tin oxide, indium oxide, or titanium oxide (Ref. 10) to enhance infrared blocking, but this will probably increase transmission losses. Due to the complex nature of this problem, more detailed studies are required before one can completely disregard the possibility of gains.

The concept involving the use of secondary reflective surfaces forward of the aperture has not been analyzed except in qualitative terms which indicate possibilities for some improvement in performance. For the concept to be effective, the secondary surfaces must be designed to reflect essentially all of the incoming flux toward the cavity aperture in a manner analogous to the operation of the Compound Parabnlic Concentrator (CPC). The basic difflculty with use of secondary surfaces is that these surfares ahsorb some of the energy, thereby decreasing the energy entering the cavity. If the secondary surfaces are cooled, at least a portion of the energy absorbed can be recaptured. Since the secondary surfaces in this concept are located near the receiver, it appears feasible to employ the heat exchange fluid of the receiver as the coolant for the secondary surfaces.

Under the above conditions, net gains appear possible. However, the incorporation of actively cooled secondary surfaces will complicate receiver design and increase costs. Detailed studies of these tradeoffs are required to quantitatively assess the merits of this approach.

\section{B. IDENTIFICATION OF ADVANCED TECHNOLOGIES}

The basic considerations discussed above, particularly the fundamental tradeoffs, provide guidance in identifying and selecting. advanced technologies for dispersed power systems. The key finding is that maximum temperatures at the receiver should be in the range of $1500^{\circ} \mathrm{F}$ to $2000^{\circ} \mathrm{F}$, since net system efficiency gains are unlikely to occur for higher temperatures. This tends to place diminished interest in advanced concepts such as thermionics and magnetohydrodynamic power systems, which usually operate at temperatures $>2000^{\circ} \mathrm{F}$. Therefore, since the present study could consider only a limited number of technologies, such advanced high-temperature concepts were not treated.

The selected temperature range corresponding to high overall system efficiency (see Figure 2-2) is also higher than the $1000^{\circ} \mathrm{F}-1200^{\circ} \mathrm{F}$ temperatures needed for cost-effective operation of steam-Rankine power systems. Thus, sceam systems have less potential for high performance. However, they may overcome this disadvantage by achieving lower costs or greater reliability. They have therefore been included, since they are derived from a proven technological foundation that is being used on present baseline solar thermal systems.

\section{Selected Technologies}

The selected technologies are presented in Figure 2-3 in terms of four basic candidate subsystems: (1) collection (concentrator and receiver), (2) energy conversion, (3) storage, and (4) transport. 


\begin{tabular}{|c|c|c|c|}
\hline COLLECTION & $\begin{array}{l}\text { ENERGY } \\
\text { CONVERSION }\end{array}$ & STORAGE & TRANS PORT \\
\hline $\begin{array}{l}\text { - PARABOLIC } \\
\text { DISH } \\
\text { - HELIOSTAT } \\
\text { - FRESNEL } \\
\text { LENS }\end{array}$ & $\begin{array}{l}\text { - STIRLING } \\
\text { - BRAYTON } \\
\text { - COMBINED } \\
\text { CYCLE } \\
\text { - STEAM }\end{array}$ & $\begin{array}{l}\text { - } \text { ADVANCED } \\
\text { BATTERIES } \\
\text { - CHEMICAL } \\
\left(\mathrm{SO}_{2}-\mathrm{SO}_{3}\right) \\
\text { - LIQUID } \\
\text { METAL } \\
\text { - SOLID } \\
\text { (BRICK)/GAS }\end{array}$ & $\begin{array}{l}\text { - } \text { CHEMICAL } \\
\text { PIPELINES } \\
\text { - ELECTRICAL } \\
\text { NETWORK } \\
\text { - LIQUID } \\
\text { METAL }\end{array}$ \\
\hline
\end{tabular}

Figure 2-3. Matrix of Candidate Subsystems

Solar thermal power plants are composed of appropriate combinations of these four basic subsystems.

Candidate collection subsystems include the parabolic dish, heliostats, and the Fresnel lens. The parabolic dish as shown in Figure 2-2 is associated with a cavity receiver at the focal point. The term heliostat refers to a two-axis tracking mirror. A field of these mirrors is deployed to reflect sunlight on a tower-mounted receiver. Heliostats are therefore associated with central receiver or power tower concepts as illustrated in Figure 2-4 where the Barstow pilot plant system (Ref. 1) is shown. For any system such as the power tower where the position of the receiver is fixed, there are cosine losses associated with varying the inclination of the heliostat mirror surfaces in relation to the position of the sun. For distributed systems where both the concentrator and receiver are moved during sun tracking, these cosine losses are avoided. The distributed system has higher potential for efficiently collecting energy, but this energy must be transported from the field to a central location. The power tower approach accomplishes this transport optically.

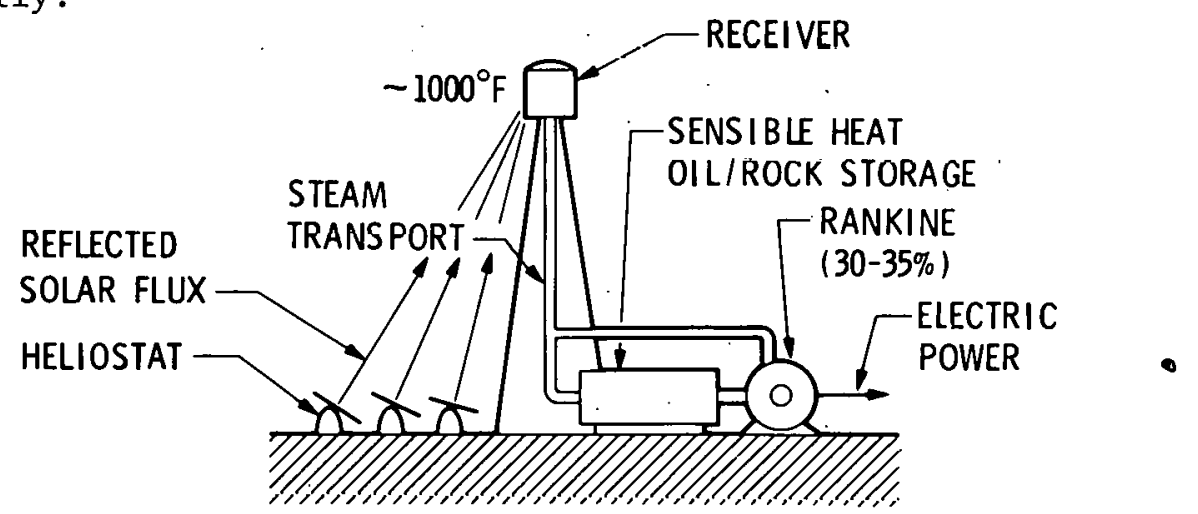

Figure 2-4. Baseline Central Receiver System (Barstow Pilot Plant) 
The Fresnel lens is made from transparent materials such as cast acrylics. It is configured with saw-tooth shaped grooves which form a series of refractive segments that focus or concentrate the solar flux passing through the lens. Fresnel lens systems can be designed for either one-axis tracking line focusing or two-axis tracking point focusing applications. Since the present study is concerned with higher temperatures and high efficiencies, the two-axis, point focusing approach was selected. For this system, the Fresnel lens would be mounted in a tracking structure functionally similar to the parabolic dish, and a cavity receiver would be located at the focal point of the lens. The focal distance behind the lens is dictated by the design of the saw-tooth pattern as well as the diameter of the lens. This system is illustrated in Figure 2-5 (see Ref. 11) where a convex 1.ens curvature, having structural advantages, is shown.

Energy conversion systems include Stirling engine and gas Brayton systems which were shown in an earlier study (Ref. 2) to have promise in the $1500^{\circ} \mathrm{F}$ to $2000^{\circ} \mathrm{F}$ temperature range. For the present study, combined cycles which can also potentially achieve high efficiencies in the desired temperature range are included. One example of a combined cycle system uses a gas Brayton topping cycle with a Rankine bottoming cycle. Steam Rankine turbine systems, used in the central receiver pilot plant (Ref. 1) are included as a baseline. Small steam engines, particularly reciprocating concepts, are also included, since they require advanced technology development to achieve efficiency levels which are theoretically attainable.

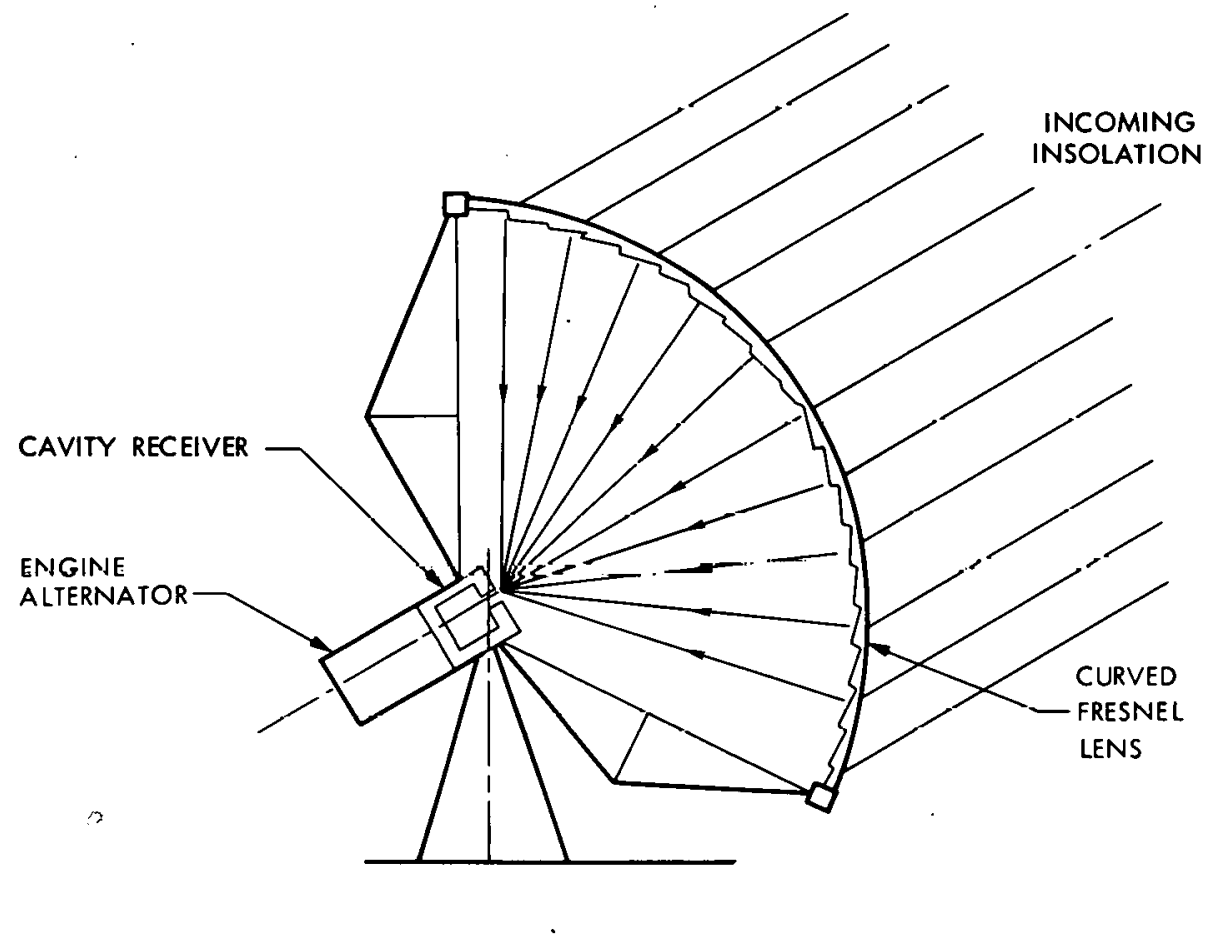

Figure 2-5. Point Focusing Fresnel Lens Collector System 
The candidate storage subsystems encompass a diversity of options. For external storage, advanced batteries were chosen. Recent progress, particularly with the Redox battery, offers encouragement regarding the availability of advanced battery storage systems in the 1985-2000 timeframe (Ref. 12). Other external storage options include pumped hydro, compressed air in underground reservoirs (caverns, aquifers, depleted gas fields, etc.), flywheels, and superconducting magnets (Refs. 13 and 14). Within uncertainty ranges associated with projecting performance and costs, it appears that several of these options could be competitive and that selection will depend on application-specific circumstances. The advanced battery was chosen as a representative system because it can be easily adapted to a wide range of applications.

Chemical storage involves the storage of thermal energy in chemical bonds. This requires a reversible endothermic-exothermic chemical reaction. In this type of reaction, thermal energy is absorbed via an endothermic reaction that yields storable chemical products. The stored energy can be released by an exothermic reaction. The potential advantages of thermochemical storage include: (1) high energy density in the form of chemical bonds, (2) possibility for efficient long-term storage at ambient temperatures and (3) relative ease of storing and transporting chemical reactants, particularly those in liquid form.

Many types of reversible chemical reactions are presently being assessed (Refs. 15 through 17). Most of the early effort has concentrated on the $\mathrm{SO}_{2}-\mathrm{SO}_{3}$ system (Ref. 18). For the present study, the following three systems were investigated.

1) Sulfur dioxide - Sulfur trioxide $\left(\mathrm{SO}_{2}-\mathrm{SO}_{3}\right)$ where $\mathrm{SO}_{3}$ is reduced to $\mathrm{SO}_{2}$ and oxygen, $\mathrm{O}_{2}$, in the endothermic reaction.

2) Methane $\left(\mathrm{CH}_{4}\right)$ where a mixture of $\mathrm{CH}_{4}$ and $\mathrm{H}_{2} \mathrm{O}$ is reduced to carbon monoxide, $\mathrm{CO}$, and hydrogen, $\mathrm{H}_{2}$, in the endothermic reaction.

3) Ammonium-hydrogen-sulfate $\left(\mathrm{NH}_{4} \mathrm{HSO}_{4}\right)$ where $\mathrm{NH}_{4} \mathrm{HSO}_{4}$ is reduced to ammonia, $\mathrm{NH}_{3}$, sulfur trioxide, $\mathrm{SO}_{3}^{4}$, and water in the
endothermic reaction.

Al1 of the above systems can operate in the desired temperature range of $1500^{\circ} \mathrm{F}$ to $2000^{\circ} \mathrm{F}$ for the endothermic reaction. The $\mathrm{SO}_{2}-\mathrm{SO}_{3}$ approach was pursued in earlier studies, e.g., Ref. 18, since it was considered to be the nearest term system. However, one disadvantage is the need to store gaseous $\mathrm{O}_{2}$. Liquids, vis-a-vis gases, generally result in more cumpacl and cost-effective atorage containers.

The methane system involves gaseous reactants, but these are considered to be suitable candidates for storage in underground reservoirs which provide extremely low-cost bulk, storage (Ref. 19). Underground gas reservoirs are available at a limited number of locations, and the size of the reservoirs is usually such that a single reservoir could service a network of small solar plants. Clearly, the methane system can only be implemented under restricted application circumstances. However, it has been included primarily to ascertain the effect of using low-cost underground storage. 
The ammonium-hydrogen-sulfate (AHS) system (Ref. 20) was chosen since it involves only liquid storage and consequently has high potential. However, it is at a much earlier development stage than either the $\mathrm{SO}_{2}-\mathrm{SO}_{3}$ or methane system.

It is recognized that selection of only three systems provides very limited insight into the potential capabilities of reversiblereaction chemical storage. These systems generaliy involve a complex design with appropriate control mechanisms, encompassing components such as reactors with catalysts, reactant separation equipment, heat exchangers, pumps, waste heat recovery turbines, and associated plumbing. Each system requires a unique combination of components that must be selected or designed to be compatible with specific requirements of the chosen reaction.

Ongoing studies under the direction of Sandia Laboratories, Livermore (SLL) will determine basic chemical storage system parameters such as throughput efficiency and costs per unit energy stored. When these studies are completed, systems can be classified according to their overall capabilities. In this context, the three selected systems could be considered to be representative of a particular class of systems yet to be defined. The estimates concerning chemical storage in this study are thus considered to be inputs for the broader overall study under way at (SLL).

On Figure 2-3, it is shown that 1 iquid metal systems have been chosen as advanced technology candidates for both storage and transport. Liquid metals such as sodium can operate in the selected temperature range, where most other liquid heat transfer media (e.g., organic fluids) decompose.

Potential advantages of liquid metal. systems include (Ref. 21):

(1) High heat transfer coefficient -- simplifies receiver design due to high flux and reduces possibility of burnouts due to localized overheating.

(2) Single phase, low pressure operation -- advantageous in terms of pumping/transport requirements and receiver design.

As discussed in Ref. 11, detailed studies involving the use of liquid metal systems are being undertaken for dispersed systems to augment activities such as Refs. 21 and 22 for central receiver concepts. Since other ongoing studies will examine the use of liquid metal systems in terms of detailed technical issues, the present study will focus mainly on identifying conceptual design arrangements that could potentially benefit from use of liquid metal technology.

Sensible heat storage involving the use of solid (brick)/gas systems is listed on Figure 2-3. This concept employs refractory materials such as $\mathrm{MgO}, \mathrm{Al}_{2} \mathrm{O}_{3}$, and $\mathrm{SiO}_{2}$ for high temperature sensible 
heat storage, and a gaseous fluid heat transfer medium (Refs. 18 and 23). One attractive arrangement involves the use of refractory material bricks arranged in a checkerboard pattern inside of an insulated container. Gaps between the bricks allow passage of the heat transfer fluid. This type of system is presently employed in the steel and glass industries. The existing technological base should expedite development of systems suitable for solar applications.

The potential advantages of this type of sensible heat storage are that it (1) operates in the desired high temperature range, (2) involves a simpler design than other high temperature approaches, (3) has potential for near-term application in view of its relatively well developed technological status, (4) could provide low-cost storage with only a small temperature drop through storage via development of a design that can maintain a thermocline during charge and discharge cycles.

Latent heat thermal storage also appears promising (Appendix B). There are detailed materials related problems which require further study. Therefore, these systems have not been included as candidates. However, data for these systems is included in Appendix B for completeness. Based on this data, latent storage should definitely be considered in future studies.

Aside from liquid metal transport as discussed previously, transport involves electrical and pipeline networks (Figure 2-3). These are essentially mature technologies where large changes in the state-of-theart are not anticipated.

\section{New Concepts}

Although the primary study effort was directed toward the selected advanced technology candidates of Figure 2-3, a major parallel activity was concerned with identifying new concepts for future study. Here, the primary criterion for selection was potential for high efficiency. Issues of complexity, cost, and technology status are not pursued in denth hut are left as subjects for follow-on studies.

As delineated earlier in terms of fundamental tradeoffs, two major objectives in formulating new concepts are (1) to reduce reradiation losses from the receiver and (2) to attain the highest possible energy conversion efficiencies in the desired temperature range of $1500^{\circ} \mathrm{F}$ to $2000^{\circ} \mathrm{F}$. For receiver reradiation loss reduction, the concept of using secondary reflecting surfaces, just ahead of the aperture appears to be promising (as discussed previously) and is therefore identified as a candidate concept worthy of further study.

For energy conversion systems, an electrochemical conversion concept (Refs. 24 and 25 ) as well as several potentially high-efficiency heat engine cycle systems were identified as candidates meriting further study. The electrochemical concept involves a high temperature electrolyzer $\left(\sim 1200 \mathrm{~K}\right.$ or $\left.1700^{\circ} \mathrm{F}\right)$ which uses solar-derived heat energy to supply. most of the energy required for electrolysis of suitable subslatices, such as water. The products of electrolysis (such as hydrogen and 
oxygen in the case of water electrolysis) are recombined in a fuel cell operating at lower temperatures $\left(2500 \mathrm{~K}\right.$ or $\left.440^{\circ} \mathrm{F}\right)$ to generate electrical energy. A small portion of this energy is used to supply the electrical needs of electrolyzers as well as parasitic energy for pumping. fluids through the system. The remaining electrical energy represents the useable output of the conversion system. This energy, divided by the solar heat energy input, is the conversion efficiency.

The basic principle (see Refs 24 and 25) of the electrochemical conversion cycle is illustrated in Figure 2-6. The enthalpy (or total energy), $\Delta H$, which is required for the decomposition reaction in the electrolyzer, is released by the recombination reaction in the fuel ce11. This enthalpy is, in general, comprised of thermal and electric energy, $\Delta G$. The fraction contributed by thermal energy increases with the temperature at which the reaction occurs. Thus, by operating the electrolyzer (decomposition reaction) at a high temperature maintained by supplying solar-derived heat, and arranging the system to allow the fuel cell (recombination reaction) to function at lower temperatures where most of the energy is released in electrical form, conversion of heat (solar thermal energy to electricity) is accomplished. Heat exchange equipment is required to maintain the desired temperature levels at both the electrolyzer and fuel cell. The hot reaction products which leave the electrolyzer must be cooled via heat exchange with the cooler recombination reaction product that leaves the fuel cell and enters the electrolyzer. 


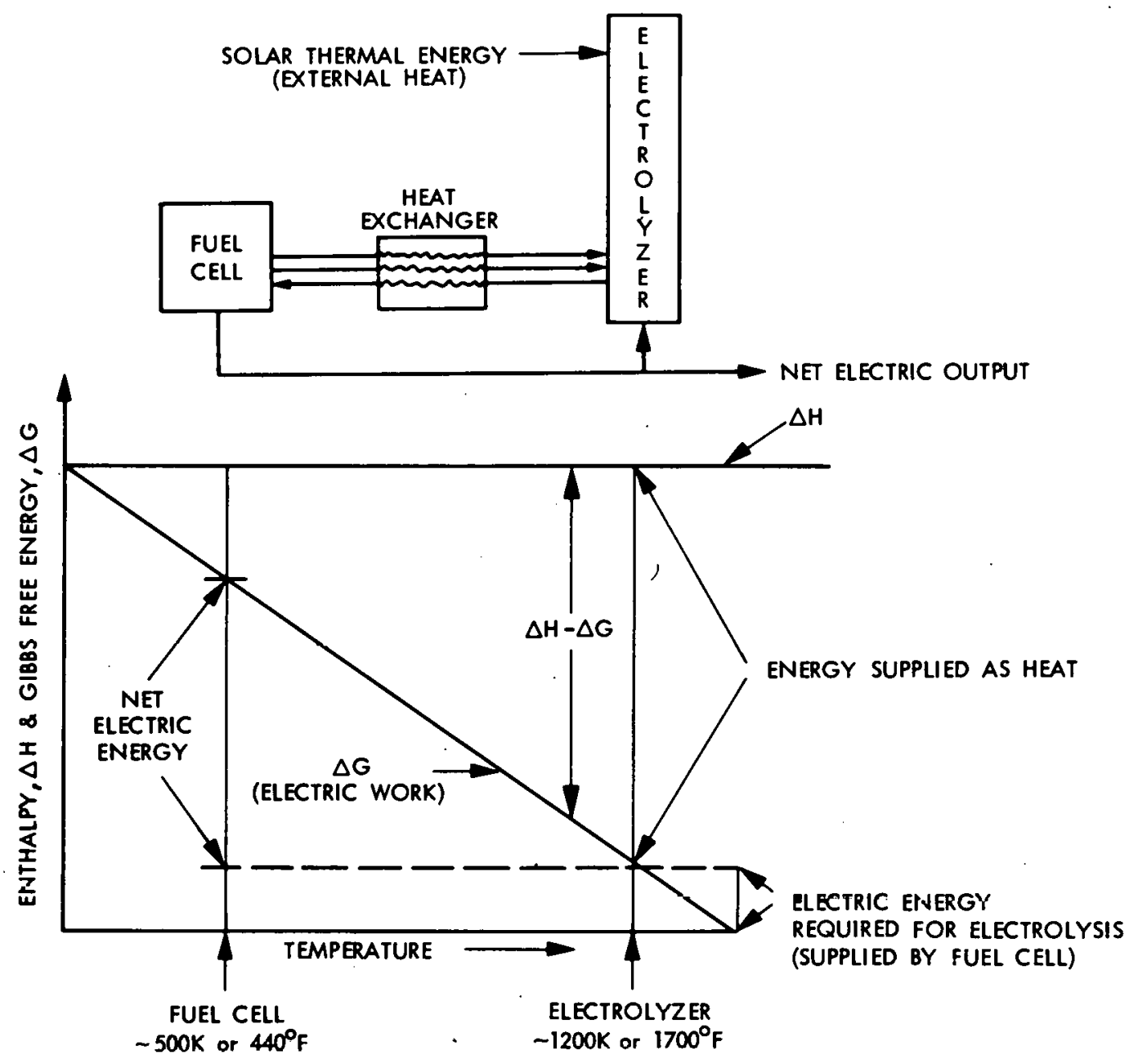

Figure 2-6. Electrochemical Conversion Cycle 
The electrochemical cycle can potentially achieve efficiencies of approximately $66 \%$ at $1500^{\circ} \mathrm{K}\left(2240^{\circ} \mathrm{F}\right)$ and $58 \%$ at $1200^{\circ} \mathrm{K}\left(1700^{\circ} \mathrm{F}\right)$

corresponding to $83 \%$ Carnot and $77 \%$ Carnot, respectively. This efficiency range is considered to be sufficiently high to permit the system to qualify as an advanced technology candidate. Another advantage is that requirements for moving parts are minimal. This implies that the system can potentially achieve high reliability.

Candidate electrochemical cycle reactions include:

$$
\begin{aligned}
\mathrm{SO}_{3} \stackrel{\text { Electrolyzer }}{\text { Fuel Cel1 }} & \mathrm{SO}_{2}+1 / 2 \mathrm{O}_{2} \\
\mathrm{H}_{2} \mathrm{O} \rightleftharpoons & \mathrm{H}_{2}+1 / 2 \mathrm{O}_{2} \\
\mathrm{CO}_{2} \rightleftharpoons & \mathrm{CO}+1 / 2 \mathrm{O}_{2} \\
\mathrm{H}_{2}+\mathrm{CO}_{2} \rightleftharpoons & \mathrm{H}_{2} \mathrm{O}+\mathrm{CO}
\end{aligned}
$$

For these reactions, effort must be expended to develop either high temperature electrolyzers or new fuel cells or both. High temperature materials are required, and much of the development effort will probably be concentrated on identifying suitable materials and compatible combinations of them. Mass production cost of electrochemical components using these materials, compared to mass production cost for heat engine conversion systems, will be a key factor in determining the extent to which the electrochemical conversion system will be implemented.

Potentially promising heat engine concepts which were not pursued in the present study include:

(1) Ternary and quarternary combined cycles which have potential for high efficiencies ( $80 \%$ Carnot) per Appendix A. Existing information pertains to large power plants of the order of a GW in power rating. Detailed scaling studies are required to determine performance and cost characteristics in the $<10 \mathrm{MW}$ power rating range which is of primary interest for the present study.

(2) Closed cycle power systems using dissociating gases can potentially achieve substantially higher cycle efficiencies compared to conventional systems employing nondissociating fluids. As discussed in Appendix A, analyses indicate that both Brayton and Stirling cycles can be improved by use of dissociating fluids such as nitrogen tetroxide $\left(\mathrm{NO}_{4}\right)$. Reactive fluid power systems are presently at a very early conceptual stage of development, and further in-depth studies are required to delineate the character of developmental problems. 
In addition to these two approaches, use of water injection in a simple Brayton cycle is worthy of further consideration for solar power system applications. Water injection raises the efficiency of the simple Braytón cycle to a level comparable to that of more costly recuperated Brayton systems (Appendix A). For some dispersed power applications where water is available, water injection may prove to be an economical option.

\section{DATA BASE COLLECTION}

The data base collection effort concentrated on the selected technologies of Figure 2-3, which were identified as having potential to achieve highly efficient solar power systems. The effort was structured to provide the following background information for each candidate subsystem:

- A description of physical features and operational characteristics.

- An assessment of present technology status and potential for future improvements.

- Adelineation of any critical advanced technology problem areas .

This background information served as the basis for projecting performance and costs of candidate subsystems. Primary emphasis was placed on subsystem efficiency and capital cost. Other considerations included operation and maintenance (O\&M) expenses, life, reliability, and downtime.

It must be recognized from the outset that projections of advanced technology in terms of expected performance and cost in a future timeframe are beset with inherent uncertainties. Therefore, projected values can be more meaningfully interpreted in a probabilistic context giving a range of uncertainty and a "most likely" value in that range. Here, the uncertainty range and most likely value are not rigorously. derivable but are instead a set of judgmental values based on insights gleaned from the available information.

Detailed findings of the data base collection activity are presented in the Appendices. A comprehensive survey of energy conversion systems is given in Appendix A. Specific aspects of energy storage systcms, particularly reversible reaction chemical concepts, were investigated; results are reported in Appendix B. Relevant information from Appendices $A$ and $B$ is combined with data on collectors (concentrators and receivers) and energy transport to give a set of power system data bases in Appendix $C$. The selection of the power system configurations developed in the Appendices will be briefly summarized in the remainder of this section. 


\section{Collectors}

Solar collectors are comprised of concentrators and receivers. Concentrators reflect sunlight toward receiver(s) where it is captured as thermal energy (Figure 2-1). Concentrators are comprised of reflective surfaces or transparent lenses with supporting structures, foundation, and tracking/control mechanisms.

a. Concentrators. Cost and performance data used for the three different two-axis tracking concentrator systems treated in this study are given in Table 2-3. Of the concentrators shown, documented in-depth mass production studies are available for only the heliostat (Refs. 26=29.) Cost rangés shown are based on Barstow pilot plant designs. Studies pertaining to advanced low cost designs are now under way and projections in the lower end of the cost range shown are anticipated. In this context, the selected nominal value of $\$ 75 / \mathrm{m}^{2}$ based on old designs has an enhanced likelihood of being achieved,

The parabolic dish concentrator is judged to be more costly than the heliostat. It requires a curved reflective surface and additional structure to support equipment (receivers, engines, generators, etc.) mounted at the focal point. Based on these considerations, the nominal cost of a mass produced dish concentrator is taken to be $\$ 90 / \mathrm{m}^{2}$ or $20 \%$ more than the nominal heliostat cost. This value is within the cost target range of $70-100 \$ / \mathrm{m}^{2}$ for distributed systems. Since this value was inferred by using mass production heliostat cost estimates as a baseline, all the assumptions and caveats pertaining to the estimates of Ref. 26 through 29 also apply to the parabolic dish costs of Table 2-2.

Table 2-2. Concentrator Cost and Performance Characteristics

\begin{tabular}{|l|c|c|c|c|c|c|}
\hline \multirow{2}{*}{$\begin{array}{c}\text { Concentrator } \\
\text { Type }\end{array}$} & \multicolumn{3}{|c|}{$\begin{array}{c}\text { Direct } \\
\text { Capital Costs,* } \\
\text { \$/m } 2 \\
\text { (1977 Dollars) }\end{array}$} & \multicolumn{3}{c|}{$\left.\begin{array}{c}\text { Optical Efficiency } \\
\text { Reflectance } \\
\text { or } \\
\text { Transmittance }\end{array}\right]$} \\
\hline & Low & High & $\begin{array}{c}\text { Most } \\
\text { Likely }\end{array}$ & Low & High & $\begin{array}{c}\text { Mot t } \\
\text { Likely }\end{array}$ \\
\hline $\begin{array}{l}\text { Heliostats } \\
\text { Pish }\end{array}$ & 45 & 100 & 75 & 0.88 & 0.95 & 0.90 \\
$\begin{array}{l}\text { Fresnel } \\
\text { Lens }\end{array}$ & 60 & 125 & 90 & 0.88 & 0.95 & 0.90 \\
\hline
\end{tabular}

*Normalized to concentrator aperture area. 
The nominal Fresnel lens concentrator cost of $\$ 85 / \mathrm{m}^{2}$ is slightly below the parabolic dish cost. The Fresnel and dish systems have fundamental similarities in that both require the support of a large surface and focal point mounted receiver assembly. The Fresnel lens system (Figure 2-5) can potentially achieve some structural advantage in terms of a simpler outer ring support for the cast lens and better weight distribution (e.g., chosen to pivot axis)? Since structural support costs are the primary cost driver, the Fresnel concentrator is ascribed a lower nominal cost than the parabolic dish.

As shown on Table:2-2, the optical efficiency (reflectance) of the heliostat and parabolic dish concentrators are taken to be the same. Presently available back silvered glass surfaces have reflectivities of $\approx 0.88$. Laboratory testing of advanced microsheets and thin fused glass has yielded reflectivities of $\approx_{0.95}$ (Ref. 30). For a system operating in the field, a nominal value of 0.90 is estimated since the surface cannot be kept as clean as laboratory test samples.

For the Fresnel lens, a portion of the energy (solar flux) impinging on the lens is reflected (from both the front and back surfaces). Additionally, a fraction of the energy is'absorbed by the. lens. Of the flux impinging on the lens, it has been estimated by Swedlow (a manufacturer of cast acrylic iresnel lenses) that $82 \%$ can theoretically pass through the lens (Ref. 31) and therefore an upper bound or high value for transmittance of 0.82 is shown on Table 2-2. Due to manufacturing errors, Swedlow estimates that transmittance might drop to as low as 0.75 with a most likely value of 0.80 .

Additionally, Swedlow has conducted studies which indicate that the appropriate geometric concentration ratio (lens aperture area to receiver opening area) for point focusing Fresnel lens systems is $\sim 1000$. It was found via computer studies that for a geometrical concentration of 875 , ninety-five percent of the flux leaving the lens enters the receiver opening. When the concentration ratio was increased to 1325 , the flux entering the receiver dropped to ninety percent. Thus, for a concentration ratio of $\sim 1000$, about $90-95 \%$ of the flux will be captured by the receiver. Achlevement of higher concentration ratios without excessive loss of flux is evidently limited by chromatic aberration effects.

It is noted that study of Fresnel lens. systems is at an early stage, particularly with regard to advanced technology possibilities. -For example, use of anti-reflective coatings to improve performance can be considered. Therefore, further study is required to delineate the ultimate potential of Fresnel lens systems.

b. Receivers. The cost and performance characteristics of towermounted central receivers and small cavity receivers for distributed systems are presented in Figure 2-7. General trends are that (1) efficiency decreases with increasing temperature due to radiation and convection heat losses while costs increase due to requirements for improved. materials and more complex designs and (2) small cavity receivers are more efficient and less costly than tower-mounted receivers. Design efficiency 


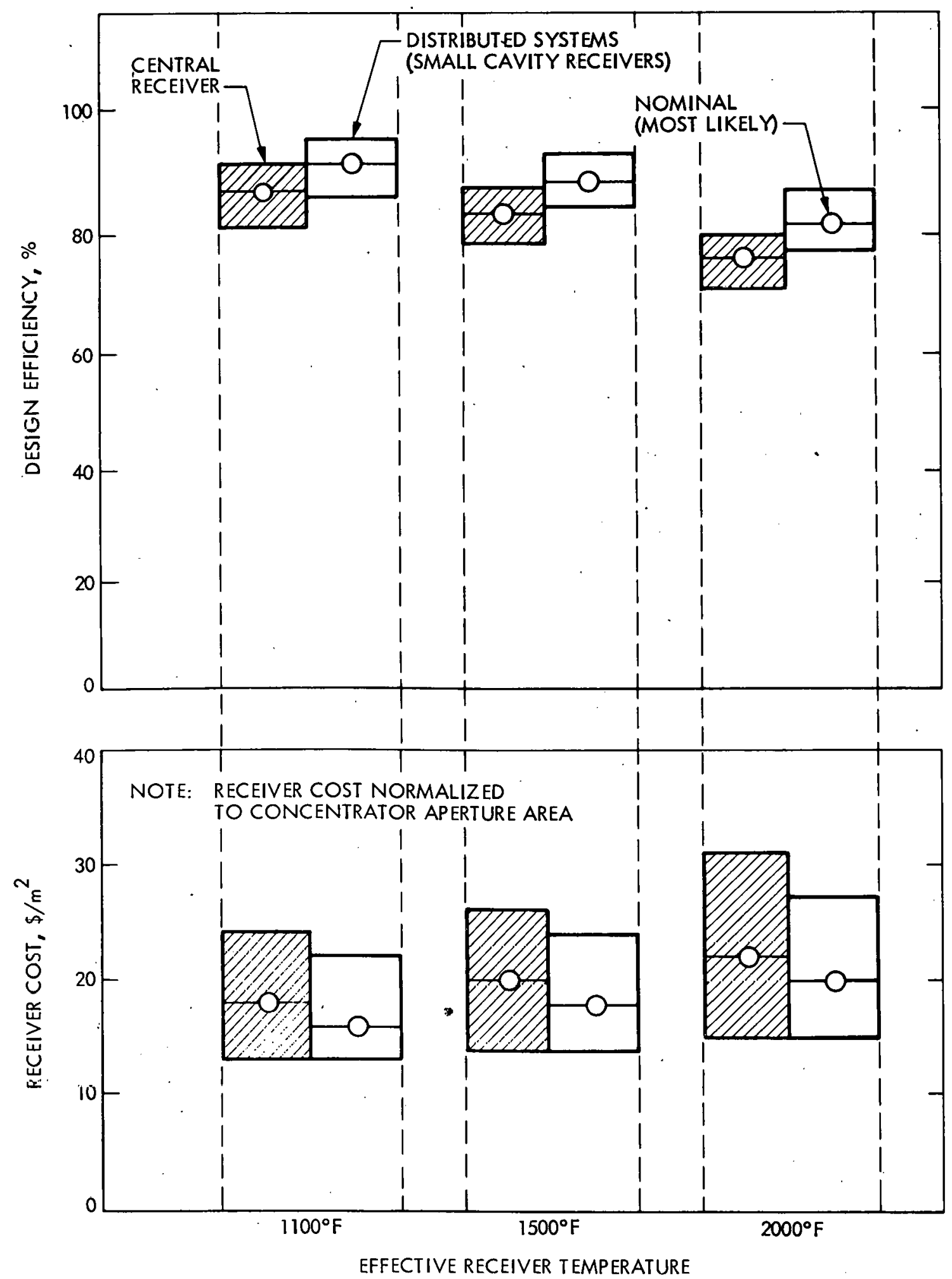

Figure 2-7. Receiver Performance and Cost Characteristics 
values are determined for an insolation of $0.8 \mathrm{~kW} / \mathrm{m}^{2}$. High, low, and most likely values used for both efficiencies and costs are shown in Figure 2-7.

The receiver efficiency is defined as the ratio of the energy in the heat transfer medium leaving the receiver to the flux approaching the receiver aperture. The heat balance on the receiver is shown in Figure 2-8. That fraction of the approaching flux which falls outside of the receiver aperture is accounted for as spillage losses. A portion of the short wave (visible spectrum) radiation entering the receiver aperture is not absorbed and this results in further losses. Of the absorbed short wave radiation, a fraction is lost via a combination of reradiation as longer wave flux and convection losses. When all of these losses are subtracted from the incident energy flux approaching the receiver, the thermal energy flux in the heat transfer fluid leaving the receiver is found.

The small cavity receiver for distributed systems is located at a short distance from the concentrator surface where spreading of the flux is small for systems with slope errors $\leq 0.1^{\circ}$ which is the regime for advanced high temperature systems. When the receiver aperture area is selected to minimize total losses, spillage losses are very small. For the tower-mounted receiver, the longer distance and the need for each mirror (heliostat) to track the sun result in optimized systems with about $4-6 \%$ spillage losses. The total receiver aperture area per unit energy flux is also higher. For these reasons, the small cavity receiver achieves higher efficiencies as shown on Figure 2-7.

The nominal cost for the small cavity receivers is taken to be less than the tower-mounted receiver since the smaller units can benefit from larger mass production. For the low-bound estimate, it was considered that both types of receivers could approach the same costs since the larger tower-mounted units could benefit from some economy of scale, e.g., less material is required to enclose and insulate a single large unit as compared to multiple small units.

\section{Energy Conversion}

Cost and performance characteristics of energy conversion systems are summarized in Table 2-3. Nominal cycle efficiency and capital costs are given as a function of temperature for major types of engines considered in the study. Supporting data and detailed characteristics such as part-load efficiency are given in Appendices $A$ and $C$,

Steam Rankine systems are suitable to temperatures of about $1100^{\circ} \mathrm{F}$, whereas Brayton and Stirling engines achieve their best performance at higher temperatures $>1500^{\circ} \mathrm{F}$. As indicated in Table $2-3$, efficiencies generally increase with temperature, but costs also tend to increase due to the need for improved materials and more sophisticated designs to withstand higher temperatures. 


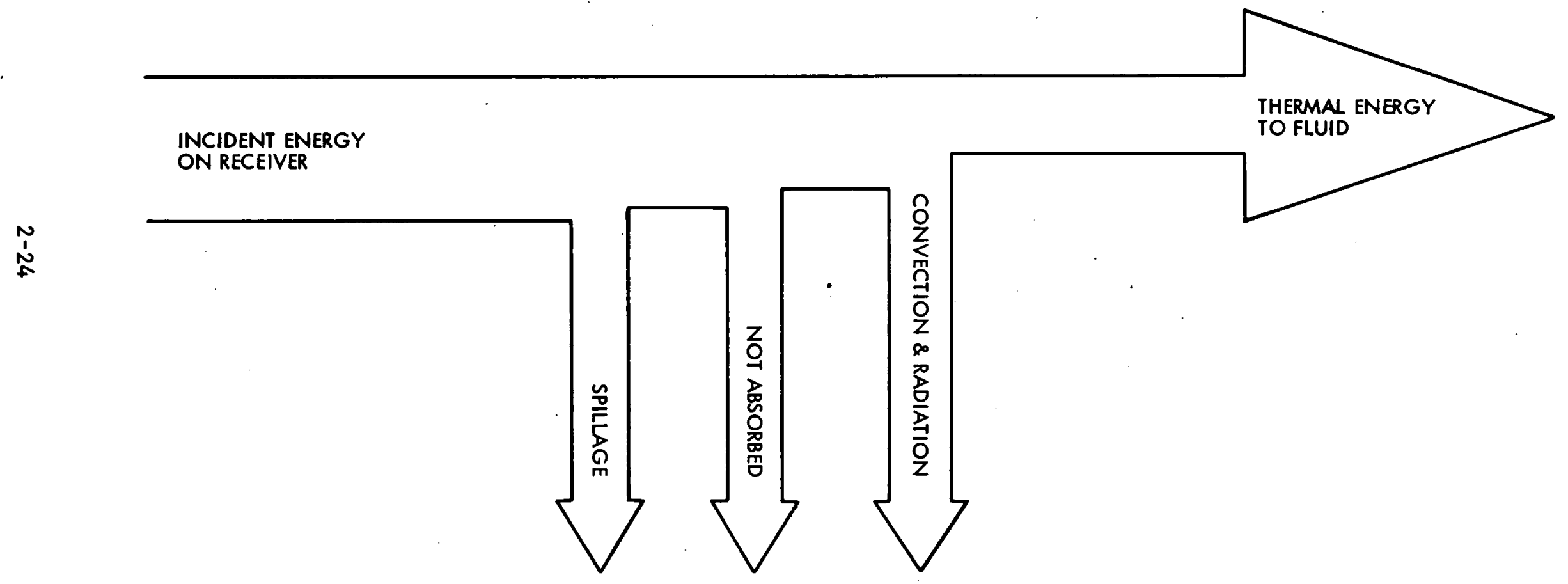

Figure 2-8. Receiver Heat $\mathrm{Balance}$ 
The values shown are based on projections of technology to the 1990-2000 time-frame. Costs are based on mass production per the basis described in Appendix A. Distributed systems employing multiple small engines will derive more benefit from mass production of engines than central systems using larger engines for the same total power or penetration of solar systems. To introduce this effect, a total solar penetration of 10,000 MW by the 1990-2000 time-frame was assumed. Then, if this penetration were to be achieved by a distributed system comprised of $20 \mathrm{~kW}$ engines, 500,000 units are required. If this same penetration were met by central $10 \mathrm{MW}$ systems, 1000 units would suffice. This mass production effect explains why smaller units on Table 2-3 generally have lower unit capital costs.

For steam Rankine engines, the $10 \mathrm{MW}$ turbine system at $33 \%$ efficiency corresponds to presently available technolugy. The small $20 \mathrm{~kW}$ energy conversion unit achieving high efficiencies approaching that of large systems requires additional technology development. Organic fluid Rankine systems are generally limited to temperatures $\angle 700^{\circ} \mathrm{F}$ due to decomposition of the fluids at higher temperatures. These cycles serve as the bottoming cycle for combined cycle systems as well as being a primary energy conversion candidate for low temperature systems.

Brayton cycles are categorized as open, closed, and subatmospheric. In the open cycle', the heated working fluid (usually air) is ingested in one part of the cycle and expelled in another, i.e., the fluid makes one pass through the cycle. For the closed cycle, the working fluid recirculates through the cycle and heat rejection is accomplished via a heat exchanger/radiator system. For the open cycle, heat rejection occurs via the exhausting of the working fluid. The subatmospheric cycle is fundamentally a closed cycle. It is distinguished from conventional closed cycles in that the working fluid acquires heat at atmospheric pressure. Then, in order to generate power, the pressure downstream of the expander (turbine) must be subatmospheric.

For recuperated cycles, the efficiencies of open and closed cycles can be nearly the same. According to the data base (see Appendix A references), open cycles are usually associated with slightly higher efficiencies along with higher costs. These trends are reflected in 'Table 2-3. Due to lower pressures resulting in less dense working fluids, the subatmospheric cycle system requires a physically larger unit for a given power level and this results in a higher unit cost. Limited developmenl work on subatmospheric cycles has been accomplished, and it is felt that efficiencies of the subatmospheric cycle relative to the conventional closed cycle are not yet definitively established. Since the subatmospheric cycle is a form of closed cycle, it has been ascribed the same value as conventional closed cycle systems for the purposes of indicating potential.

Stirling engine systems are less we11 developed than Brayton systems but can potentially achieve both higher efficiencies and lower costs according to projections in Appendix'A. Development of multicylinder crankshaft Stirling engines is under way with a major effort 
directed toward automotive applications. Small free piston units, having potential for lower mechanical losses and higher efficiency, are in an early stage of development. These units are generally limited to, lower power levels than multi-cylinder crankshaft engines and employ linear alternators which are also in an earlier stage of development than conventional rotating alternators. The characteristics shown on Table 2-3 are basically derived from available data on crankshaft Stirling engines.

\section{Transport}

For both central and distributed systems, transport from the concentrator to the receiver is optically accomplished. For $10 \mathrm{MW}$ central receiver systems, atmospheric absorption and scattering between the concentrator and receiver account for a $2 \%$ loss in energy (Ref. 32). For distributed systems, the optical transport distance is very short $(<50 \mathrm{ft})$ and losses are negligible.

Transport of thermal energy from the receiver to the energy conversion and thermal storage systems is accomplished by appropriate heat transfer media flowing through interconnecting pipelines. As shown in Table 2-4, heat transfer media considered in this study include steam, gas (helium and air) and liquid metals (sodium).

Three basic systems employing thermal transport are considered. These include (1) 10 MWe central receiver systems with options of towermounted and ground-based engines, (2) $20 \mathrm{kWe}$ distributed systems with focal point mounted engines, and (3) $140 \mathrm{kWe}$ multi-dish distributed systems where thermal energy from seven distributed dish collectors is transported to a single ground-based $140 \mathrm{kWe}$ engine.

For steam pipeline transport, the use of a pipeline network to transport steam from a field of dish collectors to a central $10 \mathrm{MWe}$ energy conversion unit is included as a point of reference. This arrangement was treated in earlier studies (e.g., Ref. 2) where the basic consideration centered around use of more efficient and already developed large steam Rankine power units. Based on projected development of advanced. small steam engines. (Table 2-3) having efficiencies and costs comparable to the large central unit, the relatively large cost of $\approx 300 \$ / \mathrm{kWe}$ (most likely) shown in Table 2-4 for the steam pipe network to a 10 MWe power unit will not be a competitive option. Further, high temperature gas and liquid metal transport are more costly than steam transport and hence extensive pipeline networks for these transport systems are not considered.

When the engine is mounted on the tower for central receiver systems or at the focal point for distributed systems, connecting pipe lengths are short and the correspondingly small costs have been included in receiver costs. Within each category of steam, gas, and liquid metal, the unit transport costs associated with the $140 \mathrm{kWe}$ multi-dish arrangement are estimated to be slightly.higher than the unit cost of transporting energy from a tower-mounted receiver to a 10 MWe ground-based. 
Table 2-4. Energy Transport System Cost and Performance Characteristics

\begin{tabular}{|c|c|c|c|c|c|c|}
\hline \multirow{2}{*}{ Syster. Description } & \multicolumn{3}{|c|}{$\begin{array}{c}\text { Direct Capital Costs }{ }^{(1)} \$ / \mathrm{kWe} \\
\text { (1977 Dollars) }\end{array}$} & \multicolumn{3}{|c|}{$\begin{array}{c}\text { Transport Efficiency } \\
\%\end{array}$} \\
\hline & Low & High & $\begin{array}{c}\text { Most } \\
\text { Likely }\end{array}$ & Low & High & $\begin{array}{l}\text { Most } \\
\text { Likely }\end{array}$ \\
\hline $\begin{array}{l}\text { Steam Pipelines } \\
\text { - } 10 \text { MWe Central Tower. } \\
\text { - } 10 \text { Me Distributed } \\
\text { - } 140 \cdot \mathrm{kWe} \text { Multi-Dish } \\
\end{array}$ & $\begin{array}{r}15 \\
250 \\
21 \\
\end{array}$ & $\begin{array}{r}22 \\
325 \\
30 \\
\end{array}$ & $\begin{array}{r}20 \\
300 \\
22 \\
\end{array}$ & $\begin{array}{l}0.97 \\
0.88 \\
0.97 \\
\end{array}$ & $\begin{array}{l}0.99 \\
0.95 \\
0.99 \\
\end{array}$ & $\begin{array}{l}0.98 \\
0.90 \\
0.98 \\
\end{array}$ \\
\hline 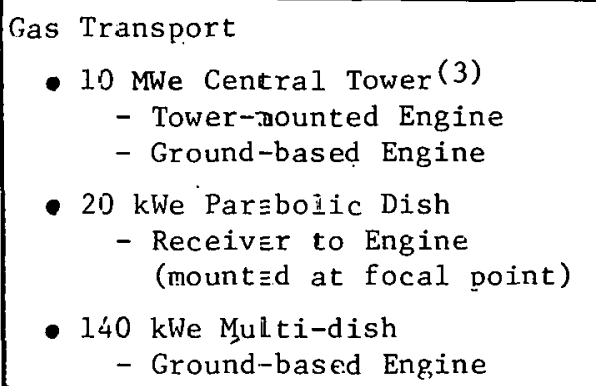 & 60 & $\begin{array}{l}\operatorname{IRC}(5) \\
90 \\
\operatorname{IRC}(5)\end{array}$ & 69 & $\begin{array}{l}0.89 \\
0.82 \\
0.95\end{array}$ & $\begin{array}{l}0.92 \\
0.87 \\
0.99\end{array}$ & $\begin{array}{l}0.30 \\
0.36 \\
0.98 \\
0.37\end{array}$ \\
\hline $\begin{array}{l}\text { Liquid Metal } \\
\text { - } 10 \text { Mwe Central Tower(4) } \\
\text { - Tower-rounted Engine } \\
\text { - Ground-based Engine } \\
\text { - } 20 \text { klve Parabolic Dish } \\
\text { - Receiver to Engine } \\
\text { (mounted at focal point) } \\
\text { - } 140 \text { kWe Multi-dish } \\
\text { - Receivers to Engine } \\
\text { (mounted on ground) }\end{array}$ & 87 & $\begin{array}{l}\operatorname{IRC}(5) \\
198 \\
\operatorname{IRC}(5)\end{array}$ & 94 & $\begin{array}{l}0.96 \\
0.90 \\
0.97\end{array}$ & $\begin{array}{l}0.98 \\
0.91 \\
0.99 \\
0.94\end{array}$ & $\begin{array}{l}0.97 \\
0.92 \\
0.98 \\
0.93\end{array}$ \\
\hline $\begin{array}{l}\text { Electrical Network } \\
\text { - } 10 \text { MWe Discributed Systems } \\
\text { - I MWe Distributed System }\end{array}$ & $\begin{array}{l}40 \\
33\end{array}$ & $\begin{array}{l}70 \\
60\end{array}$ & $\begin{array}{l}55 \\
47\end{array}$ & $\begin{array}{l}0.93 \\
0.94\end{array}$ & $\begin{array}{l}0.98 \\
0.99\end{array}$ & $\begin{array}{l}0.95 \\
0.96\end{array}$ \\
\hline
\end{tabular}

(1) Steam, gas and liçuid metal transport costs normalized to electric power (kWe) using nominal thermal to electric conversion efficiency of $33 \%$.

(2) Includes effect of pumping and thermal losses.

(3) lielium at 18 roo maximum temperature.

(4) Sodium at $1500{ }^{\circ}$ maximum temperature.
(5) InC - Included in receiver cost short pine lengths. 
engine as indicated in Table 2-4. Another general trend is that high temperature gas transport is more costly than steam transport whereas liquid metal transport is more costly than gas transport.

However, it is noted that efficiencies associated with liquid metal transport are significantly higher than gas transport. It is noted that use of larger diameter pipelines with thicker insulation could improve efficiency while increasing cost. In this context, values shown in Table 2-4 are reflective of design compromises based on engineering judgments.

In concert with the ground rules for this study, mass production of transport system components was assumed.' Additionally, mass produced components were assumed to be specifically designed to minimize time and costs associated with field assembly.

For distributed systems, focal point mounted $20 \mathrm{kWe}$ system or 140 kWe multi-dish module, energy from the collector field is transported to a central point via an electrical network (see Ref. 2). The technology for electrical connection is well established and costs are relatively low while efficiencies are also higher than a pipeline network to carry the energy to a central point.

\section{Storage}

Energy storage cost and performance characteristics are summarized in Table 2-5. The three basic categories of storage considered in this study are thermal, reversible chemical reaction, and advanced batteries. Within the thermal category, only sensible heat systems were considered. Although data for latent systems (Table 2-5) indicate that they are promising, it is felt that materials technology issues related to these systems must be explored in depth and such an effort was not possible within the scope of this study.

Of the sensible heat thermal storage candidates, liquid metal (sodium) systems are projected to be the most attractive candidate in terms of both cost and efficiency. The available data (Appendix B) indicate that storage in MgO bricks has a relatively high cost. A large portion of this cost is attributed to the vessel (tank) which contains the hot bricks arranged in a checker pattern to allow pressurized hot gases to pass by the bricks. If gas pressures in the vessel could be reduced, vessel costs could probably be reduced. However, use of lower pressure gas might require some rearrangement of the checker pattern to achieve equivalent heat transfer rates. These types of tradeoff considerations require detailed investigations which could not be performed in the present study.

It is therefore strongly emphasized that gas/solid sensible storage such as the MgO brick system should not be eliminated from consideration even though cost estimates for present designs are high. Additional study directed toward evolving lower cost designs should be undertaken to determine the potential of this approach. 
Table 2-5. Energy Storage System Cost and Performance Characteristics

\begin{tabular}{|c|c|c|c|c|c|c|}
\hline \multirow[b]{2}{*}{ Type of System } & \multicolumn{3}{|c|}{$\begin{array}{l}\text { Nominal Capital Costs } \$ / \mathrm{kWe} \\
(1977 \text { Dollars })\end{array}$} & \multicolumn{3}{|c|}{$\begin{array}{l}\text { Throughput } \\
\text { Efficiency \% }\end{array}$} \\
\hline & $\begin{array}{c}\text { Storage } \\
\text { Time } \\
3 \text { Hrs }\end{array}$ & $\begin{array}{c}\text { Storage } \\
\text { Time } \\
6 \text { Hrs }\end{array}$ & $\begin{array}{c}\text { Storage } \\
\text { Time } \\
9 \mathrm{Hrs}\end{array}$ & Low & High & $\begin{array}{l}\text { Most } \\
\text { Likely }\end{array}$ \\
\hline $\begin{array}{l}\text { Thermal(1) } \\
\text { - Sensible } \\
\text { - Oil/Rocks }(2) \\
\text { - MgO Bricks } \\
\text { - Liq. Mtls/Na } \\
\text { - Latent } \\
\text { - Fluorides } \\
\text { Reversible Chemical } \\
\text { Reaction }(1,3) \\
\text { - A H S }\left(\mathrm{NH}_{4} \mathrm{HSO}_{4}\right) \\
\text { - SO } 2 \text { - } \mathrm{SO}_{3} \\
\text { - Methanation }(4) \\
\text { Battery } \\
\text { - Redox }\end{array}$ & $\begin{array}{l}180 \\
425 \\
130 \\
100\end{array}$ & $\begin{array}{r}360 \\
525 \\
225 \\
\\
155\end{array}$ & $\begin{array}{l}305 \\
213 \\
650\end{array}$ & $\begin{array}{l}0.75 \\
0.70 \\
0.88 \\
0.70\end{array}$ & $\begin{array}{l}0.91 \\
0.68 \\
0.76 \\
0.80\end{array}$ & $\begin{array}{l}0.80 \\
0.80 \\
0.91 \\
0.76\end{array}$ \\
\hline
\end{tabular}

1. Thermal and Chemical Storage Costs Normalized to Electric Power (kWe) using nominal thermal to electric conversion efficiency of $33 \%$.

2. Baseline Storage System.

3. See Appendix B for definition of throughput efficiency; AHS denotes ammonium Hydrogen Sulfate.

4. Based on use of underground storage.

of the three reversible reaction chemical storage systems, the $\mathrm{SO}_{2}-\mathrm{SO}_{3}$ system has the lowest cost, but also the lowest throughput efficiency. The ammonium hydrogen sulfate (AHS) system has relatively low costs as well as a high throughput efficiency. The methanation system has high costs and a relatively low efficiency.

As discussed in Appendix B, reversible chemical reaction systems will have low throughput efficiencies of $240-50 \%$ unless energy recovery expanders and associated equipment are introduced in the system. Since systems with throughput efficiencies of $\sim 40-50 \%$ are not competitive, an analytical investigation was undertaken to modify baseline systems (Refs. 16 and 17) by adding energy recovery equipment. Energy recovery improves throughput efficiency (see definition in Appendix. B), but also adds to capital costs.

In terms of throughput efficiency and cost, reversible reaction systems (incorporating energy recovery equipment) are comparable to liquid metal systems. However, for all of the reversible reaction 
systems of Table 2-5, the endothermic reaction involved temperatures of $\sim 1500^{\circ} \mathrm{F}$ whereas the exothermic reaction yields heat from storage at temperatures $<1000^{\circ} \mathrm{F}$. The relatively low temperature from storage results in a 'lower heat engine cycle efficiency and obviates use of Stirling and Brayton engines which require higher temperatures for efficient. operation.

The temperature drop associated with reversible reaction systems results in a reduction in overall system efficiency as compared to systems such as liquid metal storage where temperature drops are small. It may be possible to generate higher temperatures by modifying the exothermic reaction conditions to occur, e.g., at higher pressures. These modifications would involve detailed trade-offs concerned with added costs for a higher temperature and pressure reactor as well as the need for greater pumping or compressor work.

Until further trade-off and optimization studies are performed, the ultimate capabilities of reversible reaction systems cannot be assessed. Results based on systems treated in the present study are indicative of operating conditions (temperatures) specified in current development and study activities.

The methanation storage system employs low-cost underground storage. However, costs are higher than other candidates due to the need for substantial compressor work and the associated cost of compressors. A detailed breakdown is presented in Appendix B.

The redox battery was selected as being representative of advanced battery systems. The redox battery is particularly attractive for higher storage times since it is a flow-through cell system employing simple tank storage of liquid electrolytes. For both six hours and nine hours of storage, it achieves lower costs than liquid metal storage. However, although its storage throughput efficiency is reasonably high, it is significantly lower than the liquid metal system.

\section{ADVANCED POWER SYSTEMS}

The data base for individual subsystems, summarized in the previous section, serves as the building blocks for constructing advanced power systems. Compatible or well-matched subsystems are first integrated into systems; particular effort is placed on linking them synergistically. Various system combinations are then screened, and a limited number of the most promising ones are selected for further detailed evaluation. 


\section{System Integration}

Four basic factors were instrumental in arriving at the selected subsystem configurations for the candidate systems (throughout the following 'discussion, refer to Table 2-6):

- Temperature matching

- Compatible transport fluid selection

- Structural design considerations

- Component size effects

Temperature matching was an especially dominant factor in selecting energy conversion systems. Steam Rankine systems are limited to maximum temperatures of $\sim 1200^{\circ} \mathrm{F}$ per Appendix A, whereas Brayton and Stirling cycle systems achieve high efficiencies at temperatures $>1500^{\circ} \mathrm{F}$. Therefore, Brayton or Stirling systems were generally selected for both advanced parabolic dish and heliostat central receiver solar plants because fundamental considerations as delineated in Figure 2- 2 indicate that higher system efficiencies are achieved at temperatures $>1500^{\circ} \mathrm{F}\left(\approx 800^{\circ} \mathrm{C}\right)$. Steam Rankine systems were used for the lower temperature baseline central receiver and for the Fresnel lens, which achieves concentration ratios of the order of 1000 corresponding to efficient system operation at $\sim 1000^{\circ} \mathrm{F}$. A parabolic dish system with a small advanced steam engine at the focal point was also considered to see how advanced steam technology would compare with Brayțon and Stirling systems.

For temperatures $>1500^{\circ} \mathrm{F}$, liquid metals or gases such as helium, hydrogen, and air are employed as heat transfer media to transport energy from the receiver to the engine or to energy storage. These appear to be the most promising candidates for energy transport in the high temperature range. Most fluid media such as organics are limited to temperatures of $\sim 700^{\circ} \mathrm{F}$, since they tend to decompose and degrade with time when used for higher temperature service.

Compatibility of transport fluids resulted in pairing of gas Brayton engine systems with solid/gas sensible heat storage. Here, gases such as helium can transfer energy directly from storage to the engine without an intermediate heat exchanger. Systems that use other fluids in the engine and storage systems require a heat exchanger, which results in a temperature drop as well as added costs. However, when gas transport distances are large (e.g., from the top to the bottom of a central tower), gas transport results in larger ducting and higher losses as compared to more dense liquid transport media. Therefore, the Brayton is also coupled with liquid metal transport to investigate this tradeoff.

Structural design considerations played a particularly significant role in storage selection for parabolic dish arrangements where a small engine is located at the focal point. In this case, a thermal 
Table 2-6. Candidate Advanced System

\begin{tabular}{|c|c|c|c|c|c|}
\hline \multirow{2}{*}{ Collectors } & \multirow{2}{*}{$\begin{array}{l}\text { Energy } \\
\text { Conversion }\end{array}$} & \multirow{2}{*}{$\begin{array}{l}\text { Energy } \\
\text { Storage }\end{array}$} & \multicolumn{2}{|c|}{ Energy Transport } & \multirow{2}{*}{$\begin{array}{l}\text { System } \\
\text { Ident. }\end{array}$} \\
\hline & & & Receiver-Engine & Collector Field & \\
\hline Heliostats & $\begin{array}{l}\text { Rankine (l) } \\
\text { Stirling } \\
\text { Stirling } \\
\text { Brayton } \\
\text { Brayton } \\
\text { Brayton } \\
\text { Brayton.'Rankine } \\
\text { Brayton.'Rankine }\end{array}$ & $\begin{array}{l}\text { Thermal } \\
\text { Liq Mtl } \\
\text { Battery } \\
\text { Solid/Gas } \\
\text { Liq Mtl } \\
\text { Battery } \\
\text { Solid/Gas } \\
\text { Chemical }\end{array}$ & $\begin{array}{l}\text { Steam } \\
\text { Liquid Metal } \\
\text { Helium } \\
\text { Helium } \\
\text { Liquid Metal } \\
\text { Helium } \\
\text { Air } \\
\text { Liquid Metal }\end{array}$ & $\begin{array}{l}\text { Optical } \\
\text { Optical } \\
\text { Optical } \\
\text { Optical } \\
\text { Optical } \\
\text { Optical } \\
\text { Optical } \\
\text { Optical }\end{array}$ & $\begin{array}{l}\mathrm{HR} \\
\mathrm{HS} / \mathrm{LM} \\
\mathrm{HS} / \mathrm{BAT} \\
\mathrm{HB} /(\mathrm{S} / \mathrm{G}) \\
\mathrm{HB} / \mathrm{LM} \\
\mathrm{HB} / \mathrm{BAT} \\
\mathrm{H}(\mathrm{B} / \mathrm{R}) /(\mathrm{S} / \mathrm{G}) \\
\mathrm{H}(\mathrm{B} / \mathrm{R}) / \mathrm{CH}\end{array}$ \\
\hline $\begin{array}{l}\text { Parabolic } \\
\text { Dish } \\
\\
\text { Clustered } \\
\text { Dish } \\
\text { System }\end{array}$ & $\begin{array}{l}\text { Rankine (2) } \\
\text { Stirling } \\
\text { Stirling } \\
\text { Brayton } \\
\text { Brayton } \\
\text { Brayton Subatm. } \\
\text { Brayton Subatm. (3) } \\
\text { Stirlin: } \\
\text { Brayton } \\
\text { Brayton/Rankine } \\
\text { Brayton/Rankine }\end{array}$ & $\begin{array}{l}\text { Battery } \\
\text { Battery } \\
\text { Battery } \\
\text { Battery } \\
\text { Battery } \\
\text { Battery } \\
\text { Solid/Gas } \\
\text { Liq Mtl } \\
\text { Liq Mtl } \\
\text { Liq Mtl } \\
\text { Chemical }\end{array}$ & $\begin{array}{l}\text { Steam } \\
\text { Helium } \\
\text { Liquid Metal } \\
\text { Helium } \\
\text { Liquid Metal } \\
\text { Air } \\
\text { Air } \\
\text { Liquid Metal } \\
\text { Liquid Metal } \\
\text { Liquid Metal } \\
\text { Liquid Metal }\end{array}$ & $\begin{array}{l}\text { Electrical } \\
\text { Electrical } \\
\text { Electrical } \\
\text { Electrical } \\
\text { Electrical } \\
\text { Electrical } \\
\text { Electrical } \\
\text { Electrical } \\
\text { Electrical } \\
\text { Electrical } \\
\text { Electrical }\end{array}$ & $\begin{array}{l}\mathrm{PR} \\
\mathrm{PS} \\
\mathrm{PS} / \mathrm{LM} \\
\mathrm{PB} \\
\mathrm{PB} / \mathrm{LM} \\
\mathrm{PB} / \mathrm{SUB} \\
\mathrm{PB} / \mathrm{SUB} / \mathrm{MD} \\
\mathrm{PS} / \mathrm{MD} \\
\mathrm{PB} / \mathrm{MD} \\
\mathrm{P}(\mathrm{B} / \mathrm{R}) / \mathrm{MD} \\
\mathrm{P}(\mathrm{B} / \mathrm{R}) / \mathrm{MD} / \mathrm{CH}\end{array}$ \\
\hline $\begin{array}{l}\text { Eresne 1 } \\
\text { Lens }\end{array}$ & $\begin{array}{l}\text { Rankine } \\
\text { Rankine }\end{array}$ & $\begin{array}{l}\text { Battery } \\
\text { Thermal }\end{array}$ & $\begin{array}{l}\text { Steam } \\
\text { Steam }\end{array}$ & $\begin{array}{l}\text { Electrical } \\
\text { Steam Pipes }\end{array}$ & $\begin{array}{l}\text { FR/DIS } \\
\text { FR/CEN }\end{array}$ \\
\hline
\end{tabular}

1. Baseline-First Generation System.

2. Smali Steam Engines-Efłicient Advanced Technology Designs Mounted at Focal Point.

3. Ground-Based Engina/Storage Assembly. 
storage system (4-6 hrs) appears to be too heavy and bulky for costeffective focal-point mounting. Therefore, primary energy storage is provided by ground-based batteries. The receiver, by virtue of its mass, provides some buffer storage which tends to smooth out fluctuations in the incoming insolation.

Structural aspects also influence central receiver designs. For relatively light Brayton and Stirling engine systems, a tower-top location in near proximity to the receiver is desirable to minimize transport losses, particularly for gas transport systems. Tower-top Brayton central receiver concepts are investigated in Refs. 27 and 28 . For the present study, it is tacitly assumed that energy storage systems providing of the order of $4-6$ hours of rated power will be too heavy for tower-top mounting. The possibility of ground-based battery storage is therefore introduced as an option which avoids the need for thermal transport to storage from the top to the bottom of the tower.

Also, seismic load considerations may prevent tower-top mounting of presently available Brayton engines (Ref. 28) and therefore groundbased engine design arrangements are considered. This will delineate tradeoffs between tower-top and ground-based location of the energy conversion system.

Size has a significant effect on the performance of Brayton engines (Appendix A) and also of storage systems based on liquid metal and chemical reversible reactions (Appendix B). Brayton engine performance decreases as size is reduced due to scaling effects associated with turbine blades and leakage past clearance gaps. For liquid metal storage, the external heat transfer area per unit volume of stored liquid increases as size is reduced. This results in greater losses per unit of stored energy for smaller storage systems. The same area-volume scaling relationships pertain to reactors and other elevated temperature components of reversible reaction chemical storage systems. This area-volume effect also tends to increase the cost per unit volume as size is decreased.

For parabolic dish systems, these effects of size lead to consideration of systems with multiple dish-receiver units linked or clustered together to supply heat energy to a single energy conversion/ storage module. For a multi-dish Brayton system, both the engine and storage efficiencies are higher than those of single-dish systems. However, multi-dish systems require an energy transport system between the units and the module. Such a transport system incurs losses and adds to costs.

Thus, multi-dish or clustered arrangements were primarily formulated for the purpose of examining tradeoffs between improved performance with size and transport losses. Net system gains were sought, but it is emphasized that this clustered arrangement may be advantageous even if no net gains or a slight penalty result. This potential advantage involves using either Stirling or Brayton engines that were developed for other applications. For instance, the Stirling engine is now being developed for use as an automobile power plant. An automotive 
Stirling engine linked with a cluster of dish-receiver units could provide substantial cost savings and accelerate the implementation of efficient Stirling engines for solar applications.

\section{Screening}

Candidate systems are characterized in Table 2-6 in terms of the types of subsystems comprising them. An identification code was assigned to each system. The first letter of the code refers to the type of collector: $\mathrm{H}$ denotes heliostat; $\mathrm{P}$, parabolic dish; and $\mathrm{F}$, Fresnel lens. The second letter designates the type of energy conversion system, with $R, S, B$, and $B / R$ referring to Rankine, Stirling, Brayton, and Brayton/Rankine combined cycles, respectively.

Additional letters in the code were introduced to draw distinctions among systems using the same type of collector and engine system. Specifically, the term LM refers to use of liquid metals; BAT and $S / G$ designate battery and solid/gas sensible heat storage, respectively; $\mathrm{CH}$ identifies chemical storage systems; SUB denotes a subatmospheric Brayton; and $M D$ stands for multi-dish. For Fresnel lens - Rankine (steam) systems denoted by FR, the additional terms CEN (central) and DIS (distributed) are used to distinguish between a system in which steam is transported to a central location for power generation and one in which small steam engines are coupled with Fresnel lens collectors to form small power modules.

The systems were screened to identify promising advanced technologies. The screening process was keyed to a comparative evaluation of energy costs, based on the nominal or most likely values from the data base and a plant rating of $10 \mathrm{MWe}$. As noted in earlier studies (e.g., Ref. 2), central receiver concepts tend to be less cost-effective than modular dish systems at very small sizes (on the order of $100 \mathrm{kWe}$ ). Therefore, it was decided to compare the systems at the high end (10 $M W_{e}$ ) of the plant size range most promising for dispersed power application. In thic way, potentially promising technologies for central receiver systems would not be obscured.

a. Computational Methods. The methodology used in determining energy costs is fundamentally the same as that employed in previous studies such as Ref. 2. In terms of detailed computer code structure, ease of handling via elimination of intermediate hand calculations/ manipulation of data, and reduced computer execution time, the code developed for use in the present study represents a vast improvement (Ref. 32).

The basic operation of the code is depicted in Figure 2-9. Insolation and weather data (given on an hourly basis for an entire year) and a selected plant power rating constitute basic inputs to the program, which is structured to sequentially execute three subprograms. The first of these is a performance simulation while the other two determine capital costs and energy costs. 


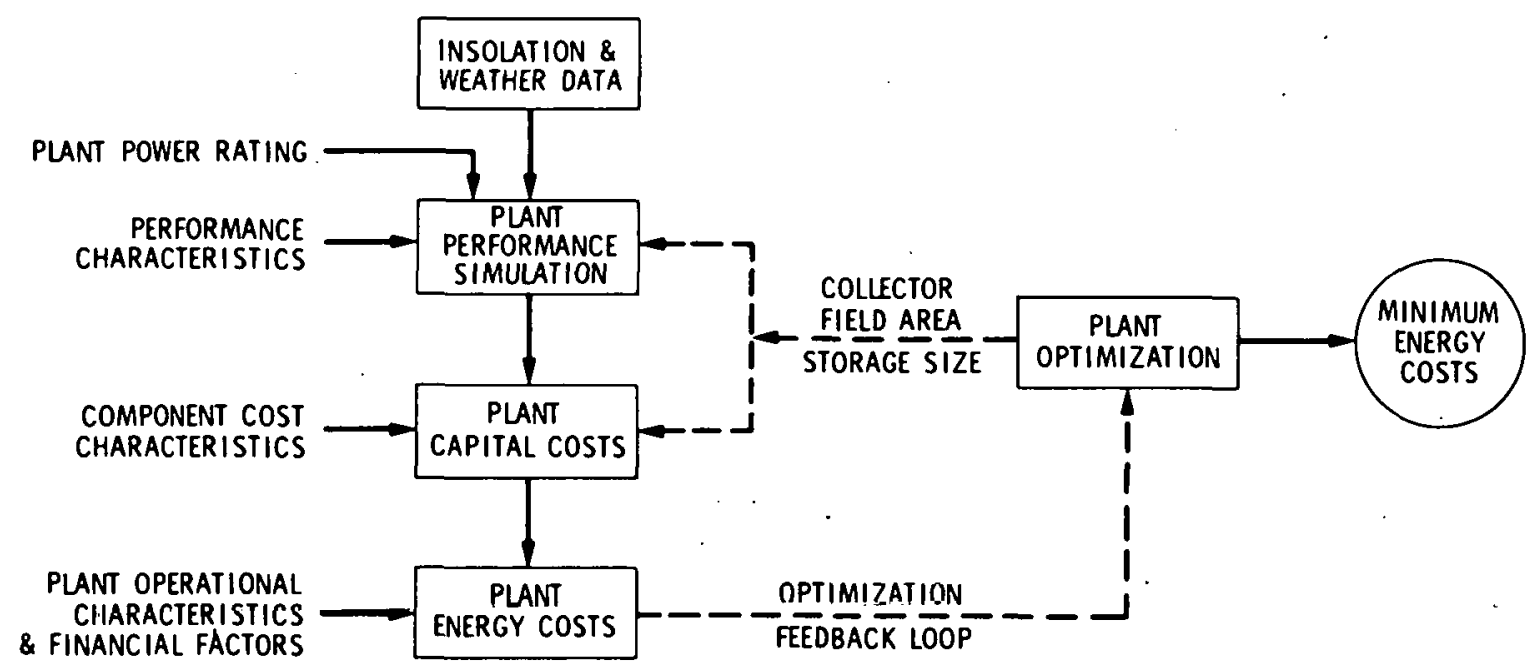

Figure 2-9. Computerized Evaluation Procedure

Performance characteristics of components (e.g., engine offdesign efficiency characteristics) constitute inputs to performance simulation. Since various types of components, particularly collectors, have different characteristics, a modular structure was created so that a number of systems could be evaluated by simply substituting appropriate modules containing the desired characteristics. This greatly facilitates use of the program in assessing different types of plants (central versus distributed) as well as configurational variations within each plant type.

Demand or load characteristics also affect plant performance simulation. The simplest choice of a constant demand is employed according to the basic data previously given. That is, the plant is asked to deliver rated power whenever it can. Any excess power is diverted to the energy storage subsystem. If energy storage is full, the excess is wasted. When the insolation level is insufficient to generate rated power, energy is withdrawn from storage until it is depleted to some minimum level determined by the characteristics of the particular storage system.

Component cost characteristics (e.g., concentrator costs per unit area) comprise the primary inputs to the capital cost subprogram. Indirect (engineering) costs, spares and contingencies, and installation costs are also input in the form of cost factors.

Plant operational characteristics (as manifest in operation and maintenance (O\&M) costs) and financial factors (encompassing items in Table 2-1 in addition to escalation rates) are required inputs for determining energy costs. The energy delivered by the plant (as determined by the performance simulation subprogram) and installed plant capital costs (as computed in the capital cost subprogram) are also necessary inputs to the energy cost subprogram. This follows 
since energy cost is essentially the annualized or "levelized" cost of capital and O\&M divided by the annual energy delivered (Ref. 3 ).

Two other basic inputs, collector field area and energy storage capacity, are controlled by the plant optimization feedback loop. The optimization algorithm is set so that a collector field area is first chosen. The storage capacity is then varied until a minimum energy cost and capacity factor are determined for each area. In this way, an envelope curve of minimum energy cost as a function of capacity factor is determined. This curve constitutes the basic output of the program.

b. Candidate System Techno-Economic Characteristics. A complete breakdown of the computer input data and associated detailed candidate system description is provided in Appendix C. Results of the energy cost comparison among candidate systems and the major factors causing energy costs to differ are summarized below.

Energy costs based on nominal or most likely values for the candidate systems of Table 2-6 are given in Tables 2-7 and 2-8 for $10 \mathrm{MW}$ central receiver and distributed system power plants, respectively. Energy costs are presented for capacity factors of 0.40 and 0.65 , where the capacity factor is defined as the actual annual energy delivered over the energy that the plant would deliver if it operated during the entire year at rated power.

Table 2-7. Nominal Energy Costs for Central Receiver Systems

\begin{tabular}{|c|c|c|c|c|}
\hline \multirow{2}{*}{$\begin{array}{l}\text { System } \\
\text { Ident. }\end{array}$} & \multicolumn{2}{|c|}{ Brief Description } & \multicolumn{2}{|c|}{$\begin{array}{l}\text { Energy Cost, } \\
\text { mills/kW-hr }\end{array}$} \\
\hline & & & $C F=0.40$ & $\mathrm{CF}=0.65$ \\
\hline HR & $\begin{array}{l}\text { Heliostat-Rankine } \\
\text { Baseline }\end{array}$ & $\left(110^{\circ} \mathrm{F}\right)$ & 102 & 122 \\
\hline$\overline{\mathrm{HS}} / \mathrm{BAT}$ & $\begin{array}{l}\text { Heliostat-Stirling/ } \\
\text { Battery }\end{array}$ & $\left(1800^{n} \mathrm{~F} \mathrm{He}\right)$ & 90 & 99 \\
\hline HS/LM & $\begin{array}{l}\text { Heliostat-Stirling/ } \\
\text { Liq. Metal }\end{array}$ & $\left(1500^{\circ} \mathrm{F}\right)$ & 74 & 79 \\
\hline $\mathrm{HB} /(\mathrm{S} / \mathrm{G})$ & $\begin{array}{l}\text { Heliostat-Brayton } \\
\text { (Closed)/MgO Bricks }\end{array}$ & $\left(2000^{\circ} \mathrm{F} \mathrm{He}\right)$ & 106 & 109 \\
\hline $\mathrm{HB} / \mathrm{LM}$ & $\begin{array}{l}\text { Heliostat-Brayton } \\
\text { (Open) Liq. Metal }\end{array}$ & $\left(1500^{\circ} \mathrm{F}\right)$ & 79 & 85 \\
\hline $\mathrm{HB} / \mathrm{BAT}$ & $\begin{array}{l}\text { Heliostat-Brayton } \\
\text { (Closed)/Battery }\end{array}$ & $\left(2000^{\circ} \mathrm{F} \mathrm{He}\right)$ & 95 & 104 \\
\hline $\mathrm{H}(\mathrm{B} / \mathrm{R}) /(\mathrm{S} / \mathrm{G})$ & $\begin{array}{l}\text { Heliostat-Combined } \\
\text { Cycle/MgO Bricks }\end{array}$ & $\left(2000^{\circ} \mathrm{F} \mathrm{He}\right)$ & 104 & 107 \\
\hline $\mathrm{H}(\mathrm{B} / \mathrm{R}) / \mathrm{CH}$ & $\begin{array}{l}\text { Heliostat-Combined } \\
\text { Cycle/Chem-AHS }\end{array}$ & $\left(1800^{\circ} \mathrm{F} \mathrm{Na}\right)$ & 85 & 9.3 \\
\hline
\end{tabular}


Table 2-8. Nominal Energy Costs for Distributed Systems

\begin{tabular}{|c|c|c|c|c|}
\hline \multirow{2}{*}{$\begin{array}{l}\text { System } \\
\text { Ident. }\end{array}$} & \multirow{2}{*}{\multicolumn{2}{|c|}{ Brief Description }} & \multicolumn{2}{|c|}{$\begin{array}{l}\text { Energy Cost, } \\
\text { mills/kW-hr }\end{array}$} \\
\hline & & & $\overline{\mathrm{CF}}=0.40$ & $\mathrm{CF}=0.65$ \\
\hline PR & $\begin{array}{l}\text { Parabolic Dish- } \\
\text { Rankine/Battery }\end{array}$ & $\left(1100^{\circ} \mathrm{F}\right)$ & 92 & 95 \\
\hline PS-1 & $\begin{array}{l}\text { Parabolic Dish- } \\
\text { Stirling/Rattery }\end{array}$ & $\left(1500^{\circ} \mathrm{F} \mathrm{He}\right)$ & 68 & 70 \\
\hline PS-2 & $\begin{array}{l}\text { Parabolic Dish- } \\
\text { Stirling/Battery }\end{array}$ & $\left(1800^{\circ} \mathrm{F} \mathrm{He}\right)$ & 63 & 65 \\
\hline PS/LM & $\begin{array}{l}\text { Parabolic Dish- } \\
\text { Stirling/Battery }\end{array}$ & $\left(1500^{\circ} \mathrm{F} \mathrm{Na}\right)$ & 67 & 69 \\
\hline $\mathrm{PB}$ & $\begin{array}{l}\text { Parabolic Dish- } \\
\text { Brayton (Closed)/ } \\
\text { Battery }\end{array}$ & $\left(2000^{\circ} \mathrm{F} \mathrm{He}\right)$ & 75 & 77 \\
\hline $\mathrm{PB} / \mathrm{LM}$ & $\begin{array}{l}\text { Parabolic Dish- } \\
\text { Brayton (Open/ } \\
\text { Battery }\end{array}$ & $\left(1500^{\circ} \mathrm{F} \mathrm{Na}\right)$ & 85 & 87 \\
\hline $\mathrm{PB} / \mathrm{SUB}$ & $\begin{array}{l}\text { Parabolic Dish- } \\
\text { Brayton (Sub)/ } \\
\text { Battery }\end{array}$ & $\left(2000^{\circ} \mathrm{F} \mathrm{He}\right)$ & 75 & 77 \\
\hline $\mathrm{PB} / \mathrm{SUB} / \mathrm{MD}$ & $\begin{array}{l}\text { Multi-Dish-Brayton } \\
\text { (Sub)/MGO Bricks }\end{array}$ & $\left(2000^{\circ} \mathrm{F} \mathrm{He}\right)$ & 97 & 101 \\
\hline $\mathrm{PS} / \mathrm{MD}$ & $\begin{array}{l}\text { Multi-Dish-Stirling/ } \\
\text { Liquid Metal }\end{array}$ & $\left(1500^{\circ} \mathrm{F} \mathrm{Na}\right)$ & 63 & 68 \\
\hline $\mathrm{PB} / \mathrm{MD}-1$ & $\begin{array}{l}\text { Multi-Dish-Brayton } \\
\text { (Closed)/Liquid Metal }\end{array}$ & $\left(1500^{\circ} \mathrm{F} \mathrm{Na}\right)$ & .70 & 76 \\
\hline $\mathrm{PB} / \mathrm{MD}-2$ & $\begin{array}{l}\text { Multi-Dish-Brayton } \\
\text { (Closed)/Liquid Metal }\end{array}$ & $\left(1800^{\circ} \mathrm{F} \mathrm{Na}\right)$ & 68 & 74 \\
\hline $\mathrm{P}(\mathrm{B} / \mathrm{R}) / \mathrm{MD}$ & $\begin{array}{l}\text { Multi-Dish-Combined } \\
\text { Cycle/L1qu1d Mctál }\end{array}$ & $\left(1800^{\circ} \mathrm{F} \mathrm{Na}\right)$ & 67 & 73 \\
\hline $\mathrm{P}(\mathrm{B} / \mathrm{R}) / \mathrm{MD} / \mathrm{CH}$ & $\begin{array}{l}\text { Multi-Dish-Combined } \\
\text { Cycle/Chem-AHS }\end{array}$ & $\left(1800^{\circ} \mathrm{F} \mathrm{Na}\right)$ & 78 & 86 \\
\hline FR/DIS & $\begin{array}{l}\text { Fresnel-Rankine/ } \\
\text { Battery }\end{array}$ & $\left(1100^{\circ} \mathrm{F}\right)$ & 90 & 92 \\
\hline FR/CEN & $\begin{array}{l}\text { Fresne1-Rankine/ } \\
\text { Central Engine }\end{array}$ & $\left(1100^{\circ} \mathrm{F}\right)$ & 102 & 120 \\
\hline
\end{tabular}


From Table 2-7, the following three candidates are selected as being the most promising in terms of nominal energy costs.

$$
\text { Reduction in Energy Cost*,\% }
$$

\section{Selected Systems}

- Heliostat-Stirling with Liquid Metal

"Transport and Storage (HS/LM)

- Heliostat-Brayton (open cycle) with Liquid Metal Transport and Storage (HB/LM)

- Heliostat-Combined Cycle with Liquid Metal Transport and Chemical AHS Storage (H(B/R)/CH)

\begin{tabular}{|c|c|}
\hline$C F=0.40$ & $C F=0.65$ \\
\hline 27 & 35 \\
\hline 23 & 30 \\
\hline 17 & 24 \\
\hline
\end{tabular}

${ }^{\star}$ Referenced to Heliostat-Rankine Baseline system (HR)

The Heliostat-Stirling system shows the largest reduction in energy cost primarily because the stirling engine has the highest projected efficiencies (Table 2-3). The Heliostat-Brayton achieves a slightly lesser reduction since the Brayton engine is projected to have lower efficiencies than the Stirling. The combined cycle (Brayton/ Rankine) with chemical storage is selected because it embraces additional technology options while also providing significant energy cost reductions.

If the combined cycle were employed with liquid metal transport and storage, reductions comparable to the Heliostat-Brayton would be achieved. The efficiency of the combined cycle is higher, but its cost is also slightly greater. When used with chemical AHS storage, the $<1000^{\circ} \mathrm{F}$ heat from storage is fed to the bottoming Rankine cycle. The temperature drop and associated reduced conversion efficiency of storage-derived heat accounts for the lesser energy reduction of chemical storage systems.

As discussed previously, the available data base gives high costs for MgO brick storage. Additionally, the gas transport (Table 2-4) required for this storage concept is associated with lower efficiencies. This explains the high energy costs for systems employing Mgo bricks.

Heliostat-Stirling and Brayton systems employing towermounted engines and ground-based battery storage also yield significant cost reductions over the baseline. However, the reductions are not as large as for liquid metal systems. The primary reasons are (1) a higher projected storage efficiency for liquid metal systems and (2) additional costs for a larger engine and associated power generation equipment. Since it was assumed that there was no thermal storage between the receiver and engine, the engine was sized to accept heat rates corresponding to peak insolation levels. The incorporation of a small amount of buffer storage ( $\sim 1 \mathrm{hr}$ ) would probably result in a more optimal system. This further detailed optimization is left as the subject for future studies. 
For the distributed systems of Table 2-8, Stirling engine arrangements generally provide the largest energy reductions due to their higher estimated efficiencies. However, other technologies are also promising with regard to potentially achieving substantial energy cost reductions over the baseline Heliostat-Rankine system of Table 2-7. Therefore, a set of candidate systems was selected to cover a range of technology options. These systems are described below:

$$
\text { Reduction in Energy Cost*, \% }
$$

\section{Selected Systems}

- Parabolic Dish-Stirling with Redox Batteries and $1800^{\circ} \mathrm{F}$ He Receiver (PS-2)

- Parabolic Dish-Brayton (closed) with Redox Batteries and $2000^{\circ} \mathrm{F}$ He Receiver (PB)

- Multi-Dish-Stirling with $1500^{\circ} \mathrm{F}$ Liquid Metal Transport and Storage (PS/MD)

- Multi-Dish-Combined Cycle with $1800^{\circ} \mathrm{F}$ Liquid Metal Transport and Storage $(P(B / R) / M D)$

- Fresnel-Rankine with Redox Batteries and $1100^{\circ} \mathrm{F} \quad 12$ Steam Receiver (FR/DIS)

* Referenced to Heliostat-Rankine Baseline system (HR)

$$
\underline{C E}=0.40 \quad \underline{C F}=0.65
$$

38

26

38

44

34

40 25

The parabolic dish-Stirling (PS-2) with an $1800^{\circ} \mathrm{F}$ receiver and focal-point mounted engine provides the largest reduction in energy costs. A similar system (PS-1) operating at $1500^{\circ} \mathrm{F}$ also achieves substantial but slightly lower reductions of $33 \%$ and $43 \%$ for capacity factors of 0.40 and 0.65 , respectively.

The parabolic dish-Stirling with liquid metal receiver (PS/LM) operating at $1500^{\circ} \mathrm{F}$ achieves performance slightly higher than (PS-1), but lower than PS-2. All three systems exhibit high potential and PS-2 was selected as being representative. It is indicated that achievement of $1800^{\circ} \mathrm{F}$ is desirable, but that a $1500^{\circ} \mathrm{F}$ system will provide most of the potential benefits.

The parabolic dish-Brayton (PB) with small $20 \mathrm{kWe}$ focal-point mounted engine provides substantial reductions: These reductions are significantly lower than the Stirling system because the cycle efficiency of small Braytons is lower than the Stirling. As discussed previously, Brayton engine efficiency drops as size decreases whereas Stirling engines maintain nearly constant efficiency with variations in size. A higher operating temperature of $2000^{\circ} \mathrm{F}$ was used to partially offset the drop in engine efficiency. However, overall system efficiency gains for operation at $2000^{\circ} \mathrm{F}$ are small due to higher receiver heat loss (see Figure 2-2). 
The parabolic dish-Brayton (subatmospheric cycle) identified as $\mathrm{PB} / \mathrm{SUB}$ on Table 2-8 achieves essentially the same reduction as the selected candidate closed-cycle Brayton system (PB). This follows because the efficiency potential of the subatmospheric cycle is assumed to be the same as the closed-cycle while costs are only slightly higher. The subatmospheric cycle is particularly compatible with vented (atmospheric pressure) cavity receivers and offers an additional system option if attractive vented cavity receivers are developed.

The selected candidate multi-dish Stirling with liquid metal transport and storage attains nearly the same energy cost reduction as the parabolic dish-Stirling with small focal point mounted engine (PS-2) and battery storage. The primary reason is that liquid metal storage is projected to be more efficient and cost-effective as compared to battery storage, particularly for systems using Stirling engines which efficiently convert stored heat to electricity. Note that in Table 2-5, storage costs were normalized to delivered power by using a nominal conversion efficiency of $33 \%$. For Stirling engines at $1500^{\circ} \mathrm{F}$, overall conversion efficiencies are $\approx 40 \%$ and this would result in unit storage costs that are about $20 \%$ lower than shown in Table 2-5, i.e., liquid metal storage costs are below redox battery costs.

The multi-dish arrangement employs seven dishes linked to a $140 \mathrm{~kW}$ engine. It is significant that this clustered arrangement can potentially achieve cost reductions comparable to the single dish with $20 \mathrm{kWe}$ engine because Stirling engines being developed for automotive applications can be used in the multi-dish arrangement.

The multi-dish combined cycle (Brayton/Rankine) also achieves sizeable reductions that are slightly less than the multi-dish Stirling. For this system and the heliostat-combined cycle system, $H(B / R) / C H$, $1800^{\circ} \mathrm{F}$ liquid metal (sodium) transport was employed. Liquid metal transport at temperatures $<1500^{\circ} \mathrm{F}$ is considered to be within presently achievable technology whereas higher temperatures such as $1800^{\circ} \mathrm{F}$ will require technology development to attain reliable systems.

The Fresnel-Rankine with small heat engines mounted at the focal point (FR/DIS) was selected in order to include the optional technologies of the Fresnel lens and advanced small steam engines. Energy: cost reductions are considerably less than high temperature Brayton and Stirling options due to lower conversion efficiencies associated with lower temperature operation. As noted previously, advanced Lechnology possibilities of the Fresnel lens have not been investigated. Further study is needed to determine how much additional improvement can be achieved.

Referring to Tables $2-7$ and $2-8$ and the selected candidate systems, it is seen that both advanced central receiver and distributed systems can potentially achieve large energy cost reductions relative to the baseline Heliostat-Rankine system. For the nominal estimates, the distributed systems achieve slightly greater reductions. Generally, two-axis tracking heliostats are less costly than distributed 
dish concentrators, but the geometrical arrangement of a fixed towermounted receiver results in optical losses associated with the so-called cosine effect and blocking and shadowing that are not encountered in distributed concentrator systems (Ref. 32). These losses of about $225 \%$ offset the lower cost for the heliostat mirror collection system relative to distributed systems.

Thus, to a first order the central receiver and distributed systems are comparable in terms of potential for providing advanced systems that can approach system cost targets. Uncertainties in the projected data base are such that it is impossible to categorically choose either of the two basic approaches as being clearly advantageous in terms of strictly techno-economic considerations.

To illustrate the gaino dcrived froin advanced rechnology, minimum cost contours for the baseline Heliostat-Rankine and the parabolic dish-Stirling are shown on Figure 2-10. These contonirs or envelope curvca were derived via the computer optimization procedure depicted in Figure 2-9. It is seen that the identified advanced configurations are approaching system targets. It is felt that further detailed trade-off and optimization studies based on these systems will result in achievement of target values.

For screening purposes, downtime (including scheduled and unscheduled maintenance) was taken to be $\approx 14 \%$, corresponding to a maximum capacity factor of 0.86 as shown on Figure 2-10. Along the minimum cost contour, both the capacity factor and collector field area increase as the load factor increases. The contour curves are relatively flat until they approach the maximum load factor limit. At this point, very large areas and storages are required and energy costs rise steeply. Hence, the primary operating capacity factor range for solar plants is considered to be between 0.40 and 0.75 .

The physical reason for the sharp increase in the contour curve at high load factors is based on weather-related characteristics. When long periods of inclement weather (e.g., several days) are encountered, the solar plant cannot deliver energy during this period unless days of storage and a collector field size large enough to fill this storage while delivering rated power are provided. If this were done, the collector field and storage system would be under-utilized during most of the operating time of the plant. To approach the maximum capacity factor, it is necessary to deliver energy during long periods of Inclement weather.

For both the baseline and advanced parabolic dish-Stirling, the minimum energy cost contours increase monotonically with capac1ty factor. The Heliostat-Rankine increases more rapidly. This more rapid increase is attributed to storage system characteristics. The oil/rock sensible thermal storage of the baseline system accepts heat at $\sim 1000^{\circ} \mathrm{F}$ but is only able to deliver heat at $500-600^{\circ} \mathrm{F}$. This results in low system efficiencies when operating from storage. As capacity factors 


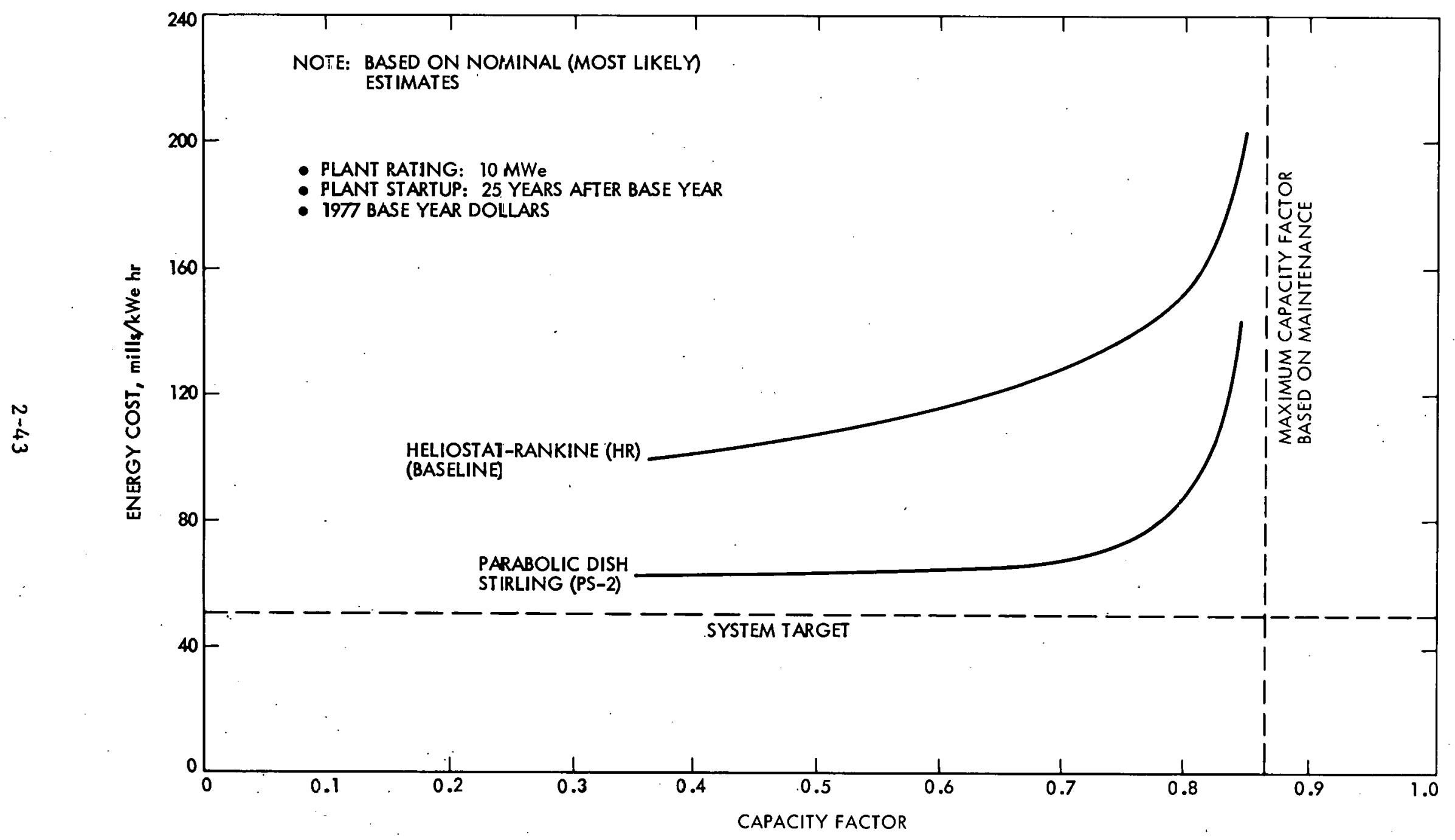

F1gure 2-10. Improvement In Minimum Energy Cost Contour 
increase, more operation from storage is required and this results in a more rapidly rising minimum cost contour curve. Advanced thermal storage systems such as liquid metals and thermocline concepts tend to have much smaller temperature drops through storage and consequently have flatter contour curves. 
EVALUATION OF SELECTED ADVANCED POWER SYSTEMS

In the preceding section, promising candidate systems and associated advanced technologies were identified via a screening procedure. This section is concerned with the evaluation of the selected advanced systems. The risk/decision analys is methodology predlcated on use of probabilistic techniques to evaluate advanced power systems is first described. Then, the benefits derived from the selected advanced technology candidates are determined with data base projection uncertainties treated in a probabilistic manner. Finally, candidate systems are ranked in terms of (1) potential benefits and (2) risk/decision criteria where benefits are weighed against factors such as developmental risk, probability of success, reliability, etc.

\section{A. RISK/DECISION ANALYSIS METHODOLOGY}

The methodology employed herein is basically an adaptation of well-established risk/decision analysis methods used in managing industrial/commercial enterprises. Since projections of advanced system techno-economics involve large uncertainties, a method specifically tailored to decision-making in an environment of large uncertainties was adopted for the present study. This method is characterized by the use of simple probabilistic techniques since more elaborate procedures cannot be meaningfully implemented when uncertainties are large and probabilistic distributions can only be roughly estimated.

\section{Basic Premise}

In decision-making the three basic factors of benefit, cost, and risk must be weighed. For the evaluation of advanced systems, the benefit is the projected cost savings over the baseline system. The cost is the advanced technology investment required to bring the advalued sysleim to the point of commereial readiness in thc projcctcd implementation time-frame. Risk is primarily governed by an assessment of probability of success in terms of the type and degree of technology development required.

The fundamental relationship that must be satisfied before undertaking a venture is as follows:

(Probability of Success) $X$ (Annual Savings) $\geq$ Equivalent Uniform Annual Coct

This simply states that a net gain is expected as a result of cost expenditures (i.e., advanced technology investment). Multiplication of the projected annual savings by the probability of success introduces the element of risk. For example, consider two advanced technology projects requiring the same investment where one has a modest projected annual savings and the other has large projected savings. The project with larger potential gains is not necessarily the best choice. 
If the high gain approach has a low probability of success, it may be less desirable than the project with a modest projected gain.

2. Probabilistic Techniques

A key element in the methodology is the projection of annual savings. These savings are the energy cost savings of the advanced system as compared to the baseline system times the annual energy delivered by the advanced power plants. The annual energy is determined by the penetration of the advanced solar system into the power network and this in turn is strongly influenced by the energy cost of these solar systems vis-a-vis other alternatives.

Energy costs depend on projections of both performance and economics of advanced systems. These projections involve large uncertainties which were treated via the range approach in previous studies (Refs. 2 and 35) where uncertainties were treated as bounds on a range of values. A nominal value corresponding to a most likely estimate within the range was selected. Nominal values for all data base parameters were used to determine nominal system energy costs. Highest efficiencies and lowest costs were combined to determine lower bound energy costs while lowest efficiencies and highest costs yielded upper bound energy costs.

An improved approach as used in the present study is to associate the uncertainty range with probabilities (Ref. 36). This probabilistic measure of energy cost uncertainties can then be related to the probability of success. In this way, the risk/decision analysis methodology can be implemented.

A four-step procedure is used to relate uncertainty ranges with probabilities. According to this procedure, it is necessary to

1) Express costs, system efficiencies, and other relevant performance parameters in terms of three point estimates (low, most likely, and high).

2) Generate random value distributions based on the three point estimates.

3) Conduct performance and economic simulations of solar thermal power plants uslng probabilistic distributions for cach parameter.

4) Generate probabilistic distributions for both capacity factor and energy costs, where capacity factor is a measure of the energy delivered and is therefore reflective of overall system performance.

Where large uncertainties exist, experience has shown that in making estimates, most people achieve their best effectiveness when estimating $10 \%$ high-low bounds and a most likely value (Ref. 37). This is the basis of the three-point estimate method illustrated on Figure 3-1. 


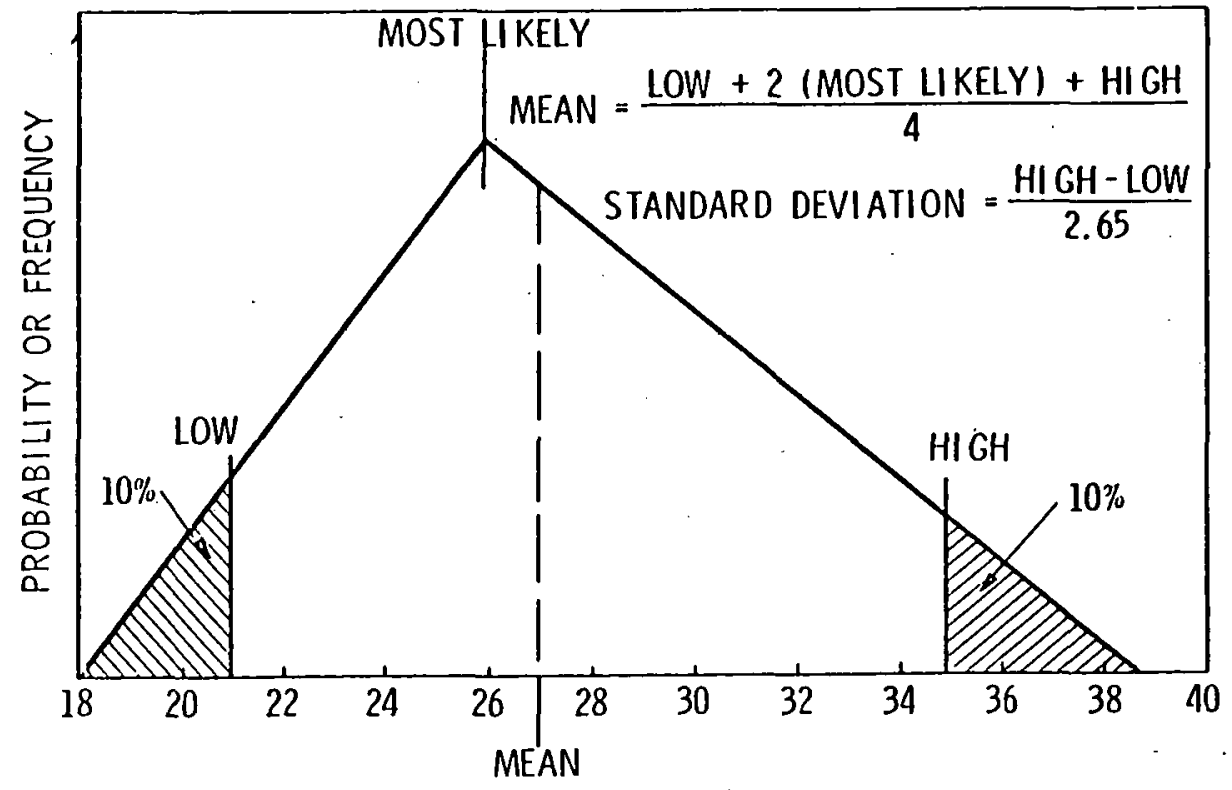

NOTE: THREE POINT ESTIMATES UTILIZED FOR OBTAINING PROBABILISTIC (RANDOM) DISTRIBUTIONS

Figure 3-1. Three-Point Estimates

For the low estimate, there is a $10 \%$ chance that the value could be lower. For the high, there is $10 \%$ chance that the value could be higher. The most likely value occurs wi.thin the range bounded by the high and low estimates and reflects the estimator's best judgement.

Based on three-point estimates of low, high, and most likely values, the mean and standard deviation are computed (see Figure 3-1). These values are then used in determining probabilistic distributions. A digital computer technique employing Monte Carlo methods was selected as a convenient way of generating random distributions.

The random distribution for costs, efficiencies and performance parameters serve as inputs to power system simulations. The simulation methodology is depicted in Figure 3-2. The power plant is comprised of subsystems that are characterized in terms of techno-economic parameters for which three point estimates and probabilistic distributions are generated.

Sets of randomly selected values are sequentially used as inputs to the power plant simulation program described previously. Corresponding values of capacity factor and energy costs are plotted as a function of frequency of occurrence. This plot is the probability distribution which reflects the effect of the probability distributions for all the input parameters. Since a large number of random sets or trials are necessary to generate a distribution curve, an approximate technique for bypassing the lengthy hour-by-hour simulation was developed (Ref. 36). The dashed line on Figure 3-2 corresponds to this computational shortcut. 


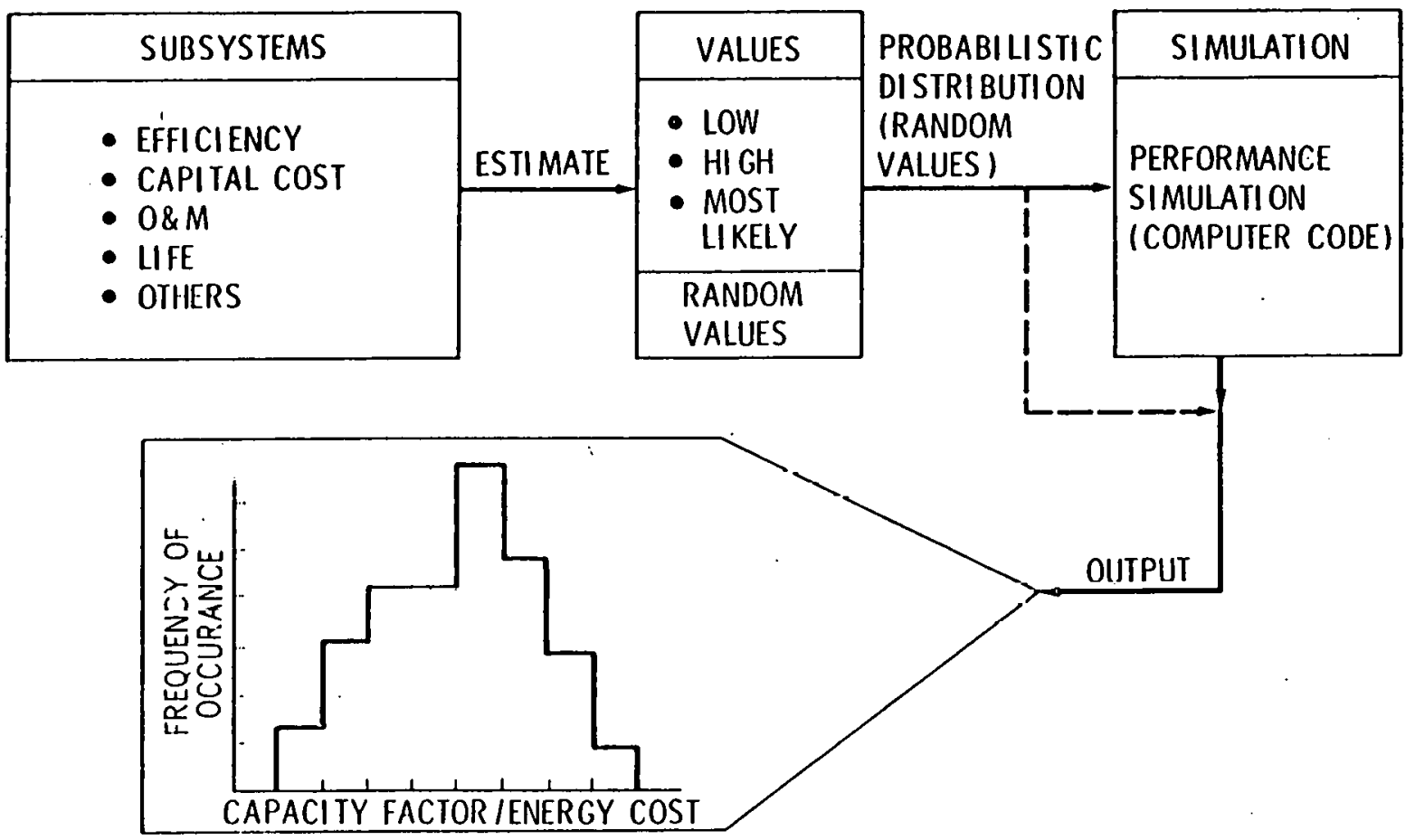

Figure 3-2. Probabilistic Simu1,ation Methodology

Cumulative probabilities are determined (integration of frequency of occurrence curves), after energy cost distribution curves are obtained via the procedures described above. These cumulative values associate the energy cost range with probabilities, i.e., each energy cost value is associated with a unique probability value. Low energy costs are associated with low probabilities while high values have high probabilities.

Returning to the fundamental decision/risk relationship, it is seen that for a projected annual savings there is a breakeven probability of success where the advanced technology investment is likely to be recovered, i.e.,

Breakeven probability of success $=\frac{\text { Equivalent Uniform Annual Cost }}{\text { Annual Savings }}$

There are many complex and interacting factors which govern estimates of probability of success. Large advanced technology expenditures (high equivalent uniform annual costs) will generally increase probability of success, but advanced technology funding is limited and a realistic assessment of options should consider this constraint. Annual savings depends on both the energy cost savings over the baseline and the penetration (number of plants built), but the penetration depends on the energy cost savings as well as the absolute value of the energy cost relative to non-solar alternatives in the implementation time-frame. 
Since a detailed examination of these complex relationships is not within the scope of the present study, a comparison approach based on first order considerations is employed. To a first order the dominating factor is energy cost savings. It directly determines annual savings. and is a primary driver with regard to penetration. By stipulating that the candidate systems be compared under the condition that the target energy cost value of $50 \mathrm{mills} / \mathrm{kW}-\mathrm{hr}$ is achieved, the cost savings and associated impact on penetration for all systems will be the same.

The systems can then be compared in terms of (1) their relative probabilities for achieving the target energy cost value and (2) relative risks as measured by factors such as technology status, materials availability, component reliability characteristics, safety, environmental impacts, and flexibility or modularity with regard to varying power plant size.

Since energy costs are the dominant considerations, the probability of success is taken to be proportional to the probability of achieving the energy cost target as weighted by relative risks, i.e., high risks reduce probability of success whereas low risks result in an increase.

\section{B. RANKING OF ADVANCED SYSTEMS}

Application of probabilistic simulation techniques to the advanced systems selected by the screening process results in energy cost ranges for each system where each value in the range is associated with a probability (Figure 3-3). The probability decreases from high to low values in the range which corresponds to the increasing difficulty of achieving low values.

In terms of the probability of achieving the cost target, all of the selected systems exhibit substantial improvements over the Heliostat Rankine (HR) baseline system. For distributed systems, the parabolic dish-Stirling (PS-2) has the highest probability whereas the heliostatStirling with liquid metal storage and transport (HS/LM) has the best probability for central receiver systems.

If the candidate systems are compared solely in terms of potential for cost savings, the systens canbe ranked in terms of their relative probability of achieving the cost target as presented on Figure 3-3.

\section{System Risk Evaluation}

The candidate systems were evaluated in terms of risk. For this purpose, each system was broken down into five major parts and each part was then rated in terms of six weighting factors. The procedure is illustrated by Table 3-1 where the baseline heliostat-Rankine system is treated.

A numerical rating scale for risk was used to determine values to be used in the subsystem wcighting factor matrix of Tahle 3-1. The scale ranges from 0 to 10 and these numerical values are related to the level of risk as follows: 

Table 3-1. Risk Factor for Heliostat-Rankine with.

Steam Transport and Oil/Rock Thermal Storage (HR)

\begin{tabular}{|l|c|c|c|c|c|}
\hline \multirow{2}{*}{$\begin{array}{c}\text { Weighting } \\
\text { Factors }\end{array}$} & Concentrators & Receivers & $\begin{array}{c}\text { Energy } \\
\text { Transport }\end{array}$ & $\begin{array}{c}\text { Energy } \\
\text { Storage }\end{array}$ & $\begin{array}{c}\text { Energy } \\
\text { Conversion }\end{array}$ \\
\cline { 2 - 6 } Technology Status & 3 & 3 & 0 & 3 & 0 \\
Materials & 3 & 3 & 0 & 3 & 0 \\
Availablability & 3 & 3 & 0 & 3 & 2 \\
Reliability & 2 & 3 & 3 & 3 & 2 \\
Safety & 0 & 0 & 0 & 3 & 2 \\
Environment & 1 & 4 & 0 & 2 & 3 \\
Flexibility, & 12 & 16 & 3 & 17 & 9 \\
Modularity & & & & & \\
\hline Subsystem Totals & 12 & & & \\
\hline
\end{tabular}

Numerical
Index

0

5

10
Level of Risk

No Risk - Technology and materials readily available; proven components having high reliability with low maintenance; no safety problems; non-polluting; highly flexible or modular design characteristics.

Moderate Risk - Technology and materials can be developed without breakthroughs; acceptable reliability with moderate maintenance; acceptable safety with implementation of straightforward procedures; pollution controllable with available and low-cost techniques; scale effects, but moderately flexible and modular.

High Risk - Technology and materials breakthroughs required; unreliable unless difficult and costly maintenance procedures are employed; potential hazards require extreme safety precautions; pollution difficult to control -- costly systems required; large scale effects result in poor flexibility and modularity.

As seen from Table 3-1, the baseline system has low risk. Numerical values $<5$ are ascribed to the element's of: the matrix. It is noteworthy that the system employs existing steam technology for energy conversion and transport which significantly reduces risk. Each advanced system candidate was evaluated in a manner similar to the baseline. These 
systems generally entail greater risk, particularly with regard to items such as advanced energy conversion systems, liquid metal transport and storage, and high temperature receivers. The Stirling engine has the highest efficiency potential but is the least well-developed and consequently has the highest risk. Liquid metal systems necessitate more stringent safety precautions and high temperature receivers require use of ceramic materials technology and design/development activity to achieve reliable operation under temperature cycling imposed by the diurnal nature of insolation availability.

Using the baseline system to normalize values, the relative probability of achieving the energy cost target is presented as a function of relative system $r i s k$ in Figure $3-4$. The relative system.risk factor is the total system risk factor for an advanced system divided by the baseline value of 57 (see Iable 3-1). It is seen that steam and inert gas systems are associated with lesser risk than liquid metal systems.

The higher risk of the Fresnel-Rankine (FR/DIS) relative to the baseline is associated with the technology status of the. Fresnel lens; the advanced small steam engine and redox battery storage. Other components are similar to the baseline. The parabolic dish-Brayton (PB) has additional risks associated with use of high temperature receivers. The parabolic dish-Stirling (PS-2) employs all of the same components as $(P B)$, but has higher risk in terms of an earlier development status for the Stirling engine. The Stirling has lesser scale effects and is inherently more flexible than the Brayton in the small size range used for dish systems and this improves its rating relative to the Brayton.

For liquid metal systems at $1500^{\circ} \mathrm{F}$, the heliostat-Brayton (HB/LM) has a lower risk than the parabolic Stirling multi-dish (PS/MD) or the heliostat-Stirling (HS/LM) primarily because Brayton engine technology is considered to be well developed. Use of liquid metals at $1800^{\circ} \mathrm{F}$ will probably require substantial development activity and hence systems in this range have a higher risk rating. For Brayton/Rankine comb Ined cycles to be beneficial, temperatures of at least $1800^{\circ} \mathrm{F}$ are desirable. For the combined cycle, parabolic multi-dish $(P(B / R) / M D)$ and the heliostat-chemical storage $(\mathrm{H}(\mathrm{B} / \mathrm{R}) / \mathrm{CH})$ shown in the $1800^{\circ} \mathrm{F}$ range, risk could be reduced by employing gas transport. However, this would reduce efficiency, increase energy costs, and thereby reduce the relative probability for these systems to achieve the energy cost target.

For all the systems shown on Figure 3-4, the relative probabilitity increases more than relative risk except for $\mathrm{H}(\mathrm{B} / \mathrm{R}) / \mathrm{CH}$ which involves chemical storage. As noted previously, reversible chemical storage systems are in a very early stage of development, and it is clear that further development and optimization are required before these systems can be regarded as viable candidates. All of the other systems offer some improvement from a gain versus risk viewpoint:. The parabolic-dish Stirling (PS-2) appears to have outstanding potential primarily due to high projected efficiencies for Stirling engines, particularly at small sizes. 


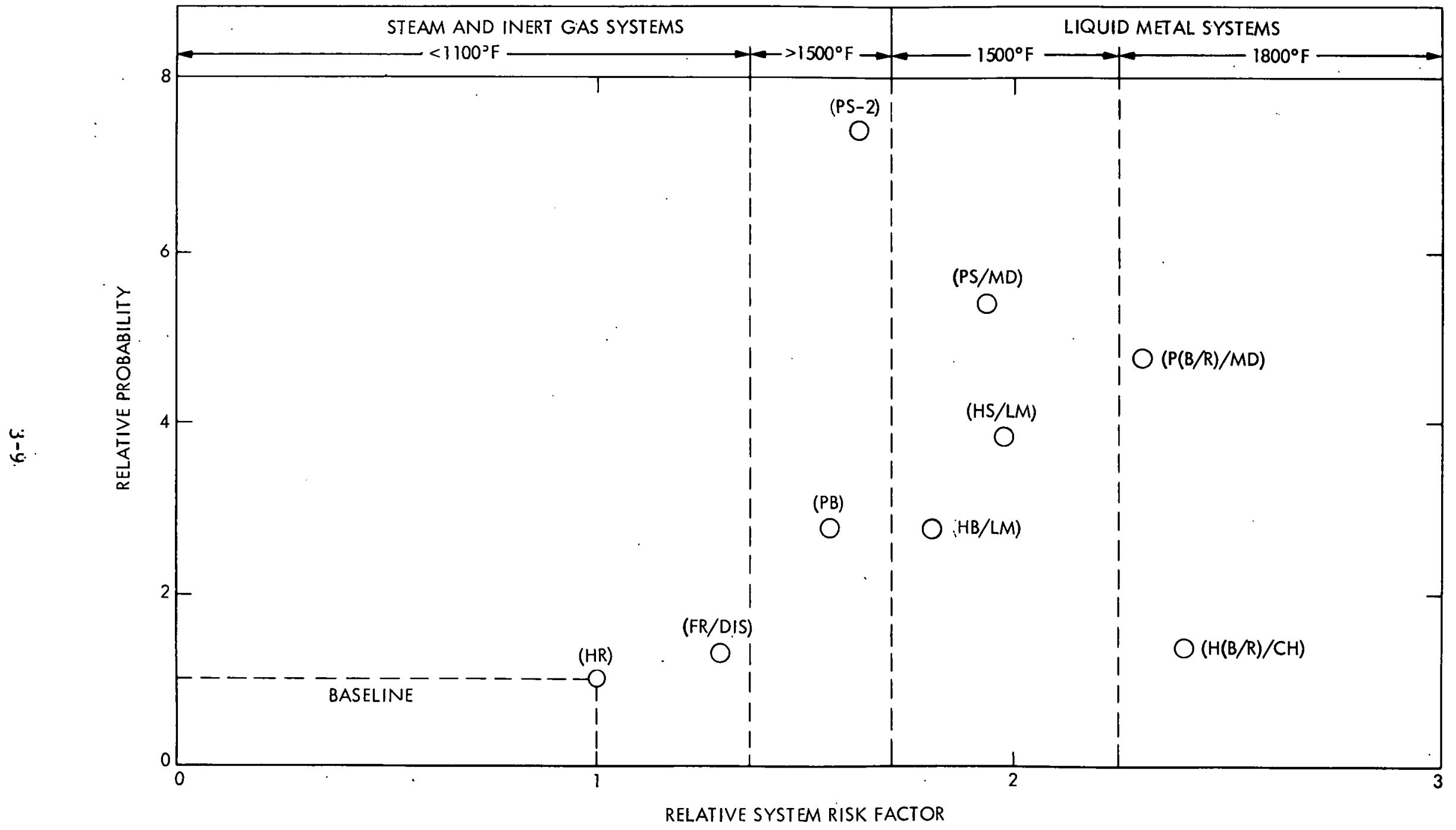

Figure 3-4. Relative Probability of Achieving Energy Cost Target 
When interpreting the results of Figure 3-4, it is significant to note that many of the systems have elements in common. Dish systems employ the same concentrators while central receivers use the same heliostats. In this context, generalizations from Figure 3-4 are as follows: (1) Stirling engines represent the most promising advanced heat engine technology, (2) Brayton and Brayton/Rankine combined cycle offer substantial gains with established technology, and (3) liquid metal technology provides advantages with some increase in risk.

\section{Advanced Technology Investment Considerations}

As discussed previously, the basic decision/risk relationship provides a basis for considering advanced technology investments in terms of potential savings and associated probability of success. The relationship can be expressed as

where

$$
\sigma_{S}[(\triangle E C)(P \times L F \times 8760)] \geqslant(R \& D) C R F
$$

$$
\begin{aligned}
\sigma_{S}= & \text { probability of success } \\
\Delta E C= & \text { Baseline energy cost }- \text { target energy cost, } \frac{\text { mills }}{\mathrm{kW} h r} \text { or } \frac{\$}{\mathrm{MW} h r} \\
\mathrm{P}= & \text { total penetration of solar power, MW } \\
\mathrm{LF}= & \text { load factor } \\
\mathrm{R} \& \mathrm{D}= & \text { total present value of research and development expenditure } \\
& \text { in base year dollars } \\
\mathrm{CRF}= & \text { capital recovery factor }
\end{aligned}
$$

Note that $\triangle E C$ is a levelized value (Ref. 3) based on present value costs expressed in base year dollars. This is consistent with use of present value advanced technology costs as defined above. For a load factor of $\mathrm{LF}=0.40, \Delta \mathrm{EC}=102-50=52 \$ /$ MWe $\mathrm{hr}$. Assuming a capital recovery period of $\approx 30$ years and an interest of $\approx 10 \%$, the capital recovery factor $\mathrm{CRF} \approx 0.10$. Using these values, the advanced technology expenditures can be determined as a function of probability of success and pellelralluH.

'The probability of success for candidate systems is evaluated by adopting the criterion that the probability of success equals the probability of achieving target energy costs for moderate system risks. For moderate risks, all elements of the matrix on Table 3-1 would be 5 and the total system risk factor SRF would equal 150. Since the probability of success is taken to be inversely proportional to SRF,

$$
\sigma_{\mathrm{S}}=\sigma_{\mathrm{ec}}\left(\frac{1.50}{\mathrm{SRF}}\right)
$$

where $\sigma_{e c}$ is the probability of achieving target energy costs. For low to moderate risk systems where SRF $\leqslant 150$, the probability of success is greater than the probability of achieving target energy costs. For moderate to high risk, SRF $\geqslant 150$, probability of success is lower. The 
above weighting improves the probability of success of low risk systems relative to higher risk systems.

The maximum allowable advanced technology expenditure to satisfy the basic relation is presented in Figure $3-5$ as a function of probability of success normalized to the value for the baseline system. The effect of penetration is shown parametrically. For a total penetration of 10,000 MW as used for mass production cost estimating in the present study, the maximum allowable advanced technology for the baseline HR system is $\approx \$ 1.5$ billion. This is the advanced technology that could be spent on the baseline system to achieve the target energy cost of $50 \mathrm{mills} / \mathrm{kWe}-\mathrm{hr}$.

Due to its higher risk and relatively low gain, $\mathrm{H}(\mathrm{B} / \mathrm{R}) / \mathrm{CH}$ has a lower probability of success than the baseline. This corresponds to a lower allowable advanced technology of $\$ 800$ million. Based on this finding, this chemical storage system should not be pursued as presently configured. Fundamental studies are needed to reconfigure reversible chemical storage to a more viable form befcre it should be considered as part of a power system.

For the remaining central receiver candidates, the increase in allowable advanced technology cost over the baseline for HB/LM and HS/LM is $\approx \$ 700$ million and $\approx \$ 1.3$ billion, respectively. This infers that $\$ 700$ million is justified for the additional technology for Brayton and liquid metal systems. The Stirling engine warrants a further $\$ 600$ million above the Brayton.

Considering distributed systems, the Fresnel-Rankine (FR/DIS) has an allowable incremental advanced technology of $\approx \$ 150$ million over the baseline. Incremental costs for Braytor: and Brayton/Rankine combined cycle systems identified as $P B$ and $P(B / R) / M D$ are $\approx \$ 900$ million and $\approx \$ 1.5$ billion, respectively. For Stirling systems, PS/MD and PS-2, incremental costs are $\approx \$ 2.5$ billion and $\$ 5$ billion.

It is thus evident that substantial advanced technology cost increments over the baseline are warranted for advanced systems since these systems liave a higher probability of surcess. Since allowable costs are a direct function of solar power penetration, it is required that sizeable penetrations be achieved. It is felt that if the target cost of 50 mills/ $/ \mathrm{kWe}-\mathrm{hr}$ is achieved, a penetration of the order of $10,000 \mathrm{MWe}$ is a reasonable estimate.

\section{Other Benefits}

In addition to direct benefits regarding efficient power generation, high temperature advanced technology systems provide other benefits primarily associated with enlarged possibilities for implementation. High temperature systems are advantageous for total energy/cogeneration applications since rejected heat from power conversion is available at temperatures suitable for many industrial/commercial processes (Ref. 38). For industrial/chemical processes requiring high temperatures, generation of high temperature is a prerequisite for using solar energy. 
MAXIMUM ALLOWABLE ADVANCED TECHNOLOGY, MILLIONS OF DOLLARS

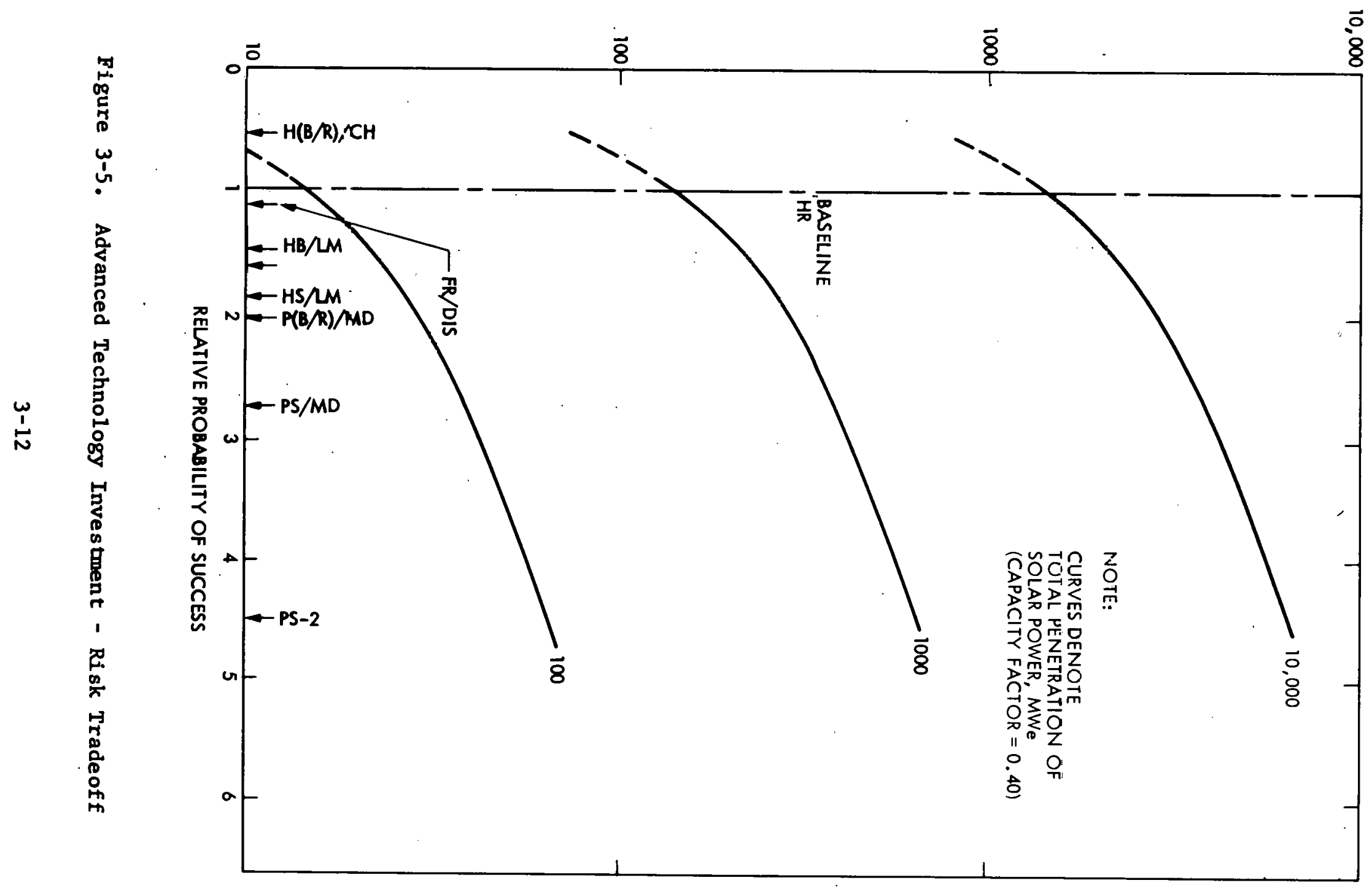


Advanced high-temperature distributed systems tend to be highly modular. Since it is difficult to transmit high-temperature thermal energy over large distances, high-temperature distributed systems are generally comprised of a large number of small heat engine-collector modules. 'This arrangement has inherent flexibility with regard to power plant size. The appropriate number of modules can be used to match the needs of the application. If power needs grow with time, additional modules can be added. Thus, the development of the required advanced technology for a basic power module can serve a wide spectrum of needs. Mass production of the same module for all these needs offers potential for low costs.

The net result of the size flexibility described above for distributed systems is that energy costs are insensitive to power system size (see Ref. 2). For smaller plants, indirect costs comprise a larger fraction of total plant costs, but electrical collection of energy from the modules is reduced. Neither of these items are major cost drivers and hence energy costs are essentially invarient over a large range of sizes.

Central receiver systems employ a large number of identical heliostats that can be mass-produced. Over a range of power plant sizes, it may be possible to use the same basic heliostats with some modifications with regard to number or orientation of mirror facets. The effect of scale on central receiver systems involves detailed and complex tradeoffs. Only limited studies have been performed (Ref. 39) and a consensus has not yet been reached.

It is generally agreed that smaller central receiver systems will have higher energy costs due to higher unit heliostat costs (greater number of facets) and/or lower performance associated with determining receiver size in the context of tradeoffs with collector cost. Here, use of small heliostat mirror facets results in a smaller receiver area and lesser reradiation losses. Studies to date indicate that central receiver systems will experience sharply increasing energy costs. for sizes belnw $\sim 1-2$ MWe. The energy cost will increase when reducing the size from 10 MWe to $1-2$ MWe but much less severely. According to data in Ref. 39, it is possible that the increase from 10 MWe to $\sim 2$ MWe could be very small.

Much further study regarding the scale effects of central receiver systems must be conducted before definitive conclusions can be drawn. However, based on the preliminary results available, it appears that both central receiver and distributed systems can meet a large range of diepersed power needs with distributed systems having an advantage for small power applications <l-2 MWe. 


\title{
SECTION IV
}

\author{
CONCLUSIONS
}

The primary thrust of the present study is to support advanced technology planning activities by identifying potentially promising advanced systems and associated technologies for dispersed solar thermal elcctric power plants in the 1990-2000 time-frame. The study focuses on a limited set of candidate technologies that appeared to be promising based on a preliminary screening and the conclusions below should be viewed in this context.

- Two-axis tracking concentrators, namely the heliostat for the central receiver and the parabolic dish for pointfocusing distributed systems, have the highest optical collection efficiencies and are therefore the most promising advanced technologies for achieving the high temperatures necessary for efficient electric power production.

- Highest power plant system efficiencies (two-axis tracking systems) occur between $1500^{\circ} \mathrm{F}$ to $2000^{\circ} \mathrm{F}$ as the result of a tradeoff between increasing engine performance with temperature and higher heat losses from the receiver.

- Advanced high temperature systems using technologies such as advanced Stirling and Brayton engines, and liquid metal transport and storage improve the probability of success for achieving the target energy cost ( $50 \mathrm{mills} / \mathrm{kWe}-\mathrm{hr}$ ) by factors as high as 4 to 5 compared to present generation (Barstow pilot plant) central receiver systems.

Higher probabilities of success for advanced technology systems warrant additional advanced technology expenditures in the over billion dollar range for a projected solar penetration uf 10,000 $\mathrm{MWe}$ in the 1900-2000 time-frame.

- Stirling engines achieve the highest projected efficiencies over a wide size range and are therefore identified as being the most attractive advanced energy conversion technology.

- Brayton and Brayton/Rankine systems provide substantial Impruvelleuls in probability of aucccoo ucing technology that has been developed to a relatively mature stage in the $1500^{\circ} \mathrm{F}$ to $2000^{\circ} \mathrm{F}$ range and their adaptatinn to hightemperature solar systems will improve the overall advanced technology program's prospects of achieving major gains.

- Liquid metal transport (short distances) and storage systems are advantageous in linking the receiver and engine since they provide high heat transfer rates coupled with relatively low pumping requirements and consequently their development 
into reliable and safe systems will greatly enhance system design flexibility.

- Storage technologies of solid/gas sensible heat and reversible chemical reactions require further basic study and optimization to improve their performance and cost characteristic to the point. where they can be considered as viable candidates for power systems. 


\section{SECTION V}

\section{RECOMMENDATIONS}

Based on a comparative analysis of a limited set of candidate advanced systems, technologies which are considered to be worthy of recommendations for substantial advanced technology effort were identified. Additionally, subsystems/components and promising new concepts that warrant further investigation were delineated. Specific recommendations are given below:

Recommendations for Substantial Advanced Technology Effort

- Focus development activity for low-cost, two-axis tracking collector systems (concentrators and receivers) on high quality concentrating surfaces $\left(<0.1^{\circ}\right.$ slope error) and high temperature receivers (including ceramic material designs) needed for the $1500^{\circ} \mathrm{F}-2000^{\circ} \mathrm{F}$ temperature range.

- Accelerate Stirling engine technology development with emphasis on optimizing the interface between the Stirling engine and the rest of the solar power system.

- Undertake a Brayton and Brayton/Rankine effort directly aimed at developing advanced technology to extract the highest possible performance within constraints of maximizing overall system cost effectiveness.

- Pursue a wide spectrum of 1iquid metal transport (including heat pipes) and storage options in a coordinated manner with emphasis on high temperature materials problems and the evolution of innovative designs for low cost mass production.

\section{Recommendations for Further Investigation}

- Conduct basic studies/investigations to determine performance and cost characteristics of both solid/gas sensible storage (e.g., $\mathrm{MgO}$ bricks) and reversible chemical reaction storage encompassing chemical transport.

- Implement tradeoff studies to delineate potential for receiver improvements by using secondary reflecting surfaces forward of the receiver aperture.

- Pursue potentially promising new concepts for energy conversion including ( 1 ) the electrolyzer-fuel cell electrochemical cycle, (2) reactive fluids for closed cycle heat engines and (3) ternary and quarternary combined cycles. 


\section{SECTION VI}

\section{REFERENCES}

1. "Recommendations for the Conceptual Design of the Barstow , California, Solar Central Receiver Pilot Plant," SAND77-8035, UC-62, Sandia Laboratories, Albuquerque, NM, and Livermore, CA. October, 1977.

2. Fujita, T., et al., "Projection of Distributed-Collector SolarThermal Electric Power Plant Economics to Years 1990-2000,". DOE/JPL-1060-77/1, Jet Propulsion Laboratory, Pasadena, CA. December, 1977.

3. Doane, J. W., et al., "The Cost of Energy from Utility-Owned Solar Electric Systems, a Required Revenue Methodology for ERDA/ EPRI Evaluations," Internal Report 5040-29, ERDA/JPL-1012-7613, Jet Propulsion Laboratory, Pasadena, CA. June, 1976.

4. Manvi, R., "Terrestrial Solar Power Plant Performance," internal report dated March 1977, Jet Propulsion Laboratory, Pasadena, CA.

5. Caputo, R.S., "An Initial Comparative Assessment of Orbital and Terrestrial Central Power Systems," Final Report 77-44, Jet Propulsion Laboratory, Pasadena, CA. March, 1977.

6. Manvi, R. and Fujita, T., "Economics of Internal and External Energy Storage in Solar Power Plant Operation," Jet Propulsion Laboratory, Paper No. 779188, Proceedings of the 12th IECEC, Washington, D. C., August 28- September 2, 1977.

7. Wen, L. C., "Thermal Optical Surface Properties and High Temperature Solar Energy Conversion," Jet Propulsion Laboratory, presented at the 2nd AIAA/ASME Thermophysics and Heat Transfer Conference, Palo Alto, CA., May 24-26, 1978.

8. Wen, L.C. "Thermal Performance Tradeoffs for Point Focusing Solar Collectors," Jet Propulsion Laboratory, Paper No. 789262, Proceedings of 13th IECEC, San Diego, CA, August 20-25, 1978.

9. Bienert, W. B. and Wolf, P. A., "Semiannual Progress Report for Heat Pipe Central Solar Receiver," DTM-76-7, C00/2839-1 Dynatherm Corp., Cockeysville, MD, November, 1976.

10. "Preliminary Design of a $10 \mathrm{~kW}$ Solar Heated Open Brayton-Cycle Engine, Phase I Report," CR 78.003, Civil Engineering Laboratory, Naval Construction Battalion Center, Port. Hueneme, CA, Sponsored by Naval Facilities Engineering Command and conducted by Arthur D. Little, Inc. (Report N68305-76-C-0014), Cambridge, MA, November, 1977. 
11. "Advanced Technology Development, Thermal Power Systems Research and Development Project, Semi-Annual Progress Report," Report No. 5102-67, Jet Propulsion Laboratory, Pasadena, CA. June, 1978.

12. Thaller, L. H., "Redox Flow Batteries," NASA Lewis Research Center, Redox Project Office, Cleveland, Ohio, presented at the Symposium on Load-Leveling sponsored by the Electrochemical Society, Atlantá, Georgia, October 10-13, 1977.

13. Fujita, T., "Preliminary Data on Electrical Energy Storage Systems for Utility Applications," Internal Report 900-738, Jet Propulsion Laboratory, Pasadena, CA. April, 1976.

14. Scheneider, T. R., (Project Manager), "An Assessment of Energy Storage Systems Suitable for Use by .Electric Utilities," EM-264, EPRI Project 225/ERDA E(11-1)-2501, Public Service Gas and Electric Company, Newark, NJ. July, 1976.

15. Mar, R. W., and Bramlette, T. T., "Thermochemical Energy Storage Systems -- A Review", SAND 77-8051, Sandia Laboratories, Livermore, CA., February, 1978.

16. Schmidt, E. W., "Chemical Energy Storage System -- Chemical Reaction Subsystem, "Technical Assessment Paper RRC 76-R-502, Rocket Research Corporation, Redmond, WA. January, 1976.

17. Schmidt, E. W., et. al., "Thermochemical Energy storage Systems", Paper No. 769116, 11th IECEC Proceedings, State Line, Nevada, September $12-17,1976$.

18. Gintz, J. R., "Technical and Economic Assessment of Phase Change and Thermochemical Advanced Thermal Energy Storage (TES) Systems" EPRI EM-256 (four volumes), prepared by Boeing Engineering and Construction Co., Seattle, WA, for EPRI, Palo Alto, CA. December, 1976.

19. Fujita, T., "Underground Energy Storage for Electric Utilities Employing Hydrogen Energy Systems," JPL Internal Report 900-744, Jet Propulsion Laboratory, Pasadena, CÁ. June, 1976.

20. Wentworth, W. E., and Chen, E., "Simple Thermal Decomposition Reactions for Storage of Solar Thermal Energy", Solar Energy Vo1. 18, pp. 205-214, 1976.

21. Springer, 'l'.H., and Thomson, W. B., "Central Station Solar Electric Power Using Liquid Metal Heat Transport," Paper No. 7.69215 , 11th IECEC Proceedings, State Line, Nevada, September 12-17, 1976. 
22. Mathur, P., et al, "System and Application Analyses Studies, Advanced Central Power Systems Projects," Report No.. ATR-77

(7690-01)-2, The Aerospace Corp., El Segundo, CA., September, 1977.

23. Gin'tz, J. R., "Advanced Thermal Energy Storage Concept Definition Study for Solar Brayton Power Plants," Report No. SAN/1300-1,2, 3,4, Boeing Engineering and Construction Co., Seattle, WA, November, 1977.

24. Hsu, M.S.S., Manow, W. E., Jr., and Goodenough, J.B., "High Efficiency Electrochemical Cycle," Paper No. 759085, 10th IECEC Proceedings, Newark, Del., August, 1975.

25. Hsu, M.S.S., and Reed, T. B., "Electrochemical Power and Hydrogen Generation from High Temperature Electrolytic Fuel Cells," Paper No. 769074,11 th IECEC Proceedings, State Line, Nevada, September $12-17,1976$.

26. Fourakis, E. and Severson, A.M., "Low-Profile Heliostat Design for Solar Central Receiver Systems," Honeywell, Inc., Systems and Research Center, Minneapolis, Minnesota, Solar Energy, Vol. 19, pp. 349-356, Pergamon Press, Great Britain, 1977.

27. "Central Receiver Solar Thermal Power: System, Phase 1, Pilot and Commercial Plant Cost and Performance," Preliminary Draft, No. MDC G6 776, Vol. VII, Book 2, pg. 179, McDonnell Douglas Astronautics Company, Huntington Beach, Ca., May 1977.

28. Powell, J.C., "Solar Pilot Plant Phase I, Preliminary Design Report, Pilot Plant Cost and Commercial Plant Cost and Performance," Report No. F3419-DR-302-III, Vo1. VII, Book 2 pg. 195, Honeywe11, Energy Resources Center, Minneapolis, Minnesota, June 1, 1977.

29. Semiannual Review of Solar Thermal Central Power Systems, San Diego, 2-3 March 1978," SAND 78-8015, prepared by Sandia Laboratories, Livermore, for Department of Energy, Division of Solar Technology, April, 1978.

30. Pettit, Richard, Sandia Laboratories, Albuquerque, Private Communication, July 1978.

31. Nixon, Gene, Swedlow, Inc., Garden Grove, Ca., Private Communication, Nov. 1977.

32. E1 Gabalawi, N; Hill, G., Bowyer, J. M.; and Slonski, M.L., "A Modularized Computer Simulation Program for Solar Thermal Power Plants," JPL Report 5102-80, Jet Propulsion Laboratory, . Pasadena, Ca., July, 1978. 
33. Grosskreutz, J.C., "Solar-Thermal Conversion to Electricity Utilizing a Central Receiver, Open-Cycle, Gas Turbine Design," EPRI ER-652, Project 475-I, Prepared by Black \& Veatch Consulting Engineers, Kansas City, Missouri, for Electric Power Research Institute, Palo Alto, CA., March 1978.

34. Gintz, J.R., et a1., "Closed-Cycle,.High-Temperature Central Receiver Concept for Solar Electric Power," EPRI ER-629, Project 377-1, Prepared by Boeing Engineering and Construction, Seattle, Washington, for Electric Power Research Institute, Palo Alto, CA., January, 1978.

35. Fujita, T.; E1 Gabalawi. N.; Caputo, R.; Herrera, G., "Comparative Evaluation of Dietributcd-Collector Sular Thermal Electric Power Plants," Paper No. 789346, Proceedings of the 13th IECEC, San Diego, CA., August. 20-25, 1978.

36. Manvi, R., and Fujita, T., "Performance and Economic Risk Evaluation of Dispersed Solar Thermal Power Systems by Monte Carlo Simulation, Paper No. 789187, Proceedings of the 13th IECEC, San Diego, Ca., August 20-25, 1978.

37. Cooper, D.0., and Davidson, L.B., "The Parameter Method for Risk Analysis," Chemical Engineering Progress, November 1976.

38. "Solar Thermal Dispersed Power Program, Total Energy Systems Project," Report No. ATR-77(7692-01)-1, August 1, 1977.

39. Holl, R.J., "Definition of Two Small Central Receiver Systems,". SAND 78-7001, UC-62, prepared by McDonnell Douglas Astronautics Company, Huntington Beach, Ca., for Sandia Laboratories, Albuquerque, N.M., January 1978. 
APPENDIX A

SURVEY

$\mathrm{OF}$

ADVANCED ENERGY CONVERSION SYSTEMS

A-1 


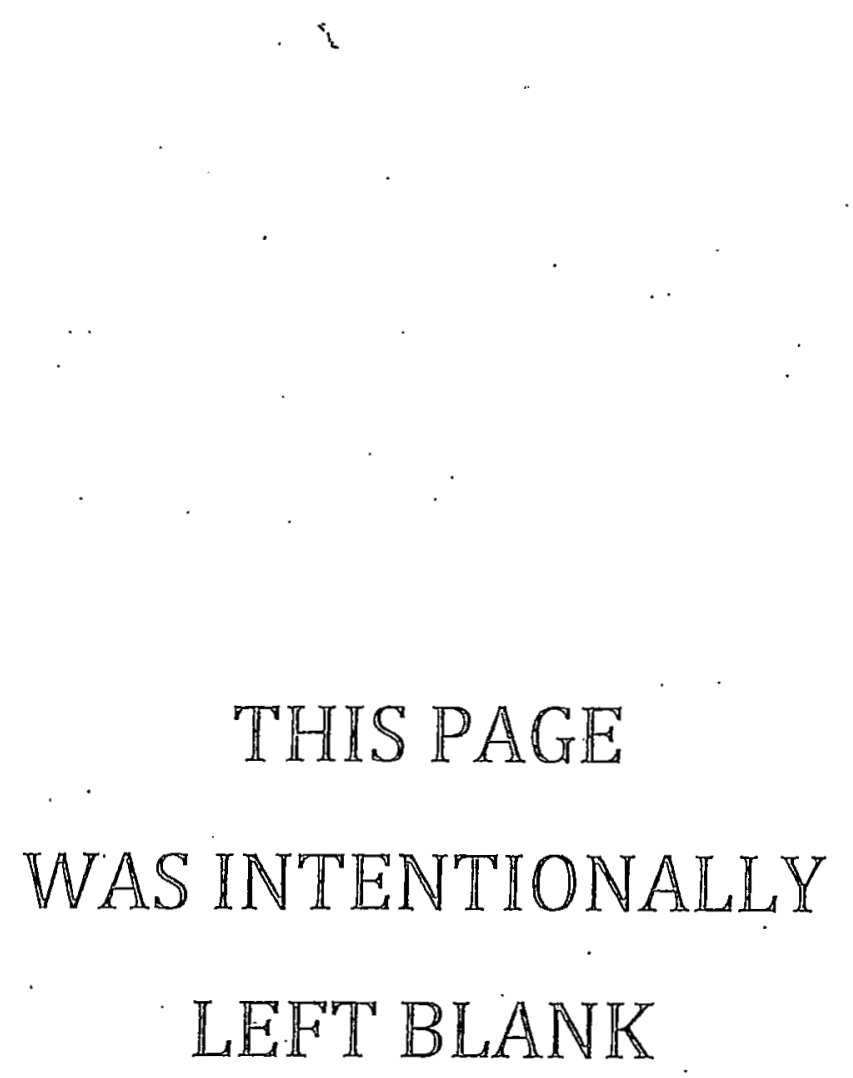




\section{APPENDIX A}

CONTENTS

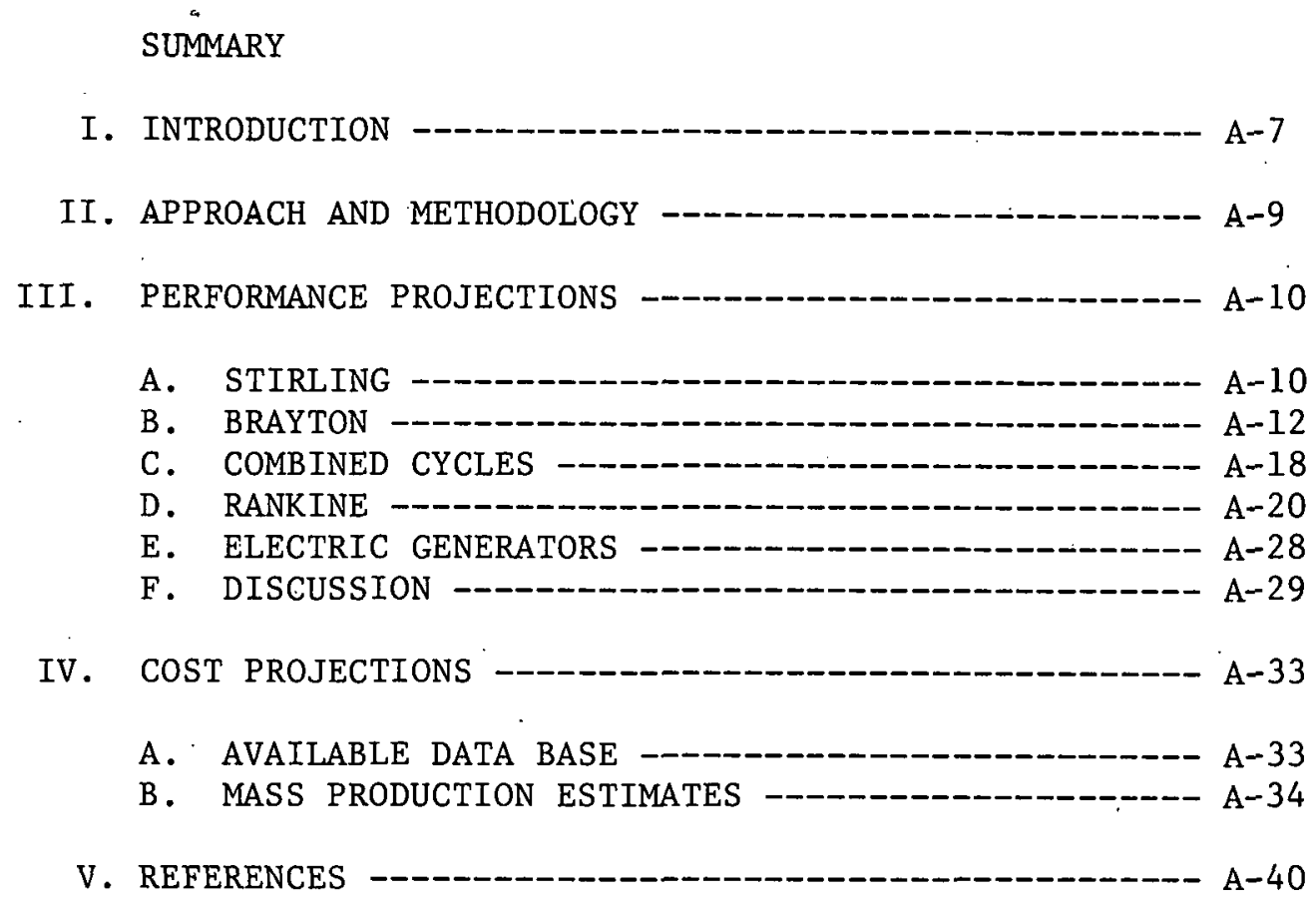


APPENDIX A

Figures

$A-1$

A-2

$A-3$

A-4 Estimated Brayton Cycle Performance

vs Engine Size -

A-5 Part-Load Characteristics of Sma11 (10 kWe).

Brayton - ---17

A-6 Estimated Brayton/Steam Rankine Combined

Cycle Efficiency - A-20

A-7 Estimated Brayton/Steam Rankine Performance

vs System Size -

A-8 Brayton/Steam Combined Cycle Part-Load

Performance -

A-9 Estimated Potassium/Steam Rankine

Combined Cycle Efficiency - - A-23

A-10 Comparison of Performance of Advanced

Steam Engine/Generator Sets with Steam

Turbines -- -

A-11 Estimated Nominal Performance of Steam

Turbines -

A-12 Estimated Efficiency of Reciprocating

Steam Engine/Generator Sets -

A-13 Estimated Performance of Reciprocating

Steam/Engine Generators vs Engine Size ----- A-27

A-14 Part-Load Performance of Reciprocating

Steam Engine/Generator Sets as Related

to Heat In rather than to Power Out -- - - - A-28

A-15 Ful1-Load Efficiency of A.C. Generators

vs Size -

A-16 Part-Load Efficiency of Typical

A.C. Generators - $4-30$ 

A-17 Performance Estimates for Energy Conversion
Systems in the Time-Frame 1985 to $2000 \ldots$
A-18 Suggested Model for the Capital Costs of Energy Conversion Systems in Volume
Production - A-37
A-19 Estimated Capital Cost of A.C. Generators in Volume Production, 1977 Dollars - -

$\underline{\text { Tables }}$

A-1 Part-Load Efficiency of Representative

Engine Systems Based on Heat Input -_-_-_- A-14

A-2 Small Engine Performance Targets ---

A-3 Current Projections of Capital and Operating and Maintenance Costs of Representative Energy Conversion Systems (Heat Engines), Based on Limited LowVolume Production, and Estimated Lifetime to Major Overhaul _- A-35

A-4 Production Cost Comparison of Small Engines for 400,000 Units per Year (Based on Current Estimates) - - A-36

A-5 Estimated Baseline Capital Cost of Advanced $100 \mathrm{kWe}$ Energy Conversion Systems for Production of 400,000 Units per Year, in Dollars per Kilowatt - A-39 
THIS PAGE

\section{WAS INTENTIONALLY LEFT BLANK}




\title{
APPENDIX A
}

\author{
SUMMARY
}

A survey was made to accumulate data on the performance and cost of advanced energy conversion systems that might be suitable as candidates for solar thermal power systems in the time-frame 1990-2000. Advanced energy conversion systems are defined as second generation systems that are beyond the state-of-the-art with respect to performance and, in most cases, are not now amenable to mass production. In addition to state-of-the-art $1000^{\circ} \mathrm{F}$ steam Rankine, used in the past as baseline technology, Stirling cycle, Brayton cycle, combined cycles, and various Rankine cycles were considered. Included in the last two categories, for example, were liquid metal topping cycles on steam Rankine, and organic Rankine bottoming to Brayton cycles. Heat engines only were considered.

For the purposes of this study, two aspects of performance were required: cycle and/or overall efficiency (ratio of heat in to electric power out) as a function of (1) peak cycle temperature and (2) engine or plant size. Of interest was the performance and cost of engines and plants in the size range $20 \mathrm{~kW}$ to $50 \mathrm{MW}$. Because of the variability of solar insolation, information was sought on the part-load performance of the candidate systems. An attempt was made as well to locate information concerning the reliability and/or lifetime of these systems.

\section{INTRODUCTION}

The purpose of this survey was to compile the required data base for candidate energy conversion systems as subsystems for solar thermal power technology development in the years 1990 to 2000 .

In a previous study (Ref. A-1), it was shown that the single largest contributor to the energy cost of solar thermal power systems is the collector-field cost. Because the collector area (and thus the cost) depends on the efficiency of the energy conversion system(s), engine efficiency has considerable influence on the total energy cost. In contrast, the capital cost of the energy conversion system was not a major contributor toward the total energy cost (Ref. A-1). Thus, in the present study the main effort was directed at performance rather than cost. An attempt was made, however, to determine the role that large-scale mass production might have on the cost of energy conversion systems.

An initial list of candidate energy conversion systems included advanced steam Rankine (baseline), advanced gas open-cycle Brayton, Stirling.cycle, and combined cycles such as Rankine with Brayton or liquid metal topping cycles. This 1 ist essentially was identified in Ref. A-l as of intermediate $(1985-2000)$ potential. Other attractive options were not excluded. 
The required performance data included basic cycle or thermal efficiency as well as overall subsystem efficiency. This overall efficiency is defined as the thermal equivalent of electricity delivered at the bus bar to the heat input to the engine subsystem. Thus, it should include all auxiliary equipment losses such as might occur in the mechanical power train, electric generator, power conditioning equipment, etc. Also desired was the part-load performance of the energy conversion system.

Cycle efficiency in the temperature range $1000^{\circ} \mathrm{F}$ to $2000^{\circ} \mathrm{F}$ was one parameter that was considered. However, with the exception of $1000^{\circ} \mathrm{F}$ steam Rankine systems, the main range of interest for peak cycle temperature was $1500^{\circ} \mathrm{F}$ to $1800^{\circ} \mathrm{F}$ where the combined collector-heat engine performance achieves an optimum. This restricted range also helps to alleviate problems related to high temperature materials, e.g., blade cooling in turbines:

Whereas turbomachinery heat engines (e.g., gas turbines) exhibit some increase in efficiency with size or rating, reciprocating heat engines indicate little or no size effect on efficiency as based on principles of similitude. Dispersed power systems utilize small engines fitted individually to single dishes or, perhaps, to a cluster of dishes supplying thermal energy to a single larger heat engine. Thus, mass production raises the prospect of cost savings for cases involving the use of many small heat engines with power levels up to, or below, those of small automotive engines. Tradeoffs in engine size and number of production units are not difficult to contemplate, as is the relation of peak cycle temperature and other state variables to performance. For the foregoing reasons, individual heat engines in the size range $20 \mathrm{~kW}$ to $50 \mathrm{MW}$ were of interest. There are constraints, however, in some cases such as Stirling engines. State-of-the-art Stirling engines are fairly small, the largest being in the range of $400 \mathrm{hp}$.

Such factors as engine size, weight and shape are important in relation to structures, stability, vibration, optical blockage and ease of maintenance, but were beyond the scope of this study. Also not included were the cost, availability, and safety aspects of the working fluids for power cycles.

Towards the latter part of this study, 'it became evident that more detailed information on component performance was necessary to account for losses in bearing friction and windage, gear box, electric generator, etc. Some of these factors depend on size. It is likely that the overall efficiency of conversion systems is even more dependent on size than thought previously, and that the total losses might become increasingly significant with decreasing engine size. Electric generator efficiency not only decreases with size but, like heat engines, displays a distinct part-load characteristic. It was not possible in this study to account for all of these influences on performance. 


\section{APPROACH AND - METHODOLOGY}

The approach was to gather performance and cost data on the various heat engines from the widest possible variety of sources. Much information was received from Lewis Research Center (LeRC), Refs. A-2 through A-5. Other information was obtained from government and industry reports, company brochures, the open literature, and private consultations with industry. References A-6 through A-13 are termed general references because they discuss a variety of heat engines. References A-14 through A-69 are broken into categories as 1isted.

The data in these references reflect many viewpoints and differ in scope, quality, quantity, and descriptive detail. Information was in the form of individual data points, curves, and data bands, some tabulated, some plotted. Included were data for existing experimental and production systems, theoretical projections, and predictions for future systems. The starting point for this study was Ref. A-13, an earlier compilation of data. More of the data was related to the effect of cycle temperature than to engine size.

Particular attention was directed towards classifying the data according to the particular efficiency specified, i.e., (thermal) efficiency, overall, or "plant" efficiency. The latter term is sometimes used in describing large power system efticiencies, particularly Rankine systems that include boiler efficiencies.

As the data became available, efficiency was plotted as a function of temperature and size. Clearly, this methodology does not isolate these two effects because concomitant changes in other variables are 1.ikely to occur. Larger systems tend to become more complex with the addition of recuperation/regeneration, intercooling, reheat, feedwater heating, etc., as the case may be. Combined cycles are particularly difficult to characterize because of numerous variables.

Curves were traced through the data. They were labeled low, nominal and high to reflect an uncertainty to be utilized later in sensitivity analyses for selected candidate solar thermal power systems. In terms of subjective judgment, these curves tended to reflect state-of-the-art, mid-term, and far-term technology, respectively. An additional bias, of course, was the complexity of the engine systems being reviewed. For example, a simple Brayton cycle would yield relatively low performance compared to an advanced recuperated. Brayton cycle. Relatively greater reliance was placed on sources that compared several heat engines rather than just one type. Relative performance trends were thereby elucidated because, presumably, Llie basis and ground rules for comparison were the same. 


\section{PERFORMANCE PROJECTIONS}

\section{A. STIRLING}

Descriptions of the Stirling cycle, and the history, development and current status of Stirling engines are presented at length in Refs. A-11, A-14, A-27 and A-28, and will be treated only briefly here.

From the performance point of view, the Stirling and Ericsson cycles are attractive because they alone, of all current heat engine cycles, offer the potential of achieving Carnot efficiency. This is true because, in principle, the compression and expansion processes are isothermal. In real engines perfect isothermal processes cannot be achieved, Besides high pcrformance, otlier advantages of Stirling engines often stated are long lifetime, quiet and reliable operation, and low pnllutinn levele. Etirling engines uperate at low rpm and therefore do not require costly, high-reduction gear trains.

Mechanical-drive Stirling engines already have achieved thermal efficiency in excess of $40 \%$. Advanced far-term engines are expected to achieve efficiencies in the 50 to $60 \%$ range. It is conceded that free-piston Stirling engine development lags behind the mechanicaldrive type by several years. Free-piston Stirling engines have achieved about $30 \%$ thermal efficiency, and $40 \%$ or more is expected in the near-term. Free-piston engines offer the option of direct generation of electricity using linear alternators.

Stirling engines are being developed by several companies in the United States and abroad, but none as yet are available commercially. Many small engines in the range of a few $\mathrm{kW}$ to $20 \mathrm{~kW}$ have been built and tested for research purposes. Several European companies are developing engines in the automotive size range. The Department of Energy currently is evaluating the use of larger Stirling engines for stationary production of power (Ref. A-28). The effect of size on engine performance is expected to be minimal. However, in actual practice, the performance of very small engines may become degraded due to heat transfer and fluid dynamics effects that do not scale proportionately. Larger size units can be constructed by coupling several small units (Ref. A-26). Apparently, the largest single unit built to date has been in the range of 400 hp (Ref. A-20).

Stirling engines are closed-cycle machines; the current choice of working fluids is helium or hydrogen. Heat is applied externally using another heaced fluid such as alr. Thus, the engines are readily adaptable to a wide variety of heat sources, including solar, and many different fuels. Internal heat transfer and fluid dynamics in Stirling engines and in the regenerators and heaters are extremely complex. The achievement of higher heater temperatures (exceeding $1500^{\circ} \mathrm{F}$ ), and thus higher performance, is beset by several problems associated with advanced materials development. 
Technology risk areas that require further development include the heater head (cost and durability) and seals for the pistons and piston rods to prevent working fluid contamination. In solar applications, additional work is needed to develop heat transport systems to the heater head and stable control systems. Mass production techniques require further study. It is anticipated that the course of Stirling engine mass production trends will be similar to that of automotive engines. Costs are projected to parallel Diesel engines (Ref. A-11). The lifetime of Stirling engines still is an open question. It is encouraging that laboratory engines have run in excess of 25,000 hours (Ref. A-27).

Clearly, there is a long way to go before higly reliable, high performance Stirling engines can be made available in mass production quantities at. low cost. There is no reason to expect that current problems cannot be overcome if intensive advanced technology is pursued. At this writing there is another report that soon may become available generally (it is not included in References A-14 through A-28): "Design Manual for Stirling Engines," by W. R. Martini, University of Washington Joint Center for Graduate Study, a report written for DOE under a grant administered by NASA-LeRC.

In Figure A-1, estimated cycle efficiencies are plotted for Stirling heat engines over a wide temperature range. Cycle efficiency, without generator, is given, rather than overall efficiency, because it is more conventional, and because little data for overall efficiency is available. Also included in Figure $\mathrm{A}-1$ are curves indicating various fractional values of Carnot efficiency for comparison purposes (shortdashed curves). Note that the Stirling cycle efficiency curves have steeper slopes than do the Carnot curves.

Early in this study, a considerable body of data was plotted to estimate the effect of size on Stirling engine cycle efficiency. In the range of 5 to $100 \mathrm{kWe}$ output, a significant effect of size was shown in the faired, estimated curves. This data was applied to experimental engines developed for different temperature and pressure conditions and for a wide span of development in the time frame. It was concluded that the data did not reflect the effect of engine size. Reciprocating engines should not exhibit much effect of size on efficiency, e.g., see Ref. A-28. Therefore, it is now assumed that Stirling cycle efficiency is independent of engine size for the purposes of this study.

A curve of typical part-load relative efficiency for the Stirling engine is shown in Figure A-2. The curve applies to constant speed and constant temperature operation, and was estimated from performance data available for the P-75 United Stirling engine. A similar, but slightly lower curve was obtained from Philips-Ford data given in Ref. A-11. In the present computer simulation of solar thermal power systems part-load characteristics in terms of power out (as shown in Figure $\mathrm{A}-2$ ) are not directly used. It is more convenient to use heat input (varying) rather than power input for the calculations. Part:-load efficiency of Stirling (and other) engines is tabulated in Table A-1 as a function of heat input. 


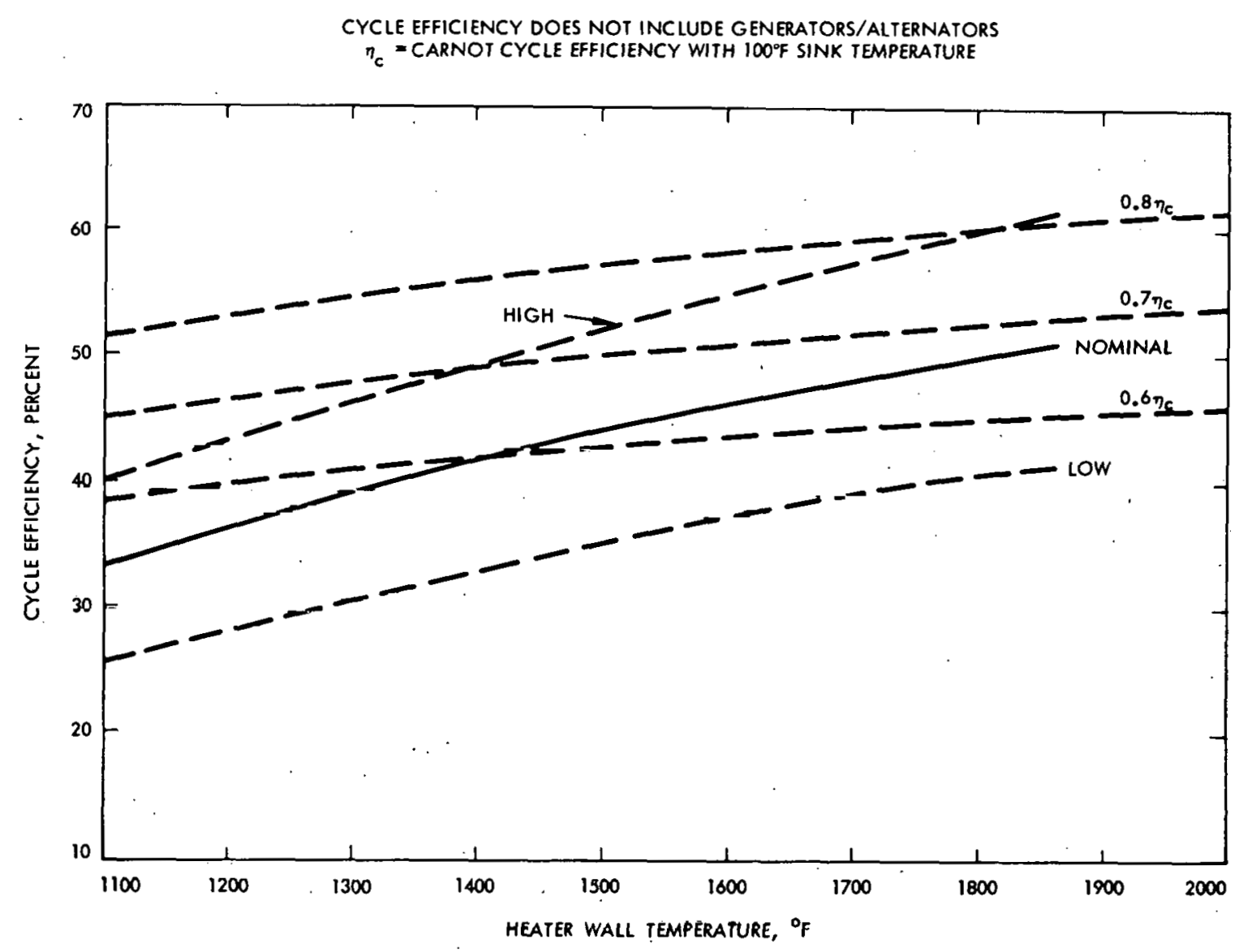

Figure A-1. Estimated Stirling Cycle Efficiency

\section{B. BRAYTON}

The Brayton cycle has been used successfully for many years in aircraft jet engines. They are not, however, very efficient. Description and analysis is available in many textbooks. In principle, the Brayton cycle can be utilized in reciprocating engines but much more attention has been focused on gas turbine development. Gas turbines commonly are used by utilities to generate electric power during peak demands. . Such usage is limited because simple gas turbines are relatively inefficient and require clean fuels. They employ high rotational speeds, thus considerable gear reduction, and require careful manufacture. Relatively little effort has been devoted to developing small engines (of interest for solar thermal dispersed power applications) in the size range below several hundred horsepower. Reference 29 through 50 are typical of recent Brayton cycle development. Current technology status of very large gas turbines is given in Ref. A-48. Recent developmerits in versatile automotive size gas turbines are given in Ref. A-49. 
CONSTANT SPEED, CONSTANT HEATER AND COOLER TEMPERATURE, VARIABLE MEAN PRESSURE

ESTIMATED FROM UNITED STIRLING DATA, P-75 ENGINE

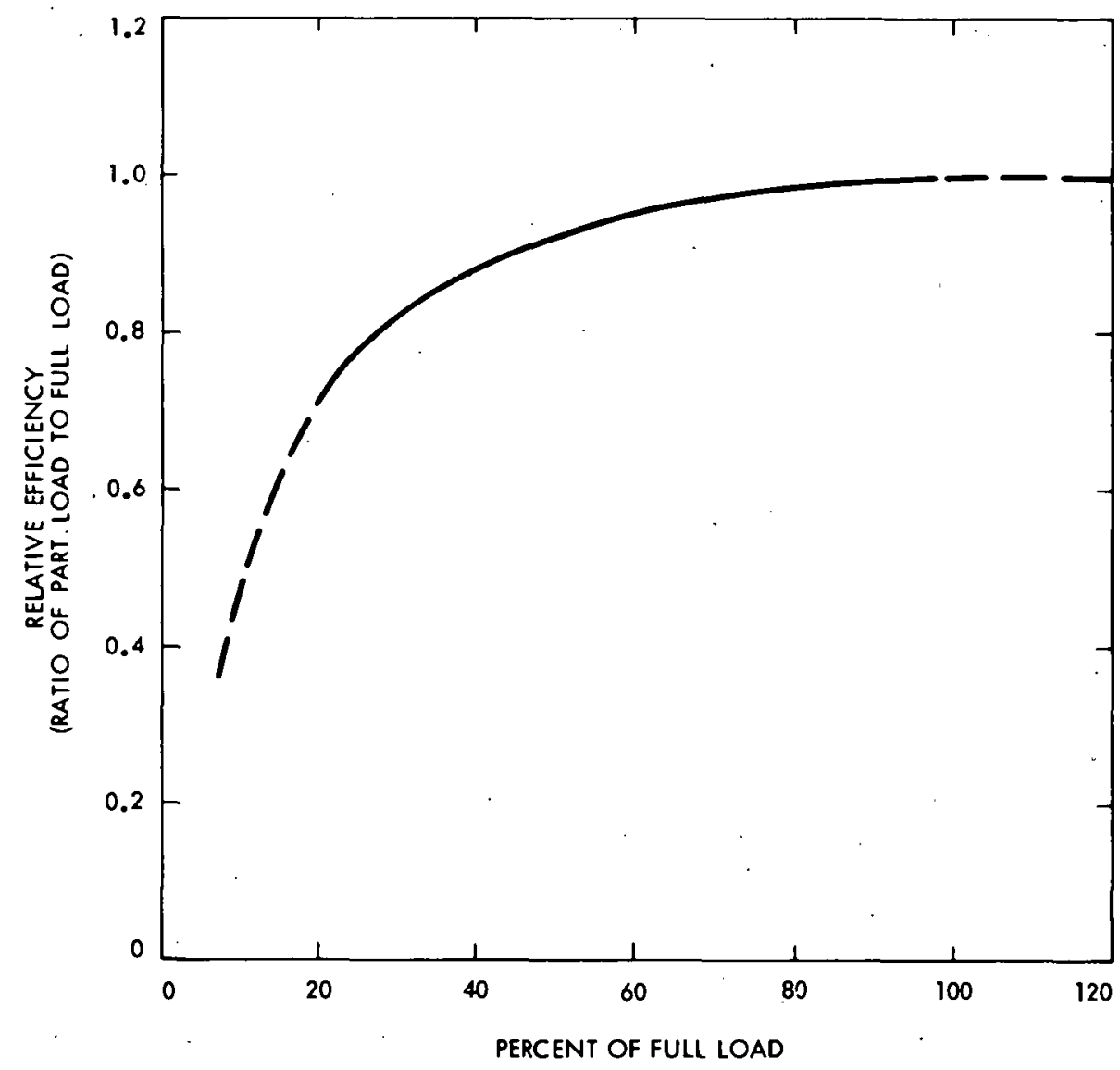

Figure A-2. Estimated Part-Load Performance of Stirling Engines

The ideal efficiency of the simple Brayton cycle is dependent only on the cyetem pressure ratio. In practice, the cycle efficiency depends on peak cycle temperature, ambient temperature, pressure ratio, and component efficiencies of the turbine and compressor. Materials considerations limit the current peak cycle temperature to a maximum of about $1700^{\circ} \mathrm{F}$, or perhaps $1800^{\circ} \mathrm{F}$, according to LeRC personnel. Higher temperatures require turbine blade cooling by water or gas. Ceramic or cermet turbine blade technology may extend this range considerably. In the far tcrm, cycle temperatures of the order of $2800^{\circ} \mathrm{F}$ may become possible.

Brayton cycles may be open or closed. Although closed simple cycles exhibit only slightly higher efficiencies than open cycles ( $t$ wo or three percentage points), the machinery generally is smaller and more compact (especially in diameter and weight) than open-cycle machines of equivalent rating. A variety of, working fluids such as argon, krypton, and xenon may be used in closed-cycle machines. Such working fluids offer better heat transfer characterist1cs than air 
Table A-1. Part-Load Efficiency of Representative Engine. Systems Based on Heat Input

\begin{tabular}{|c|c|c|c|c|c|c|}
\hline \multirow{2}{*}{\multicolumn{2}{|c|}{$\begin{array}{l}\text { Heat . Input } \\
\text { Ratio } \\
\frac{Q_{\text {in }}}{\left(\bar{Q}_{\text {in }}\right)^{\text {rated }}}\end{array}$}} & \multicolumn{5}{|c|}{ Values of Efficiency Ratio $\eta / \eta$ rated } \\
\hline & & $\begin{array}{c}\text { Recip. } \\
\text { Steam }\end{array}$ & $\begin{array}{l}\text { Open-Cycle } \\
\text { Brayton }\end{array}$ & $\begin{array}{c}\text { Subatmospheric } \\
\text { Brayton }\end{array}$ & $\begin{array}{l}\text { Stirling } \\
\text { Engine }\end{array}$ & $\begin{array}{c}\text { Combined Cycle } \\
\text { Brayton/Steam }\end{array}$ \\
\hline (5) & $\begin{array}{l}.10 \\
.15 \\
.20 \\
.30 \\
.40 \\
.50 \\
.60 \\
.80 \\
1.00 \\
1.20\end{array}$ & $\begin{array}{l}- \\
- \\
.61 \\
.74 \\
.805 \\
.865 \\
.915 \\
.975 \\
1.0 \\
.975\end{array}$ & $\begin{array}{l}.53 \\
.64 \\
.72 \\
.835 \\
.905 \\
.960 \\
.990 \\
1.01 \text { (peak) } \\
1.0 \\
.96\end{array}$ & $\begin{array}{l}- \\
- \\
.28 \\
.53 \\
.68 \\
.78 \\
.8 h \\
.98 \\
1.0 \\
.96\end{array}$ & $\begin{array}{l}- \\
- \\
.25 \\
.74 \\
.845 \\
.90 \\
.91 \\
.985 \\
1.0 \\
1.0\end{array}$ & $\begin{array}{l}.10 \\
.56 \\
.765 \\
.92 \\
.975 \\
1.005 \\
1.02 \\
1.02 \\
1.0 \\
.97\end{array}$ \\
\hline
\end{tabular}

\footnotetext{
(1) Bailey (LeRC), "Nominal" (15 kWe)

(2) Estimated from AiResearch/Garrett data (10 kWe)

(3) Estimated from United Stirling data, Ford Aeroneutronic P-75 engine, constant speed (67 kW)

(4) Estimated from UTC data, very large coal-fired plants

(5) Estimate by extrapolation
}

when considering associated heat exchangers. Closed-cycle systems do not require gas filtering so that they have an advantage in environments that potentially are dust laden (deserts). The question of system response to varying load conditions is important for solar applications. Open and closed cycle systems each have their advocates, but closedcycle systems generally have a somewhat better part-load performance. All considered, the tradeoffs in performance and cost between open and closed Brayton cycles still are not wholly clear, especially for systems of small size.

The traditional effective method to increase Brayton cycle performance is recuperation, wherein waste exhaust heat from the turbine is used to preheat the gaseous working fluid leaving the compressor. In large complex gas turbine systems utilizing multi-stago comprç3ors and turbines, intercooling (between compressor stages) and reheat (between turbine stages) may be used effectively. Such measure may not be cost effective in small solar thermal systems. Recuperators are temperature limited by materials. Thermal cycling of high-temperature commercial recuperators poses a challenging problem from the standpoint of durability and replacement cost. 
Because high-temperature gas Brayton cycles have a high exhaust temperature, they are excellent candidates for topping cycles on lowertemperature cycles, especially Rankine cycles. According to Ref. A-5, steam Rankine cycles are not viable candidates for bottoming unless the top cycle peak temperature exceeds $1700^{\circ} \mathrm{F}$. Below that value, organic Rankine cycles offer a better thermal match between top and bottom cycles. Even currently, however, steam Rankine bottoming cycles are utilized commercially (Ref. A-42). Potentially, Brayton cycles may be used as bottom cycles to high-temperature liquid metal top cycles $\left(\sim 1800^{\circ} \mathrm{F}\right)$. All considered, Brayton cycles offer a versatile range of possibilities for power conversion systems.

State-of-the-art durability of gas turbines is excellent for systems operated at steady-state, part-load conditions. Commercial gas turbine/generator sets have run in excess of 70,000 hours without need of overhaul (Ref. A-50). The high rotational speed of (even) current gas turbines, compounded by high cycle temperatures, requires close attention to turbine blade-erosion in the presence of any particulate inclusion in the working fluid.

The high gas temperatures employed in advanced Brayton cycles are a disadvantage in those solar power systems that require considerable transport distances, e.g., point-focusing dispersed systems in which a single ground-based engine may receive thermal energy from several dish modules. Large gas-line pipes with thick layers of insulation are required to prevent excessive heat loss. In such instances, the cost of the transport subsystem may become appreciable in the process of maintaining high overall power conversion efficiency.

The dependence of overall open-cycle Brayton efficiency on cycle temperature estimated herein is shown in Figure A-3. Curves for various fractional values of Carnot efficiency are shown for comparison; the Brayton curves have steeper slopes than the Carnot curves; this might be interpreted to mean that Brayton open-cycle efficiency improves relatively more as the cycle temperature increases. The effect of engine size is shown in Figure A-4. These curves are meant only to show the trend of efficiency with engine size; they do not necessarily correlate with the cemperature curves sliuwa in Figure A-3.

A variety of Brayton cycle part-load characteristics are presented in Figure A-5. These curves were estimated from data made available to JPL by the AiResearch Mfg. Co. (see Ref. A-50). Although these curves apply to small $10 \mathrm{kWe}$ systems, they may be considered typical of Brayton cycles generally. Until recently, small gas turbines have been well known for their poor part-load efficiency. However, with further turbine development for automotive applications has come improvement in part-load efticiency due to urilization of multiple shaft variable geometry machines (see Ref. A-49). It is unclear whether machines of such complexity will find application for solar thermal systems. Larger systems than indicated in Figure A-5 may have somewhat better performance.

The so-called subatmospheric cycle (see Figure A-5) is one in which the peak cycle pressure is approximately atmospheric and the turbine operates in the subatmospheric range (see Ref. A-11 for a brief discussion). One advantage of this cycle for solar power applirations is that heat exchangers and transport lines may operate at low 
OPEN-CYCLE GAS TURBINE WITH RECUPERATION

$\eta_{c}=$ CARNOT CYCLE EFFICIENCY WITH 100'F SINK TEMPERATURE

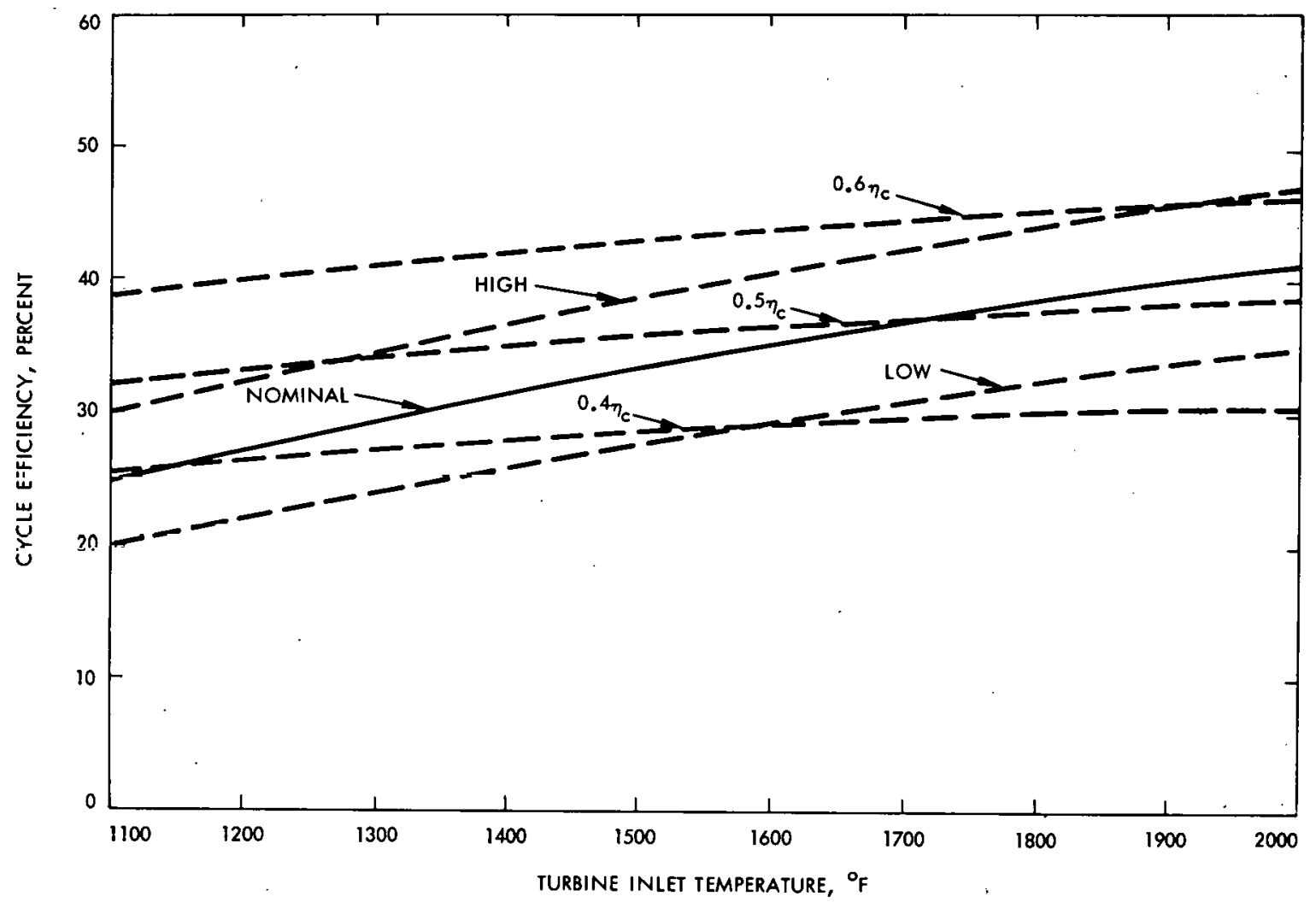

Figure A-3. Estimated Brayton Cycle Efficiency

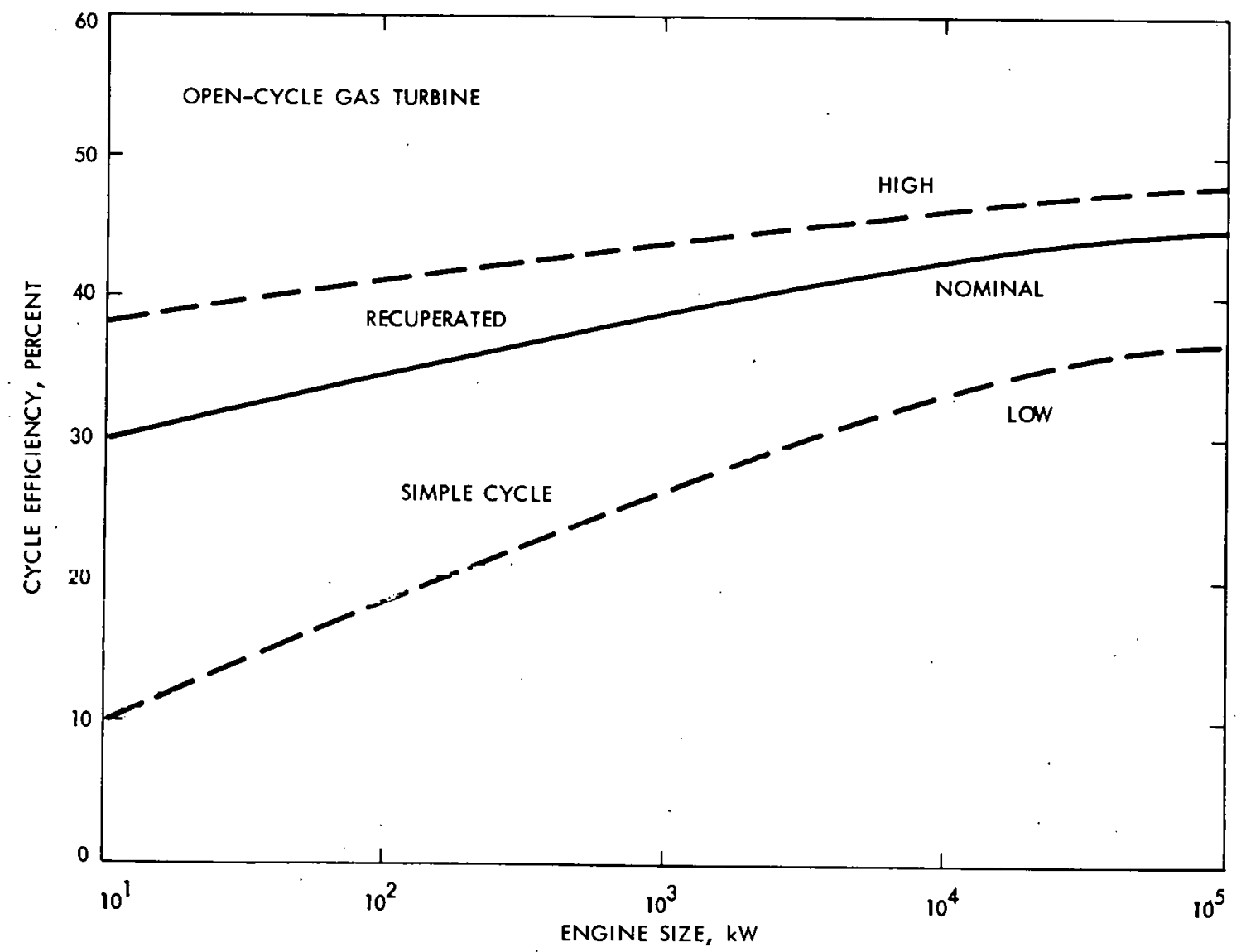

Figure A-4. Estimated Brayton Cycle Performance vs Engine Size A-16 


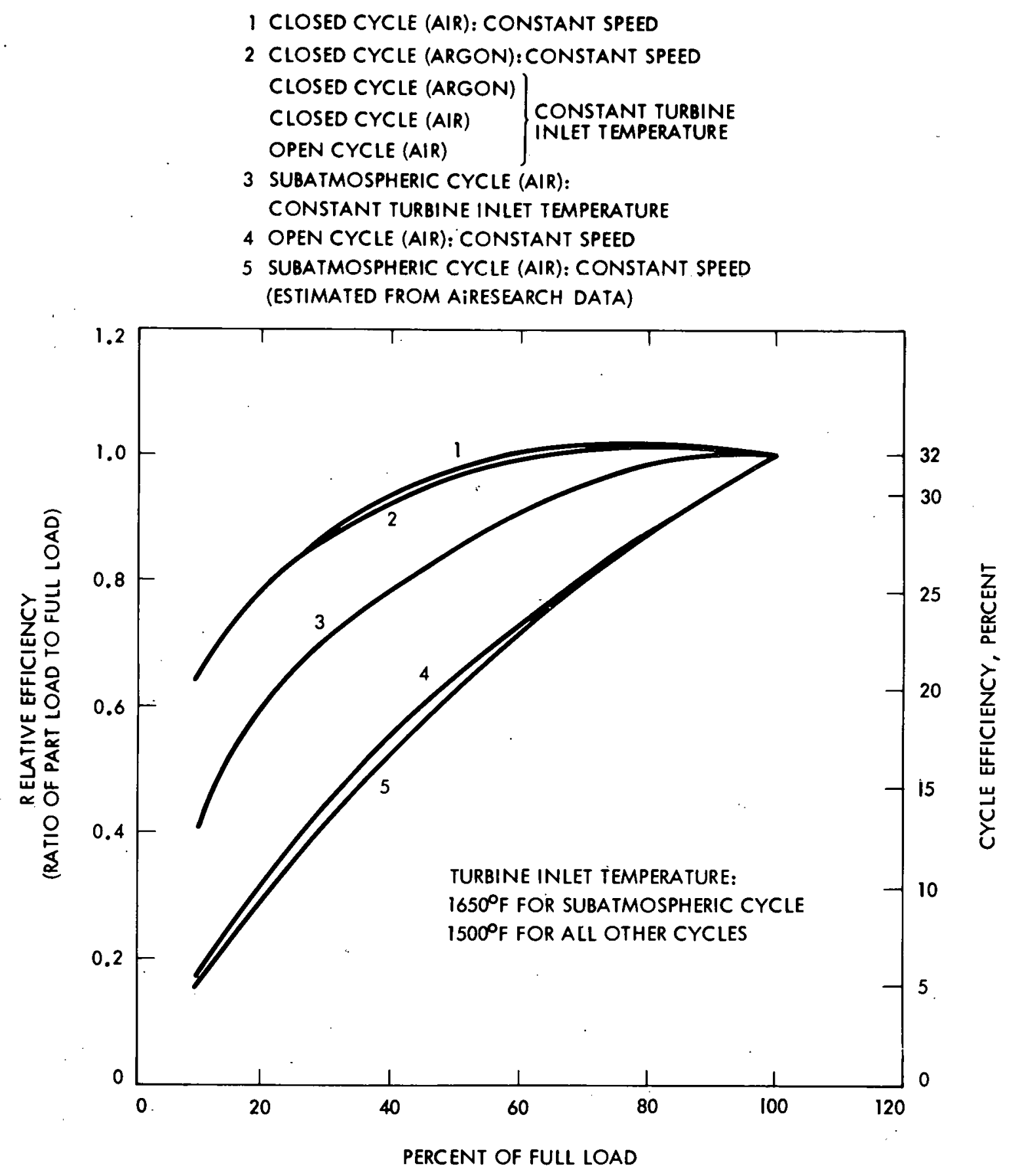

F1gure A-5. Part-Load Characterist1cs of Sma11 (10 kWe) Rrayton Eng Ines 
(atmospheric) pressure; this could effect considerable cost savings and enhance reliability. Two of the curves in Figure A-5 (Curves 2 and 3) were chosen to be presented in terms of turbine heat input rather than power out (part-load). This data is tabulated in Table A-1.

\section{COMBINED CYCLES}

An effective method of increasing energy conversion efficiency of single systems is to employ so-called combined cycles. An almost endless variety of combined cycles appears possible and even a limited discussion of all these possibilities is beyond the scope of this report. Topping cycles may be employed gainfully in instances when the available heat source (e.g., solar or fossil fuel combustion) is sufficiently greater than the level actually being utilized (e.g., a steam Rankine cycle) so that some high-grade thermal energy is being wasted. By tnterposing a higher temperature topping system, gains in efficiency may be realized. Bottoming cycles are useful in instances when the reject heat from an existing system is at a temperature sufficiently high that it can be used as an input heat source for a lower temperature system. An example of the latter is to incorporate an organic Rankine system as a bottoming cycle to a Diesel engine (see, for example, Refs. A-66 and A-67).

Combined cycles historically have been used in connection with electricity production by utilities. In the years 1920 to 1950 , mercury topping cycles were used by some utilities. This gave way. to advancing technology in the steam power cycle (Ref. A-54). Potassium topping cycles are being investigated for large power-generation systems (Refs. A-53 through A-57). Thus, most of the information available for liquid metal topping applies to very large systems. It would appear. that consideration of combined cycles for solar power application might be limited to central tower concepts. It is too soon to draw this conclusion, however, and future advanced téchnology on reliable advanced power conversion systems in small sizes could present opportunities for combined cycles that now appear remote.

The most likely candidates for solar power systems are combinations of Rankine cycles or Rankine-Brayton combinations. To date, all bottoming cycles have been Rankine cycles (Ref. A-69). Binary, tertiary, and even quaternary cycles have been considered from a theoretical point of view (Refs. A-51 and A-53) and show high performance potential. Based on current Stirling engine technology, in which rather low reject temperatures are the rule, it does not appear that Stirling cyclee have much potential as topping cycles on low temperature systems. Rather, they may be used as bottoming cycles, but this option has not been explored. Based on current and projected near-term technology, it seems clear that the role of organic Rankine systems in combined cycles is that of the bottoming cycle. This is due to the fact that their upper temperature limit is probably no greater than $900^{\circ} \mathrm{F}$, and this value has not yet been achieved. The primary limitation on organic working 
fluids is long-term fluid stability, as well as associated safety problems and hazards. The use of organic fluids for Rankine cycles is relatively new, so that a large data base does not yet exist. As a result, emphasis in this study was placed on other systems.

A yery real engineering problem in combined cycles is the thermal matching of the two (binary), or more, systems. Each candidate combined cycle must be analyzed and optimized to produce the best overall result. An optimal combined cycle is not necessarily composed of topping and bottoming cycles that have been optimized individually. The most reliable and cost-effectlve systems are difficult to identify because of the multiplicity of variables and dearth of experience. Although higher energy conversion system efficiencies are possible with combined cycles, the tradeoff with higher capital costs, greater system complexity (with attendant higher operating and maintenance costs), and safety and system control problems must be considered (see Ref. A-54). Combined cycles may be engineered successfully in very large capacity systems, but their utility and cost effectiveness in numerous smallpower applications (e.g., solar dispersed power systems) reamins questionable in view of the current status of technology development.

The thermal mismatch (mentioned above) between the individual cycles of a combined-cycle system was addressed in a brief theoretical study (Ref. A-5). In that study, it was determined that the Brayton closed-cycle in the temperature range $1500^{\circ} \mathrm{F}$ to $1800^{\circ} \mathrm{F}$ combined better with an organic Rankine bottoming cycle than with a steam Rankine cycle. steam Rankine bottoming cycles are more efficient, however, when Brayton cycle temperatures above $1800^{\circ} \mathrm{F}$ are utilized. Yet, combined Brayton and steam Rankine cycles appear frequently in the literature, e.g., see Refs. A-29, A-33, and have been proposed for large scale industrial application by Solar Engineering (Ref. A-42).

Two examples of combined cycles have been selected herein to illustrate the performance potential of advanced power conversion systems: 1) open-cycle gas Brayton with steam Rankine bottoming, and 2) closed-cycle potassium vapor with steam Rankine bottoming: Both cases are projected for use in large stationary power plants and, in fact, most of the available informacton pertains to such utilization. Brayton/Rankine combined cycles are discussed in Ref. A-33 for large plants. As mentioned previously, the Brayton/Rankine cycle is being touted for present day stationary power generation (Ref. A-42). Little work has been done, however, on small-size systems below about $1500 \mathrm{kWe}$. During the 1960's several small liquid metal turbines were developed for space power applications, e.g., see Ref. A-52. In contrast to water, an advantage of liquid metals is that they have a high boiling point (high temperature) at modest boiler pressure. In the condensing cycle, however, water has the advantage. The differences in water and potassium can be used to advantage in the combined cycle.

The estimated cycle efficiency for the two combined cycles cited is shown in Figures $A-6$ and A-9, respectively, as a function of peak cycle temperature of the upper (topping) cycle. There is no claim that 
$\eta_{c}=$ CARNOT CYCLE EFFICIENCY WITH $100^{\circ} \mathrm{F}$ SINK TEMPERATURE

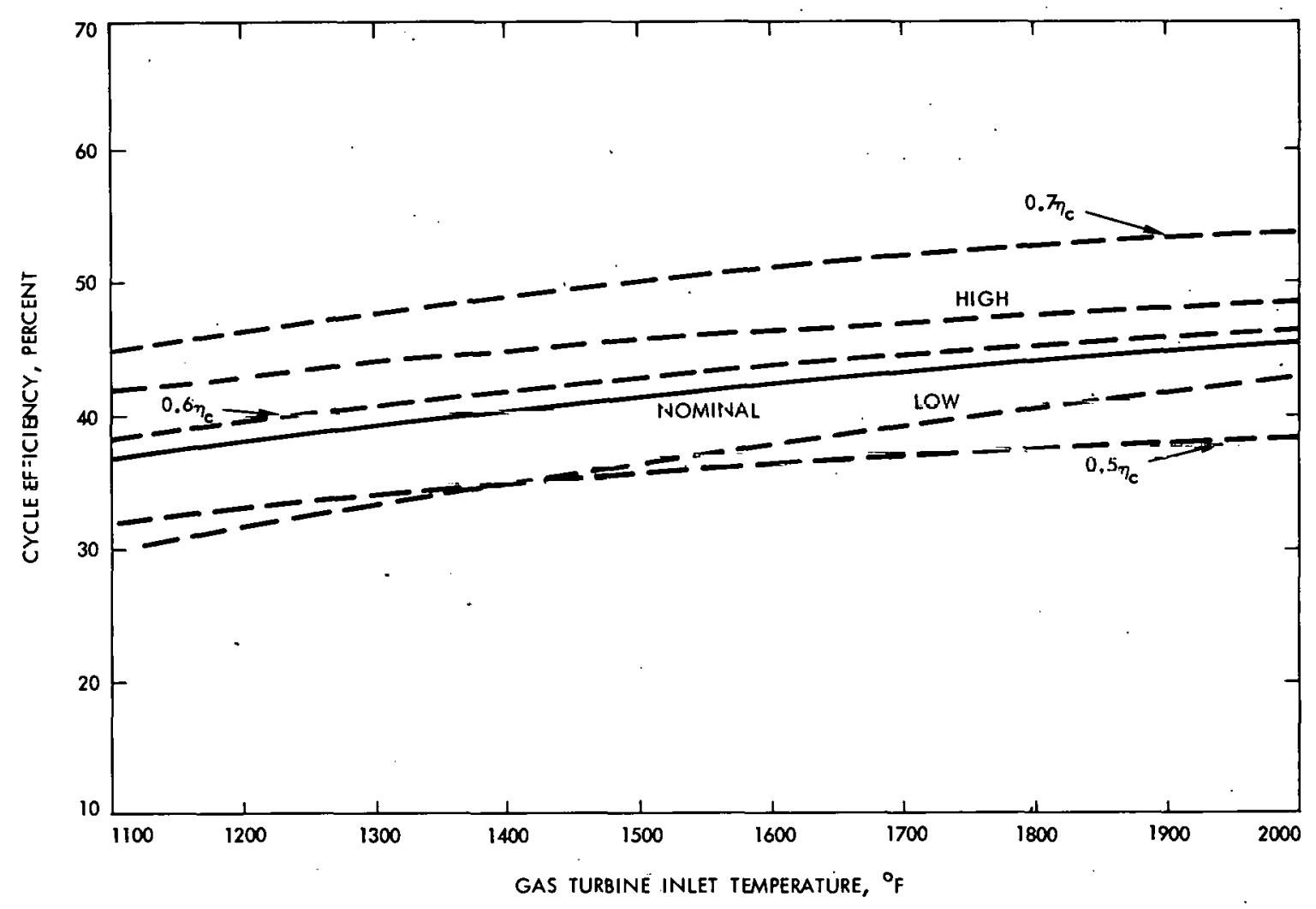

Figure A-6. Estimated Brayton/Steam Rankine Combined Cycle Efficiency

the results are optimal. Note, in both cases, that the trends of the curves are rather flat and parallel closely the fractional Carnot curves. The estimated effect of size on the efficiency of the Brayton/Rankine combined cycle is shown in Figure A-7. (the curves for sizes less than $1000 \mathrm{kWe}$ have been extrapolated for lack of data). These curves show trends only and do not necessarily correlate with the temperature curves shown in Figure A-6. The single case for part-load performance (very large plant) that could be found is shown in Figure A-8. Sufficient data for plant size effects and part-load could not be found for the potassium/steam Rankine combined cycle.

\section{RANKINE}

The Rankine cycle has been used for well over a century in applications ranging from steamboats to nuclear power plants. Its principles are understood thoroughly. Water heated to a vapor state (or superheat) in a boiler is expanded through turbine blades, or pistons, to a low pressure, condensed back to a liquid state, and returned under pressure back to the boiler. There are several refinements that help to achieve higher efficiencies in more sophisticated 


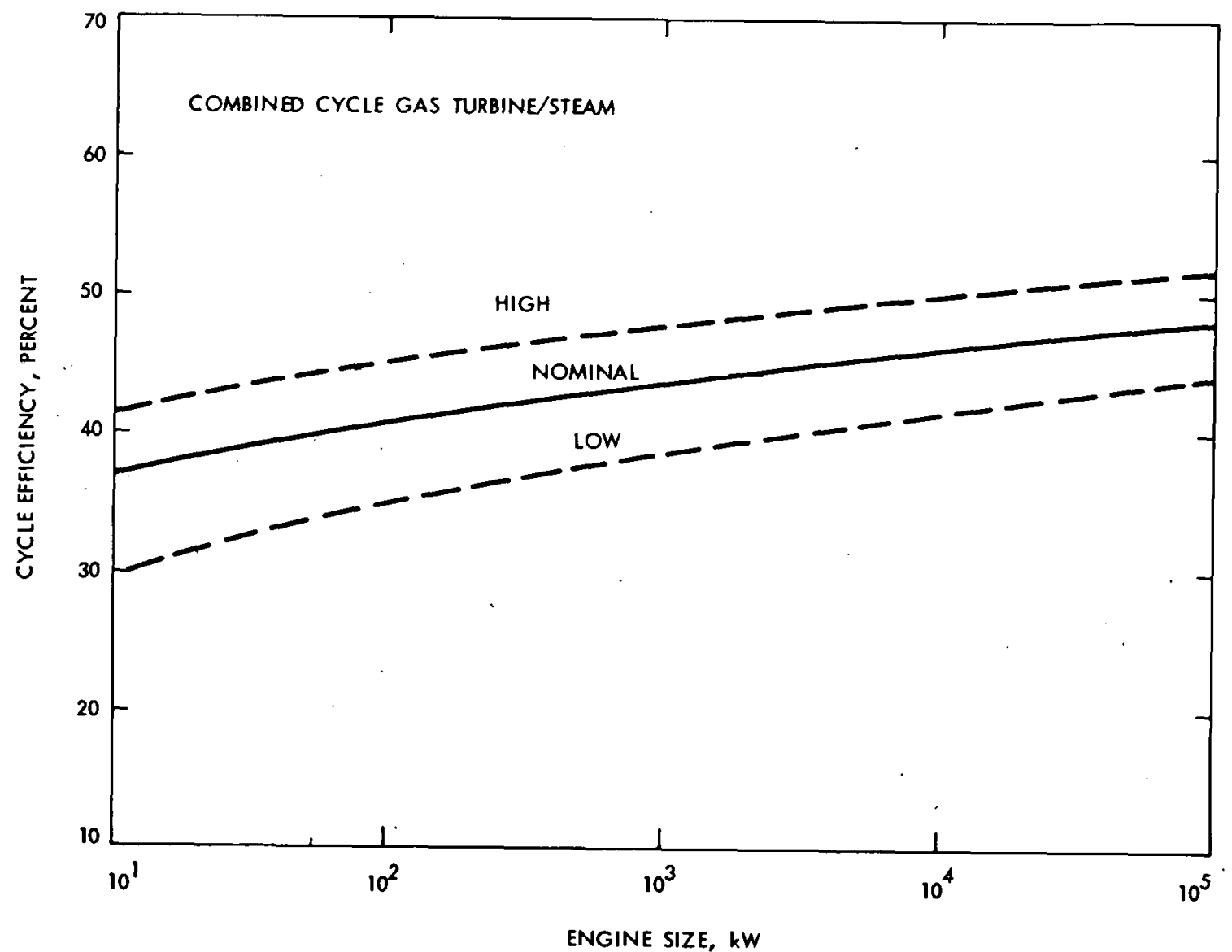

Figure A-7. Estimated Brayton/Steam Rankine Performance vs System Size

systems. Among these are reheat between expander stages and feedwater heating. Numerous textbooks and voluminous literature (not cited herein) are devoted to the Rankine cycle and steam power plants. This branch of engineering was in vogue a generation ago but declined in popularity with the advent of the space age. Renewed interest is due to automotive and solar pnwer applications. The main background used herein are Refs. A-2 and A-11. Fluids other than water have, of course, been used for Rankine cycles, e.g., liquid metals and organic fluids. Comments on such fluids will be given at the end of this section.

Modern stationary steam power plants in the 300 to 500 MWe size range achieve power conversion thermal efficiencies (net electric output to heat input) of $42 \%$ (Ref: A-2). This is accomplished with multistage turbines using steam at $1000^{\circ} \mathrm{F}$ and 2400 psia with single reheat and multiple feedwater heating. Current technology is limited to $1200^{\circ} \mathrm{F}$, or perhaps $1100^{\circ} \mathrm{F}$. Considerable advanced technology will be required to achieve $1200^{\circ} \mathrm{F}$ or. greater. Higher temperatures require water or ever higher purity and feedwater treatment to forestall erosion and corrosion effects in expander stages. Commercial turbine/ generatnr sets in the 30 to $50 \mathrm{kWe}$ size range have efficiencies 
1000 MW GASIFIED COAL-FIRED POWER PLANT TURBINE INLET TEMPERATURE 2200'F

UNITED TECHNOLOGY RESEARCH CENTER (REF. A-35)

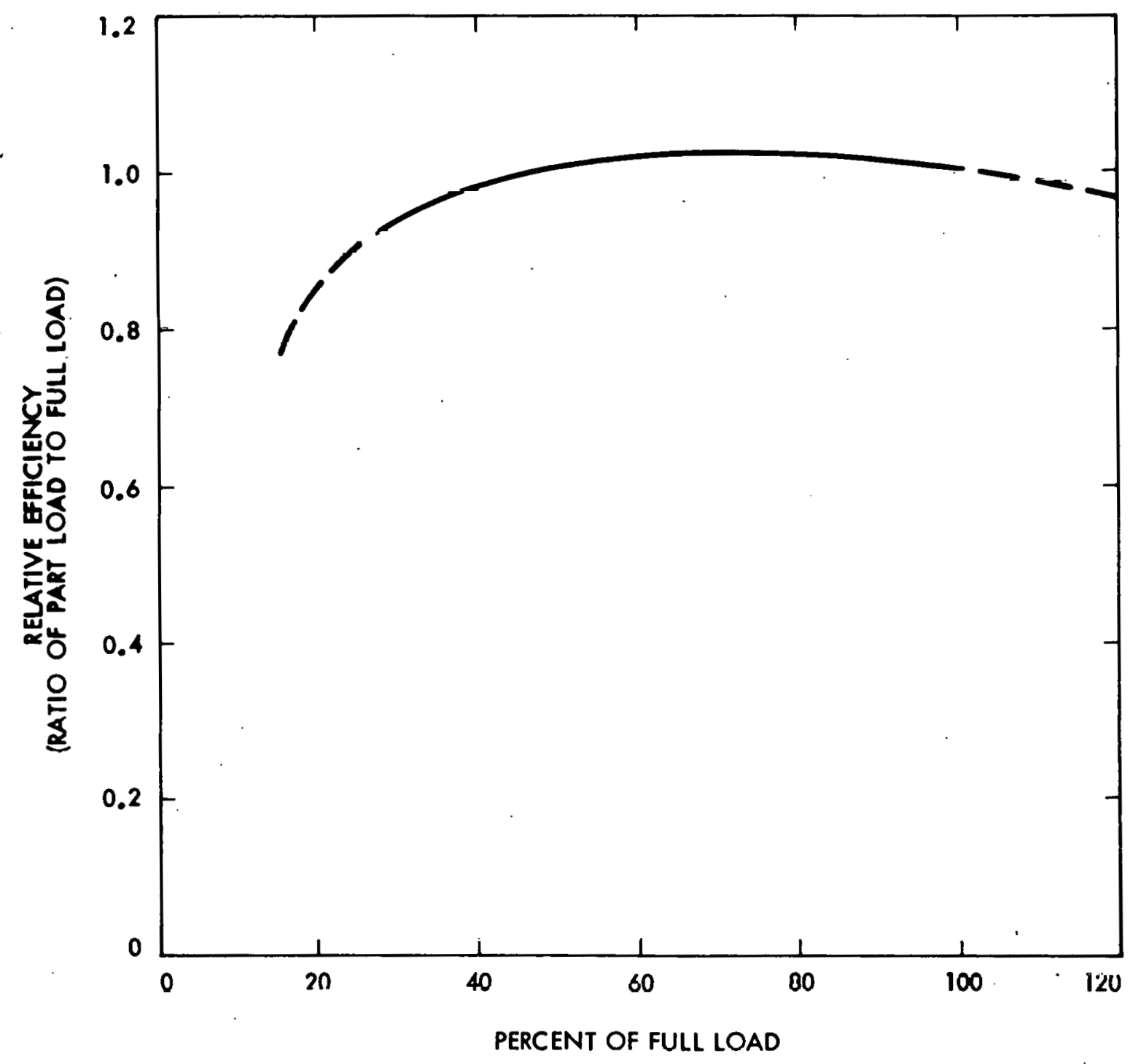

Figure A-8. Brayton/Steam Combined Cycle Part-Load Performance 
$\eta_{c}$ - CARNOT CYCLE EfFICIENCY WITH 100\% SINK TEMPERATURE

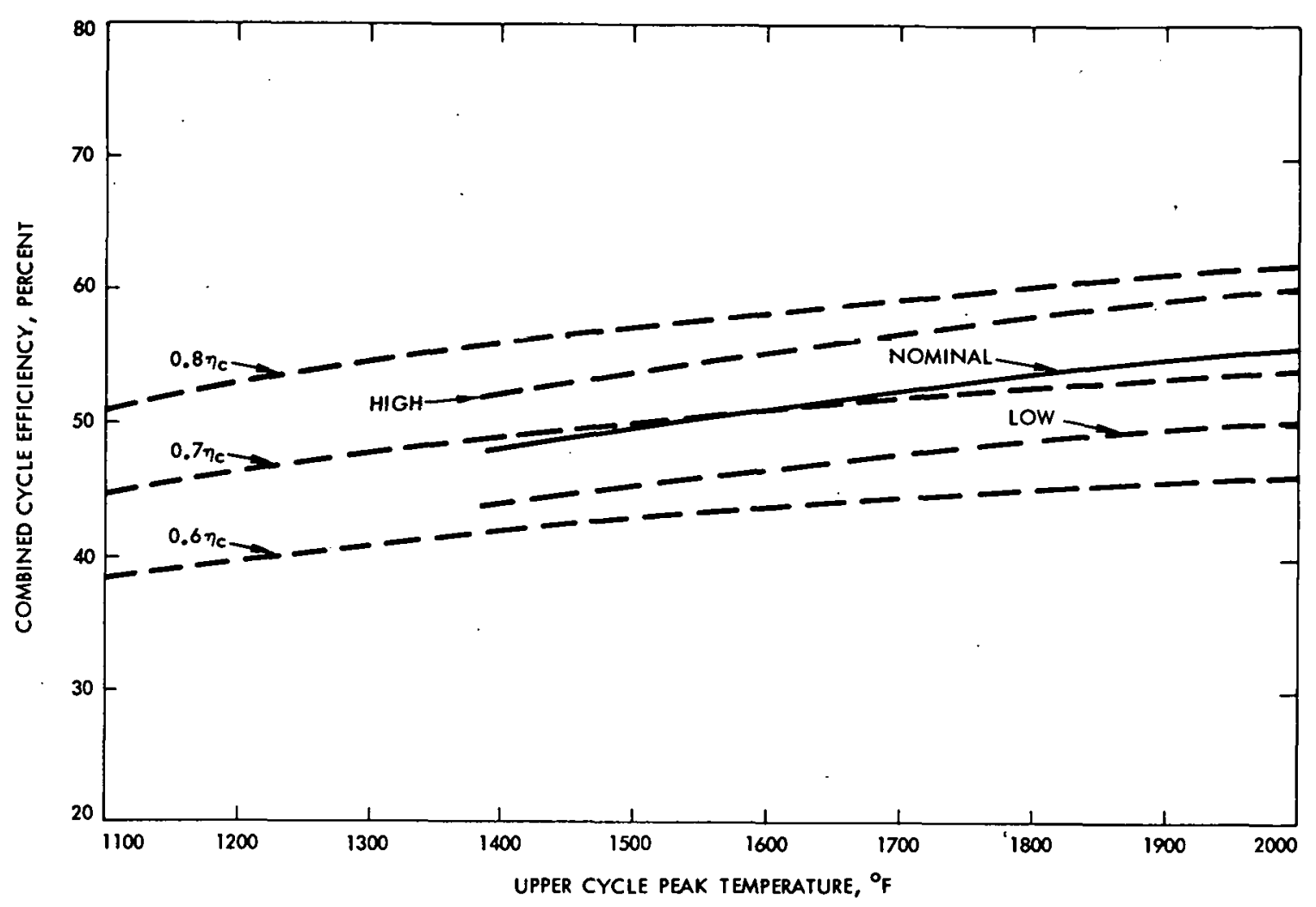

Figure A-9. Estimated Potassium/Steam Rankine Combined Cycle Efficiency

typically less than one-third that of the large modern steam plants. This is due to a combination of economic and technical constraints such as fuel costs, lower temperature and pressure steam, and simpler system configurations for the smaller systems.

Prior to the widespread introduction of modern turbines, the steam reciprocating engine was the prime mover for electric power generation. In the early 1900 's engines up to $5000 \mathrm{hp}$ were in use with reported power conversion efficiencies up to $21 \%$. Steam conditions typically were $400^{\circ} \mathrm{F}$ and 250 psig. Rotating speeds generally were low, typically $450 \mathrm{rpm}$, so that reliability and life characteristics were very good. The efficiency crossover point favoring steam turbines over engines generally is in the range 500 to $1000 \mathrm{~kW}$. Little work has been expended on small-size steam turbines; most are single stage and have relatively low efficiency. Thus, in the smaller size, current development favors reciprocating expanders over steam turbines. Impetus for development work on reciprocating expanders was gained from interest in automotive applications, e.g., see Refs. A-70, A-71, and $\mathrm{A}-72$. 
Experimental steam engines for automotive application typically may use steam at temperatures up to $1100^{\circ} \mathrm{F}$ and pressures up to 2500 psia, and rotational speeds up to $5500 \mathrm{rpm}$. Reduced life cycle requirements permit these advanced operational conditions (Ref. A-2). For solar power applications, with much longer life cycle requirements, more modest conditions probably will be employed, e.g., $1050^{\circ} \mathrm{F}, 1500$ psia, and $1800 \mathrm{rpm}$. A significant trend in modern steam engines compared with their early counterparts is reduced size and weight. Modern engines may have a specific weight as low as $3 \mathrm{lb} / \mathrm{hp}$, a twenty-fold reduction compared to early engines. A broad comparison of steam engines for solar power application and automotive application, and contrasting requirements, is given in Ref. A-2.

Based on current technology, it is estimated that steam engine/ generator ceto in jiscs ranging up to $100 \mathrm{kWe}$ wlll be favored over steam turbines for solar power application, unless small, efficient multistage steam turbines are developed. A performance comparison between engine/generator sets (baseline, alternate, and advanced projections of LeRC) and current commercial steam turbines is shown in Figure A-10. Note that the increasing performance with increasing size of steam turbines is associated with higher steam conditions and more complex systems. Boiler efficiency has not been included because in solar power applications the boiler is replaced by a receiver that is part of the solar collector. Based on LeRC data, the performance of nominal steam turbines at $1000^{\circ} \mathrm{F}$ has been estimated for a wide size range (Figure A-11); projected improvements in performance will be obtained for higher steam temperatures, except that the smaller size range performance still remains to be demonstrated.

The estimated performance of steam engine/generator sets as a function of steam temperature is shown in Figure A-12 in terms of overall, rather than cycle, efficiency. The flat trends reflect a true temperature dependence characteristic of the steam Rankine cycle, and they are slightly less steep in slope than the fractional Carnot curves. The corresponding effect of engine size is shown in Figure A-13. Only slight effects of size are anticipated, except in the range of $10 \mathrm{kWe}$ to $20 \mathrm{kWe}$. A thorough discussion of size effects is given in Ref. A-2 . Part-load efficiency is shown in Figure A-14, but it is plotted as a function of variable heat input rather than power out. Values for the nominal case are listed in Table A-1.

A future decision point in the design of small power level steam expanders will be to continue development of higher performance singlestage devices as opposed to multistage devices. The final evaluation will require a conceptual design and performance assessment for specific applications and must consider durability and cost as well as efficiency. Multistage devices permit the use of inter-stage reheat, higher efficiency and life, but also have higher cost. Preliminary considerations of small reciprocating expanders, using experience gained with Diesel engines (Ref. A-2), indicates that reciprocating engines have many attractive features. However, it is too early to make a final choice because advanced technology on small, high performance multistage turbines has not been pursued vigorously. 
CONDENSER 3.5 INCHES Hg, BOILER NOT INCLUDED

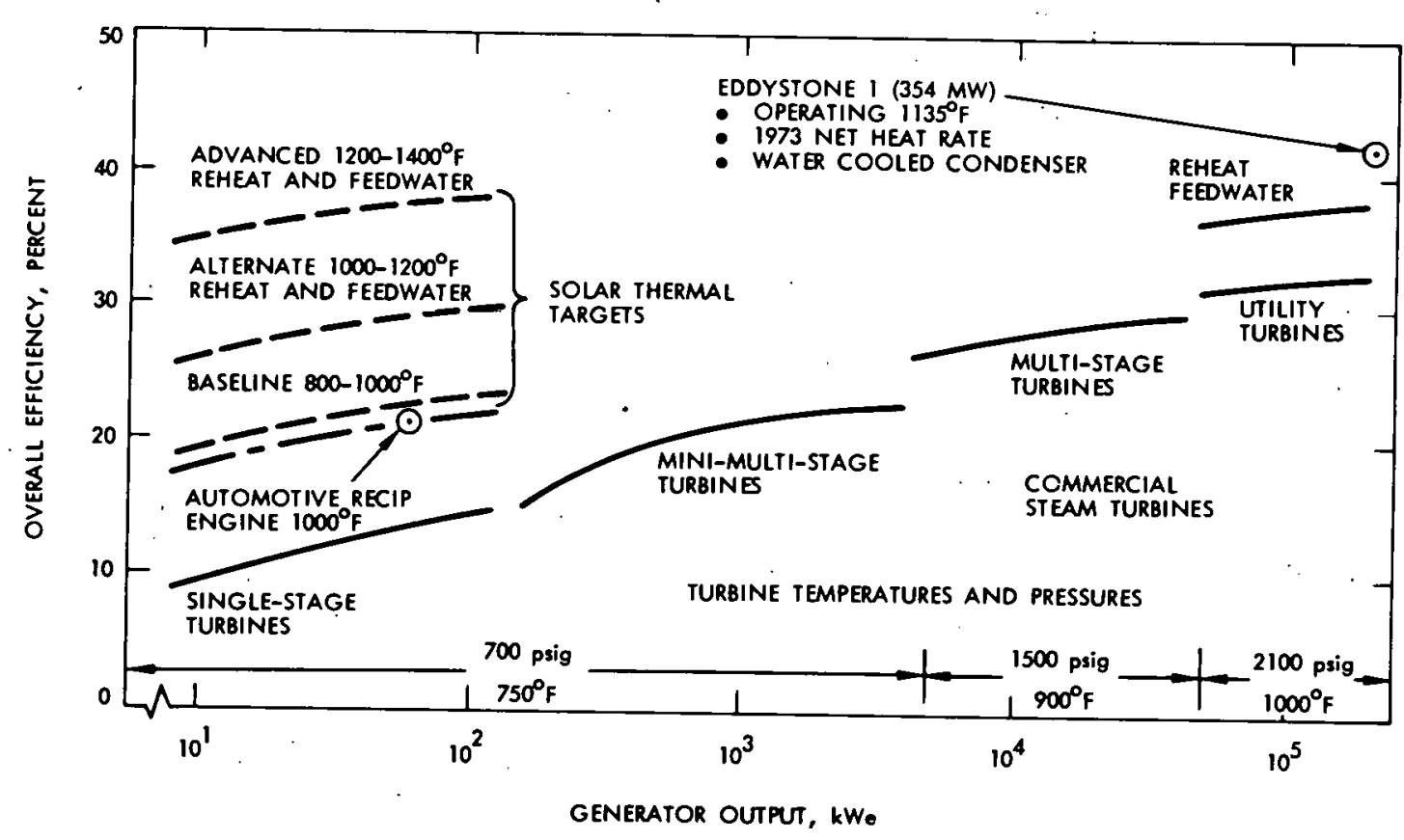

Figure A-10. Comparison of Performance of Advanced Steam Engine/ Generator Sets with Commercial Steam Turbines

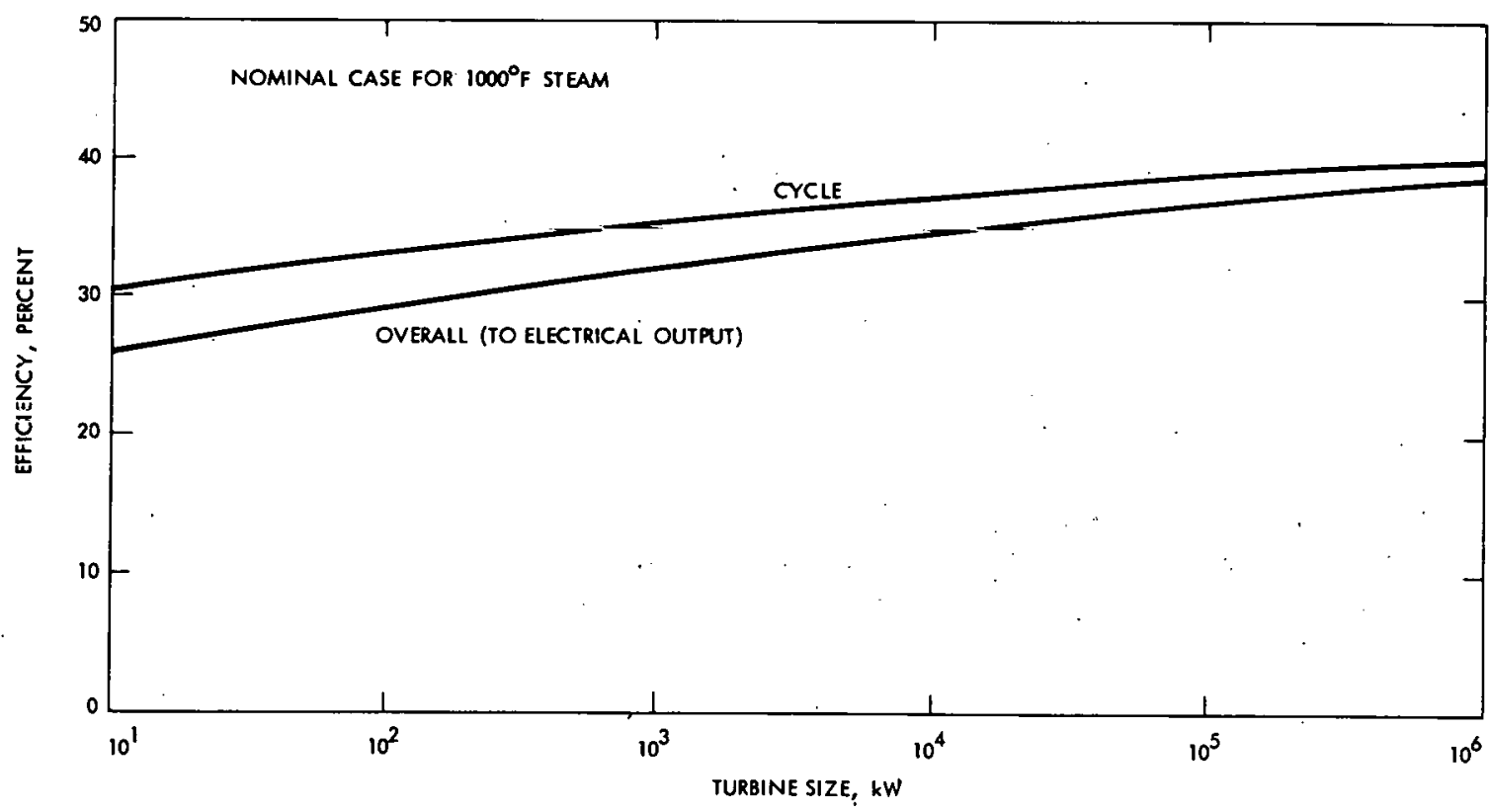

Figure A-11. Estimated Nominal Performance of Steam Turbines 
$\eta_{c}=$ CARNOT CyCLE EFFICIENCY WITH $100^{\circ} \mathrm{F}$ SINK TEMPERATURE

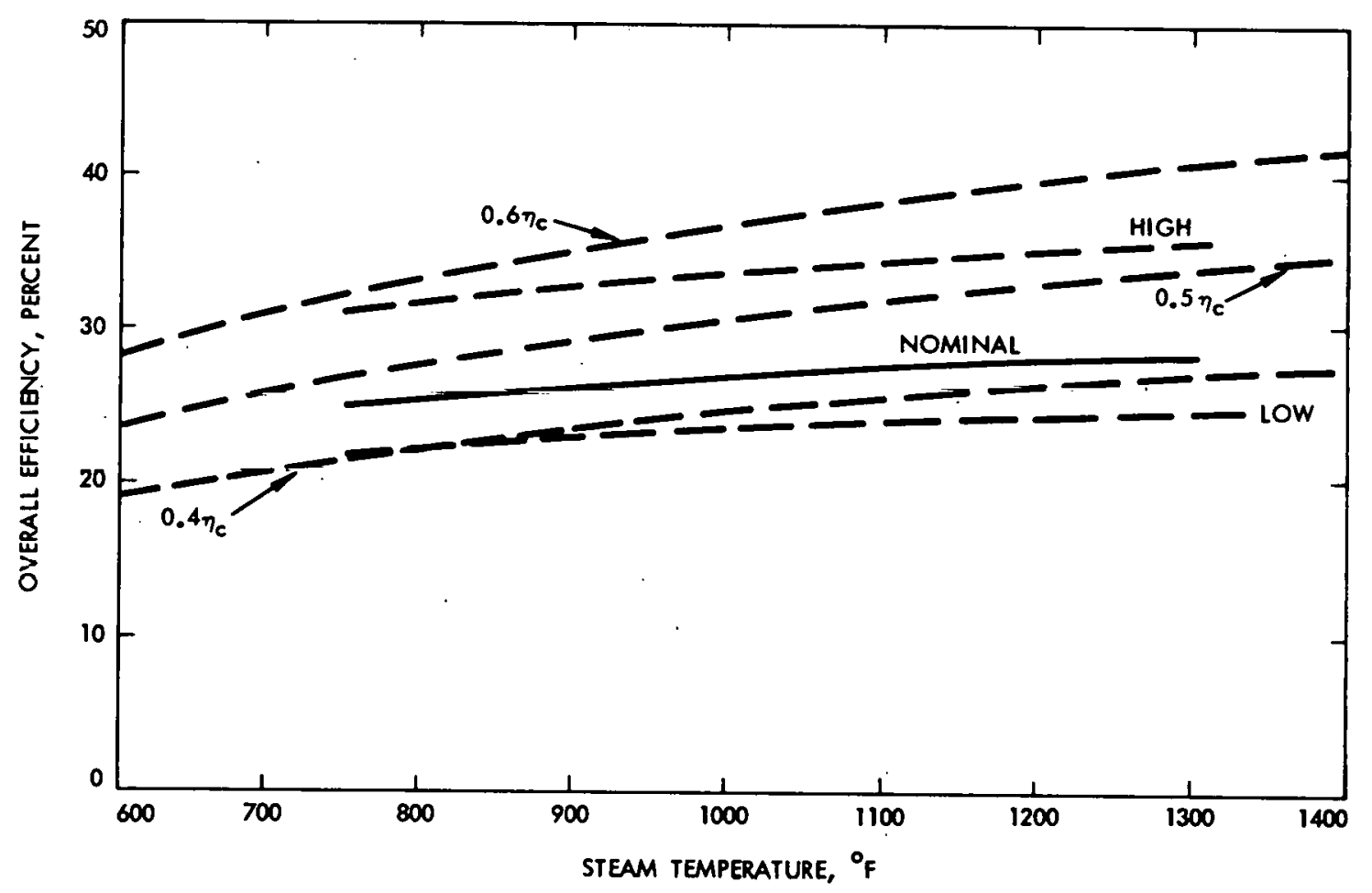

Figure A-12. Estimated Efficiency of Reciprocating Steam Engine/Generator Sets

The material presented thus far in this section pertains to water as the working fluid for Rankine cycles. The use of liquid metals and organic fluids for Rankine cycles was discussed briefly in the Combined Cycles section. Liquid metals are used generally at much higher temperatures than water, whereas organic.fluids are more appropriate for low temperatures. Organic working fluids remain vaporized at conditions of temperature and pressure where steam will condense. (Erosion by droplets is not an insignificant problem in steam systems using high velocities.) An additional advantage of organic fluids, and liquid metals is that high density (compared to water) permits the design of very compact turbines that are much smaller than steam turbines of comparablc power output, e.g., see Refs. A-52, A-54 and A-62. The efficiency of organic Rankine cycles under current development generally is better than simple, single-stage steam cycles but poorer than multistage steam cycles (Refs. A-2 and A-11). Most organic Rankine turbines are of single-stage design. 


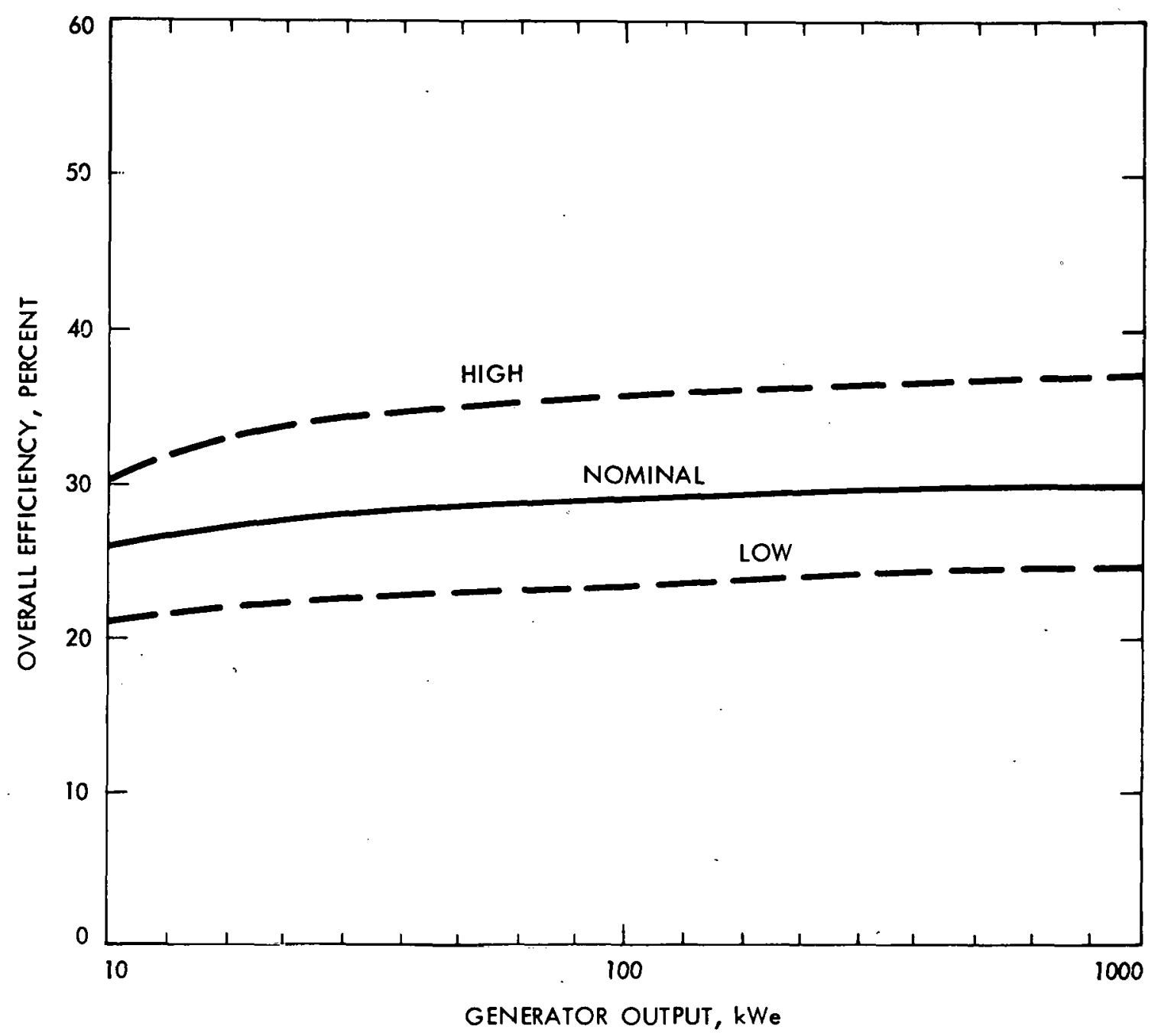

Figure A-13. Estimated Performance of Reciprocating Steam Engine/ Generators vs Engine Size

Many Rankine cycle fluid candidates, particularly organic fluids, possess. interesting physical properties, e.g., see Refs. A-62, A-73, and A-74. Wetting fluids such as water have a vapor saturation curve of negative slope in a temperature-entropy diagram. Thus, sufficient 1sentropic expansion of fluid from the superheat region will result in a vapor containing moisture. In contrast, organic fluids may possess almost vertical vapor saturation curves (the so-called isentropic fluids) or vapor saturation curves that have positive slope (the socalled drying fluids). In the latter case isentropic expansion of a vapor actual,1.y can produce superheat. 


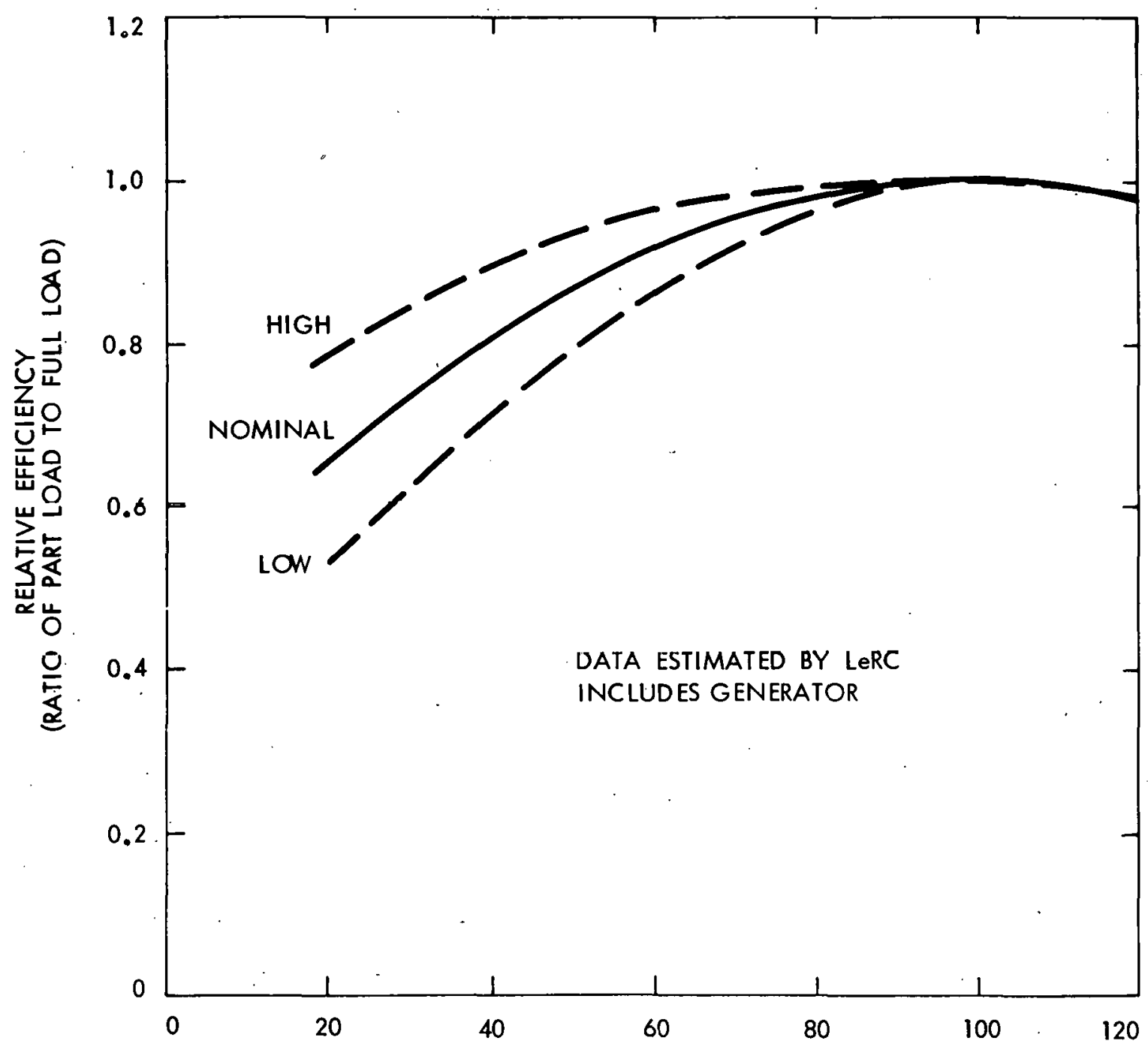

PERTENT OF RATEU HEAI INPUT, $\left(Q_{\text {in }}\right.$ rated

Figure A-14. Part-Load Performance of Reciprocating Steam.Engine/ Generator Sets as Related to Heat In rather than to Power Out

\section{E. ELECTRIC GENERATORS}

The performance of generators/alternators is an important aspect of power conversion systems for solar thermal generation of electricity. Performance varies with design, size (electric output) and rotational speed. Large, modern A.C. generators may be hydrogen cooled. Fullload efficiency of A.C. generators is shown in Figure A-15. Faired curves based on data compiled by LeRC are shown for premium/advanced units as compared with commercial units. Note that large decreases in efficiency are common in units of less than $1000 \mathrm{kWe}$ output. Electric generators, like heat engines, display part-load characteristics. These characteristics have been improved by industry through many years of advanced technology. A range of performance for small $10 \mathrm{kWe}$ to $20 \mathrm{kWe}$ machines is shown in Figure $A-16$, as based on information received from the AiResearch Mfg. Co. (Ref. A-75). 


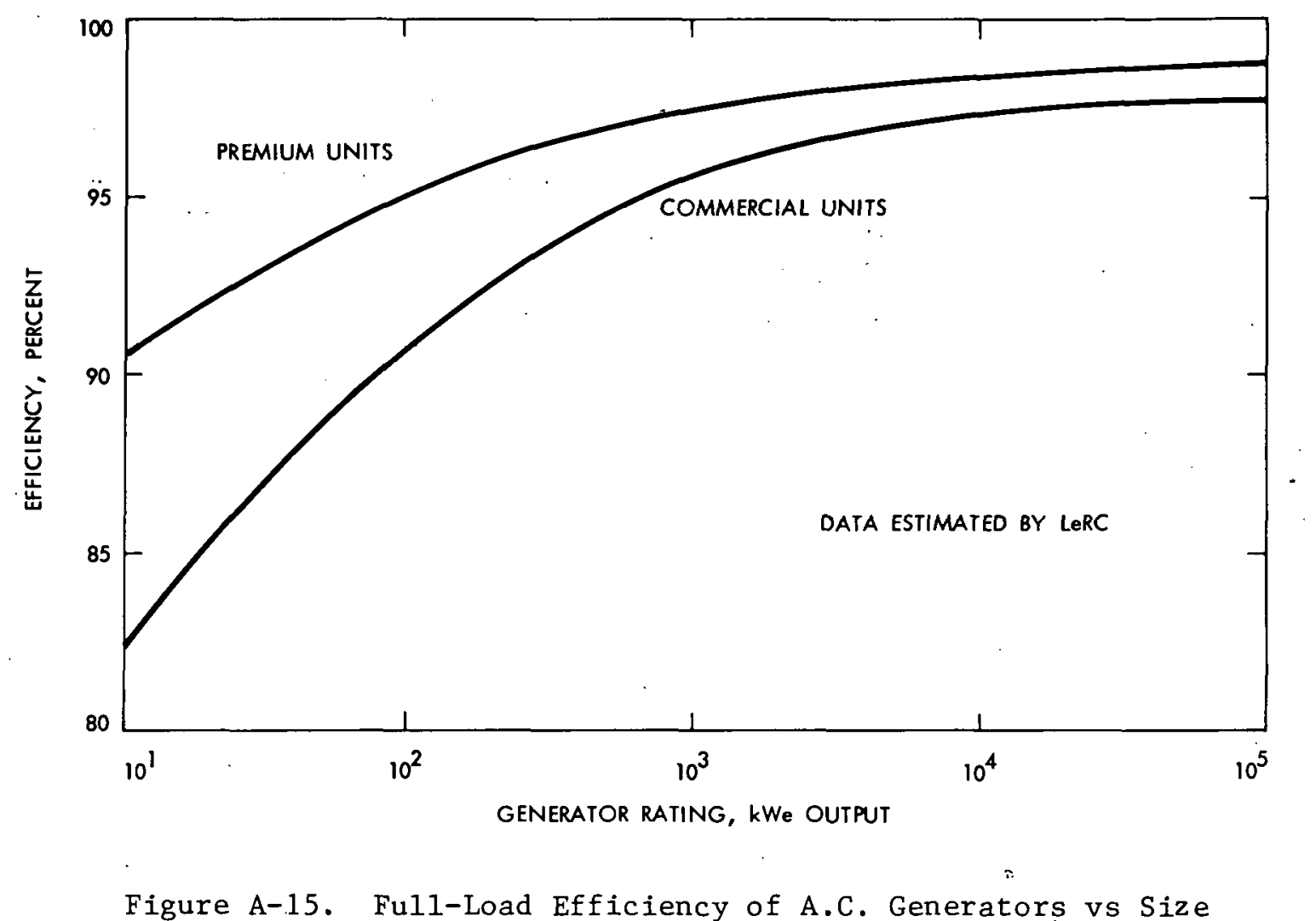

F. DISCUSSION

The tradeoffs implicit in the use of many small heat engines vs fewer large engines in solar thermal power systems is complex, and there still are many unknowns. In addition to performance and cost, which may be influenced greatly by mass production and considerations of operation and maintenance, there are questions of long-term reliability, advantages of modularity, and development costs. Other Important questions concern transient operation and controls. Many of these questions are interrelated and so they cannot be dealt with independently. Nevertheless, it appears that the overall power conversion efficiency of small versus large engine systems has not received the attention that is warranted.

The overall efficiency of power conversion systems (defined as useful power out divided by heat input) includes the thermal cycle efficiency as well as the efficiency of the generator or alternator, mechanical subunits, gear box, auxiliary equipment, and any electrical equipment such as rectifiers/inverters. The product of all these efficiencies determines overall efficiency. Depending partly. on the type of engine, the thermal efficiency of small heat engines falls off with decreasing size. That of generators and other subunits does 


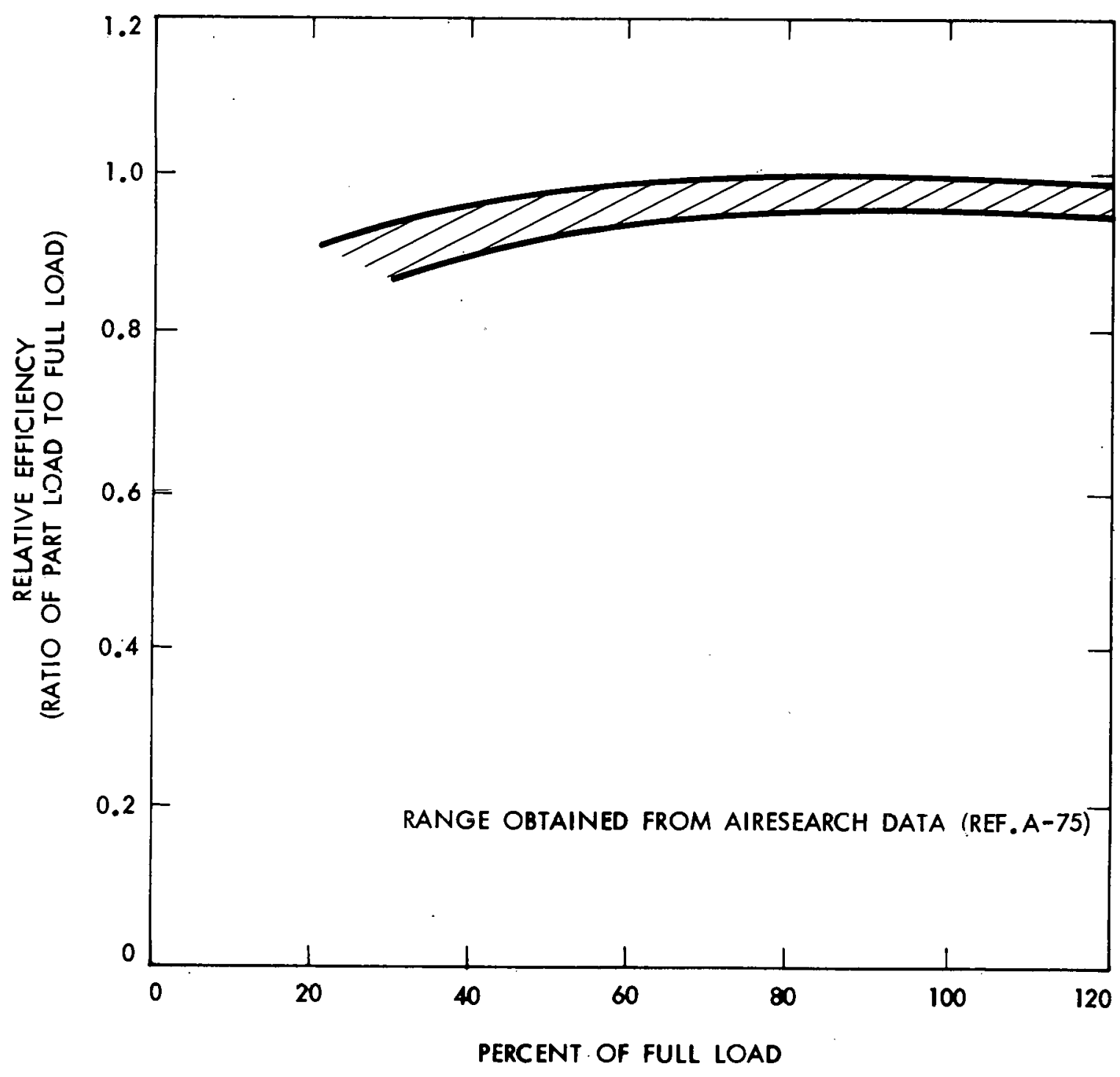

Figure A-16. Part-Load Efficiency of Typical A.C. Generators

likewise. Note for example the results shown in Figures $A-4, A-7, A-11$, $A-13$, and $A-1 b$. Gearbox efficiencies fall between 0.97 to 0.99

(Ref. A-75) over a wide range of power, input speed, and reduction ratio, so that they appear not to be a critical item from the performance standpoint. The qucstions of reliability and lifetime, uf cuurse, are entirely different matters.

Another question that relates to the choice of small or large engine systems is part-load performance and transient response. Clearly, more definitive studies will be needed to characterize the overall performance of power conversion systems as a function of engine size. Reduction in costs through large-scale mass production might favor lower-performance small engine systems over much larger engines that would be produced in smaller volume. 
In view of the potential use of small engines with point-focusing solar power systems, it is useful to project performance improvements for advanced technology systems compared with near-term expectations. In Table A-2 are shown some performance targets for small engines as compiled by LeRC (Ref. A-2); indicated are the cycle temperature, engine configuration, and expected degree of improvement.

Other performance projections for various candidate energy conversion systems have been estimated herein based on a review of the current literature. These projections are shown in Figure A-17; data bands on the points plotted indicate uncertainty and opinion differences. For reasons mentioned earlier, the upper limit of cycle temperature has been constrained to about $1800^{\circ} \mathrm{F}$; further gains might be achieved at higher temperatures. Performance projections indicate that efficiency may approach 70 to 80 percent of theoretical Carnot efficiency (based on $100^{\circ} \mathrm{F}$ sink temperature). Several of the systems depicted in Figure A-17 warrant further description. "External" Diesel systems refér to Diesel engines reconfigured to accept either external combustion or an external heat source such as solar thermal input (Ref. A-6). "Advanced" Stirling engines are those designed to use dissociating fluids as the working fluid (this will be discussed subsequently). The supercritical cycle, known also as the Feher cycle when $\mathrm{CO}_{2}$ (carbon dioxide) is used, may operate entirely in the supercritical range of the working fluid. The Feher cycle is discussed in some detail in Reference A-6.

Table A-2. Small Engine Performance Targets (Data compiled by LeRC, Ref. A-2)

\begin{tabular}{|c|c|c|c|c|c|c|}
\hline \multicolumn{2}{|c|}{ ENGINE } & \multirow[t]{2}{*}{$\begin{array}{c}\text { DATA } \\
\text { AVAILABLE }\end{array}$} & \multirow{2}{*}{$\begin{array}{c}\text { CYCLE } \\
\begin{array}{c}\text { TARGET } \\
\% \\
20^{+}\end{array}\end{array}$} & \multirow{2}{*}{$\begin{array}{l}{ }^{\text {TEMP. }}{ }^{\circ} \\
1000\end{array}$} & \multirow{2}{*}{\begin{tabular}{l}
\multicolumn{1}{c}{ ENGINE } \\
CONFIGURATION \\
$\begin{array}{l}\text { Recip./no Reheat } \\
\text { From TEC }\end{array}$
\end{tabular}} & \multirow{2}{*}{\begin{tabular}{l}
\multicolumn{1}{c}{ IMPROVEMENT } \\
$100 \%$ Over Single \\
stage Turbine
\end{tabular}} \\
\hline $\begin{array}{l}\text { Baseline } \\
\text { Steam }\end{array}$ & $(\sim 15 \mathrm{~kW})$ & & & & & \\
\hline $\begin{array}{c}\text { Alternate } \\
\text { Steam }\end{array}$ & $(-15 \mathrm{~kW})$ & 1982 & $30^{+}$ & 1000 & $\begin{array}{l}\text { Reheat and } \\
\text { Feedwater Heat }\end{array}$ & $\begin{array}{l}50 \% \text { Over Baseline } \\
\text { Steam }\end{array}$ \\
\hline $\begin{array}{l}\text { Baseline } \\
\text { Brayton }\end{array}$ & $(\sim 15 \mathrm{~kW})$ & 1980 & 27 & 1500 & $\begin{array}{l}\text { Existing Open } \\
\text { Cycle w/Recup. } \\
\text { Added }\end{array}$ & $\begin{array}{l}80 \% \text { Over Simple } \\
\text { Cycle Brayton }\end{array}$ \\
\hline $\begin{array}{l}\text { Alternate } \\
\text { Brayton }\end{array}$ & $(\sim 15 \mathrm{~kW})$ & 1982 & 35 & & $\begin{array}{l}\text { Temp. \& Recup. } \\
\text { Effectiveness } \\
\text { Impruved }=\text { Myy } \\
\text { be Closed Cycle }\end{array}$ & $\begin{array}{l}30 \% \text { Over Baseline } \\
\text { Brayton }\end{array}$ \\
\hline Stirling & $(\sim 15 \mathrm{~kW})$ & $\begin{array}{l}\text { Advanced } \\
\text { Technology }\end{array}$ & 42 & 1500 & $\begin{array}{l}\text { Adapted to Solar } \\
\text { May use Sodium } \\
\text { Heat Pipe }\end{array}$ & $\begin{array}{l}>50 \% \text { Over Baseline } \\
\text { Brayton \& } 1500^{\circ} \mathrm{F}\end{array}$ \\
\hline $\begin{array}{l}\text { Advanced } \\
\text { Steam }\end{array}$ & $(<200 \mathrm{~kW})$ & $\begin{array}{l}\text { Advanced } \\
\text { Technology }\end{array}$ & 40 & & $\begin{array}{l}\text { Higher Temp., } \\
\text { Reheat \& Mult. } \\
\text { Feedwater Heat }\end{array}$ & $\begin{array}{l}\text { Up to } 100 \% \text { over } \\
\text { Baseline Steam }\end{array}$ \\
\hline $\begin{array}{l}\text { Advanced } \\
\text { Organic }\end{array}$ & $(<200 \mathrm{~kW})$ & $\begin{array}{l}\text { Advanred } \\
\text { Technology }\end{array}$ & 30 & 600 & $\begin{array}{l}\text { High Effic. } \\
\text { Expander in } \\
\text { Dual Cycle }\end{array}$ & $\begin{array}{l}>35 \% \text { Over Existing } \\
\text { Units c } 600^{\circ} \mathrm{F}\end{array}$ \\
\hline
\end{tabular}




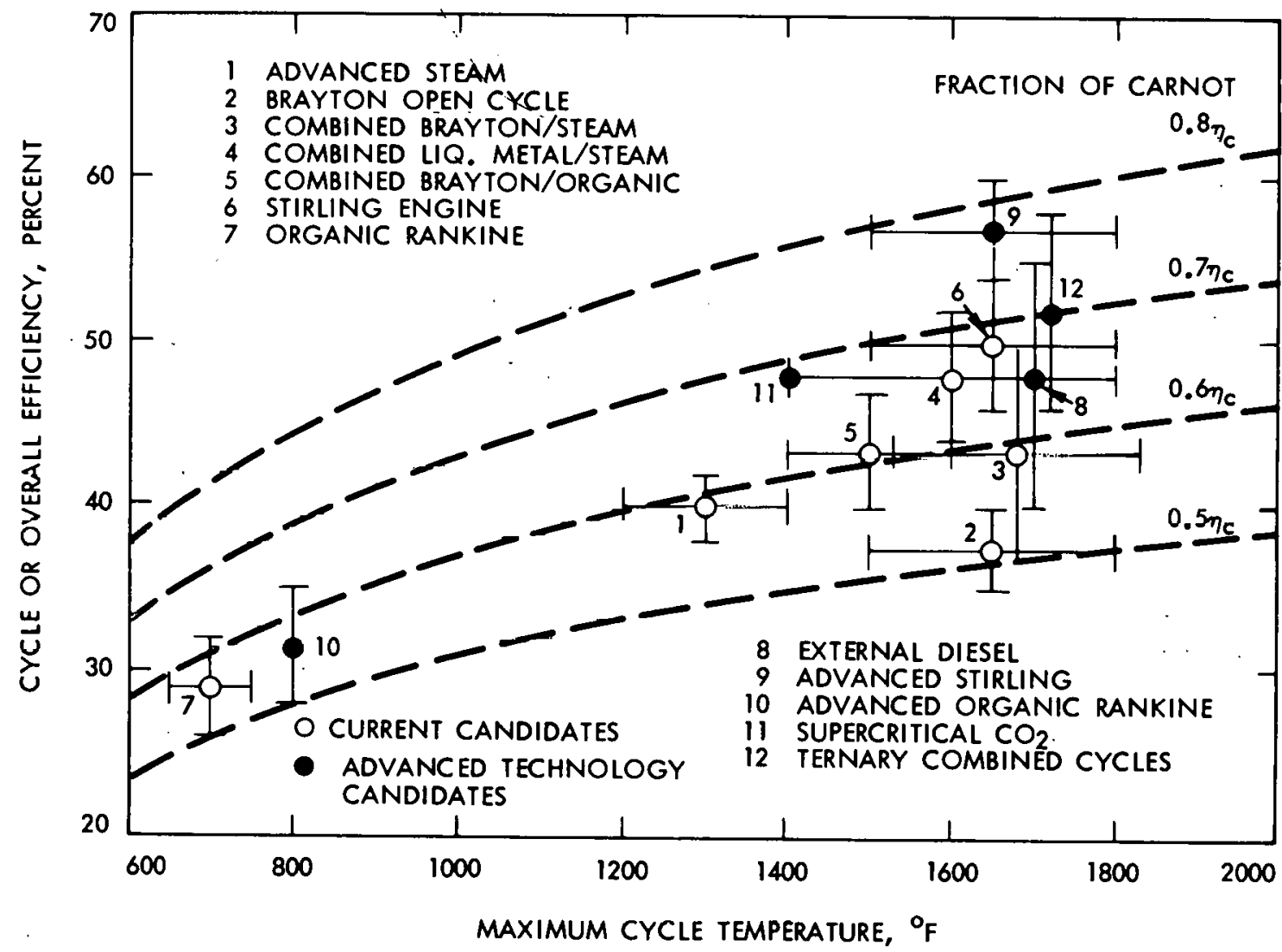

Figure A-17. Performance Estimates for Energy Conversion Systems in the Time-Frame 1985 to 2000

In some instances it may be worthwhile to consider measures that improve cycle efficiency using simple cost-effective techniques. Recuperated gas Brayton cycles clearly yield performance improvements compared to the simple unrecuperated cycle. Capital costs rise dramatically, however, as the effectiveness and size of the recuperator increase (Ref. A-61). The technique of water injection in a simple Brayton cycle, either into the compressor or into the combustor, is really an old idea. Water injection can be used to decrease compressor work, lower turbine inlet temperature without reducing output power, and otherwise render the simple Brayton cycle as efficient, or better, than recuperated cycles of greater cost (Ref. A-76). In gcncral, theoretical cycle efficiency occurs at higher compressor pressure ratios with water injection compared with the simple air cycle. Several examples from the literature are cited herein, e.g., Refs. A-76 and A-77. In Ref. A-76, heat rejection from the turbine is used in a waste heat boiler to preheat water that then is injected into the combustion chamber. In Ref. A-77, which discusses water injection for automotive application, a recuperator also is used, but it exhausts to a condenser that collects water from the turbine exhaust gases so that extra water need not be supplied separately. 
The proposed use of dissociating gases in power cycles is relatively recent, and the technology is as yet undeveloped. The use of such fluids. as $\mathrm{N}_{2} \mathrm{O}_{4}$ (nitrogen tetroxide) is routine in the case of rocket engines, so that there has been some experience in the technology of handling such fluids. Dissociation and recombination of chemical species can be utilized, in general, to reduce compression work and to achieve enhanced cycle efficiency. The thermodynamic effects are complex and cannot be discussed in detail here. Gas turbine cycles utilizing dissociating fluids have been analyzed in Refs. A-78 and A-79; it appears that improvements in base cycle efficiency of the order of 10 points are possible. Use in Stirling engines is discussed in Ref. A-80, wherein twice the power output is obtained without increases in size, weight, or cost of engine.

\section{COST PROJECTIONS}

\section{A. AVAILABLE DATA BASE}

A goal was to establish capital costs in volume production, and associated operating and maintenance costs, for the several candidate energy conversion systems with application to solar thermal power systems. This task met with only limited success. A brief survey was conducted to determine what information was available. Emphasis was placed on capital cost, with secondary emphasis on operating and maintenance (O\&M) costs, which often are taken as a fixed percentage of capital costs anyway. Costs of technological development were not considered. Because energy costs were to be an output of this (current) study, they were not investigated specifically. In the literature cited herein, most of the data applied to large stationary fossilfueled power plants in very limited production, information not well suited for the present study. Cost information to varying degrees of completion and usefulness can be found in References $A-2, A-3, A-7$, $A-8, A-11, A-16, A-17, A-28, A-33, A-34, A-35, A-46, A-47, A-53, A-56$, $A-59, A-61, A-63, A-65$ and $A-68$; costs related to solar thermal systems can be found in References $A-3, A-11, A-16, A-17, A-34, A-46, A-47$, $A-65$ and $A-68$.

Although power systems for automatic applications differ from solar power applications in performance requirements and subsystem design requirements (Ref. A-27), they provide insight into small engine mass production costs that are unavailable elsewhere. However, reliability, lifetime, life cycle costs and operating and maintenance costs for automotive applications differ considerably from solar power applications. The volume production costs of Stirling engines have been compared to Diesel engines (Ref. A-11) because of the inherent similarities of the two engines. It might be thought too that valuable insight into volume production costs for jet engines (commercial and military) might find application in gas turbines for solar thermal power systems. The technology of jet engines. is perhaps a decade ahead of 
industrial gas turbines and, judging from the literature, it appears that there is little communication between experts of the two technologies. There is such a disparity between performance and life cycle requirements of aircraft gas turbines and their counterparts for solar power applications that the technology parallels are doubtful.

A cross-section of representative costs, and lifetime to major overhaul, is shown in Table A-3 for several power conversion systems. These values were derived from the literature and apply mainly to large plants in only limited production. They should be viewed as conservative (industrial) near-term projections and not as mass production targets for far-term solar thermal application. The values termed low, nominal, and high reflect some ambivalence associated not only with uncertainty but also the timeframe of accomplishment. The low values correspond, probably, with both optimistic estimates as well as longer projected development times. The highest cost system is the potassium/ steam Rankine combined cycle. According to Ref. A-81, the potassium/ water binary cycle, depending on complexity, may cost a factor of 1.3 to 3 times a steam Rankine system of comparable size (for $1000 \mathrm{mWe}$ output systems).

Some available information for production costs of small (mainly automotive) engines is shown in Table A-4. These estimates are for production of 400,000 units per year. Projected costs of automotive engines were obtained from Refs. A-72 and A-82. The last entry, organic Rankine turbines, was obtained by methods outlined in the next section. Included in Table A-4 are costs per unit weight as well as costs per unit power output. It is of interest that most mass produced items today (appliances, pumps, etc.) cost somewhere between 1 and 5 \$/1b; wide-bodied aircraft like the L-1011 and DC-10 cost about $8 \$ / 1 b$. From this observation it might be concluded that small massproduced engines for solar power application should not cost more than approximately $2.5 \$ / 1 b$ in current dollars.

For this study it was desirable to have, for reference and use, a general model of mass production costs of energy conversion systems. To this end, work was initiated earlier in an internal JPL memo (Ref. A-83). The results of this model are presented in the next section.

\section{B. MASS PRODUCTION ESTIMATES}

It is clear from the literature and company data that the specific cost $(\$ / \mathrm{kW})$ of power conversion systems decreases with increasing size, or capacity, of the system. Sample curves showing this relationship for gas turbines and organic Rankine turbines are given in Ref. A-11, which also contains some information regarding mass production of organic Rankine turbines. The latter data from Ref. A-11 was crossplotted on log-log paper and interpolated and extrapolated in several 
Table A-3. Current Projections of Capital and Operating Maintenance Costs of Representative Energy · Conversion Systems (Heat Engines), Based on Limited Low-Volume Production, and Estimated Lifetime to Major Overhaul

\begin{tabular}{|c|c|c|c|c|c|c|}
\hline SYSTEP & ITEM & UNIT & LOW & NOMINAL & HIGH & COMMENTS \\
\hline \multirow{3}{*}{ STIRLING } & Capital Cost & $\$ / \mathrm{kW}$ & 100 & 150 & $\begin{array}{l}\text { Uninstalled, for } \\
\text { production of } \\
5000 \text { units/yr }\end{array}$ \\
\cline { 2 - 7 } & $\begin{array}{c}\text { o \& M Expense } \\
\text { per year }\end{array}$ & $\$ / \mathrm{kW}$ & 3 & 7 & 14 & $\begin{array}{l}\text { Based on lifetime } \\
\text { rather than capital cost }\end{array}$ \\
\cline { 2 - 7 } & Lifetime & hours & 5000 & 10,000 & 25,000 & $\begin{array}{l}\text { Between overhauls } \\
\text { (Diesel trucks today } \\
\text { get 5000 hr) }\end{array}$ \\
\hline
\end{tabular}

\begin{tabular}{|c|c|c|c|c|c|c|}
\hline \multirow{3}{*}{$\begin{array}{l}\text { OPEN-CYCLE } \\
\text { BRAYTON }\end{array}$} & Capital Cost & $\$ / \mathrm{kW}$ & 150 & $\begin{array}{c}200 \\
.\end{array}$ & 230 & $\begin{array}{l}\text { Installed Cost, } 10 \text { to } 100 \mathrm{MW} \\
\text { Limited production } \sim 100 \\
\text { per year. Costs for small } \\
\text { units (10 to } 100 \mathrm{~kW} \text { ) may be } \\
3 \text { times higher, or more }\end{array}$ \\
\hline & $\begin{array}{l}0 \& M \text { Expense } \\
\text { per year }\end{array}$ & $\$ / \mathrm{kW}$ & 7.2 & 11 & 13 & Based on $3000 \mathrm{hr}$ per year \\
\hline & Lifetime & hours & 15,000 & 20,000 & 30,000 & \\
\hline
\end{tabular}

\begin{tabular}{|c|c|c|c|c|c|c|}
\hline \multirow{3}{*}{$\begin{array}{l}\text { BRAYTON/ } \\
\text { STEANI } \\
\text { RANKINE } \\
\text { CONBINED } \\
\text { CYCLE }\end{array}$} & Capital Cost & $\$ / \mathrm{kW}$ & 160 & 250 & 450 & $\begin{array}{l}\text { Limited production. } \\
\text { Very large coal-fired } \\
\text { power plants }\end{array}$ \\
\hline & $\begin{array}{l}\text { O \& M Expense } \\
\text { per year }\end{array}$ & $\$ / k w$ & 8 & 14 & 27 & $\begin{array}{l}\text { Large plants only, } \\
\text { affected by fuel cost. }\end{array}$ \\
\hline & Lifetime & hours & 15,000 & 20,000 & 25,000 & \\
\hline
\end{tabular}

\begin{tabular}{|c|c|c|c|c|c|c|}
\hline \multirow{3}{*}{$\begin{array}{l}\text { POTASSIUN/ } \\
\text { STENI } \\
\text { RANKINE } \\
\text { COMBLNED } \\
\text { CYCLE }\end{array}$} & Capital Cost & $\$ / \mathrm{kW}$ & 270 & 370 & 500 & $\begin{array}{l}\text { Very limited production. } \\
\text { Very large coal-fired } \\
\text { power plants }\end{array}$ \\
\hline & $\begin{array}{l}\text { o \& M Expense } \\
\text { per year }\end{array}$ & $\$ / K W$ & $\begin{array}{l}17.5 \\
06.5 \% \mathrm{cc}\end{array}$ & $\begin{array}{l}27.8 \\
07.5 \% \mathrm{cc}\end{array}$ & $\begin{array}{c}42.5 \\
08.5 \% \mathrm{cc}\end{array}$ & $\begin{array}{l}\text { Large plants only. } \\
\text { Does not include fuel. }\end{array}$ \\
\hline & i.iferime & hours & 5000 & 10,000 & 20,000 & Based partly on Ref. A-54 \\
\hline
\end{tabular}


Table A-4. Production Cost Comparison of Small Engines for 400,000 Units per Year (1) (Based on current estimates)

\begin{tabular}{|c|c|c|c|c|c|c|c|c|}
\hline Source & Engine & bhp & $\mathrm{kW}$ & Wt., lb & $\begin{array}{c}\cos t \\
\$\end{array}$ & $\$ / k W$ & $\$ / 1 b$ & Comments \\
\hline & Brayton, single shaft & 103 & 76.8 & 515 & 1392 & 18.1 & 2.7 & $\begin{array}{l}\text { Alternate auto } \\
\text { engines }\end{array}$ \\
\hline JPL Auto Report & $\begin{array}{l}\text { Brayton, free turbine } \\
\text { Stirling }\end{array}$ & $\begin{array}{l}107 \\
119\end{array}$ & $\begin{array}{l}79.8 \\
88.8\end{array}$ & $\begin{array}{l}293 \\
554\end{array}$ & $\begin{array}{l}1604 \\
1619\end{array}$ & $\begin{array}{l}20.1 \\
18.2\end{array}$ & $\begin{array}{l}5.5 \\
2.9\end{array}$ & $\begin{array}{l}\text { Equiv. } 150 \mathrm{hp} \\
1974 \text { dollars }\end{array}$ \\
\hline $\operatorname{Ref} \cdot A-72$ & Rankine & 141 & 105.2 & 709 & 1781 & 16.9 & 2.5 & \\
\hline $\begin{array}{l}\text { Selcuk, et. a1. } \\
\text { JPL Report } \\
\text { Ref.A-16 }\end{array}$ & Stirling, swash plate & 30 & 22.4 & 220 & $\begin{array}{r}1070 \\
700\end{array}$ & 47.8 & 4.9 & $\begin{array}{l}\text { Solar engine } \\
\text { designs }\end{array}$ \\
\hline $\begin{array}{l}\text { Fortgang } \\
\text { JPL }\end{array}$ & $\begin{array}{l}\text { Brayton, tree turbine } \\
\text { Brayton, free turbine }\end{array}$ & $\begin{array}{l}100 \\
150\end{array}$ & $\begin{array}{l}14.6 \\
112\end{array}$ & $\begin{array}{l}428 \\
473\end{array}$ & $\begin{array}{l}2002 \\
2108\end{array}$ & $\begin{array}{l}26.8 \\
18.8\end{array}$ & $\begin{array}{l}4.7 \\
4.5\end{array}$ & $\begin{array}{l}\text { Auto engines } \\
\text { Follow-on to } \\
\text { APSES }\end{array}$ \\
\hline $\begin{array}{l}\text { Prelim. ATSP } \\
\text { Report } \\
\text { Ref. A-83 }\end{array}$ & $\begin{array}{l}\text { Stirling } \\
\text { Stirling } \\
\end{array}$ & $\begin{array}{l}100 \\
150\end{array}$ & $\begin{array}{l}74.6 \\
112\end{array}$ & $\begin{array}{l}706 \\
845\end{array}$ & $\begin{array}{l}2208 \\
2399\end{array}$ & $\begin{array}{l}29.6 \\
21.4\end{array}$ & $\begin{array}{l}3.1 \\
2.8\end{array}$ & 1977 dollars \\
\hline $\begin{array}{l}\text { Bailey } \\
\text { LeRC } \\
\text { Ref. A-2 }\end{array}$ & $\begin{array}{l}\text { Recip. Steam, high } \\
\text { Recip. Steam, high } \\
\text { Recip. Steam, low } \\
\text { Recip. Steam, low }\end{array}$ & $\begin{array}{r}40 \\
150 \\
40 \\
150\end{array}$ & $\begin{array}{r}\sim 30 \\
112 \\
\sim 30 \\
112\end{array}$ & $\begin{array}{r}144^{\circ} \\
543 \\
78 \\
177\end{array}$ & $\begin{array}{l}1622 \\
3054 \\
1348 \\
2099\end{array}$ & $\begin{array}{l}54.1 \\
27.3 \\
44.9 \\
18.7\end{array}$ & $\begin{array}{r}11.3 \\
5.6 \\
17.3 \\
11.9\end{array}$ & 1977 dollars \\
\hline $\begin{array}{l}\text { OTA Report } \\
\text { Ref. A-11 }\end{array}$ & Organíc Rankine & 134 & 100 & - & - & 110 & - & $\begin{array}{l}\text { Installed cost } \\
1976 \text { dollars }\end{array}$ \\
\hline
\end{tabular}

${ }^{(1)}$ Bare selling cost of engine does not include heat exchangers, boilers, generators, batteries, gears/ transmissions, controls, etc.

iterations (Ref. A-83). The final result was capital cost expressed in $\$ / \mathrm{kW}$ for a family of turbine sizes plotted against the number of production units per year. These curves then were normalized (arbitrarily) to the value $\mathrm{N}=10^{6}$ units per year. It is believed that in the years. 1990 to 2000 the number of heat engines that will be required yearly for solar power applications will be hundreds of thousands, if not millions, of units.

The data manipulation referred to above resulted in what has been used herein as a "mass production cost model" for energy conversion systems (Figure A-18). It is suggested for general usage only because better information is not available. Without real justification, it has been used even to scale costs of subsystem units such as generators. The general trends of the curves, if not their absolute levels and shapes, must be approximately correct. The curves in Figure A-18 have been used to scale costs for all power conversion systems. It is encouraging that the relative costs of known systems (large systems in low volume production as well as small systems in relatively large volume production) scale approximately in accordance with Figure A-18. Figure A-18 may be used to estimate system costs by a ratio process. If a single point is known, i.e., the absolute cost of a given size conversion system for a known volume production, then the relative cost of a different size system at a different rate of volume production can be estimated by forming the appropriate relative cost ratio and then calculating the absolute cost of the system in question. 


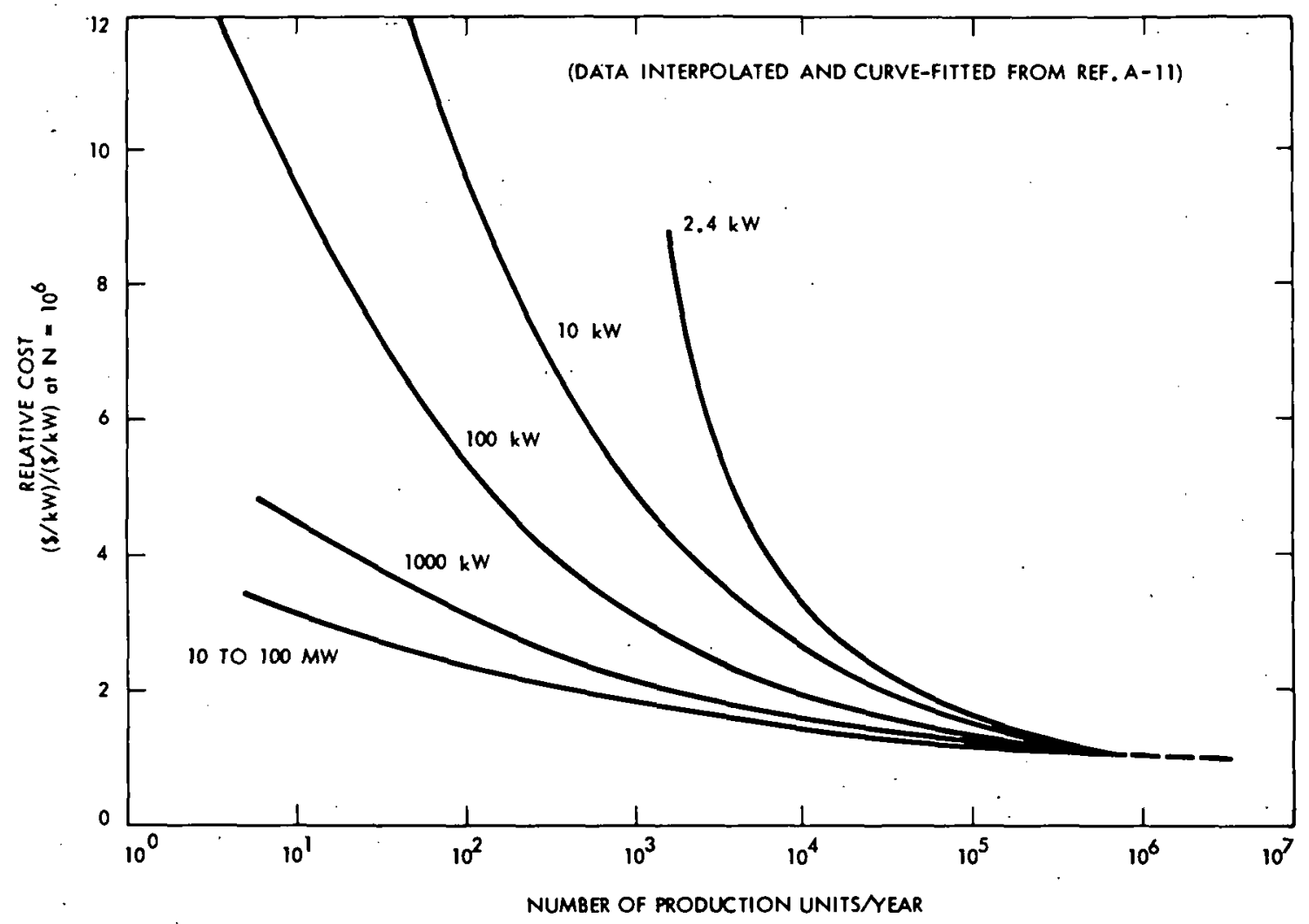

Figure A-18. Suggested Model for the Capital Costs of Energy Conversion Systems in Volume Production

The curves shown in Figure A-18 are not learning curves, as can be demonstrated by plotting the results in log-log coordinates. Learning curves, which originated in the aircraft industry several decades ago, have gained wide acceptance in predicting production costs (Ref. A-84). Learning curves plot as straight lines in $\log -10 g$ coordinates (Ref. A-85). They are not accurate for predicting production costs for $\mathrm{N}>10^{4}$ units because, ultimately, the curves cross a cost value equivalent to material costs alone. In contrast, the curves shown in Figure A-18 exhibit a varying percent learning with increasing number of production units $\mathrm{N}$; in $\log -\log$ coordinates the curves approach zero slope at arbitrarily high $\mathrm{N}$. This behavior is more in keeping with realistic results.

The total capital cost of candidate energy systems, including heat exchangers, auxiliary equipment, generators, control equipment, etc., was estimated for current purposes. Base engine costs were estimated. for baseline $100 \mathrm{kWe}$ output engines produced at the rate of 400,000 units per year. Component costs were estimated using the results of Ref. 68 and other sources. Recuperator costs for Brayton 
cycles were scaled from results (for large plants). given in Ref. A-34. Recuperator costs for open and closed air and helium Brayton cycles are significantly different. A fixed cost of $10 \$ / \mathrm{kW}$ was assumed for controls, and a fixed cost of $11 \mathrm{\$} / \mathrm{kW}$ was assumed for electric generators as estimated from'Figure A-19. In Figure A-19, the lower dashed curve for 400,000 units per year was obtained using Figure A-18 and results from Ref. A-2. The final results are listed in Table A-5.

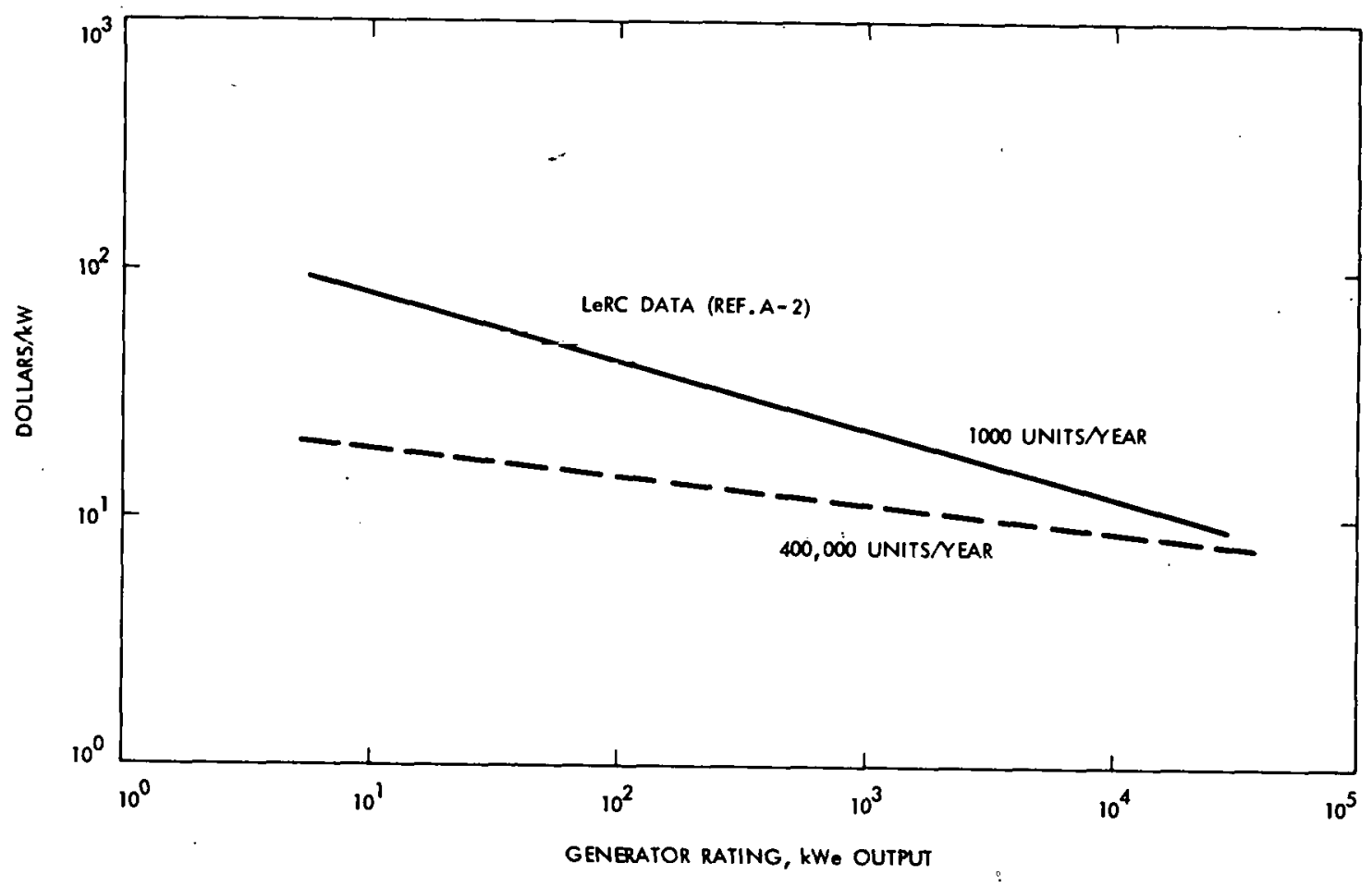

Figure A-19. Estimated Capital Cost of A.C. Generators in Volume Production, 1977 Dollars 
Table A-5. Estimated Baseline Capital Cost of Advanced

$100 \mathrm{kWe}$ Energy Conversion Systems for Production of 400,000 Units per Year, in Dollars per Kilowatt

\begin{tabular}{|c|c|c|c|c|c|}
\hline Engine & $\begin{array}{l}\text { Base } \\
\text { Engine }\end{array}$ & Auxiliaries & $\begin{array}{l}\text { Electric } \\
\text { Generator }\end{array}$ & Controls & Total \\
\hline Stirling & 23 & 15 & 15 & 10 & 63 \\
\hline $\begin{array}{l}\text { Brayton, Recup. } \\
\text { Open Cycle }\end{array}$ & 21 & 19 & & & 65 \\
\hline $\begin{array}{l}\text { Brayton, Recup. } \\
\text { Closed Air Cycle }\end{array}$ & 9 & 24 & & & 58 \\
\hline $\begin{array}{l}\text { Brayton, Recup. } \\
\text { Closed He Cycle }\end{array}$ & 18 & 24 & & & 67 \\
\hline $\begin{array}{l}\text { Combined Brayton/ } \\
\text { Steam Rankine }\end{array}$ & 22 & 25 & & & 72 \\
\hline $\begin{array}{l}\text { Steam Rankine } \\
\text { Reciprocating }\end{array}$ & 29 & 15 & 1 & 1 : & 69 \\
\hline
\end{tabular}


APPENDIX A

V. REFERENCES

A-1. Fujita, T., El Gabalawi, N., Herrera, G., and Turner, R. H.: Projection of Distributed-Collector, Solar-Thermal Electric Power Plant Economics to Years 1990-2000. Jet Propulsion Laboratory, Thermal Power Systems Research and Development Project, prepared for DOE, Report DOE/JPL-1060-77/1, December, 1977.

Information Received from NASA-Lewis Research Center

A-2. Bailey, M.: Performance and costs for reciprocating steam Rankine systems, commercial steam turbine/generator Eystems and cunmercial gas turbine/generator sets. History and status of steam Rankine systems. Projected performance of small heat engines for solar power application. 1977-1978.

A-3. Heller, J.: Theoretical performance of small open-cycle and closed-cycle gas turbine systems for solar power application. Projected life-cycle costs of several $30 \mathrm{kWe}$ heat engine systems. 1977-1978.

A-4. Cameron, H. and Valentine, H.: Performance estimates for Stirling engine systems. Prelliminary design data for $15 \mathrm{kWe}$ solar Stirling engine. 1977-1978.

A-5.. Stochl, R.: Theoretical performance calculations for closedcycle gas turbine with bottoming by ammonia and organic fluids. 1978.

\section{Genera1 References \\ (Consideration of several energy conversion systems)}

A-6. Anon.: The U.S. Energy Problem, Vol. 2, Appendices, Part B. See Appendix L, Alternate Cycles. Inter Technology Corp., Prepared for NSF, Report NSF-RANN 71-1-3, November, 1971.

A-7. Task I Oral Briefing, Westinghouse Elertric Corp., Prcparen ful NAUA-LEwis Research lenter, Study of Advanced Energy Conversion Techniques for Utility Applications using Coal and Coal Derived Fuels, May, 1975.

A-8. Anon.: Study of Advanced Energy Conversion Techniques for Utility Applications Using Coal or Coal Derived Fuels. Summary Presentation of Results of Task I, prepared for NASA-Lewis Research Center by General Electric, May 27, 1975.

(1) Under preparation by LeRC personnel is a "Handbook of Energy Conversion Components for Solar. Power Systems" 
A-9. Mauro, R. L.: Reliability and Research Boost Small Generating Units. Public Power, 34: 10-12, March-April, 1976.

A-10. Salter, R. M.: Solar Residential Electrification with High-Performance Heat Engines. J. Energy (AIAA), 1:137-144, 1977.

A-11. Anon.: Energy Conversion, Chapter XIII, Application of Solar Technology to Today's Energy Needs, Office of Technology Assessment, U.S. Congress, June, 1977.

A-12. Penny, M. M., Bourgeois, S. V., and Cain, W. C.: Development Status and Environmental Hazards of Several. Candidate Advanced Energy Systems. Proc. 12th. IECEC, 1:646-654, Washington, D. C. August 1977.

A-13. Roschke, E. J.: Compilation of Performance Data for Candidate Energy Conversion Systems. Jet Propulsion Laboratory, unpublished internal document, November 17, 1977.

\section{Stirling Engines}

A-14. Percival, W. K.: Historical Review of Stirling Engine Development in the United States from 1960 to 1970. Prepared for EPA under Contract No. 4-E8-00595, July 197.4 .

A-15. Spigt, C. L. and Daniels, A.: The Philips Stirling Engine - A Progress Report. Proc. 10th IECEC, 1:919-926, Univ. of Delaware, August, 1975.

A-16. Selcuk, M. K., Finegold, J., French, R. and Caputo, R.: Preliminary Evaluation of a Parabolic Dish-Small Heat Engine Central Solar Plant. Jet Propulsion Laboratory, JPL Document 900-749, July, . 1976.

A-17. Ponds, R. L. and Fox, R. J.: A Solar/Stirling Total Energy System. Joint Conference, "Sharing the Sun -- Solar Technology in the Seventies." Volume 5, Solar Thermal and Solar Ocean, editor K. W. Boer, pp. 77-91, Winnipeg, Canada, August, 1976.

A-18. Michels, A. P. J.: The Phillips Stirling Engine--A Study of Its Efficiency as a Function of Operating Temperatures and Working Fluids. Proc. 11th IECEC, 2:1506-1510, Sahara Tahoe, Nevada, September, 1976.

A-19. Pedroso, R. I.: The Stirling Engine -- Engineering Considerations in View of Future Needs. Proc.11th IECEC, 2:1498-1505, Sahara Tahoe, State Line, Nevada, September; 1976.

A-20. Cuttica, J. J.: Stirling Cycle Engine .... New Look at an Old Idea. Public Power, 34:50-52, Sept.-Oct., 1976. 
A-21. Selcuk, M. K., Moynihan, P. I., Wu, Y. C., and Day, F. D.: Solar Stirling Experiments, Paper presented at the Izmir International Symposium on Solar Energy, Izmir, Turkey, August 1972.

A-22. Benson, G. M.: Thermal Oscillators. Proc. 12th IECEC, 2:14781487, Washington, D. C., August, 1977.

A-23. Urieli, I., Rallis, C. J., and Berchowitz, D. M.: Computer Simulation of Stirling Cycle Machines. Proc. 12th IECEC, 2:15121521, Washington, D. C., August, 1977.

A-24. Stephens, J. R., Witzke, W. R., Watson, G. K, , Johnston, J, R., and Croft, W. J.: Materials Technology Assessment for Stirling Engines. NASA work performed for DOE, report CONS/1011.-2.2 and NASA TM-73789, October, 1977.

A-25. Anon.: Stirling Engine Program. Presentation by Ford, Powertrain Research Office, DOE-Advanced Automotive Power Systems, Contractors Coordination Meeting, October, 1977.

A-26. Anon.: United Stirling Brochure. KB United Stirling (Sweden) $A B$ and $C o$. (current).

A-27. Livingston, F., Leibowitz, L., Finegold, J, , and Dowdy, M.: Informal information package prepared by Jet Propulsion Laboratory for DOE, Division of Solar Technology. In four parts: "Review of $\mathrm{KB}$ United Stirling (Sweden) $\mathrm{AB}$ and Co.," "Status and Potential of Stirling Engines for Solar Thermal Power," "Stirling Engines for Solar Energy Utilization," and "Stirling Power System," December 13, 1977.

A-28. Hoagland, L., and Percival, W.: A Technology Evaluation of the Stirling Engine for Stationary Power Generation in the 500 to 2000 Horsepower Range. Amtech Corp. Report No. 78-2. Preliminary draft report prepared for DOE, Division of Conservation Research and Technology, January, 1978.

\section{Brayton Cycle and Combined Cycles, Gas Turbines}

A-2y. Bammert, K., and Buende, R.: Comparison of Nuclear Power Plants with Closed-Cycle Helium Turbine and with Steam Turbine Cycle for Combined Power and Steam Generation. Trans. ASME, Series A, $\mathrm{J}$. of Engineering for Power, 95: 111-18, 1973.

A-30. Bammert, K., Rurik, J., and Griepentrog, H.: Highlights and Future Development of Closed-Cycle Gas Turbines. Trans. ASME, Series A, J. of Engineering for Power, 96: 342-348, 1974.

A-31. Jerie, J.: Part Load Specific Fuel Consumption of Gas Turbines. Trans. ASME, Series A, J. of Engineering for Power, 96: 303-304, 1975. 
A-32. Anon.: Closed Cycle Gas Turbine Status. Company publication MS 3736-0, AiResearch Mfg. Co., Garrett Corp., June, 1975.

A-33. Rice, N. C., Robson, F. L., Giramonti, A. J., and Smith, E. B.: Open-Cycle Gas Turbine Topping Systems. Proc. 10th IECEC, 2:209217, Univ. of Delaware, August, 1975.

A-34. Anon.: Closed-Cycle High-Temperature Central Receiver Concept for Solar Electric Power. Boeing Engineering and Construction Division of the Boeing Company, Seattle, Washington, Research Project 377-1, J. R. Gintz - Program Manager. Summary Report prepared for EPRI, EPRI ER-403-SY, August 1976 (Final Technical Report has been submitted to EPRI.)

A-35. Robson, F. L., Giramonti, A. J., Blecher, W. A., and Mazzella, G.: Fuel Gas Environmental Impact: Phase Report. United Technology Research Center. Prepared for EPA under Contract No. 68-02-1099, Report No. EPA-600/2-75-078, November, 1975. (Advanced combined gas and steam (COGAS) cycles.)

A-36. Anon.: DOT/NASA Comparative Assessment of Brayton Engines for Guideway Veh-icles and Buses. NASA SP-354, Volume I - Summary, Volume II - Analysis and Results, 1975.

A-37. Ushiyama, I.: Theoretically Estimating the Performance of Gas Turbines under Varying Atmospheric Conditions. Trans. ASME, Series A, J. of Engineering for Power, 98:69-78, 1976.

A-38. Fayweather, D. J., Rackley, R. A., and Robbins, F. A.: Advanced Marine Closed Brayton Engines. Proc. 11th IECEC, 1:177-183, Sahara Tahoe, Nevada, September 1976.

A-39. Neal, J.: New Gas Turbines Could Provide Fuel Benefits. Public Power, 34:28-30, Nov.-Dec., 1976.

A-40. Anon.: High Temperature Turbine Technology Program, Phase I Frogram and System Definition, Topical Report - Overall Plant Design Description Liquid Fuel Combined Cycle Electric Power Plant, Westinghouse Electric Corp., DOE Report, FE-2290-19, January, 1977.

A-41. Alberte, T.: Allison's New 570 Gas Turbine. Diesel and Gas Turbine Progress, 43:20-22, March, 1976.

A-42. Wadman, B.: Broad Use Capability Combined Cycle Gas Turbine Systems. Diesel and Gas Turbine Progress, 43:24-26, March, 1976.

A-43. Wadman, B.: 5000 HP Range 990 Industrial Gas Turbine Program Advances. Diesel and Gas Turbine Progress, 43:29-30, March, 1976.

A-44. Anon.: Solar Thermal Conversion to Electricity Utilizing a Central Receiver, Open Cycle Gas Turbine Design. Black and Veatch Consulting Engineers. Research Project 475-1, E. McBride- 
Program Manager. Summary Report prepared for EPRI, EPRI ER-387SY, March, 1977.

A-45. Mock, E. A.: Closed Cycle Gas Turbine Optimization - Procedures and Examples, Lecture Notes for VKI Lecture Series - Closed Cycle Gas Turbines, von Karman Institute for Fluid Dynamics, Brussels, Belgium, May, 1977. AiResearch Report 31-2635.

A-46. Grosskreutz, J. C., McBride, E. J., and Gray, D. C.: Solar Thermal Conversion to Electricity Utilizing a Central Receiver, Open Cycle Gas Turbine Design. Proc. 12th IECEC, 2:1209-1217, Washington, D. C., August, 1977.

$\Lambda$ 47. Bloomfield, II. S., and Calogeras, J. E.: Tecluical and Ecununlc Feasibility Study of Solar/Fossil Hybrid Power Systems. NASA TM-73820, Decenber, 1977.

A-48. Robson, F. L.: Review of State of the Art Gas Turbine and Projection of Future Technology. United 'l'echnology Research Center. Report No. R77-954110-1, 1977.

A-49. Kronogard, S. 0.: Three-Shaft Automotive Turbine-Transmission Systems of the KTT Type - Performance and Features. Trans. ASME, Series A, J. of Engineering for Power, 100:95-110, 1978.

A-50. Roschke, E. J.: Gas Turbine Cycles for Dispersed Power Systems. Jet Propulsion Laboratory, Trip Report (AiResearch Mfg. Co., Phoenix, Arizona), unpublished internal document, February 8, 1978.

\section{Liquid Metal Cycles, Potassium Topping}

A-51. Simmons, L. D.: Optimization of Staged Rankine Energy Conversion Cycles for High Efficiency. Proc. 7th IECEC, 279-287, San Diego, California, September, 1972 .

A-52. Wilson, A. J.: Space-Power Spinoff Can Add 10+ Points of Efficiency to Fossil-Fueled Power Plants. Proc. 7 th IECEC, 260-268, San Diego, California, September, 1972.

A-53. Rajakovics, G. E.: Energy Conversion Process with about $60 \%$ Efficicncy for Central Power Stations. Froc. Tth IECEC, 1100= 1106, San Francisco, August, 1974.

A-54. Gutstein, M., Furman, E. R., and Kaplan, G. M.: Liquid-Metal Binary Cycles for Stationary Power. NASA TN D-7955, August, 1975.

A-55. Fraas, A. P.: Comparison of Helium, Potassium, and Cesium Cycles. Proc. 10th IECEC, 1:486-495, Univ. of Delaware, August, 1975.

A-56. Himmelblau, A.: Analysis of Combined Potassium Topping, Steam Bottom Cycles Using Fluidized-Bed Combustion of Consol Char. 
Final Report prepared by Energy Resources Co., DOE Report, FE2201-10, February, 1977 .

A-57. Holcomb, R. S.: Potassium Vapor Topping Cycle Technical Progress Report for January 1 to March 31, 1977. Oak Ridge National Laboratory, ORNL/TM-6042, December, 1977.

Organic Rankine Cycles and Bottoming

A-58. Angelino, G., and Moroni, V.: Perspectives for Waste Heat Recovery by Means of Organic Fluid Cycles. Trans, ASME, J. Eng. for Power (Series A), 99:75-83, .1973.

A-59. Barber, R. E.: Rankine-Cycle Systems for Waste Heat Recovery . Chem. Engineering, 81:101-106, November, 1974.

A-60. Sternlicht, B.: Low-Level. Heat Recovery Takes on Added Meaning as Fuel Costs Justify Investment. Power, 119:84-87, April, 1975.

A-61. Sternlicht, B.: The Equipment Side of Low-Level Heat Recovery. Power, 119:71-77, June, 1975.

A-62. Garay, P. N.: Application of Chemical Fluids in a Rankine Cycle Plant. Proc. 10th IECEC, 1:1435, Univ. of Delaware, August, 1975.

A-63. Klooster, H. J.: Practical Rankine Cycles for Process Plants. Proc. 10th IECEC, 1:1439-1442, Univ, of Delaware, August, 1975.

A-64. Rhinehart, H.: Bottoming Cycle Gives More Power with Same Fuel. Public Power, 34:22 26, July-August, 1976.

A-65. Barber, R. E.: Solar Power Organic Rankine Cycle Engines Characteristics and Costs. Proc. 11th IECEC, 2:1151-1156, Sahara Tahoe, Nevada, September, 1976.

A-66. Anon.: Organic Rankine Cycle Systems. Flyer for commerical systems, Thermo Electron, Corp., January, 1977.

A-67. Cheek, R. M., and Lacey, P. D.: $600 \mathrm{~kW}$ Organic Rankine Cycle Waste Heat Power Conversion System. Proc. 12th IECEC, 2:10951099, Washington, D. C., August, 1977 .

A-68. Barber, R..E.: . Current Costs of Solar Powered Organic Rankine Cycle Engines. Solar Energy, 20:1.-5, 1978.

A-69. Foster-Pegg, R. W.: Steam Bottoming Plants for Combined Cycles. Trans. ASME, J. Eng. for Power, 100:203-211, 1978. 


\section{Additional References}

A-70. Brooks, R. D., Eckard, S. E., Frank, R. G., and Barber, K. F.: De'sign of Reciprocating Single Cylinder Expanders for Rankine Cycle Engines. Proc. 7th IECEC, 269-278, San Diego, September, 1972 .

A-71. Amann, C. A., Sheridan, C. D., Sagi, C. J., and Skellenger, G. D.: The Uniflow Steam Expander - Its Relation to Efficiency of the SE-101 Power Plant. Proc. 7th IECEC, 960-970, San Diego, September, 1972 .

A-72. Stephenson, R.: Should We Have a New Engine? An Automobile Power Systems Evaluation. Report No. SP 43-17, Jet Propulsion Laboratory, Pasadena, August, 1975.

A-73. Wigmore, D. B., Niggemann, R. E., and O'Sullivan, J. B.: The Specification of an Optimum Working Fluid for a Small Rankine Cycle Turboelectric Power System. Proc. 7th IECEC, 303-314, San Diego, September, 1972.

A-74. Miller, D. R., Thompson, Q. E., Hull, H. R., and Barber, K. F.: Working Fluids for Automotive Rankine Engines. Proc. 7 th IECEC, 315-326, San Diego, September, 1972.

A-75. Robbins, F. A.: Private communication concerning generator, gearbox and rectifier/inverter efficiencies. AiResearch Mfg. Co., Phoenix, Arizona, April, 1978.

A-76. Maples, G., Jasper,..M. T., and Maples, D.: Performance of a Gas Turbine Power Plant with Water Injection from a Waste Heat Boiler. Proc. 5th IECEC, 1:4-76 to 4-81, Las Vegas, September, 1970.

A-77. Moore, B. E., Harden, G., and Ewbank, W. J.: The Wet Brayton Cycle, Proc. 8th IECEC, 121-125, Univ. of Pennsylvania, Philadelphia, August, 1973.

A-78. Luchter, S.: A Survey and Comparison of the Supercritical and Dissociating Gas Power Cycles. Proc. 5th IECEC, 1:2-1 to 2-5, Las Vegas, September, 1970.

A-79. Chikovani, V, V., Daitocv, M. E., And Krylnt, O, I.: Applibabiun of Chemically Reacting Working Bodies in a Solar Gas-Turbine System. Applied Solar. Energy (Translation of Geliotekhnika), 11: $63-69,1975$.

A-80. Metwally, M. M. and Walker, G: : Stirling Engines with a Chemically Reactive Working Fluid - Some Thermodynamic Effects. Trans. ASME, J. Eng. for Power (Series A), 99:284-287, 1977.

A-81. Mohr, P. B.: Some Economic Aspects of Power Conversion for Fusion Reactors. Proc. 5th IECEC, 1:1-109 to 1:113, Las Vegas, Sept, 1970. 
A-82. Fortgang, H., Private communication concerning automobile engine mass production costs, preliminary Automobile Technology Status and Projection (ÁTSP), follow-on to JPL APSES Report (Ref. 72), February, 1978.

A-83. Roschke, E. J.: Energy Conversion System Mass Production Cost Model. Jet Propulsion Laboratory, unpublished internal document, March, 1978.

A-84. Wilson, F. W. and Harvey, P. D.: Manufacturing Planning and Estimating Handbook, McGraw-Hill Book Co., New York, 1963. (Chapter 16, Manufacturing-Time Forecasting Curves.)

A-85. Kivenko, K.: Predict Your Production Costs with Learning Curves. Production Engineering, 47-49, August, 1977. 
APPENDIX B

ENERGY TRANSPORT AND STORAGE INVESTIGATION 


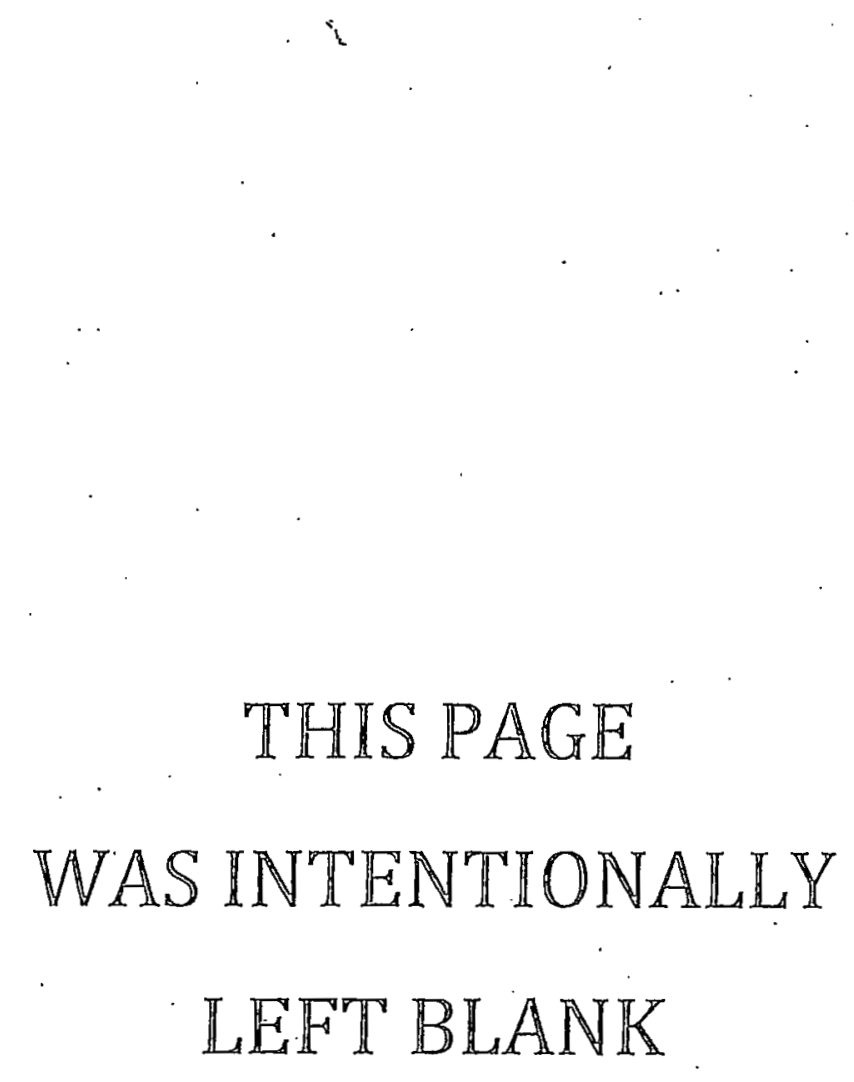


SUMMARY

I. INTRODUCTION - B-8

II. APPROACH AND METHODOLOGY - B-8
A. COST ESTIMATES
$B-10$
B. EFFICIENCY
$B-10$
C. EXPECTED LIFE
$B-10$
D. OPERATING CHARACTERISTICS
$B-11$

III. ROCK-OIL (HITEC) ENERGY STORAGE -

IV. MAGNESIUM OXIDE BRICK STORAGE -

V. LIQUID METAL STORAGE -

VI. PHASE CHANGE MATERIAL (PCM) - B-17

VII. REVERSIBLE CHEMICAL REACTION STORAGE (RCR) ------- B-21

VIII. METHANATION REACTION -

IX. $\mathrm{SO}_{2}-\mathrm{SO}_{3}$ ENERGY STORAGE -

X. AMMONIUM HYDROGEN SULFATE STORAGE (AHS) - -

XI. EXTERNAL ENERGY STORAGE (Battery Storage) ------- B-29.

XII. REFERENCES --_- B-32

\section{Figures}

B-1 Energy Transport System Capital Costs ------- B-6

B-2 Advanced Energy Slutage Systems Costs - - 2 -... B-7

B-3 Energy Balance for Energy Transport and Internal Energy Storage Systems - - - - B-11

B-4 HITEC-Rock Thermal Energy Storage - -

B-5 MgO Brick-Sensible Heat Storage --_-_-_- B-14

b-6 Liquid Sodium Sturage --

B-7 Phase Change Material Energy Storage --.--- B-20

B-8 Simplified Schematic of Chemical Energy System Based on Steam Reforming -

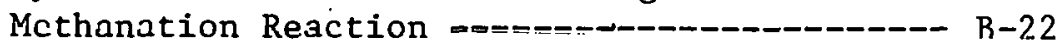

B-9 Process Flow Sheet for $\mathrm{SO}_{2}-\mathrm{SO}_{3}$ System -.- $\mathrm{B}-25$ 
B-11 Two-Tank Electrically Rechargeable

Redox Flow Cell -

$\underline{\text { Tables }}$

B-1 Energy Transport \& Storage Technologies ----- B-9

B-2 Summary of Performance and Cost Chararteristics for HITEC-Rock Energy

Storage --

B-3 Comparison of Properties Cast Iron and Magnesia Brick - B-14

B-4 Summary of Performance and Cost Characteristics for Magnesium Oxide

Brick Storage Energy Storage - - - - - - - B-15

B-5 Summary of Performance and Cost Characteristics for Liquid Metal

(Sodium) Energy Storage --_-_-_m-_-_---- B-18

B-6 Candidate PCM Salts - B-18

B-7 Selected Metal Fluoride Salts - B-19

B-8 Summary of Performance and Cost Characteristics for Molten Salt

Storage $($ Power $=10 \mathrm{MWe}$ ) - B-20

B-9 Summary of Performance and Cost

Characteristics for $\left(\mathrm{CO}-\mathrm{H}_{2}\right)$,

Methanation RCR Energy Storàge ---_----- B-24

B-10 Summary of Performance and Cost

Characteristics for $\mathrm{SO}_{2}-\mathrm{SO}_{3}$

Energy Storage --_- B-26

B-11 Summary of Performance and Cost

Characteristics for Ammonium

Hydrogen Sulfate Energy Storage -

B-12 Summary of Performance and Cost

Characteristics for Redox Battery

Energy Storage 


\section{APPENDIX B}

\section{SUMMARY}

A survey was made to accumulate data on the projected performance and cost of advanced energy storage systems that might be suitable as candidates for applications in the time-frame 1990-2000. Advanced energy storage systems are defined as second generation systems that are beyond the state-of-the-art with respect to performance and, in most cases require considerable advanced technology. In addition to the state-of-the art $650^{\circ} \mathrm{F}\left(\sim 350^{\circ} \mathrm{C}\right)$ sensible, thermal energy storage, used in the past as baseline technology, high temperature sensible and latent heat storage, advanced battery technologies, and chemical energy storage were considered. For thermal energy transport, in addition to steam, liquid metal and gas were considered.

For the purposes of this study, the following aspects of performance were required: (1) charging temperature, (2) discharging temferature, (3) overall thermal efficiency, and (4) energy transport and storage size. Of interest was the performance and cost of energy transport in the size range $60 \mathrm{kWth}$ to $60 \mathrm{MWth}$, and energy storage in the size range $15 \mathrm{KWe} \mathrm{hr}$ to $1000 \mathrm{MWe} \mathrm{hr}$. Because of the need to provide an impartial assessment of various advanced energy storage technologies suitable for their integration into a solar thermal power plant, information was sought on both internal (energy storage before the energy conversion system) and external (energy storage after the energy conversion system) storage technologies. Hence, the purpose of this investigation was to gather and analyze the required data base for candidate energy transport and storage systems as subsystems for solar thermal power technology development in the years 1990 to 2000. The results of this investigation are summarized in Figure $\mathrm{B}-1$ and $\mathrm{B}-2$. The per unit capital costs are reported in 1977 dollars.

Thermal energy transported by steam has the lowest per unit capital cost of all energy transport systems. It is not suitable for high temperature work, because the operating pressure becomes excessively high. Compared to steam, gas transport and liquid metal transport are several times more expensive. Gas transport is expensive because of its size (low energy density), and liquid metal because of its special containment. High temperature insulation also adds to a significant cost increase.

Phase change materials offer opportunities for lowest per unit capital costs for thermal energy storage, up to nine hours. However, they are only attractive for lower temperatures, in the range $500 \rightarrow 1000^{\circ} \mathrm{F}$.

For high temperature energy storage $\left(\geq 1500^{\circ} \mathrm{F}\right)$ liquid metal appears to be the better candidate. The reversible chemical reaction candidates (AHS and $\mathrm{SO}_{2}-\mathrm{SO}_{3}$ ) are also attractive. However, considerable advanced technology is required to bring these systems to fruition. 
Capital Cost, $\$ / k W t h$

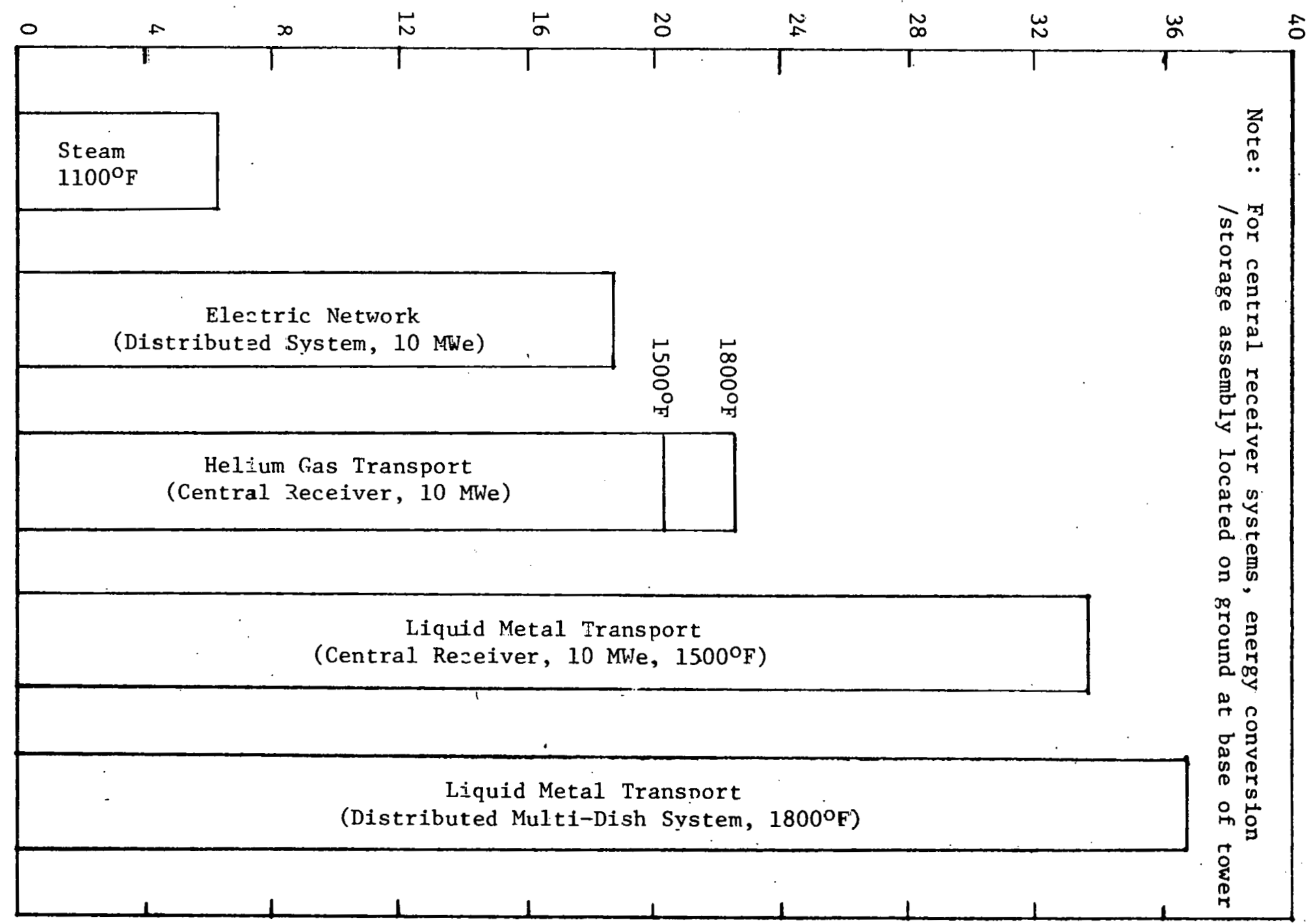




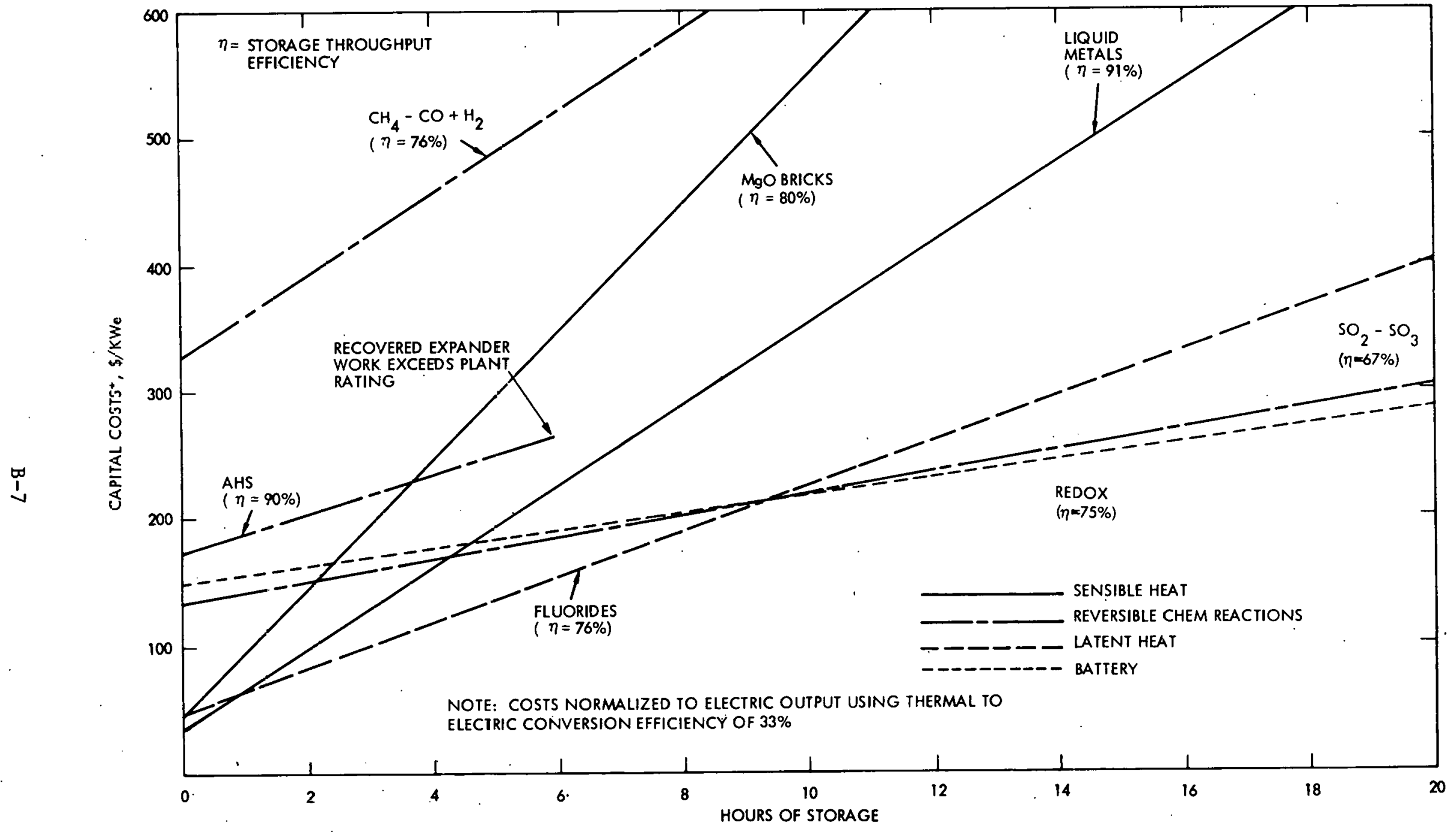

Fizure B-2. Advanced Energy Storage System Costs 
For large storage capacities, advanced battery storage offer the best overall opportunities. This candidate is not very size sensitive, and therefore looks attractive for both central and dispersed solar power plants.

\section{INTRODUCTION}

Insolation varies from hour to hour, day to day, week to week and season to season. Hence, a major constraint to the evolution of solar thermal power systems is the need to provide continuous operation during periods of solar outage. During sunshine hours, heat will be transported from the receiver to the energy converston and storage systems. In a solar plant provided with an internal energy storage, during postsunshine hours, stored heat will again be transported from storage to the energy conversion systems. A plant provided with external energy storage will essentially shut down its energy conversion system during post-sunshine hours and will supply external energy from its storage. A number of energy storage technologies which have the potential to meet the needs of a solar thermal power plant, are currently under development by DOE (References B-1, B-2). The development status of some internal (thermal and chemical) and external (Redox battery) storage technologies, specifically oriented towards providing diurnal energy storage for solar power plant systems is reviewed.

Because of the time and resource constraints, the investigation is limited to the advanced energy transport and storage technologies listed. in Table B-1.

\section{APPROACH AND METHODOLOGY}

Much technical information on the technologies 1isted in Table B-1 was obtained from ongoing work sponsored by DOE, industry reports, open literature, and private communications with knowledgeable professionals.

The assembled data reflect many view points and differ in scope, quality, quantity and descriptive detail. In literature, several definitions of system efficiency exist, and reported cost data were not developed under uniform life assumptions. In this investigation, we have screened and analyzed assembled data to develop reliable capital coeto and perfurmance characteristics which are compatible with our solar power systems computer simulation methodology. Our investigation of energy transport and storage technologies assuraes equal life and identical duty requirements. 
Table B-1. Energy Transport \& Storage Technologies

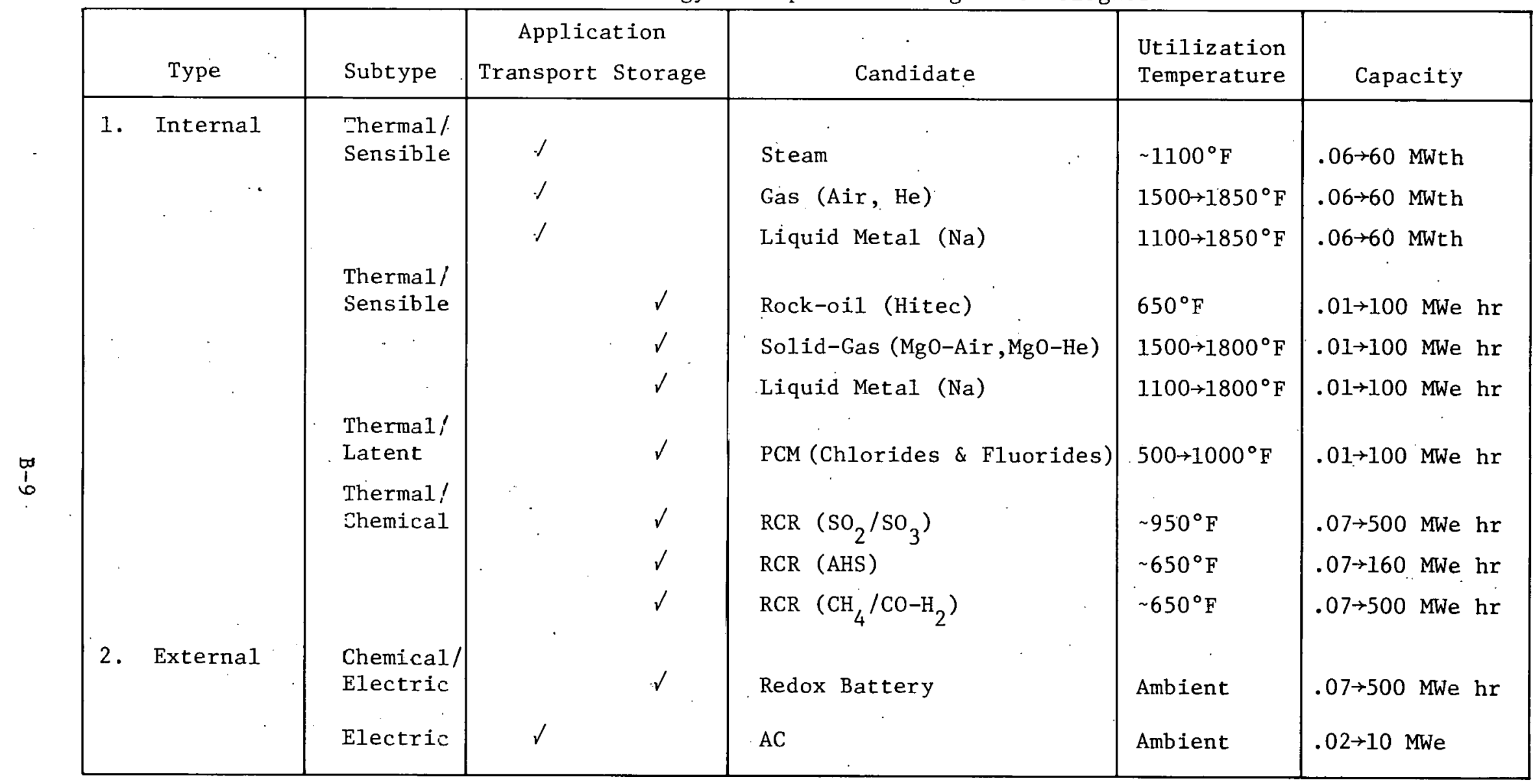
3. Heat Exchange:
Conventional Tube/Shell
4. Containment:
Welded Stee1, Prestressed Cast Iron, Prestressed Concrete Steel Lined and Un1ined Natural Aquifers.
5. Piping: Welded Ste $\epsilon 1$, Provided with High Temperature Insulation. 


\section{A. COST ESTIMATES}

The per unit capital cost of energy transport can be represented by $\$ / k W t h$. This cost includes the pumps, piping, insulation, control, and ancillary equipment required. Note that the per unit capital cost is a function of the energy transport system size. The capital costs of energy storage systems, in first approximation, can be described as a sum of two terms. The per unit capital cost $(\mathrm{C}, \$ / \mathrm{kWe})$ is:

$$
C(\$ / k W e)=C_{p}(\$ / k W e)+C_{s}(\$ k W e h r) \cdot T \text { (hours of storage) }
$$

where $C_{p}$ is due to power related equipment and $C_{S}$ is due to storage capacity related equipment.

\section{B. EFFICIENCY}

In our simulation work, we have consistently used the expression:

$$
\text { Efficiency }=\frac{\text { EOutputs }}{\sum \text { Inputs }}=\frac{\text { Inpuls }-\sum \text { Losses }-\sum \text { Auxiliaries }}{\sum \text { Inputs }}
$$

This deceptively simple definition needs careful handling when applied to solar thermal power systems. We have considered both internal (thermal) and external (electric) energy storages. In the operation of these systems, both heat and work are transferred across the system boundaries. Especially, in the charging of reversible chemical reaction systems, a significant amount of expansion work is available in some systems. Conceptually one can visualize the energy transport and internal energy storage systems as shown in Figure B-3, from which is seen that,

$$
\text { Efficiency }=n=\frac{\left(Q_{i}-Q_{L}\right)+\left(W_{0}-W_{i}\right) / n P}{Q_{i}}
$$

For external energy storage systems, the efficiency is as given in equation $(B-2)$. Since the overall efficiency of a solar thermal power plant is the product of subsystem efficiencies, equation ( $B-3$ ) is compatible with such a concept. The numeric values quoted for thermal energy transport and thermal energy storage are based on the definition of equation (D-3).

\section{EXPECTED LT.TF.}

Equipment life is generally related to its basic design and operating mode. It is very difficult to estimate the actual life of some of the advanced energy transport and storage systems considcred in this study. It is believed that adequate life is usually accomplished by proper design and maintenance. Therefore, it is assumed that all systems have the same life of 30 years. 


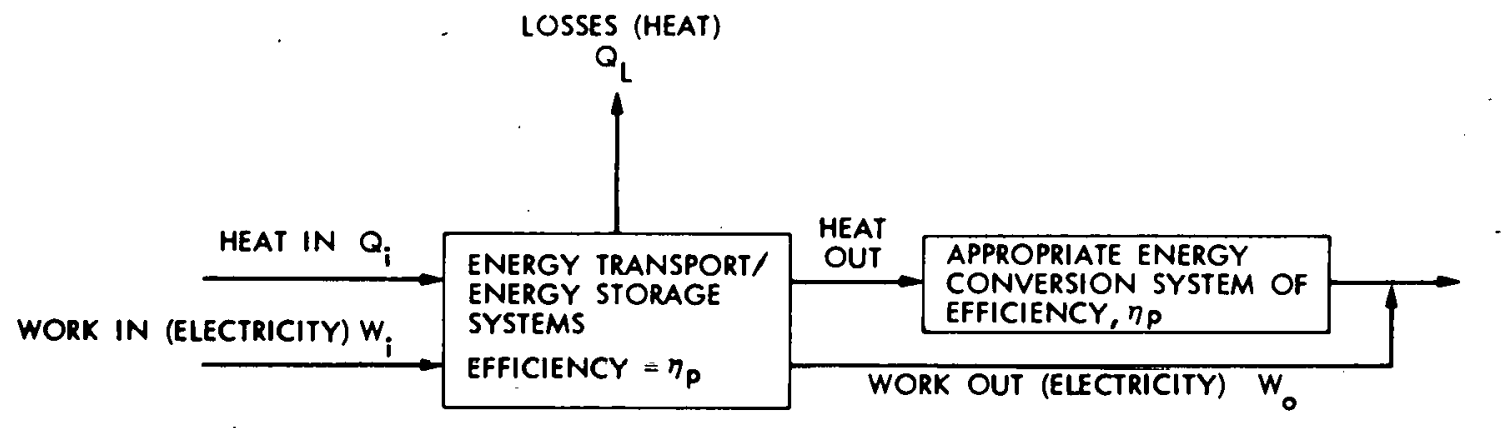

Figure B-3. Energy Balance for Energy Transport and Internal Energy Storage Systems

\section{OPERATING CHARACTERISTICS}

Since most of the advanced systems under consideration are still conceptual, we have not investigated the load following, part load operation, and transient stability of energy transport and storage systems. It is assumed that all energy storage systems are capable of undergoing the required duty cycle without any penalties.

\section{ROCK-OIL (HITEC) ENERGY STORAGE}

Rock-0il sensible energy storage is characterized by using the thermal energy directly to charge the storage system, retrieving it as thermal energy, and the converting it into electrical energy as shown in Figure B-4. Desirable properties for the sensible thermal/storage medium include low-cost, high-heat capacity, high-temperature capability, low-vapor pressure so that it can be stored at atmospheric pressure, non-corrosive, high-thermal conductivity, non-toxic, and safe.

Several recent studies (References B-1 to B-4) have addressed the issues of medium selection, their costs and performance. HITEC-Rock system has been recommended for Barstow pilot plant and we have adopted this energy storage for the baseline solar thermal power plant.

HITEC is attractive for its high-temperature capability (up to $950^{\circ} \mathrm{F}$ ). Its heat transfer properties are quite sufficient (specific heat $\left.=0.37 \mathrm{Btu} / 1 \mathrm{bm}-{ }^{\circ} \mathrm{F}\right)$ but its cost is somewhat high ( 25 cents/1b). Its limited availability is of more serious concern. Current systems employing HITEC in industrial process heating are all significantly smaller than that needed for, the solar plant. In fact, one 10 MWe plant would require five times the current annual production of HITEC. 


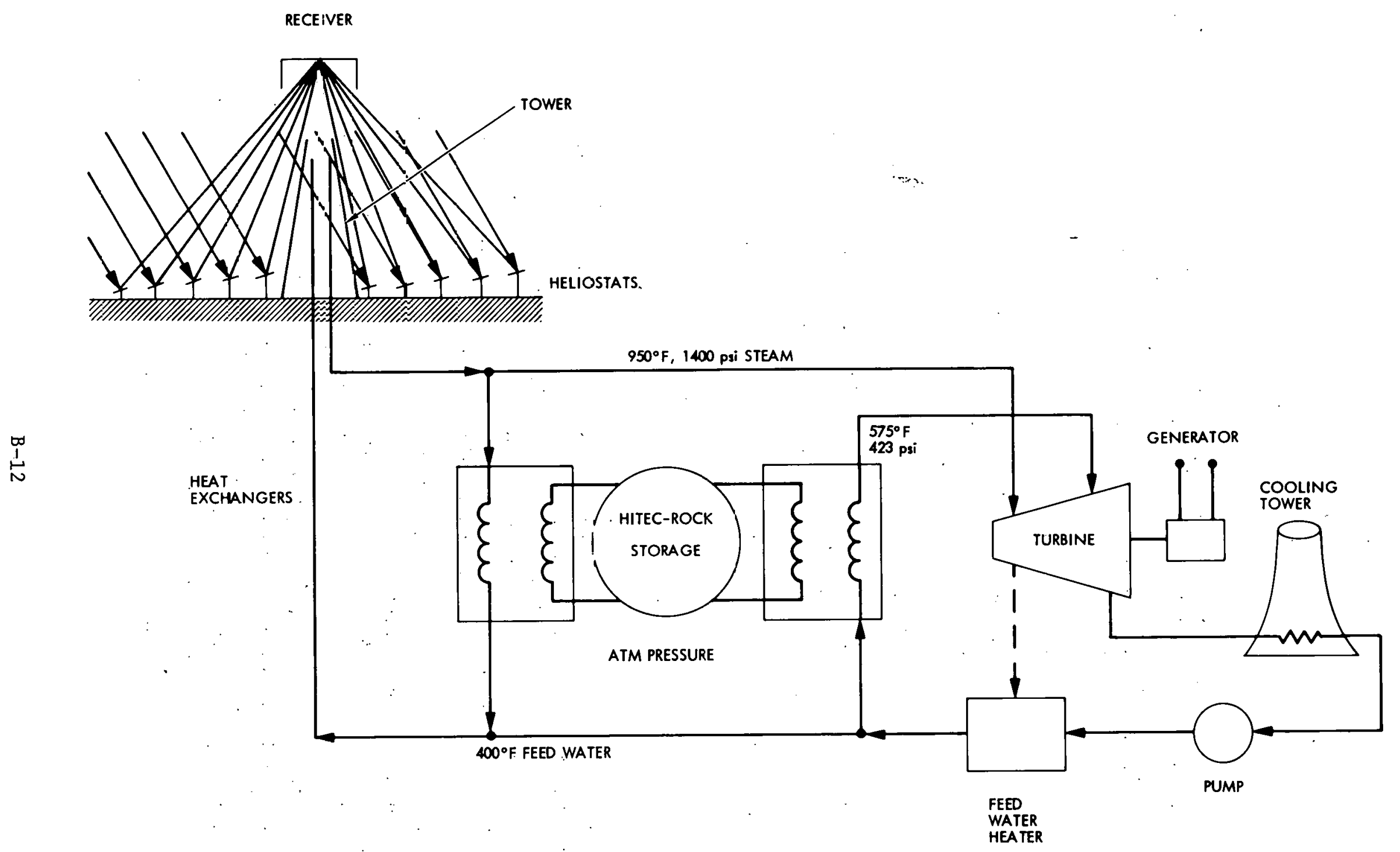

Figure B-4. HITEC-Rock Thermal Energy Szorage 
Since the single major cost of this type of energy storage system is HITEC material cost (which amounts to $\sim 70 \%$ of the total cost), packing of storage tanks with crushed rock (specific heat $=0.21 \mathrm{Btu} / \mathrm{lb}-{ }^{\circ} \mathrm{F}$ ) will bring dówn the material costs. However, the long term behavior of crushed rock under high-temperature thermal cycling is not well understood and needs development of experimental data.

In this study, we have estimated the approximate cost of HITECRock system. The current indication is that the HITEC temperature will vary between $650^{\circ} \mathrm{F}$ as its high and storage temperature of $450^{\circ} \mathrm{F}$ as its de-energized temperature, and so the material remains a liquid throughout the operating range since it freezes at $288^{\circ} \mathrm{F}$ at atmospheric pressure. The storage system is comprised of a tank.storage at atmospheric pressure which holds HITEC and rock heat exchangers that allow thermal input and output to and from the storage, plumbing, insulation for the tank and plumbing, pumps and controls. The estimated costs are shown in Table $\mathrm{B}-2$.

\section{MAGNESIUM OXIDE BRICK STORAGE}

Recently Boeing Company (Reference B-3) investigated the use of cast iron and refractory material such as $\mathrm{MgO}$ as potential sensible heat storage media for Brayton powered solar power plants. A comparison of the key characteristics of $\mathrm{MgO}$ and cast iron is shown in Table B-3.

Table B-2. Summary of Performance and Cost Characteristics for HITEC-Rock. Energy Storage

\begin{tabular}{|c|c|c|c|}
\hline Storage Capacity (MWe hr) & 50 & 100 & 150 \\
\hline Heat in, $Q_{i}$ (MWth) & 170 & 338 & 508 \\
\hline Heat Loss, $Q_{L}$ (MWth) & 17 & 35 & 54 \\
\hline Pump Work (MWe hr) & 6.3 & 12.7 & 19 \\
\hline Expander Work (MWe hr) & - & - & - \\
\hline Storage Efficiency, ${ }_{\mathrm{S}}$ & 0.8 & 0.79 & 0.78 \\
\hline $\begin{array}{l}\text { Power Related Costs }\left(\$ \times 10^{6}\right) \\
\text { Heat Exchangers } \\
\text { Plumbing } \\
\text { Pumps }\end{array}$ & 0.9 & 1.20 & 1.30 \\
\hline $\begin{array}{l}\text { Energy Related Costs }\left(\$ \times 10^{6}\right) \\
\text { Tank } \\
\text { HITEC } \\
\text { Insulation }\end{array}$ & 2.1 & 4.40 & 6.6 \\
\hline$C_{p}(\$ / k W e)$ & 40 & 40 & 40 \\
\hline $\mathrm{C}_{s}(\$ / \mathrm{kWe} \mathrm{hr})$ & 52 & 52 & 52 \\
\hline
\end{tabular}


Table B-3. Comparison of Properties Cast Iron and Magnesia Brick

\begin{tabular}{lrc} 
& Cast Iron & Magnesia Brick \\
\hline Cost $(\$ / \mathrm{kg})$ & 0.66 & 0.32 \\
Thermal Conductivity $\left(\mathrm{W} / \mathrm{m}-{ }^{\circ} \mathrm{C}\right)$ & 29.3 & 5.07 \\
Heat Capacity $\left(\mathrm{J} / \mathrm{kg}-{ }^{\circ} \mathrm{C}\right)$ & 837 & 1,130 \\
Linear Expansion $(\%)$ & 1.10 & 1.09 \\
Density $\left(\mathrm{kg} / \mathrm{m}^{3}\right)$ & 7,900 & 3,000 \\
For a $\Delta \mathrm{T}=264^{\circ} \mathrm{C}$ & & \\
Storage capacity $(\mathrm{kJ} / \$)$ & 3.34 .8 & 932.2 \\
Storage density $(\mathrm{kJ} / \mathrm{g})$ & 220.9 & 298.3 \\
Storage volume $\left(\mathrm{MJ} / \mathrm{m}^{3}\right)$ & 1,746 & 894.9 \\
\hline
\end{tabular}

MgO bricks also retain high strength at elevated temperatures $1500^{\circ} \mathrm{F}$ and are resistant to spalling, and hence are selected for the present study. Checker work construction techniques for these bricks are part of the standard industry practice as shown in Figure B-5.

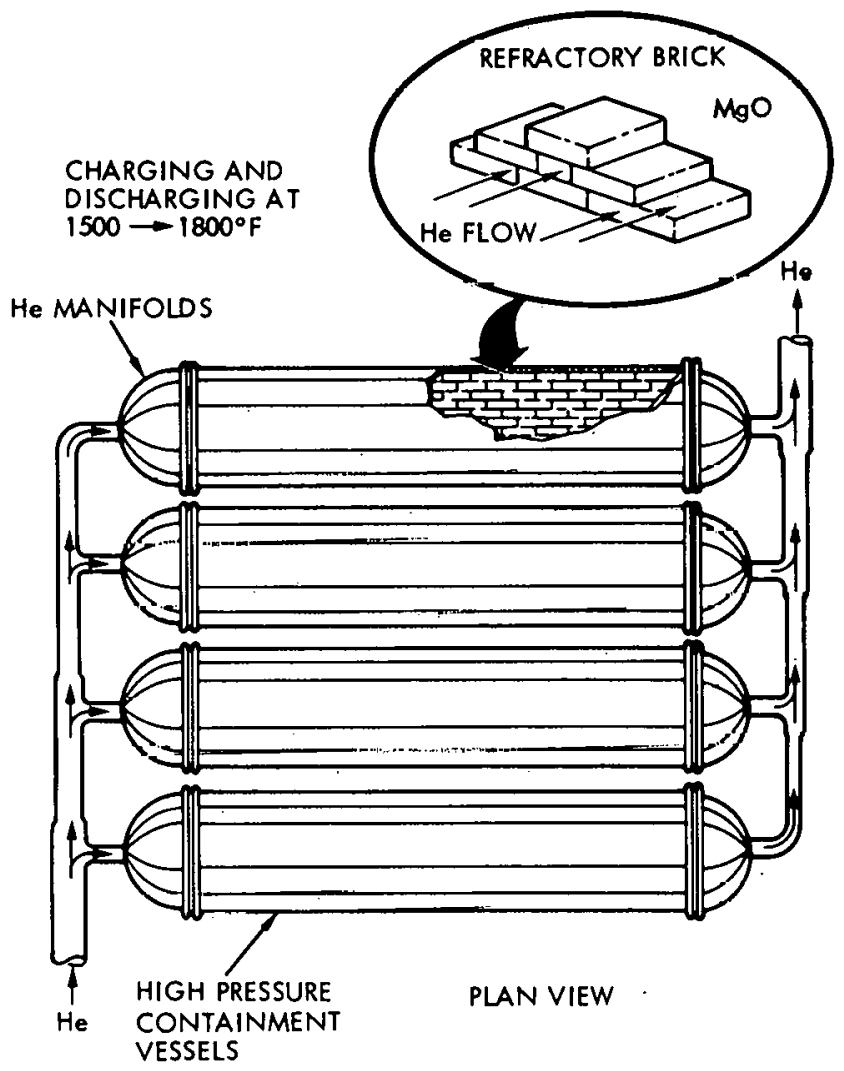

Figure B-5. MgO Brick-Sensible Heat Storage 
The storage medium can be contained in several insulated pressure vessels. The working fluid (helium or air) is distributed by a cascaded manifold system with a refractory diffuser. The tank is made of $\sim 3$ inch thick carbon steel and has to be designed in accordance with ASME Boiler and Pressure Vessel Code. The fluid circulation system compressor should be sized to overcome the pressure drop in the brick storage.

The estimated performance and costs are shown in Table B-4. The costs include tank fabrication, refractory brick inventory, gas circulation, plumbing, and insulation. DOE has sponsored current research to assess the applicability of prestressed cast iron vessel (PCIV) in this storage (Reference B-5). The PCIV concept offers a potential low-cost alternative to the welded steel pressure vessel approach adopted in this study.

\section{LIQUID METAL STORAGE}

Liquid metals have been found to be excellent heat transport and storage media for systems designed to operate at temperatures from 1200 to $1800^{\circ} \mathrm{F}$. The size of the piping and major pieces of equipment together with the pumping power requirements can be kept lower than if gases were employed. However, the corrosion problems presented by liquid metals require that the structural materials be selected with care. Furthermore, the systems must be designed for a high degree of

Table B-4. Summary of Performance and Cost Characteristics for Magnesium Oxide Brick Storage Energy Storage

\begin{tabular}{|c|c|c|c|}
\hline Storage Capacity (MWe hr) & 50 & 100 & 150 \\
\hline Heat in, $Q_{i}$ (MWth hr) & 150 & 260 & 388 \\
\hline Heat Loss, $Q_{L}$ (MWth $h r$ ) & 15 & 25 & 42 \\
\hline Circulation Work (MWe hr) & 5 & 11 & 17 \\
\hline Expander Work (MWe hr) & - & - & - \\
\hline Storage Efficiency, $n_{s}$ & 0.8 & 0.78 & 0.76 \\
\hline $\begin{array}{c}\text { Power Related Costs }\left(\$ \times 10^{6}\right) \\
\text { Circulation Compressors, } \\
\text { Manifolds and Diffuser }\end{array}$ & $0.6^{\circ}$ & 0.70 & 0.80 \\
\hline $\begin{array}{l}\text { Energy Relaced Cosls }\left(\$ \times 10^{6}\right) \\
\text { Tanks } \\
\text { MgO } \\
\text { Insulation }\end{array}$ & 2.4 & 4.8 & 7.2 \\
\hline $\mathrm{Cp}(\$ / \mathrm{kWe})$ & 50 & 50 & 50 \\
\hline Cs ( $(\$ /$ kWe hr) & 50 & 50 & 50 \\
\hline
\end{tabular}


leak-tightness to minimize contamination of the liquid metal by water vapor or oxygen if corrosion rates are to be kept small. With proper design, construction, and operation liquid metal systems have been operated at temperatures of $\sim 1200^{\circ} \mathrm{F}$ and higher with corrosion rates of less than 0.0001 inch/year (Reference $\mathrm{B}-6$ ). The heat transport and storage systems must be designed for providing preheating and good drainage to avoid difficulties with liquid freezing. Sodium appears to have mainly cost and performance advantages over other liquid metals (Reference $B-7$ ) and hence is the selected candidate for analysis in this study.

A simple schematic of the liquid sodium storage system is shown in Figure B-6. Since all operation of this system is from stored sodium, there is no distinction between daytime or nighttime operation, nther. than the auxiliary or parasitic power requirements. This configuration allows all of the five desirable operating sequences: (1.) direst operation (2), direct plus storage system discharge (3) direct plus storage system charge (4) storage system charge only and (5) storage system discharge only. Recently, a conceptual design for a 100 WWe solar tower employing liquid sodium as a heat transfer fluid and as a storage medium was generated using this configuration (Reference B-8).

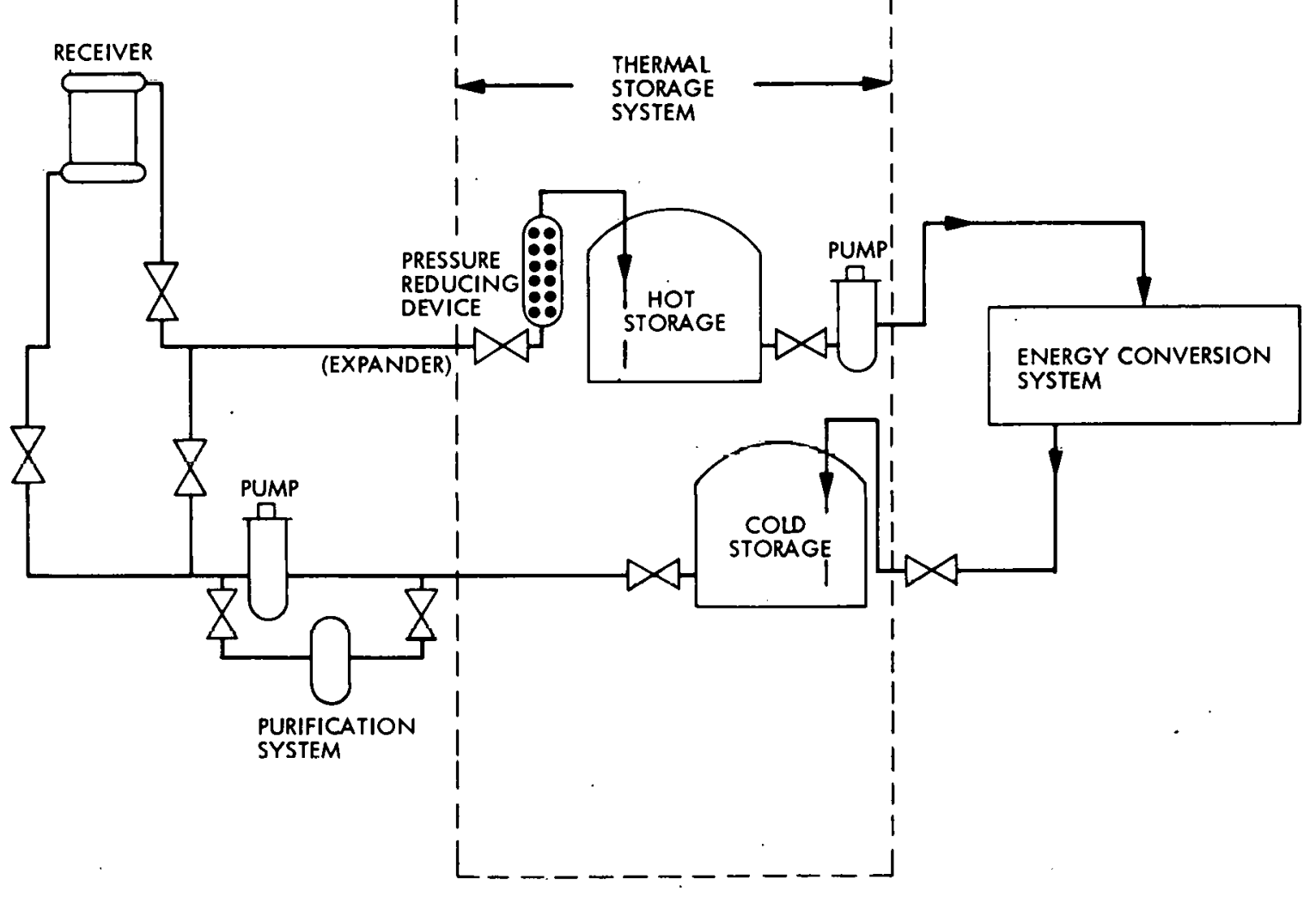

Figure B-6. Liquid Sodium Storage 
The liquid sodium energy storage system as shown in Figure B-6 consists of a hot sodium storage tank, cold sodium storage, pumps, and interconnecting piping. The storage system costs are dominated by the cost of the tanks and the sodium. For this reason (Reference B-6) examined in detail the tank height versus diameter relationship as well as the number of tanks. It concluded that for a system with stainless steel hot tank and carbon steel cold tank, single tanks with a height to diameter ratio of $1: 2$ gave the lowest cost system. This included material, labor, insulation, electrical preheat, interconnecting piping, and valves.

The 347 stainless steel has been the most popular variety of stainless steel for high temperature liquid sodium transport and storage because of its Colombium stabilization. Type 3.04 stainless steel has also been proved to be in every way as resistant to corrosion in sodium as type 347 up to $1000^{\circ} \mathrm{F}$. For liquid temperatures of interest in this study $\left(1500-1800^{\circ} \mathrm{F}\right)$ candidate materials are Type 347 stainless steels, Inconel, Nichrome, Hastelloys, and Cobalt alloys. Ceramics such as $\mathrm{Al}_{2}$ 03, $\mathrm{BeO}, \mathrm{MgO}$ are as resistant to corrosion in sodium as any of the austenitic stainless steels.

The experience with liquid sodium containment at temperatures $1500-1800^{\circ} \mathrm{F}$ is extremely limited. No reliable data exists on liquid metal resistance, temperature dependent mechanical strength or metallurgical stability. Much work needs to be.done in this area to develop satisfactory designs of low cost. Components such as insulation, 1iquid metal pumps, valves, and controls already exist in connection with nuclear work, and their cost can be brought down considerably by mass production techniques and elimination of nuclear specs for these components. Cost and performance estimates based on our judgment are shown in Table B-5.

\section{PHASE CHANGE MATERIAL (PCM)}

The latent heat of fusion has long been considered an attractive mechanism for thermal. energy storage. The reasons are the high potential energy storage density.at temperatures in excess of $500^{\circ} \mathrm{F}$, and the convenience of operating over a relatively narrow temperature range.

The candidate phase change material (PCM), in addition to having the proper transition temperature and high latent heat must also have satisfactory chemical and physical properties, especially an adequate thermal conductivity. Also, it must be stable, containable, cheap, and preferably non-poisonous.

Several of the PCM salts shown in Table B- 6 have been used in commercial molten-salt heaters and in adyance development heaters (Reference $B-9$ ). 
l'able B-5. Summary of Performance and Cost Characteristics for Liquid Metal (Sodium) Energy Storage

\begin{tabular}{|c|c|c|c|}
\hline Storage Capacity (MWe hr) & 50 & 100 & 150 \\
\hline Heat in, $Q_{i}$ (MWth hr) & 170 & 332 & 500 \\
\hline Heat Loss, $Q_{L}($ MWth hr) & 7 & 13 & 28 \\
\hline Pump Work (MWe hr) & 3 & -7 & 10 \\
\hline Expander Work (MWe hr) & $\begin{array}{l}\text { Accounted } \\
\text { in Net } \\
\text { Pump Work }\end{array}$ & $\begin{array}{l}\text { Accounted } \\
\text { in Net } \\
\text { Pump Work }\end{array}$ & $\begin{array}{l}\text { Accounted } \\
\text { in Net } \\
\text { Pump Work }\end{array}$ \\
\hline Storage Efficiency, $n_{S}$ & 0.91 & 0.90 & 0.89 \\
\hline $\begin{array}{l}\text { Puwer Related Costs }\left(\$ \times 10^{6}\right) \\
\text { - Pumps } \\
\text { - Valves } \\
\text { - Piping }\end{array}$ & 0.4 & 0.5 & 0.6 \\
\hline $\begin{array}{l}\text { Energy Related Costs }\left(\$ \times 10^{6}\right) \\
\text { - Tanks (Stainless steel } \\
\quad \text { and Carbon steel) } \\
\text { - Insulation } \\
\text { - Sodium }\end{array}$ & 2.1 & 3.00 & 4.50 \\
\hline$C_{p}(\$ / k W e)$ & 40 & 40 & 40 \\
\hline $\mathrm{C}_{\mathrm{S}}(\$ / \mathrm{kWe} \mathrm{hr})$ & 31 & 31 & 31 \\
\hline
\end{tabular}

In general, fluorides possess the "best" thermal properties of all PCM and therefore have received a great deal of attention (Reference B-10 and $B-11)$. These slats are abundant, relatively inexpensive for large production rates, and chemically and thermally stable. Mixtures of various fluoride salts provide a wide variation in cost, melt temperature, and heat of fusion. Table B-7 lists some selected metal fluoride salts currently under investigation, their heat of fusion and their estimated selling price. Table B-8 summarizes the performance and cost characteristics of a PCM storage device shown in Figure B-7.

Table B-6. Candidate PCM Salts

\begin{tabular}{lcc}
\hline $\begin{array}{c}\text { Type } \\
\text { (Single Salt) }\end{array}$ & Melting Point Range $\left({ }^{\circ} \mathrm{F}\right)$ & Heat of \\
\hline Chlorides & $475-1765$ & $31-250$ \\
Nitrates & $500-1100$ & $40-150$ \\
Hydroxides & $600-850$ & $59-380$ \\
Bromides & $1000-1400$ & $50-101$ \\
Carbonates & $1,300-2500$ & $101-260$ \\
Fluorides & $1500-2400$ & $160-450$ \\
\hline
\end{tabular}


Table B-7. Selected Metal Fluoride Salts

\begin{tabular}{|c|c|c|c|c|c|c|c|}
\hline \multirow[b]{2}{*}{$\begin{array}{c}\text { Temperature } \\
\text { Range }{ }^{\circ} \mathrm{C}\end{array}$} & \multirow[b]{2}{*}{$\begin{array}{c}\text { Composition } \\
\text { (Wt. \%) }\end{array}$} & \multirow{2}{*}{$\begin{array}{l}\text { Melting } \\
\text { Point } \\
{ }^{\circ} \mathrm{C}\end{array}$} & \multirow{2}{*}{\multicolumn{2}{|c|}{\begin{tabular}{cl}
\multicolumn{2}{c}{ Estimated } \\
Selling & Price \\
$\$ / \mathrm{kg}$ & $\$ / \mathrm{m}^{3}$
\end{tabular}}} & \multirow{2}{*}{$\begin{array}{l}\text { Heat } \\
\mathrm{kJ} / \mathrm{mole}\end{array}$} & \multicolumn{2}{|c|}{ of Fusion } \\
\hline & & & & & & $\mathrm{kJ} / \mathrm{kg}$ & $\mathrm{MJ} / \mathrm{m}^{3}$ \\
\hline $250-300$ & $70 \mathrm{Na}_{3} \mathrm{AIF}_{6} / 30 \mathrm{~A}_{-}^{*} \mathrm{Cl} 1_{3}$ & 300 & 0.66 & & & & \\
\hline $401-450$ & $27.1 \mathrm{LiF} / 11.9 \mathrm{NaF} / 55.1 \mathrm{KF} / 5.9 \mathrm{MgF}^{2 *}$ & 449 & 1.33 & 3.424 & 7.0 & 699 & 1807 \\
\hline $451-475$ & $29.2 \mathrm{LiF} / 11.7 \mathrm{NaF} / 59.1 \mathrm{KF}^{*}$ & 454 & 1.42 & 3.567 & 4.09 & 414 & 1046 \\
\hline $476-500$ & $1.9 \mathrm{LiF} / 42.6 \mathrm{KF} / 55.5 \mathrm{AlF}_{3}$ & 490 & 0.47 & & & & \\
\hline $526-550$ & $5.8 \mathrm{NaF} / 28.9 \mathrm{KCl} / 65.3 \mathrm{Na}_{2} \mathrm{CO}_{3}$ & 538 & 0.07 & & & & \\
\hline $551-575$ & $25.9 \mathrm{Na}_{2} \mathrm{CO}_{3} / 38.8 \mathrm{NaCl} / 35.3 \mathrm{NaF}$ & 575 & 0.09 & & & & 0 \\
\hline $576-600$ & $11.5 \mathrm{MgF}_{2} / 88.5 \mathrm{MgCl}_{2}$ & 596 & 0.16 & & & & \\
\hline $601-625$ & 35. $2 \mathrm{LiF} / 38.3 \mathrm{NaF} / 26.5 \mathrm{CaF}_{2} *$ & 615 & 1.36 & 3.790 & 5.83 & 636 & 1795 \\
\hline $626-650$ & $45.2 \mathrm{NaF} / 54.8 \mathrm{ZnF}_{2}$ & 635 & 0.64 & & & & \\
\hline
\end{tabular}

† Based on ambient densities

* Considered in present study. 
Table B-8. Summary of Performance and Cost Characteristics for Molten Salt Storage (Power $=10$ MWe)

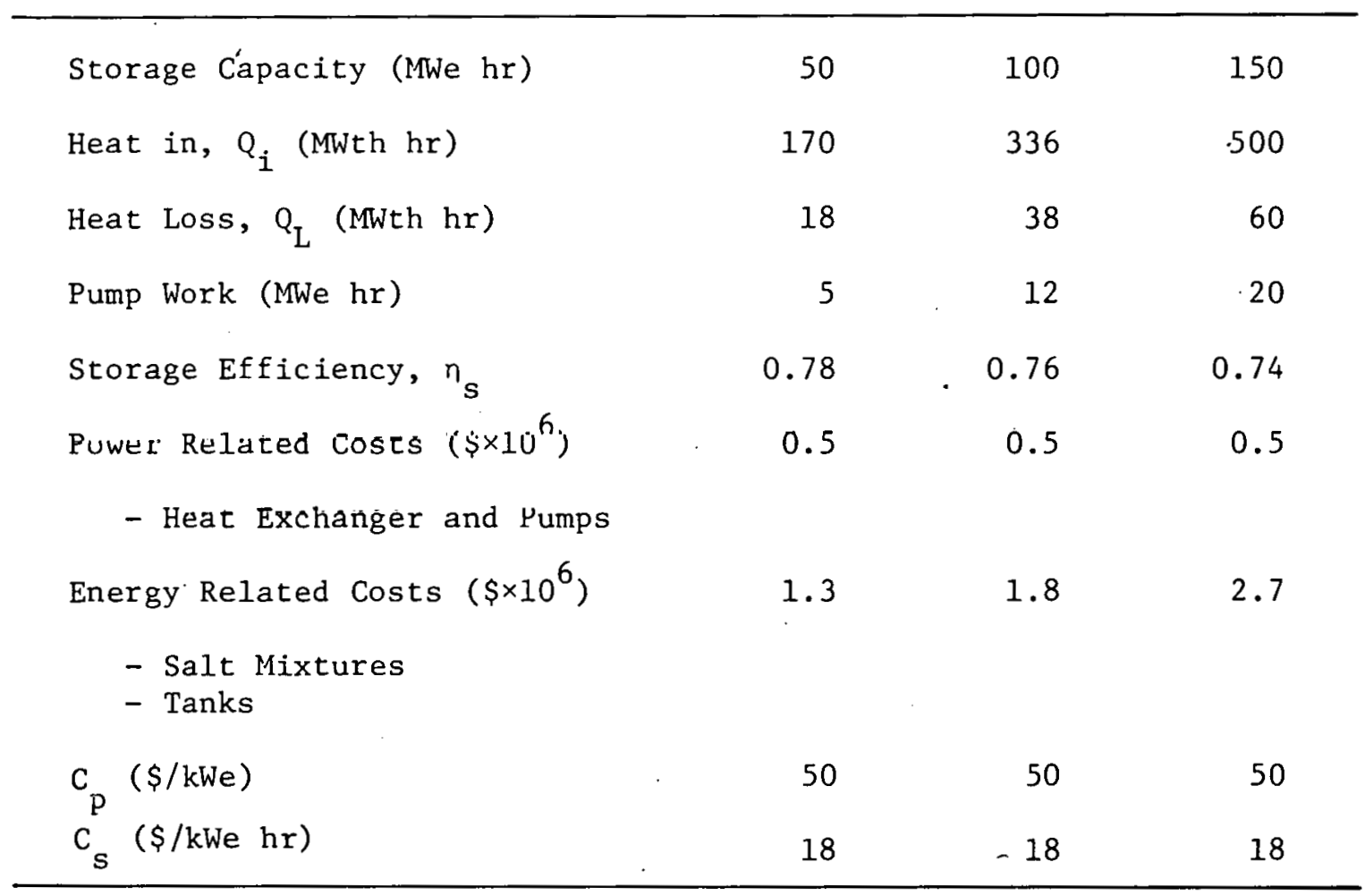

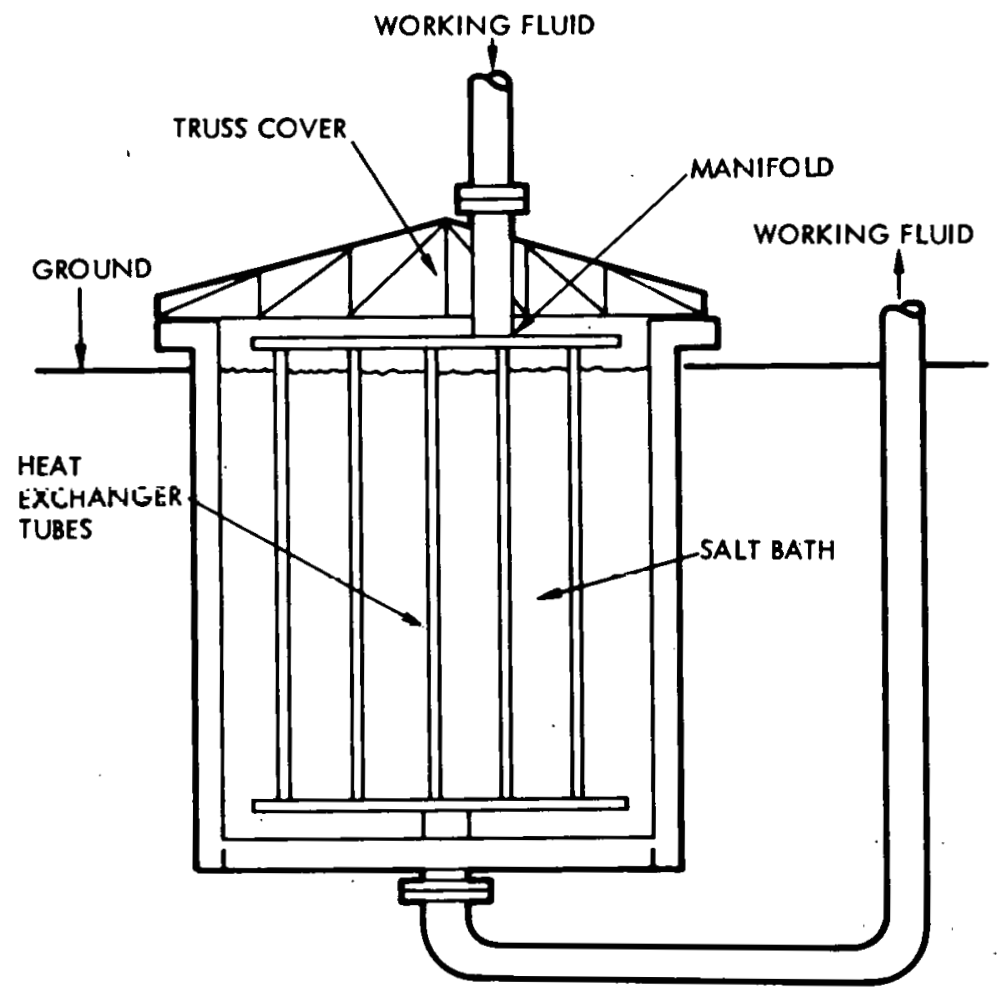

Figure B-7. Phase Change Material Energy Storage 
VII. REVERSIBLE CHEMICAL REACTION STORAGE (RCR)

The storage of thermal energy as the heat of reaction of a reversible chemical system has long been considered an attractive possibility. In these systems, a reversible chemical reaction consumes thermal energy (endothermic reaction) by transforming chemicals into a storable, higher potential energy state during periods of excess energy supply, such as during hours of sunlight. During periods of low or no insolation, the chemical energy storage is called upon to give up the stored heat by the recombination heat of reaction (exothermic reaction) of stored chemicals.

Reversible chemical reaction storage (RCR) systems can be categorized according to the temperature regime in which they operate, by the physical state of the reactants (gas, liquid or solid), and by the volume change associated with the reaction (Reference $\mathrm{B}-12$ ). The reactions are easier to conduct if all reactants are gases at reaction temperature. The products are easier to store if they are liquids at ambient temperature. A compromise has to be sought between these contradictory requirements. Reference $B-12$ discusses in detail the selection criteria for candidate RCR systems and performance of some of these systems. The selection criteria included energy storage capacity per unit mass or per unit volume, the reaction rates, availability of proper separation techniques of the reaction products, cost of chemicals, toxicity, corrosiveness, and inflammability of the involved chemicals. In our study, we have chosen to investigate (1) the methanation reaction (2) the sulfur trioxide reaction and (3) ammonium hydrogen sulfate reaction.

\section{METHANATION REACTION}

The interest in this system derives from the pioneering work of German investigators (Reference B-1) who have been studying the use of the reaction, $\mathrm{CH}_{4}+\mathrm{H}_{2} \mathrm{O} \leftrightarrow \mathrm{CO}+3 \mathrm{H}_{2}$, for the long distance transmission of nuclear heat. General Electric company is currently studying the use of this reversible chemical reaction for both transport (chemical heat pipes), and energy storage. The basic scheme for the use of methanation reaction is shown in Figure $B-8$. During sunlit hours, the heat from the receiver is absorbed in the endothermic reactor (reformer) where the previously stored low enthalpy reactants $\left(\mathrm{CH}_{4}, \mathrm{H}_{2} \mathrm{O}\right)$ are converted to high enthalpy products $\left(\mathrm{CO} / \mathrm{H}_{2}\right)$. After heat exchange with incoming reactants, the products are then stored at nearly ambient temperature conditions. Although the reverse reaction is thermodynamically favored, it will not nccur at low temperatures and in the absence of a catalyst. Hence, the intrinsic storage time is practically infinite. The higher enthalpy products are recovered from storage and the reverse, exothermic reaction (methanation) is run to recover the stored heat after sundown. It is necessary to store the gases at high pressures of $\geq 70 \mathrm{~atm}$ in order to achieve reasonable energy storage density. The storage could be in 


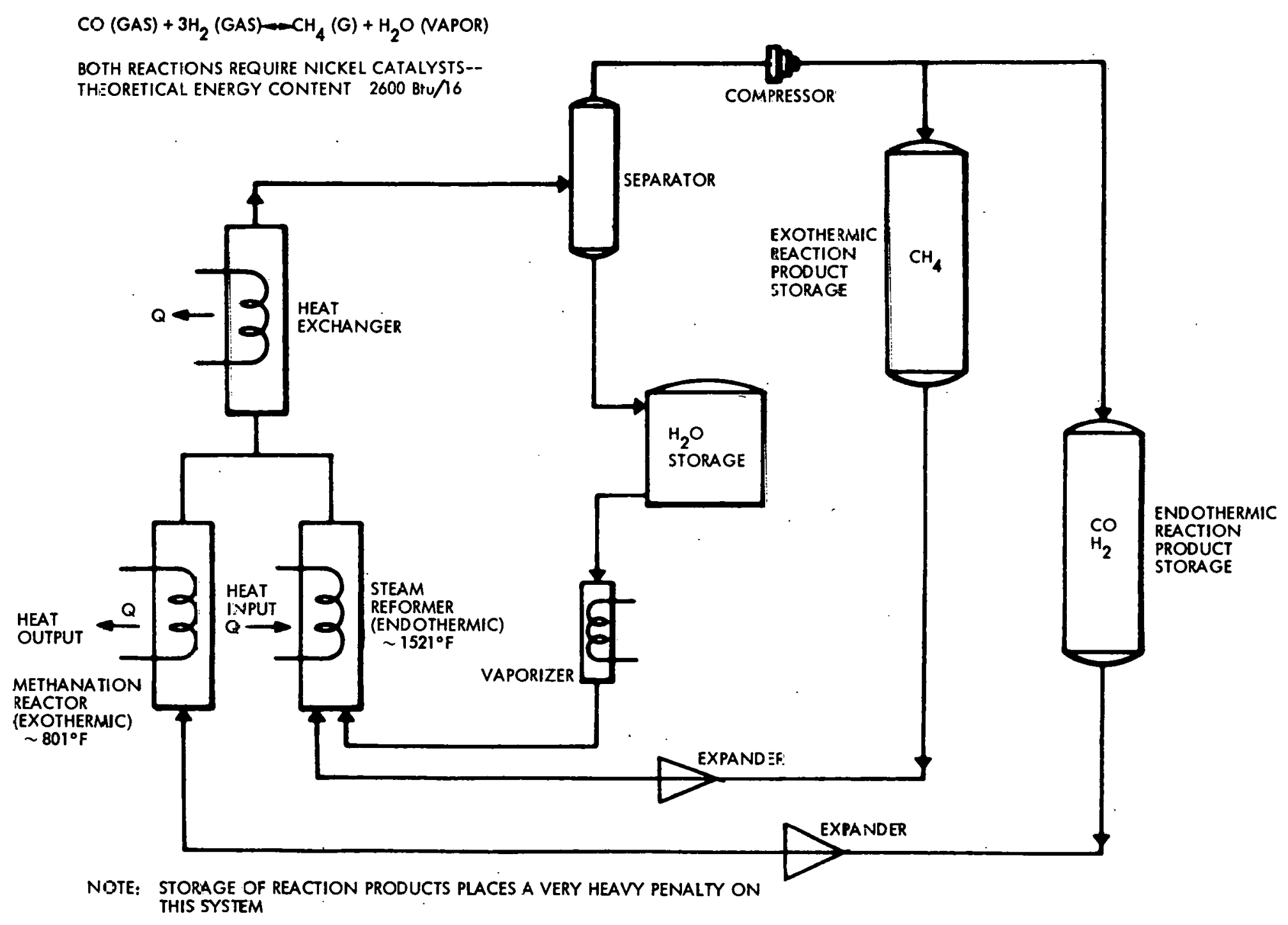

Figure B-8. Simplified Schematic of Chemical Energy System Eased on Steam Reforming - Methanation Reaction 
steel tanks or in. underground mined caverns. The latter will be most economical if a suitable site is available. One concern in the design of an underground storage system would be the contamination of high enthalpy products by the naturally released impure gases in storage which could lead to the poisoning of the catalysts employed in the reactors. Another concern is the diffusion through the rock of 1 ight gases such as hydrogen. In our analysis we have assumed steel storage vessels to avoid these unresolved concerns. Table B-9 summarizes the performance and cost estimates.

\section{IX. $\mathrm{SO}_{2}-\mathrm{SO}_{3}$ ENERGY STORAGE}

The sulfur trioxide dissociation was first proposed at the Naval Research Laboratory (Reference B-10). In this concept, sulfur trioxide will be dissociated to sulfur dioxide and oxygen with heat absorption during sunlit hours. After sundown, these chemicals will be recombined to release heat. Before systems can be implemented based upon this reaction, a catalyst must be found capable of withstanding the hightemperature endothermic reaction conditions. DOE has recently sponsored a study (Refernce B-1) to evaluate the ability of currently available catalysts to function in the required environment and, if necessary, to develop new, more lasting catalysts.

Commercially available vanadium and platinum catalysts appear to degrade at high temperature because of evaporation and hence are not favored at the present time. Fe and Mn catalysts are being tested at high temperatures for prolonged times to test their utilization. Molten catalysts have also been investigated, but have been found unattractive because of their high melting points.

A processes flow sheet of the $\mathrm{SO}_{2}-\mathrm{SO}_{3}$ energy storage system describing the major system components and fluid physical conditions is shown in Figure B-9. During the sunlit hours, part of the dissociation product $\left(\mathrm{SO}_{3}, \mathrm{SO}_{2}, \mathrm{O}_{2}\right)$ is transported after being cooled and compressed to the exothermic reactor to produce steam at $\sim 1000^{\circ} \mathrm{F}$ and 1500 psia. The rest of the products are separated and stored for later use past sundown. Steam is produced in the tubes embedded in the fixed bed catalytic reactor. The bottom part of the vertical tubes serve as preheaters. The estimated performance and costs are shown in Table B-10.

\section{AMMONIUM HYDROGEN SULFATE STORAGE (AHS)}

$$
\begin{aligned}
& \text { Use of the reactions } \\
& \mathrm{NH}_{4} \mathrm{SO}_{4}(Z)+\mathrm{Na}_{2} \mathrm{SO}_{4}(z)=\mathrm{Q}_{i} \rightarrow \mathrm{Na}_{2} \mathrm{~S}_{2} \mathrm{O}_{7}+\mathrm{H}_{2} \mathrm{O}(g)+\mathrm{NH}_{3}(g) \\
& \mathrm{Na}_{2} \mathrm{~S}_{2} \mathrm{O}_{7}(z)+\mathrm{Q}_{i} \rightarrow \mathrm{Na}_{2} \mathrm{SO}_{4}(z)+\mathrm{SO}_{3}(g) \\
& \mathrm{NH}_{3}(g)+\mathrm{H}_{2} \mathrm{O}(g)+\mathrm{SO}_{3}(g) \rightarrow \mathrm{NH}_{4} \mathrm{HSO}_{4}(z)+\left(\mathrm{Q}_{0}\right) \\
& \underset{\mathrm{B}-23}{ }
\end{aligned}
$$


Table B-9. Summary of Performance and Cost Characteristics for $\left(\mathrm{CO}-\mathrm{H}_{2}\right)$, Methanation RCR Energy Storage

\begin{tabular}{|c|c|c|c|}
\hline Storage Capacity (MWe hr) & 50 & 100 & 150 \\
\hline Heat in, $Q_{i}$ (MWth hr) & 171 & 338 & $500^{\circ}$ \\
\hline Heat Loss, $Q_{L}$ (MWth hr) & 14 & 24.5 & 40 \\
\hline $\begin{array}{l}\text { Pump Work (MWe hr) } \\
\text { (Compressor) }\end{array}$ & 18 & 38 & 57 \\
\hline Expander Work. (MWe hr) & 10 & 20 & 30 \\
\hline Stontage Efficiency $n_{s}$ & 0.76 & 0.75 & 0.74 \\
\hline $\begin{array}{l}\text { Power Related Costs }\left(\$ \times 10^{6}\right) \\
\text { - Reactors (Reformer an } \\
\text { - Heat Exchanger } \\
\text { - Compressor }\end{array}$ & 1.55 & 1.70 & 1.95 \\
\hline $\begin{array}{l}\text { Energy Related Costs }\left(\$ \times 10^{6}\right) \\
\text { - Chemical Inventory } \\
\text { - Storage Tanks } \\
\text { - Water Tank }\end{array}$ & 4.50 & 5.10 & 6.60 \\
\hline$C_{p}(\$ / k W e)$ & 330 & 330 & 330 \\
\hline$c_{s}(\$ / k W e h r)$ & 35 & 35 & 35 \\
\hline
\end{tabular}

for thermal energy storage appears promising for several reasons. It possesses a high heat of reaction, which will lead to a high energy density. The reaction products are condensable which facilitates storage, and the liquid and gas phases involved minimize heat transfer problems associated with the reactor. The thermal reactions are complete and require no catalyst (Reference B-12). Problems which must be resolved include:

- Development of a means of separating the products

- Selection of materials for containment

- Development of complete operational cycles with heat recuperation and work extraction by means of expanders. 
REACTION: $25 \mathrm{O}_{2}(G)+\mathrm{C}_{2}(G)-2 \mathrm{SO}_{3}(G)$. REQUIRES (PLAIINUM OR VANADIUM:

CATALYSTS. THERMAL ENERGY CONTENT = $531 \mathrm{BrU} / \mathrm{lbm}$

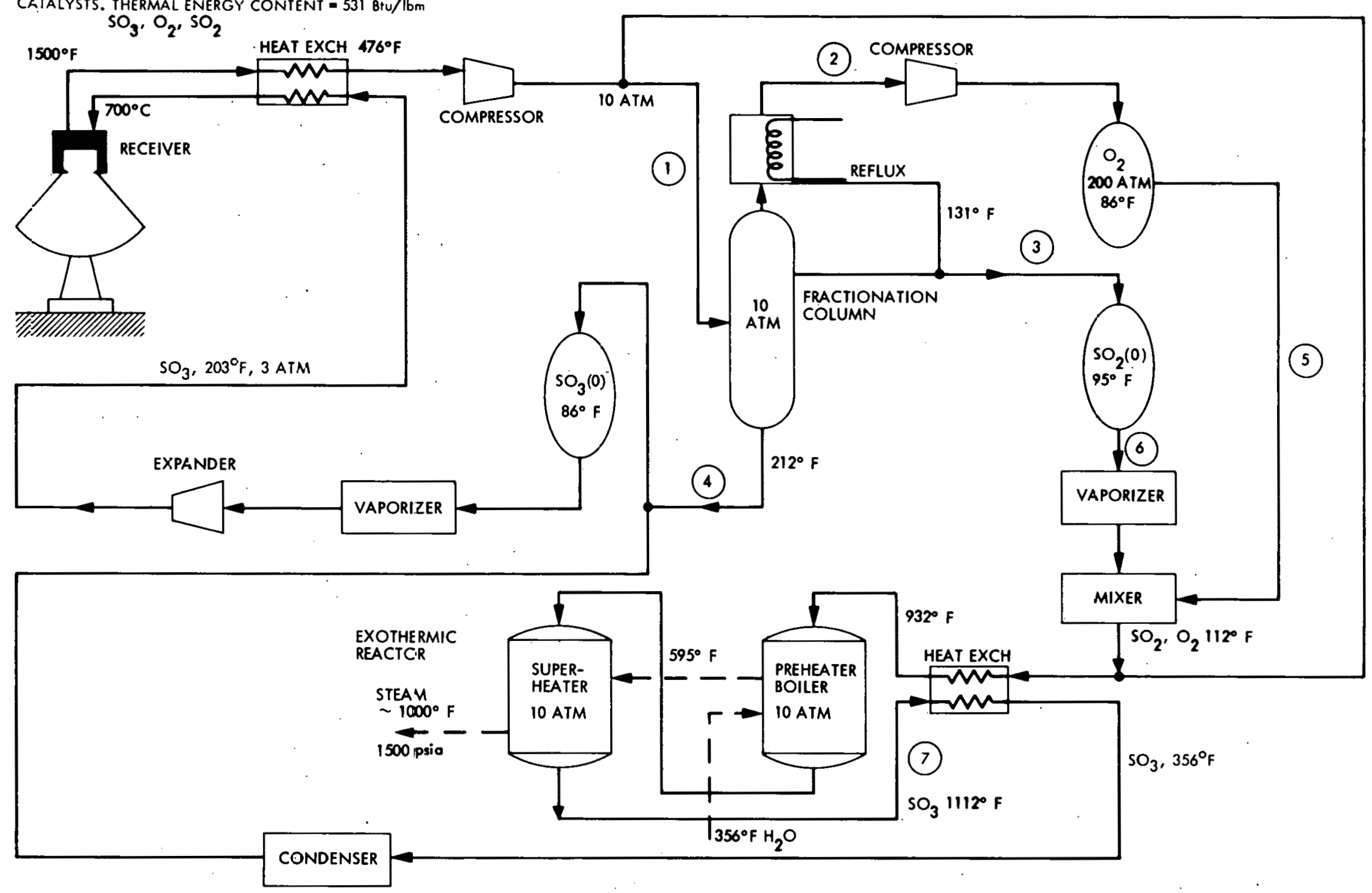

Figure B-9. Process Flow Sheet for $\mathrm{SO}_{2}-\mathrm{SO}_{3}$ System 
Table B-10. Summary of Performance and Cost Characteristics for $\mathrm{SO}_{2}-\mathrm{SO}_{3}$ Energy Storage

\begin{tabular}{|c|c|c|c|}
\hline Storage Capacity (MWe hr) & 50 & 100 & 150 \\
\hline Heat in $Q_{i}$ (MWth hr) & 155 & 306 & 431 \\
\hline Heat Loss $Q_{L}$ (MWth $\left.h r\right)$ & 18 & 38 & 58 \\
\hline Pump Compressor Work (MWe hr) & 18 & 37 & 52 \\
\hline Expander Work (MWe hr) & 7 & 14 & 21 \\
\hline Storage efficiency, $\eta_{s}$ & 0.67 & 0.66 & 0.65 \\
\hline $\begin{array}{l}\text { Power Related Costs }\left(\$ \times 10^{6}\right) \\
\text { - Reactors } \\
\text { - Hear Exchanger } \\
\text { - Compressor } \\
\text { - Catalyst }\end{array}$ & & & \\
\hline $\begin{array}{l}\text { Energy Related Costs ( } \$ \mathrm{x} 10^{6} \\
\text { - Chemical Inventory } \\
\text { - Storage Tanks }\end{array}$ & 0.5 & 0.9 & 1.25 \\
\hline$C_{p}(\$ / k W e)$ & 130 & 130 & 130 \\
\hline $\mathrm{C}_{\mathrm{s}}(\mathrm{s} / \mathrm{kWe} \mathrm{hr})$ & 9 & 9 & 9 \\
\hline
\end{tabular}

Some data on AHS cycle is available from recent work at the University of Houston (Reference B-13). A process schematic of the type of energy storage system is shown in Figure $B-10$. The first two reactions listed above are required during charging involving the carrier reactant, $\mathrm{Na}_{2} \mathrm{SO}_{4}$ which is cycled between reactions one and two in order to keep the temperature down and aid in the separation of products.

The process, at the current stage of development, contemplates no separation of the ammonia and water since they can be conveniently condensed and stored as an equimolal mixture resulting in lowered costs for tank storage. In the discharge side reaction, the AHS synthesis, involves bringing together $\mathrm{NH}_{3}, \mathrm{H}_{2} \mathrm{O}$ and $\mathrm{SO}_{3}$ as gases to form the product as a liquid. As seen flum lhe procees schematic, the endothermic reactions take place at a very high pressure of $\sim 143$ atmospheres, whereas the exothermic reaction takes place at $\sim 1$ atm pressure. This process offers significant opportunitites for the recovery of expansion work if suitable expander devices are incorporated at appropriate places. In the present study, we have considered this possibility of work recovery. Additionally, large amounts of heat are rejected in the $\mathrm{NH}_{3}$ and $\mathrm{SO}_{2}$ condensation which are low grade waste heat streams. It is also possible to improve the overall utilization of this waste heat during the charging cycle. 


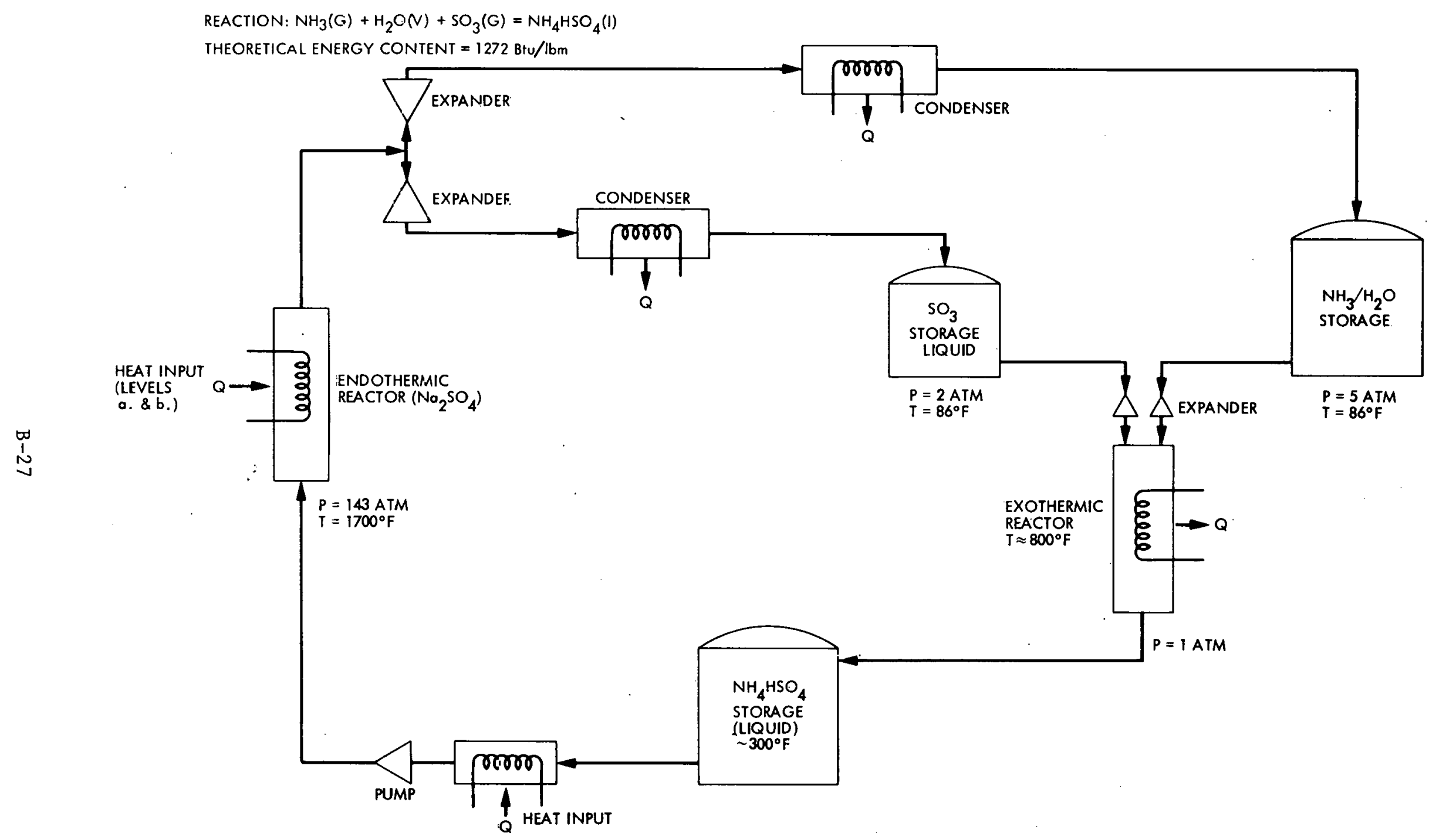

Figure B-10. Simplified Schematic of the Amnonium Hydrogen Sulfate System 
The operational cycle as shown poses some problems if energy storage for more than six hours is considered. Expander power itself in such a case can exceed 10 MWe. Hence no energy conversion system is needed during the charging cycle. Estimated performance and costs are shown in Table $B-11$. This reversible chemical energy storage cycle appears to be attractive. The key to success depends on working out reactor designs, better utilization of work as heat recovery; and minimizing the temperature drop between charging and discharging of the energy storage cycle.

Table B-11. Summary of Performance and Cost Characteristics for Ammonium Hydrogen Sulfate Energy Storage

\begin{tabular}{|c|c|c|c|}
\hline Storage Capacity (MWe hr) & 10 & 30 & 60 \\
\hline Heat in, $Q_{i}($ MWth hr) & 33 & 120 & 191 \\
\hline Heat Loss, $Q_{L}$ (MWth hr) & 4.1 & 12.6 & 28 \\
\hline Pump and Compressor Work (MWe hr) & 8.1 & 24.7 & 50 \\
\hline Expander Work (MWe hr) & 8.5 & 25 & 52 \\
\hline Storage Efficency, $\eta_{\mathbf{s}}$ & 0.91 & 0.9 & 0.89 \\
\hline $\begin{array}{l}\text { Power Related Costs }\left(\$ \times 10^{6}\right) \\
\text { - Reactors } \\
\text { - Expanders } \\
\text { - Compressors }\end{array}$ & 1.6 & 1.6 & 1.6 \\
\hline $\begin{array}{l}\text { Energy Related Costs }\left(\$ \times 10^{6}\right) \\
\text { - Chemical Inventory } \\
\text { - Storage Tanks }\end{array}$ & 0.2 & 0.6 & 1.2 \\
\hline$C_{p}(\$ / k W e)$ & 160 & 160 & 160 \\
\hline $\mathrm{C}_{\mathrm{s}}(\$ / \mathrm{kWe} \mathrm{hr})$ & 20 & 20 & 20 \\
\hline
\end{tabular}




\section{EXTERNAL ENERGY STORAGE (Battery Storage)}

Battery energy storage is a well known form of chemical energy storage in which direct current electricity is electrochemically converted to chemical energy during charging and during discharge chemical energy is converted electrochemically into d-c electricity. Advantages of battery energy storage are: (a) an absence of moving parts, (b) rapid system response (c) compactness and modularity. A large number of electrochemical systems have been investigated recently (References $\mathrm{B}-2, \mathrm{~B}-14$ and $\mathrm{B}-15$ ). In our study, we have focused on redox battery energy storage.

Redox batteries using various inorganic couples in aqueous solutions have been proposed for energy storage (Reference B-15). A proposed iron-chromium system is shown in Figure B-11. The redox battery is characterized as an electrically rechargeable flow cell based on two redox couples which are a pair of oxidation-reduction reactions. In either oxidized or reduced states, the ions remain soluble in their electrolytes. The cell is comprised of two compartments separated by an anion permeable selective ion exchange membrane and containing inert carbon electrodes. Separate electrolytes flow from external storage tanks into the compartments. In one compartment an oxidation reaction releases electrons which pass through the electrode to the load and finally into the electrode of the other compartment where a reduction reaction uses these electrons to release anions. These anions in turn pass through the membrane to participate in the oxidation reaction. The cell is recharged by reversing the direction of current flow. The development of redox batteries is still at a preliminary stage. Key cost-determining considerations are: the electrodes and current densities, electrode deterioration, charge-discharge efficiencies, and selective membranes. Much of the rest of the system - tanks, pumps, piping, and inorganic salts are currently available at reasonable costs. Table B-12 summarizes the performance and cost characteristics. 


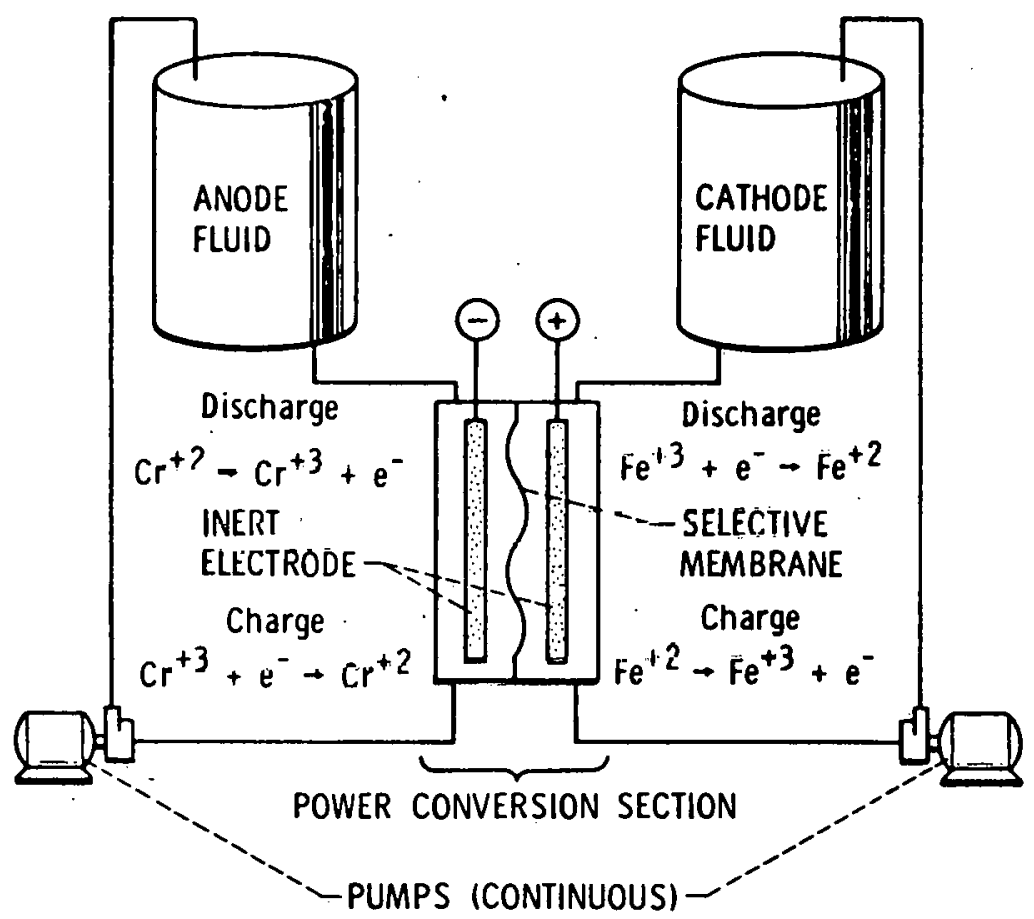

Figure B-11. Two-Tank Electrically Rechargeable Redox Flow Cell

Table B-12. Summary of Performance and Cost Characteristics for Redox Battery Energy Storage

\begin{tabular}{llll}
\hline Storage Capacity (MWe hr) & 50 & 100 & 150 \\
Electrical Energy in (MW hr) & 67 & 133 & 200 \\
Heat in, Q (MWth hr) & 0 & 0 & 0 \\
Heat loss, Q (MWth hr) & 12 & 23 & 35 \\
$\quad$ (I. R Losses) & 5 & 10 & 15 \\
Pump Work (MWe hr) & 5.75 & 0.75 & 0.75 \\
3turage Efficiellcy, n.s & &
\end{tabular}


Table B-12. Summary of Performance and Cost Characteristics for Redox Battery Energy Storage (Cont)

\begin{tabular}{|c|c|c|c|}
\hline $\begin{array}{l}\text { Power Related Costs }\left(\$ 10^{6}\right) \\
\text { - Membrane } \\
\text { - Electrodes } \\
\text { - Cell Modules } \\
\text { - Pumps } \\
\text { - Power Conditioning }\end{array}$ & 1.00 & 1.00 & 1.00 \\
\hline $\begin{array}{l}\text { Energy Related Costs }\left(\$ 10^{6}\right) \\
\quad \text { - Fluid Tanks } \\
\text { - Salts }\end{array}$ & 0.85 & 1.20 & 1.55 \\
\hline$C_{p}(\$ / k W e)$ & 150 & 150 & 150 \\
\hline$c_{s}(k W e ~ h r)$ & 7 & 7 & 7 \\
\hline
\end{tabular}




\section{APPENDIX B}

\section{REFERENCES}

B-1. DOE, "Proceedings of Second Annual Thermal Energy Storage Contractor's Information Exchange Meeting," September 1977, Gatlinburg, TN, DOE Publication No. CONF-770955, September 1977.

B-2. Public Service Electric and Gas Co., "An Assessment of Energy Storage Systems Suitable for Use by Electric Utilities," ERDA Report No. E(11-1)-2501, July 1976.

B-3. Gintz, J.R., "Advanced Thermal Energy Storage Concept Definiliun Study for Solar Brayton Power Plants," Boeing Engineering and Curstruction Co., Keport No. SAN/1300-1,2,3,4, Seattle, WA, November 1977.

B-4. Martin Marietta Co. "Central Receiver Eolar Therüd Power Systems, Phase 1," Report for ERDA, 1976.

B-5. Gilli, P.V., "Thermal Energy Storage Using Prestressed Cast-Iron Vessels, (PCIV)," ERDA Contract E(11-1)-2886.

B-6. Lyon, R.L., et al., "Liquid Metals Handbook," ONR, AEC, and Bureau of Ships, Supt. of Documents, Wash., D.C., June 1952.

B-7. Vant-Hu11, L., et al., "Liquid Metal Coded Solar Central Receiver Feasibility Study and Field Analysis," Univ. of Houston, Report No. OR05178-78-1, October 1977.

B-8. Rockwell International Energy Systems Group, "Conceptual Design of Advanced Central Receiver Power Systems," DOE Contract No. EG-77-C-03-1483, Semi.Annual Review, September 1978.

B-9. Grumman Aerospace Corporation, "Thermal Energy Storage Heat Exchanger," report prepared for NASA, Report No. NASA CR 135244, October 1977.

B-10. Bramlete, T., et al., "Survey of High Temperature Thermal Energy Sturage," Sandia Laboratories, March 1976.

B-11. Boruck, A., "Survey and Selection of Inorganic Salts for Applicatinn to Thermal Encrgy Starage," ERDA, June 1976.

B-12. Schmidt, E.W., "Chemical Energy Storage System-Chemical Reaction Subsystem," Rocket Research Corporation Technical Assessment Paper RRC 76-R-502, Redmond, WA, January 1976.

B-13. Wentworth, W.E., Prengle, W.E., and Hildebrandt, A. F., "Development of Operational Chemical Cycles for the Storage of Energy," Final Report, DOE Contract EG-77-C-04-3974, Univ. of Houston, Houston, TX. 
B-14. Kalhammer, F.R., and Schneider, T.R., "Energy Storage," Annual Review of Energy, Vol: 1, 1976.

B-15. Warshay, M., and Wright, L.0., "Cost and Size Estimates for An Electrochemical Bulk Energy Storage Concept," Energy Storage Section of the 148th Meeting of the Electrochemical Society, Dallas, TX, NASA TMX-71805, October 1975. 
APPENDIX C

SYSTEM SIMULATION DATA BASE

C-1 


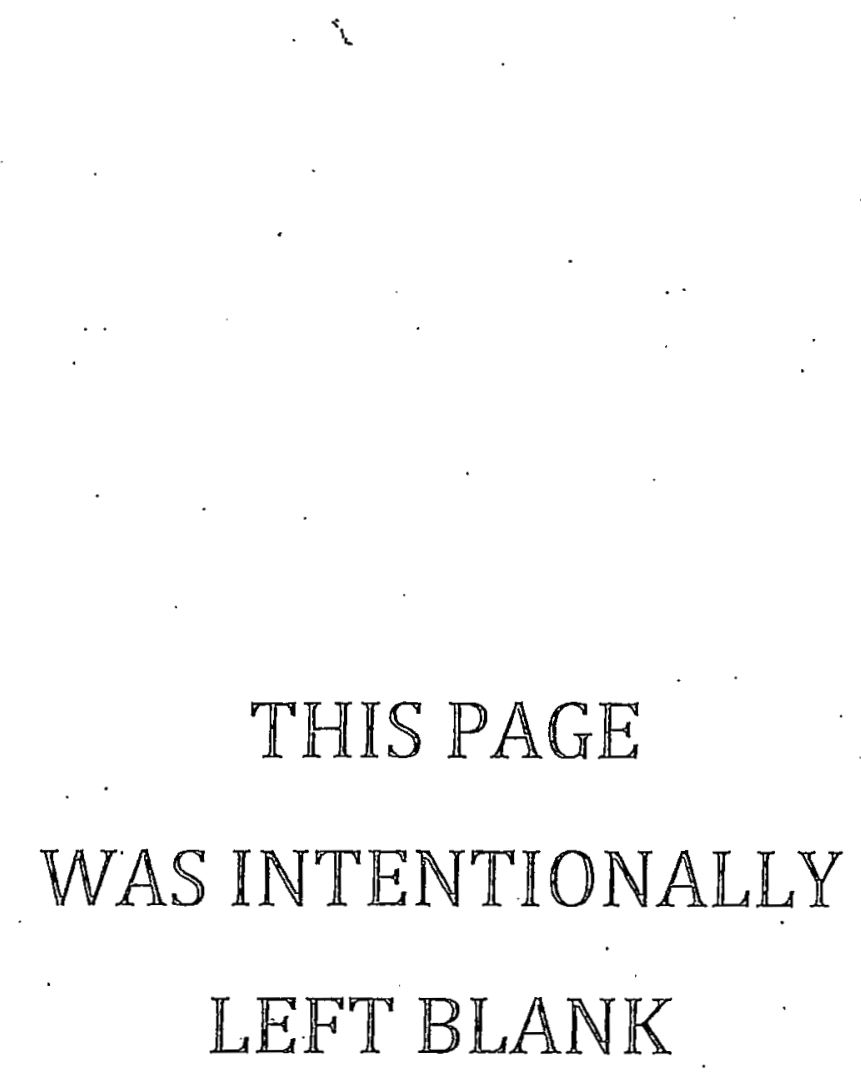




\section{APPENDIX C}

Accumulated data on the performance and cost of advanced solar thermal power plant subsystems that might be suitable candidates in the timeframe 1990-2000 were screened and evaluated to determine the data base for this study. In this appendix the data utilized is arranged in two groups. The first group of data is common to all the systems considered in this study. The second group lists the data appropriate for the particular system.

Group 1: Data Common to All Systems

Table C-1. Economic Assumptions

Plant Construction Time, Years

\begin{tabular}{lcc} 
& \multicolumn{2}{c}{ Annual Growth Rates, \% } \\
\cline { 2 - 3 } & $1977-1987$ & After 1987 \\
\hline General Price Leve1 & 5.0 & 4.2 \\
Labor (Construction) & 7.0 & 6.2 \\
Manufactured Goods & 4.3 & 3.8 \\
O\&M (3/4 Labor, 1/4 Goods) & 6.3 & 5.6 \\
Other (Insurance, Taxes, Profit, etc.) & 5.0 & 4.2 \\
Installed Capital & 6.2 & 4.8 \\
\hline
\end{tabular}

Table C-2. Performance Assumptions

\begin{tabular}{lccc}
\hline & Low & Most Likely & High \\
\hline Collector Optical Reflectance & 0.88 & 0.90 & 0.92 \\
Receiver Absorptance & 0.92 & 0.95 & 0.96 \\
Scheduled Maintenance Factor & 0.89 & 0.90 & 0.95 \\
Unscheduled Maintenance Factor & 0.95 & 0.96 & 0.97 \\
Inplant Elcctric Transport Efficiency & 0.95 & 0.95 & 0.95 \\
Correction Factor for Auxiliary Power & 0.97 & 0.97 & 0.97 \\
\hline
\end{tabular}

Group 2: Individua1 Systems

Data for individual selected systems are presented in Tables C-3 through $\mathrm{C}-11$. The first four systems are for central receivers (including the baseline) while the remaining five encompass selected distributed systems. The low, most likely, and high values used in the probabilistic simulation program are presented. 
Table C-3. Data Base for System HR

\begin{tabular}{|c|c|c|c|}
\hline \multicolumn{4}{|c|}{$\begin{array}{l}\text { Central Receiver, Rankine Steam Cycle } \\
\sim 1100^{\circ} \mathrm{F} \text {, Rock Oil Storage, LF }=0.4\end{array}$} \\
\hline & Low & Most Likely & High \\
\hline Atmospheric Attenuation & 0.97 & 0.98 & 0.99 \\
\hline Collector-Receiver Matching & 0.941 & 0.958 & 0.980 \\
\hline Geometric Tracking Efficiency & 0.702 & 0.738 & 0.771 \\
\hline Receiver Efficiency & 0.920 & 0.944 & 0.956 \\
\hline Energy Transport Efficiency & 0.94 & 0.96 & 0.98 \\
\hline Energy Storage Efficiency & 0.70 & 0.80 & 0.825 \\
\hline $\begin{array}{l}\text { Power Plant Efficiency (Direct) } \\
\text { Power Plant Efficiency (Stored) }\end{array}$ & $\begin{array}{l}0.290 \\
0.205\end{array}$ & $\begin{array}{l}0.298 \\
0.208\end{array}$ & $\begin{array}{l}0.310 \\
0.221\end{array}$ \\
\hline Capital Cost ( $\$ / \mathbf{k W e})$ & 800 & 1323 & 1764 \\
\hline $\begin{array}{l}\text { First Year Operation \& Maintenance } \\
\text { Cost }(\$ / \mathrm{k} W \mathrm{We})\end{array}$ & 6 & 7 & 9 \\
\hline
\end{tabular}

Table C-4. Data Base for System (HS/LM)

Central Receiver, Stirling Engine, Liquid Metal

Transport and Storage, LF $=0.4$

\begin{tabular}{llcc} 
& Low & Most Likely & High \\
\hline Atmospheric Attenuation & 0.97 & 0.98 & 0.99 \\
Collector-Receiver Matching & 0.941 & 0.958 & 0.980 \\
Geometric Tracking Efficiency & 0.702 & 0.738 & 0.771 \\
Receiver Efficiency & 0.90 & 0.92 & 0.95 \\
Energy Transport Efficiency & 0.87 & 0.89 & 0.910 \\
Energy Storage Efficiency & 0.88 & 0.91 & 0.92 \\
$\begin{array}{l}\text { Power Plánt Efficiency (Direct) } \\
\text { Power Plant Efficiency (Stored) }\end{array}$ & 0.400 & 0.401 & 0.415 \\
Capital Cost (\$/kWe) & 0.398 & 0.400 & 0.412 \\
$\begin{array}{l}\text { First-Year Operation \& Maintenance } \\
\text { Cost (\$/kWe) }\end{array}$ & 790 & 1258 & 1675 \\
\hline
\end{tabular}


Table C-5. Data Base for System (HB/LM)

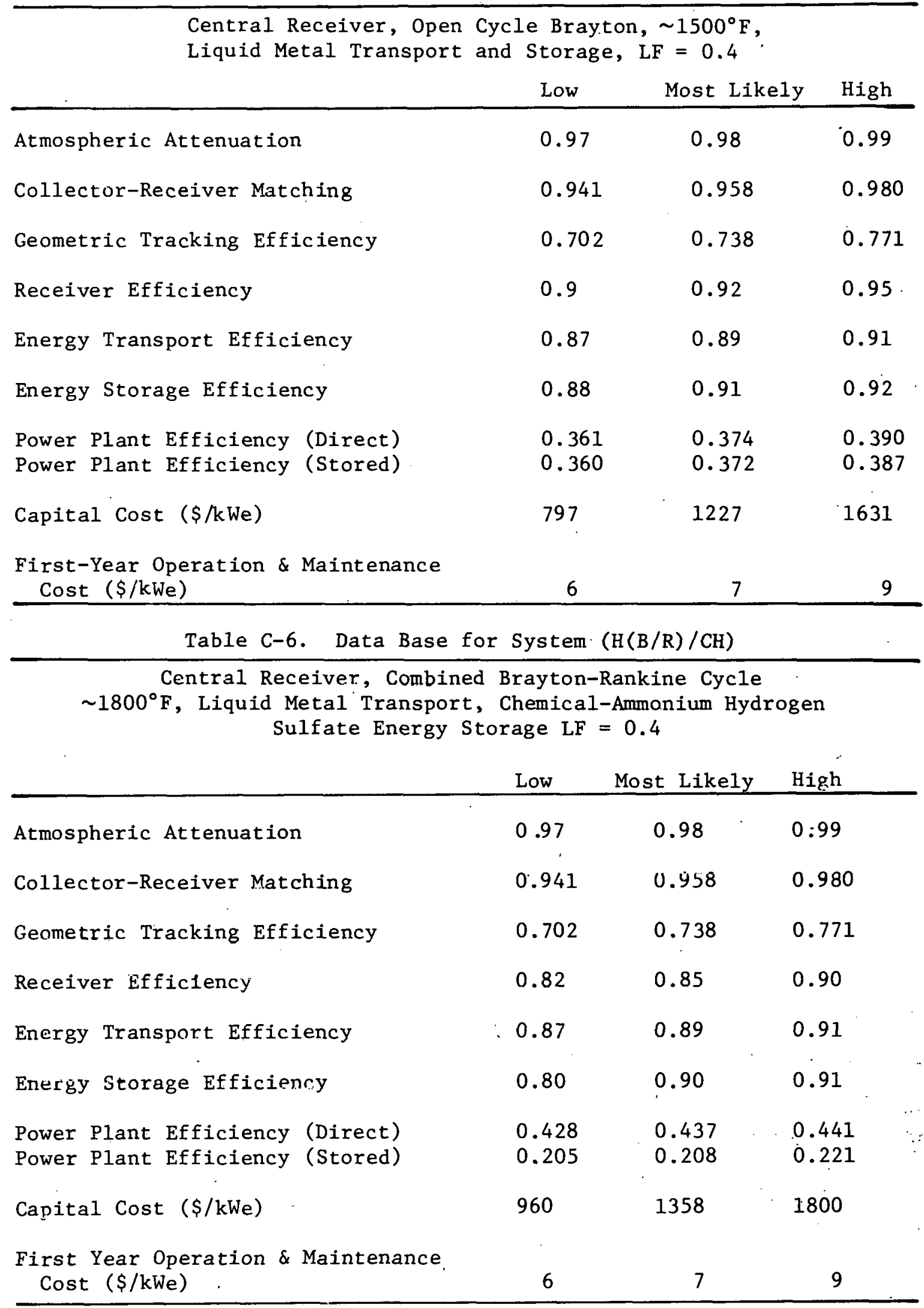


Table C-7. Data Base for System (PS-2)

\begin{tabular}{|c|c|c|c|}
\hline \multicolumn{4}{|c|}{$\begin{array}{c}\text { Dịstributed Dish, Stirling Engine } \sim 1800^{\circ} \mathrm{F}, \\
\text { Redox Battery Storage, LF }=0.4\end{array}$} \\
\hline & Low & Most Likely & High \\
\hline Atmospheric Attenuation & 1.0 & 1.0 & 1.0 \\
\hline Collector-Receiver Matching & 1.0 & 1.0 & 1.0 \\
\hline Geometric Tracking Efficiency & 1.0 & 1.0 & 1.0 \\
\hline Receiver Efficiency & 0.860 & 0.874 & 0.890 \\
\hline Energy 'Tranoport Efficiency & 0.94 & 0.975 & 0.980 \\
\hline Energy Storage Efficiency & 0.7 & 0.75 & 0.80 \\
\hline Power Plant Efficiency (Direct) & 0.440 & 0.456 & 0.475 \\
\hline Power Plant Efficiency (Stored) & - & - & - \\
\hline Capital Cost $(\$ / k W e)$ & 696 & 1123 & 1500 \\
\hline $\begin{array}{l}\text { First-Year Operation \& Maintenance } \\
\text { Cost }(\$ / \mathrm{kWe})\end{array}$ & 7 & 8 & 9 \\
\hline
\end{tabular}

Table C-8. Data Base for System (PB)

Distributed Dish, Closed Cycle Brayton $\sim 2000^{\circ} \mathrm{F}$, Redox Battery Storage, $L F=0.4$

\begin{tabular}{lccc} 
& Low & Most Likely & High \\
\hline Atmospheric Attenuation & 1.00 & 1.00 & 1.00 \\
Collector-Receiver Matching & 1.00 & 1.00 & 1.00 \\
Geometric Tracking Efficiency & 1.00 & 1.00 & 1.00 \\
Receiver Efficiency & 0.824 & 0.838 & 0.840 \\
Energy Transport Efficienry & 0.741 & 0.976 & 0.989 \\
Energy Storage Efficiency & 0.70 & 0.75 & 0.80 \\
$\begin{array}{l}\text { Power Plant Efficiency (Direct) } \\
\text { Power Plant Efficiency (Stored) }\end{array}$ & 0.438 & 0.438 & 0.438 \\
Capital Cost (\$/kWe) & - & - & - \\
First-Year Operation \& Maintenance & 784 & 1142 & 1525 \\
Cost (\$/kWe) & 7 & & 9 \\
\hline
\end{tabular}


Table C-9. Data Base for System (PS/MD)

Distributed Dish, Stirling Engine $\sim 1500^{\circ} \mathrm{F}$, Seven-Dish Per Module, Liquid Metal Transport and Storage, $\mathrm{LF}=0.4$

\begin{tabular}{|c|c|c|c|}
\hline & Low & Most Likely & High \\
\hline Atmospheric Attenuation & 1.00 & 1.00 & 1.00 \\
\hline Collector-Receiver Matching & 1.00 & 1.00 & 1.00 \\
\hline Geometric Tracking Efficiency & 1.00 & 1.00 & 1.00 \\
\hline Receiver Efficiency & 0.90 & 0.92 & 0.93 \\
\hline Energy Transport Efficiency & 0.894 & 0.912 & 0.926 \\
\hline Energy Storage Efficiency & 0.880 & 0.91 & 0.92 \\
\hline $\begin{array}{l}\text { Power Plant Efficiency (Direct) } \\
\text { Power Plant Efficiency (Stored) }\end{array}$ & $\begin{array}{l}0.400 \\
0.398\end{array}$ & $\begin{array}{l}0.401 \\
0.400\end{array}$ & $\begin{array}{l}0.415 \\
0.412\end{array}$ \\
\hline Capital Cost $(\$ / k W e)$ & 654 & 1006 & 1350 \\
\hline $\begin{array}{l}\text { First-Year Operation \& Maintenance } \\
\text { Cost }(\$ / \mathrm{kWe})\end{array}$ & 7 & 8 & 9 \\
\hline \multicolumn{4}{|c|}{ Table C-10. Data Base for System (PP $(B / R) / M D)$} \\
\hline \multicolumn{4}{|c|}{$\begin{array}{c}\text { Distributed Dish, Combined Brayton-Rankine Cycle } \sim 1800^{\circ} \mathrm{F} \text {, } \\
\text { Liquid Metal Transport and Storage } \mathrm{LF}=0.4\end{array}$} \\
\hline & Low & Most Likely & High \\
\hline Atmospheric Attenuation & 1.00 & 1.00 & 1.00 \\
\hline Collector-Receiver Matching & 1.00 & 1.00 & 1.00 \\
\hline Geometric Tracking Efficiency & $1: 00$ & 1.00 & 1.00 \\
\hline Receiver Efficiency & 0.860 & 0.874 & 0.888 \\
\hline Energy Transport Efficiency. & 0.891 & 0.901 & 0.916 \\
\hline Ënergy Storage Efflclency & 0.880 & 0.90 & 0.915 \\
\hline Power Plant Efficiency (Direct) & 0.423 & 0.44 & 0.45 \\
\hline Power Plant Efficiency (Stored) & 0.420 & 0.43 & 0.44 \\
\hline Capital Cost $(\$ / k W e)$ & 720 & 1032 & 1390 \\
\hline $\begin{array}{l}\text { First-Year Operation } \& \text { Maintenance } \\
\text { Cost }(\$ / k \text { W } \Theta)\end{array}$ & 7 & 8 & 9 \\
\hline
\end{tabular}


Table C-11. Data Base for System (FR/DIS)

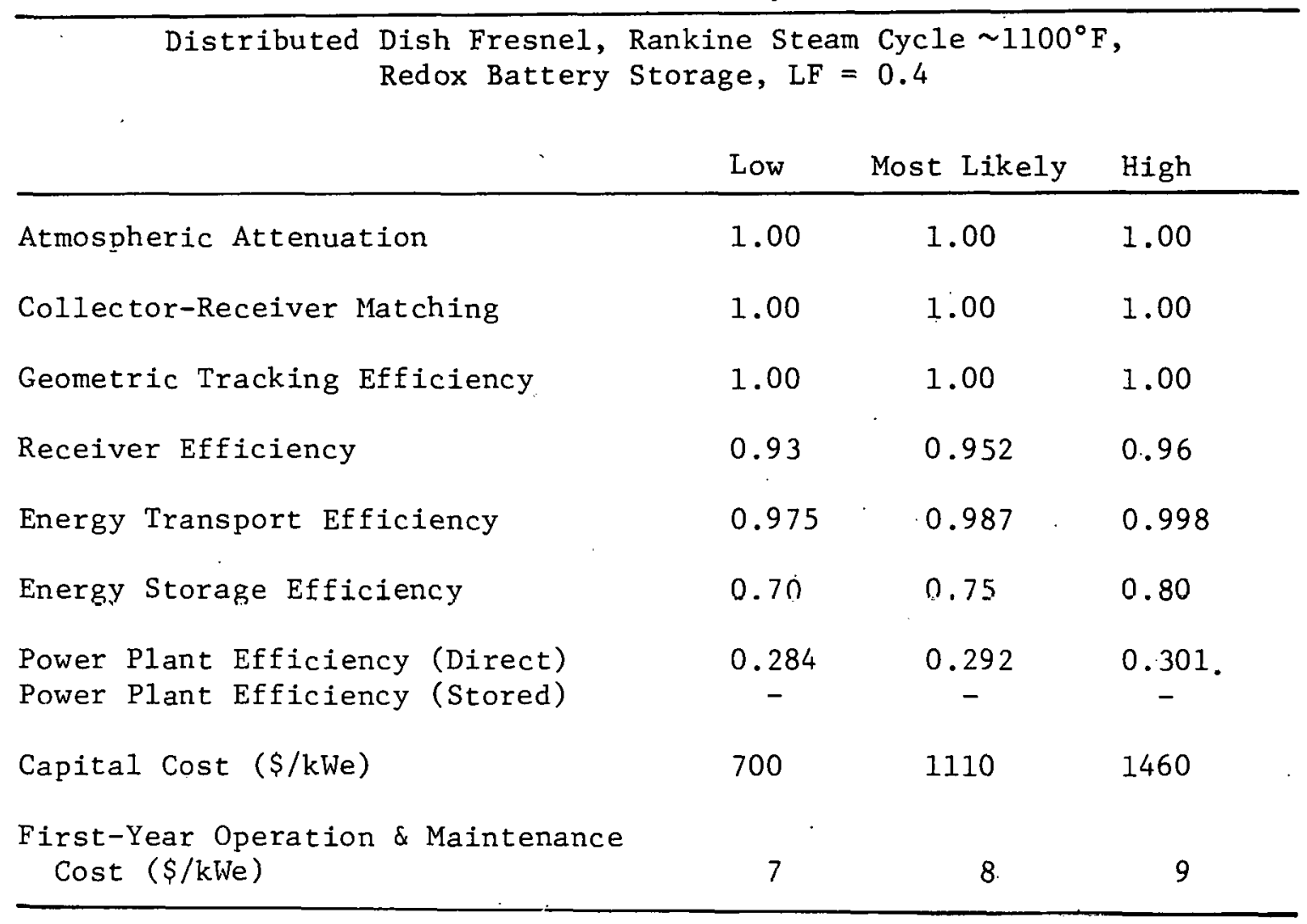

